\title{
Non-convulsive aspects of epilepsy in children
}

\author{
Citation for published version (APA):
}

Nicolai, J. (2009). Non-convulsive aspects of epilepsy in children. [Doctoral Thesis, Maastricht University]. Datawyse / Universitaire Pers Maastricht. https://doi.org/10.26481/dis.20090306jn

Document status and date:

Published: 01/01/2009

DOI:

10.26481/dis.20090306jn

Document Version:

Publisher's PDF, also known as Version of record

\section{Please check the document version of this publication:}

- A submitted manuscript is the version of the article upon submission and before peer-review. There can be important differences between the submitted version and the official published version of record.

People interested in the research are advised to contact the author for the final version of the publication, or visit the DOI to the publisher's website.

- The final author version and the galley proof are versions of the publication after peer review.

- The final published version features the final layout of the paper including the volume, issue and page numbers.

Link to publication

\footnotetext{
General rights rights.

- You may freely distribute the URL identifying the publication in the public portal. please follow below link for the End User Agreement:

www.umlib.nl/taverne-license

Take down policy

If you believe that this document breaches copyright please contact us at:

repository@maastrichtuniversity.nl

providing details and we will investigate your claim.
}

Copyright and moral rights for the publications made accessible in the public portal are retained by the authors and/or other copyright owners and it is a condition of accessing publications that users recognise and abide by the legal requirements associated with these

- Users may download and print one copy of any publication from the public portal for the purpose of private study or research.

- You may not further distribute the material or use it for any profit-making activity or commercial gain

If the publication is distributed under the terms of Article $25 \mathrm{fa}$ of the Dutch Copyright Act, indicated by the "Taverne" license above, 
Non-convulsive aspects of epilepsy in children 
(C) Joost Nicolai, Maastricht 2009

ISBN 9789052788104

Universitaire Pers Maastricht

Omslagontwerp: Caroline van der Linden 


\title{
Non-convulsive aspects of epilepsy in children
}

\author{
Proefschrift \\ Ter verkrijging van de graad van doctor \\ aan de Universiteit Maastricht, \\ op gezag van de Rector Magnificus, \\ Prof. mr. G.P.M.F. Mols \\ volgens het besluit van College van Decanen, \\ in het openbaar te verdedigen \\ op vrijdag 6 maart 2009 om 14:00 uur \\ door \\ Johannes Nicolai \\ Geboren op 12 mei 1966
}

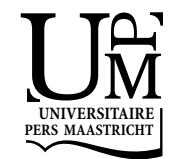


Promotores

Prof. dr. J.S.H. Vles

Prof. dr. A.P. Aldenkamp

\section{Copromotor}

Dr. J.B.A.M. Arends, Epilepsiecentrum Kempenhaeghe

\section{Beoordelingscommissie}

Prof. dr. L.J.I. Zimmermann (voorzitter)

Dr. M.V.H.M. van Kranen-Mastenbroek

Prof. dr. O. van Nieuwenhuizen, Universiteit Utrecht

Prof. dr. H.W.M. Steinbusch

Prof. dr. J.T. Swaab-Barneveld, Universiteit Leiden 


\section{CONTENTS}

Chapter 1 General introduction 7

Chapter 2 Cognitive and behavioral effects of nocturnal epileptiform

discharges in children with benign childhood epilepsy with centrotemporal spikes

Chapter 3 The pathophysiological mechanisms of cognitive and behavioral disturbances in children with Landau-Kleffner syndrome or epilepsy with continuous spike-and-waves during slow-wave sleep

Chapter 4 EEG characteristics related to educational impairments in children with benign childhood epilepsy with centrotemporal spikes

Chapter 5 The relative influence of interictal activity vs. non-convulsive seizures on cognition in children with epilepsy

Chapter 6 Neurodevelopmental delay in children exposed to antiepileptic drugs in utero: a critical review directed at structural study-bias

Chapter 7 Cognitive side effects of valproic acid-induced hyperammonemia in children with epilepsy

Chapter 8 Discussion

Chapter 9 Summary

Samenvatting in het Nederlands

Dankwoord

Curriculum Vitae

Publicaties 


\section{ABBREVIATIONS}

ABFEC, atypical benign focal epilepsy of childhood

ADHD, attention deficit and hyperactivity disorder

BAEP, brainstem auditory evoked potential

BCECTS, benign childhood epilepsy with centrotemporal spikes

CNS, central nervous system

CSF, cerebrospinal fluid

CSWS, epilepsy with continuous spike-and-waves during slow-wave sleep

EA, epileptiform activity

EEG, electroencephalography

ESES, electrical status epilepticus during slow sleep

FSIQ, full scale intelligence quotient

IgG, immunoglobulin $\mathrm{G}$

IgM, immunoglobulin $\mathrm{M}$

ILAE, International League Against Epilepsy

LKS, Landau-Kleffner syndrome

MEG, magnetoencephalography

MFFT, Matching Familiar Figures Test

MRI, magnetic resonance imaging

PA, paroxysmal activity

PET, positron emission tomography

PIQ, performance intelligence quotient

REM, rapid eye movement

SW, spike-and-wave

TCI, transitory cognitive impairment

VIQ, verbal intelligence quotient 


\section{Chapter 1}

General introduction 
Epilepsy is a chronic disorder defined by the occurrence of recurrent (two or more) unprovoked epileptic seizures. In this definition, the term "unprovoked" indicates that seizures are not triggered by fever, intoxication, drug withdrawal, or any other acute physical disruption. Epilepsy in childhood and adolescence is frequent; the overall prevalence of active epilepsy (at least one seizure in last 5 years) in the Netherlands is 4.8 per $1000,{ }^{1}$ in children it ranges from 1.1 - 4.1 per 1000 , depending on age and gender. ${ }^{2}$ It is important to recognise that the diagnosis "epilepsy" in children consists of a large spectrum of completely different epilepsy syndromes, ranging from benign to very severe. The prognosis can be excellent, for example in benign childhood epilepsy with centrotemporal spikes (BCECTS), the most common benign partial childhood epilepsy syndrome. In case of this epilepsy syndrome, more than $99.8 \%$ of children are seizure free at the age of 18 -years, whether treated or not. ${ }^{3}$ But the global development of children can deteriorate disastrously as well in malignant childhood epilepsy syndromes like West syndrome or Lennox syndrome.

In a particular child, the epilepsy syndrome and the classification of seizure aetiology commonly do not change when the child gets older. But there are a few exceptions. For example, it has been described that Panayiotopoulos syndrome -a benign partial childhood epilepsy syndrome- is followed by BCECTS in a small percentage of children. ${ }^{4}$ Moreover, in less than $1 \%$ of children with BCECTS, children show an atypical evolution into one of the epilepsy syndromes with cognitive deterioration: the Landau-Kleffner syndrome, epilepsy with continuous spike-and-waves during slowwave sleep (CSWS), or atypical benign focal epilepsy of childhood (ABFEC). ${ }^{5}$

Cognition in children with epilepsy is determined by many factors: the epilepsy syndrome and the possible underlying brain disorder, the number of seizures, frequency of electroencephalographic epileptiform activity, antiepileptic medication, side effects, genetic and social factors. The epilepsy syndrome and eventually underlying brain disorder commonly can not be cured, although there are rare exceptions, for example in pyridoxin-dependent seizures. However, the other factors that possibly determine cognition can often be influenced. Number and length of seizures and the frequency of electroencephalographic epileptiform activity can be influenced by medication. Antiepileptic drug regimes give rise to side effects disturbing cognition, alertness, behaviour or mood. For example, phenobarbital is no option for children going to primary or secondary school because of the severe side effects on cognition, but is an option in neonates. These side effects have to be kept in mind when choosing medication and during follow-up of children with epilepsy.

Two case histories are described to illustrate the aforementioned problems.

A 4-year-old boy visited our outward-department because his parents had noticed a gradual alteration of behaviour in the last weeks. His medical history was characterized by the occurrence of pneumococcal meningitis at the age of 6 weeks complicated by multiple brain infarcts, hydrocephalus and seizures. At the age of 5 months, infantile spasms were seen. EEG recording revealed hypsarrhythmia and the diagnosis of a symptomatic West syndrome secondary to multiple brain infarctions was made. Sei- 
zures were initially therapy resistant and treatment with phenobarbital, vigabatrin and nitrazepam was necessary to control the spasms. After admission for almost 3 months, he was discharged again. Severe cerebral paresis and vision disturbance was gradually noted. Shortly after his fourth birthday and gradually in about 4 weeks, he became less alert, slept more, and did not smile anymore to his relatives. Eating and drinking had become more troublesome. His parents had not noted vomiting, downward eye deviation, or any other sign of increased intracranial pressure. At that moment he used valproic acid $200 \mathrm{mg}$ bid (27 mg/Kg/day), phenobarbital $25 \mathrm{mg}$ bid (3.3 mg/Kg/day) and topiramate $32 \mathrm{mg}$ bid $(4.3 \mathrm{mg} / \mathrm{Kg} /$ day). The last adjustment of anti-epileptic medication was lowering of the valproic acid dose, 4 months earlier.

On physical examination he had a severe spastic tetraparesis, more prominent on the left-side of his body. He was able to follow objects visually, showing a continuous, horizontal, asymmetric nystagmus similar to the abnormal eye movements seen before. Mainly from the description by his mother, we concluded that he suffered from a global deterioration of consciousness. The etiological differential diagnosis ranged from hydrocephalus due to failure of the internal ventricular drain, non-convulsive epileptic status, postictal disturbances due to an increased frequency of epileptic seizures, till a hyperammonemic encephalopathy related to valproic acid treatment.

It may be difficult to determine the relation between hyperammonemia and altered behaviour. Hyperammonemia is one of the biochemical signs of liver failure, for example in liver cirrhosis, but is also seen in valproic acid treatment. Clinical symptoms are sometimes clear, for example in a comatose child who has started valproic acid acid therapy a few days earlier. ${ }^{6}$ But in children treated with valproic acid acid and adults as well, signs of hyperammonemic encephalopathy are often not recognised. ${ }^{7}$

Looking for hyperammonemia first, we decided to start with the determination of ammonia. Capillary ammonia was $255 \mu \mathrm{mol} / 1$ (normal $<43 \mu \mathrm{mol} / \mathrm{l}$ ), suggesting the diagnosis of valproic acid-induced hyperammonemic encephalopathy. Several prospective studies have shown a decrease in ammonia concentrations after supplementing Lcarnitine. $^{8}$ Supplementation of L-carnitine $1650 \mathrm{mg} /$ day (660-330-660mg; $\approx 100$ $\mathrm{mg} / \mathrm{Kg} /$ day) resulted in clear improvement of consciousness. Ammonia was measured 2 weeks after initiation of L-carnitine; the concentration had decreased to $105 \mu \mathrm{mol} / \mathrm{l}$. Consciousness and his cheerfulness had become normal again. L-carnitine was lowered and maintained at $330 \mathrm{mg}$ bid $(\approx 40 \mathrm{mg} / \mathrm{Kg} /$ day). In this case, the decrease of ammonia after initiation of L-carnitine supplementation and continuation of all antiepileptic medication, and the concomitant improvement of consciousness proved the diagnosis of valproic acid-induced hyperammonemic encephalopathy.

The second case history describes the complicated course of a child with BCECTS. In this 6-year-old boy nocturnal, partial, hemifacial motor seizures exhibiting secondary generalisation occurred. Initially, the diagnosis of benign childhood epilepsy with centrotemporal spikes was made. Because three secondary generalized seizures had occurred within a few weeks, treatment with valproic acid acid was initiated. Six months later, he developed diurnal attacks of simple, partial, hemifacial seizures with drooling and inability to speak. Independent from the hemifacial motor seizures, he experienced 
coloured hallucinations and periods of blurred vision lasting several minutes. Because of the atypical evolution, magnetic resonance imaging of the brain was performed, that revealed no abnormalities. A new electroencephalogram showed right-sided, temporal spike-wave activity spreading to parietal, and sporadic left-sided centrotemporal spikes. Clobazam was added to his medication; all signs disappeared, although the electroencephalographic pattern did not change. Approximately 3 months later, he showed short periods of loss of muscular tone leading to head nods many times a day. Less frequently, episodes of epileptic pseudo-ataxia with loss of control of limb coordination lasting for 1-2 seconds were noted. In addition, brief episodes of headache resulted in frequent non-attendance from school. Whole-night electroencephalogram recording revealed frequent, multifocal epileptiform activity during sleep (70- 90\%), with a high number of bilateral synchronized epileptiform discharges. The dose of clobazam was gradually increased. Every time the clobazam dosage was increased, the atonic seizures, pseudo-ataxia, and episodes of headache disappeared, but only for a few weeks. Because of the partial seizures of different origins, the atonic seizures, and the finding of multifocal, frequent epileptiform activity with major activation during sleep, the diagnosis of atypical benign partial epilepsy of childhood (ABFEC) was rendered. The introduction of carbamazepine led to a severe increase in seizure frequency within a few days and therefore was discontinued. More than 2 years after the onset of seizures, this boy was still manifesting frequent seizures, despite treatment with a combination of valproic acid, clobazam, sulthiame, and levetiracetam. With the initiation of prednisone $2 \mathrm{mg} / \mathrm{Kg} /$ day, his seizure frequency decreased dramatically, but after the withdrawal of steroids, seizures reappeared. Since the introduction of intravenous immunoglobulin, he is seizure-free and attending school again.

These two case histories illustrate that care of children with epilepsy is more than suppression of seizures by antiepileptic drugs. It's often also about learning, attention, or behavioural problems related to the epilepsy syndrome or related to numerous seizures or (nocturnal) epileptiform activity with deterioration of global cognitive function or deterioration of language in the most severe spectrum. Cognition and behaviour can also deteriorate due to side effects of antiepileptic medication or severe metabolic derangements due to the medication. Knowledge of this diverse spectrum is a prerequisite for physicians treating children with epilepsy.

The thesis focuses on several issues: I: the effect of nocturnal icterictal epileptiform activity in benign childhood epilepsy with centrotemporal spikes (Chapter $2 \& 4$ ) and II: in the severe spectrum of benign childhood epilepsy (Chapter 3); III: The effect of interictal epileptiform activity and short non-convulsive seizures on cognition (Chapter 5); IV: the cognitive effects of intrauterine exposure to antiepileptic drugs (Chapter 6); and V: the cognitive effects of valproic acid-induced hyperammonemia (Chapter 7). 


\section{REFERENCES}

1 Shackleton DP, Westendorp RG, Kasteleijn-Nolst Trenité DG, de Boer A, Herings RM. Dispensing epilepsy medication: a method of determining the frequency of symptomatic individuals with seizures. J Clin Epidemiol 1997; 50: 1061-8.

2 RIVM Nationaal Kompas Volksgezondheid. Versie 3.13, 17 april 2008. http://www.rivm.nl/vtv/object_document/o2101n17762.html

3 Bouma PA, Bovenkerk AC, Westendorp RG, Brouwer OF. The course of benign partail epilepsy of childhood with centrotemporal spikes: a meta-analysis. Neurology 1997; 48: 430-7.

4 Panayiotopoulos CP. Benign childhood partial seizures and related epileptic syndromes. London: John Libbey; 1999.

5 Fejerman N, Caraballo R, Tenembaum SN. Atypical evolutions of benign localization-related epilepsies in children: are they predictable? Epilepsia 2000; 41: 380-90.

6 Coulter DL, Allen RJ. Secundary hyperammonaemia: a possible mechanism for valpoate encephalopathy. Lancet 1980; 8181: 1310-1.

7 Carr RB, Shrewsbury K. Hyperammonemia due to valproic acid in the psychiatric setting. Am J Psychiatry. 2007; 164: 1020-7.

8 Gidal BE, Inglese CM, Meyer JF, et al. Diet and valproate-induced transient hyperammonemia: effect of 1carnitine. Pediatr Neurol. 1997; 16: 301-305. 



\section{Chapter 2}

Cognitive and behavioral effects of nocturnal epileptiform discharges in children with benign childhood epilepsy with centrotemporal spikes

Joost Nicolai, Albert P. Aldenkamp, Johan Arends, Jacobiene W. Weber, Johan S.H. Vles.

Epilepsy \& Behavior 2006; 8: 56-70 


\begin{abstract}
This review addresses the effects of subclinical localized epileptiform discharges during sleep in children with benign childhood epilepsy with centrotemporal spikes (BCECTS) on cognition and behavior. A diversity of educational deficits, behavioral impairments, language delay, and neuropsychological test results have been reported in children with BCECTS. The occurrence of atypical seizure characteristics seems to be related to language delay and several atypical EEG characteristics are related to cognitive or behavioral problems. It remains to be shown whether treatment of nocturnal discharges in children with BCECTS is indicated to improve cognitive and behavioral problems.
\end{abstract}




\section{INTRODUCTION}

There is a complex reciprocal interaction between sleep and epilepsy. Sleep has a marked influence on epilepsy, affecting the timing of seizures and the frequency, morphology, and spread of interictal discharges, while on the other side, epilepsy can alter sleep patterns and lead to sleep disruption. ${ }^{1}$ Seizures (a clinical symptom) and icterictal subclinical discharges (an EEG phenomenon) have to be distinguished. In children with epilepsy, the amount of subclinical epileptiform discharges commonly increases during sleep. It is controversial, whether this activation of interictal encephalographic discharges in sleep is of clinical relevance. It is assumed that severe encephalographic epileptiform activity in childhood causes cognitive deterioration by disturbing the formation of synapses. ${ }^{2}$ Problems in attention or language processing in children with BCECTS are considered a result of a mild epileptic encephalopathy due to frequent discharges in sleep. ${ }^{3}$ Kohrman \& Carney ${ }^{4}$ and Stores ${ }^{5}$ hypothesized that cognitive underachievement in some children with epilepsy may in part be secondary to poor daytime alertness due to sleep fragmentation. On the contrary, it is suggested that seizures $^{6}$ or subclinical discharges ${ }^{7}$ and neuropsychological deficits are different clinical manifestations of the same unknown, genetically determined, pathogenetic mechanism. This raises the question whether localized epileptiform discharges during sleep directly cause problems in cognition and behavior.

We focused on BCECTS because we consider BCECTS the ideal model for studying the effects of localized encephalographic discharges in sleep for three reasons; I: Especially in BCECTS, children often have a very low frequency of seizures and these are mainly partial simple seizures with retained consciousness. Postictal deficits in cognition or behavior are therefore a minor problem; II: Children often do not get antiepileptic medication, and when medication is given monotherapy often is sufficient. Evidently, an effect of antiepileptic medication on cognition and behavior is absent in those without medication; III: During sleep, encephalographic epileptiform activity is much more frequent than when awake. Even, about $30 \%$ of children with BCECTS have encephalographic epileptiform activity in sleep only. So, children with BCECTS with low frequent seizures, no antiepileptic medication, no epileptiform activity in wake, and marked activation of epileptiform activity in sleep are theoretically excellent candidates for studying the effects of localized nocturnal discharges on cognition and behavior.

In this review we discuss the effects of subclinical encephalographic epileptiform activity during sleep on cognitive, behavioral, and other clinical features in children with BCECTS. We will not discuss the phenomenon of transitory cognitive impairment in BCECTS. ${ }^{8}, 9$ TCI is used for brief episodes of impaired cognitive function during an epileptic discharge, and has to be separated from the effects of nocturnal discharges on cognition. ${ }^{10}$ 


\section{STRATEGY AND SELECTION CRITERIA}

Data for this review were identified in January 2005 by searches from Medline, and cross-references from relevant articles. For Medline, the search terms ("cognitive" or "behavior"), and ("sleep" or "nocturnal"), and ("centrotemporal" or "rolandic") were combined. Only articles in English or articles with a detailed abstract in the English language were used.

\section{BCECTS}

The International League Against Epilepsy has defined BCECTS in the 1989 classification of epilepsies and epileptic syndromes; "BCECTS is a syndrome of brief, simple, partial, hemifacial motor seizures, frequently having associated somatosensory symptoms which have a tendency to evolve into generalized tonic-clonic seizures. Both seizure types are often related to sleep. Onset occurs between the ages of 3 and 13 years (peak 9-10 years), and recovery occurs before the age of 15-16 years. Genetic predisposition is frequent, and there is a male predominance. The EEG has blunt highvoltage centrotemporal spikes, often followed by slow waves that are activated by sleep and tend to spread or shift from side to side.". ${ }^{11}$

Because of increasing confusion about the definition, Lundberg and Eeg-Olofsson recently proposed a new classification in order to delineate BCECTS. They defined; I: BCECTS "pure" according to the original definition; II: BCECTS "plus" including BCECTS with special features like affective symptoms or speech dyspraxia, and BCECTS with abnormal EEG patterns; III: BCECTS-related disorders as ABFEC, CSWS and Landau-Kleffner syndrome; and IV: structural brain lesions with signs and symptoms as in BCECTS. 12

\section{BCECTS with atypical clinical characteristics}

Four typical types of seizures can be separated: simple partial somatosensory seizures ("aura"); simple partial hemifacial motor seizures with speech arrest and drooling; seizures with loss of consciousness and gurgling or grunting noises; and secondary generalized tonic-clonic seizures. ${ }^{13}$ However, atypical features in BCECTS are not uncommon. ${ }^{14,15}$ The distinction is made on the presence of atypical seizure characteristics, ${ }^{14,15,16}$ atypical EEG features, ${ }^{14}$ seizure control requiring more than one antiepileptic drug, ${ }^{17}$ or the existence of behavioral or cognitive problems. ${ }^{18}$.

Wirrell et al retrospectively studied 42 children with BCECTS. ${ }^{14}$ The authors found atypical clinical characteristics such as status epilepticus, developmental delay, daytime only seizures, screaming as a seizure component, postictal Todd's paresis, or attention deficit disorder with or without Tourette syndrome, in $50 \%$ of children. Developmental delay was noticed in eight children (19\%). Atypical EEG features such as an unusual location of spikes, atypical spike morphology, and abnormal background pattern were noticed in $31 \% .{ }^{14}$ Verrotti et al followed 64 children with common BCECTS and 11 children with BCECTS with atypical seizures (diurnal seizures, screaming as a sei- 
zure component, aura, or postictal Todd's paralysis) for a period of at least eight years. At the end of follow-up, 5/64 children ( $8 \%$ ) with common seizures showed language delay, compared to $5 / 11$ of children $(46 \%)$ with atypical seizures $(\mathrm{p}<0.0001) .{ }^{15} \mathrm{Vi}$ nayan et al studied 50 children with BCECTS. 26 children $(52 \%)$ had atypical seizure characteristics, including leg jerking, lateral body torsion, unilateral body sensations, epigastric pain and ictal blindness. Abnormal language function was significantly correlated to the occurrence of atypical seizure characteristics $(p=0.021)$. However, the absolute numbers or percentages were not mentioned in this article. ${ }^{19}$

In conclusion, atypical clinical characteristics are frequent in children with BCECTS. Especially, atypical seizure characteristics are related to a high incidence of language delay.

\section{Seizures, spike and wave related symptoms, paraictal symptoms, and status epilepticus of BCECTS}

The symptoms of BCECTS can be classified into three categories: I: classical focal seizures; II: spike and wave related symptoms; and III: paraictal symptoms..$^{20,21}$ Classical (and atypical) focal seizure characteristics have been described in the previous heading. Spike and wave related symptoms are brief neurological or neuropsychological signs that have a relatively strict temporal relation with individual parts of focal or generalized epileptiform discharges, for example facial twitches or the phenomenon of TCI. ${ }^{21}$ A paraictal symptom is defined as an acquired progressive or fluctuating motor or cognitive deficit. Motor symptoms like intermittent drooling, ${ }^{22}$ oromotor dyspraxia, ${ }^{23}$ or linguistic problems ${ }^{24,25}$ are considered paraictal symptoms, but a postictal deficit like Todd's paresis is not. ${ }^{21}$ In status epilepticus of BCECTS drooling, difficulties in swallowing and anarthria do occur as well. 16,26,27

In summary, symptoms due to seizures, spike-and-wave related symptoms, paraictal symptoms, and status epilepticus of BCECTS are distinguished.

\section{BCECTS, Landau-Kleffner syndrome, CSWS and ABFEC}

Less than $1 \%$ of children with BCECTS evolve into the Landau-Kleffner syndrome, CSWS, or ABFEC. ${ }^{28}$ Many authors consider the usage of carbamazepine in children with BCECTS a risk factor for the development of Landau-Kleffner syndrome, CSWS, or $\mathrm{ABFEC}{ }^{2,16,29-35}$ but, this only happens rarely ${ }^{34}$. Also phenobarbitone can cause an aggravation in children with BCECTS.34,36

In a retrospective reexamination of 26 children who developed Landau-Kleffner syndrome, CSWS, or ABFEC, and 352 children with uncomplicated BCECTS, Fejerman et al were not able to predict a complicated evolution of BCECTS. In both the group of children with Landau-Kleffner, CSWS, or ABFEC and the uncomplicated group the authors found typical clinical features and typical EEG records at seizure onset. $^{31}$ 
Massa et al studied sleep recordings of 7 children initially diagnosed with BCECTS who developed the Landau-Kleffner syndrome later. At onset, sporadic seizures occurred, mainly during sleep. All had partial seizures with contractions of face and arm. Secondary generalized seizures occurred rarely. After several months, atypical absences (in 6/7 children) and auditory agnosia (in 7/7 children) developed. Attention deficit, impulsiveness, and aggressiveness were noticed in all. In order to predict the development of Landau-Kleffner syndrome, the first made EEG's were analyzed retrospectively and compared to 6 children with uncomplicated BCECTS. A specific EEG pattern in the first sleep registration was recognized in those children who developed the Landau-Kleffner syndrome. Unilateral localized slow-waves, bilateral independent spike-and-wave discharges, and major activation of spike-and-wave discharges during sleep exceeding $40 \%$ of the first sleep cycle and $30 \%$ of the following cycles was seen in all children in the Landau-Kleffner group and never recorded in the children with uncomplicated BCECTS. ${ }^{18}$

In conclusion, it is not possible to predict the development of Landau-Kleffner syndrome, CSWS, or ABFEC on early seizure characteristics. It is unclear whether this deterioration can be predicted by looking for EEG characteristics in early EEG recordings.

\section{Cognitive and behavior problems in BCECTS}

In 1972, Blom et al noted that none of his patients had experienced difficulties at school or in choosing a profession later. ${ }^{37}$ Beaumanoir et al were the first to describe cognitive problems in children with BCECTS. ${ }^{38}$ In 10 children, tests of cognitive function were performed. One girl had a low IQ; she had average or below average scores on all tests. Two children with a predominantly left-sided focus performed below normal on a recognition test and two children with a right-sided focus obtained a low score on visuomotor coordination (Bender test). However, in spite of their results, the authors concluded that there is no evidence to indicate that rolandic spikes in epileptic children are relevant. ${ }^{38}$

Lerman \& Kivity compared two groups of children with BCECTS. In their retrospective study of BCECTS, doctors still believed that BCECTS was a chronic disorder and advised the parents to protect the child and restrict its activities. In the second, prospective group, doctors were aware of the benign course of BCECTS and advised parents not to overprotect their children or restrict their activities. In the first group mild behavior and learning difficulties were common. Those problems were hardly noticed in the second group. Behavior and learning problems improved after phenobarbitone was replaced by other antiepileptic medication. ${ }^{39}$ In accordance with the study by Lerman \& Kivity, Camfield and Camfield stated that BCECTS only disrupts the development of a child if it interferes with the child's changes for normal friendships. ${ }^{40}$

Heijbel \& Bohman studied 16 children with BCECTS. 13 children were seizurefree for more than one year. Their mean IQ was slightly higher, but not significantly different from healthy controls. The children with BCECTS showed significant worse 
scores on visuomotor coordination (Bender test) compared to controls. No differences were noticed regarding school adjustment and behavior. ${ }^{41}$

Beaussart \& Faou studied 355 children who had presented with a seizure and showed EEG characteristics of BCECTS. 31 children (9\%) showed neuropsychiatric abnormalities or possible encephalopathy. ${ }^{42}$ But, no definition of "neuropsychiatric abnormalities" or "possible encephalopathy" was given in this article.

Loiseau et al studied 168 children with BCECTS. 28 children (16.7\%) had a mildly subnormal IQ, learning difficulties, inattention, hyperactivity, or emotional liability. Surprisingly, the authors found that the social level in adulthood for children with BCECTS seemed to be higher than for children without epilepsy. ${ }^{43}$

Piccirilli et al selected 22 children with BCECTS in order to study hemispheric lateralization of language. 14 had a left-sided electroencephalographic focus and eight children a right-sided. Children were asked to perform two tasks simultaneously. A verbal task was given to repeat the names of four animals. This verbal task was combined with right or left hand finger tapping. In children with a right-sided electroencephalographic focus and in healthy controls, the verbal task showed more interference on the right hand than on the left hand tapping rates. In children with a left-sided electroencephalographic focus, the interference was equal on left hand and right hand performance. These results suggest involvement of the right hemisphere in language in children with a left-sided focus. The authors concluded that epileptiform activity in BCECTS can modify the hemispheric lateralization of language. ${ }^{44}$

D'Alessandro et al reported the neuropsychological data of 44 children with BCECTS. The authors selected children who were seizure-free for more than 6 months and without medication. Specific cognitive problems were found on attention, language, and visuomotor coordination tasks. Children with a bilateral spike or spikewave focus had the worst scores. The Wechsler FSIQ, PIQ, and VIQ were within the normal range. In a follow-up assessment, 11 children were retested when they were free of both seizures and EEG abnormalities for more than four years. The problems in attention, language and visuomotor coordination had disappeared in all. ${ }^{45,46}$

Deonna et al reported three children with BCECTS. They all suffered from speech disturbances like word finding difficulties, poor articulation, phonological errors, and stuttering. Language comprehension was normal in all. One girl also showed anxiousness and aggressiveness and she refused to go to school. ${ }^{24}$

Piccirilli et al studied attention problems in children with BCECTS. 14 children with a left-sided rolandic focus, 14 children with a right-sided focus, 15 children with a bilateral focus, and 15 controls were examined with the cancellation task. This is a complex test involving several skills. In children with no major cognitive impairments, successful examination mainly depends on attention. Children with a right-sided or bilateral focus did significantly worse than children with a left-sided focus. There was no difference between children with a left-sided focus and controls. ${ }^{47}$

Wirrell et al found that in a group of 42 children with BCECTS, eight (19\%) had a mild developmental delay. No neuropsychological testing was done in this study. ${ }^{14}$ 
Morooka et al studied 18 children with BCECTS. Eight (44\%) children had developmental disabilities; learning disabilities, hyperkinesis, ADHD, abnormal behavior, and clumsiness were noted. ${ }^{48}$

Weglage et al studied 40 children with centrotemporal spikes. 20 had partial simple seizures, and 20 had an EEG made because of headache. The control group consisted of 40 children matched for age, sex, and socioeconomic status. The children with centrotemporal spikes and rolandic seizures did not differ from the children with centrotemporal spikes and headache. Combined, they did significantly worse on the Wechsler FSIQ and PIQ, visual perception, short-term memory, psychiatric status and some subtests in a fine motor performance task, compared to the controls. ${ }^{49}$

In a study about language dysfunction in children with BCECTS, Staden et al studied 20 children prospectively. Children were selected because of BCECTS, irrespective of a history of learning or language problems. 13 children $(65 \%)$ showed language difficulties in two or more of 12 language tests. Eight children had specific language impairment and five had language and intelligence problems. ${ }^{50}$

Croona et al studied 17 children with BCECTS with typical seizure manifestations and EEG characteristics, and 10 controls matched for age, sex and estimated intelligence. The children with BCECTS did worse on auditory-verbal memory and auditoryverbal learning as well as some of the executive functions. ${ }^{51}$

Gündüz et al studied 20 children with BCECTS. All were treated with carbamazepine and were seizure-free. 10 children (50\%) had language delay or learning problems. ${ }^{52}$

Metz-Lutz et al prospectively studied 22 children with BCECTS after a first epileptic seizure. Within the first half year, nine children began with academic problems. In five children, behavioral problems were noted as well. In 14 children (64\%) neuropsychological testing showed significant problems in short term memory, learning and attention. The children were retested 18 months later. The children whose EEG had become completely normal in sleep and wake, showed significantly higher scores than the children whose EEG still showed epileptic activity. ${ }^{53}$

Deonna et al studied neuropsychological and EEG results in 22 children with benign partial epilepsy; 19 had BCECTS and three had benign partial epilepsy with occipital spikes (Panayotopoulos type). Nine children were on medication at the moment they were included; seven of them used carbamazepine. 21/22 children had normal IQ's. Four children had delayed language development and needed speech therapy. Eight children had isolated weak scores in one or several neuropsychological tests. The children were retested 8-27 months later. The four children with delayed language development had improved, but none had reached normal levels. In the children with problems in neuropsychological tests, most results had improved while some other test results did not. In all children, several EEG's were recorded. The relation between neuropsychological test results and EEG findings was only described in three children with BCECTS and progressive paroxysmal EEG activity. In one boy, retesting showed slower speech. In another boy stagnation of oral language development was found. In 
a third child it was impossible to conclude whether poor results were due to poor cooperation, family situations, or other factors. ${ }^{54}$

Yung et al retrospectively analyzed cognitive and behavioral problems in 56 children with seizures and EEG characteristics suggestive for BCECTS. Seven children $(12 \%)$ manifested mild or moderate intellectual problems, eight $(14 \%)$ had behavioral problems, and eight (14\%) had specific learning disabilities. 41 children (72\%) had no cognitive or behavioral problems. ${ }^{55}$

Chevalier et al studied 13 children with benign focal childhood epilepsy. In most children the EEG showed a rolandic focus. Seven children were on medication. 13 matched controls were studied as well. Four tests for measuring impulsivity and control of inhibition were used: the Continuous Performance Test, Stop Signal Paradigm, the Stroop Test, and the MFFT. The children with epilepsy did worse on the MFFT, made more errors on the interference condition on the Stroop test, and had a longer response time to the Stop Signal compared to controls. In the epilepsy group, no difference between children with or without medication was found. ${ }^{56}$

Schouten and Oostrom studied 15 children with BCECTS in the age of seven-years or older at time of diagnosis. Nine children $(60 \%)$ were treated with antiepileptic drugs. Two children (13\%) already had repeated a year at school, and six children (40\%) received special education at school. In a control group of 48 children, these percentages were $21 \%$ and $27 \%$ respectively. During the year after diagnosis those numbers did not increase in both children with BCECTS and controls. ${ }^{57}$

Hommet et al analyzed cognition in 23 adolescents and young adults completely recovered from BCECTS. No difference was noticed between the persons recovered from BCECTS and 33 healthy controls with respect to memory, language and executive functions. ${ }^{58}$

Al-Twaijri and Shevell retrospectively analyzed the medical records of 66 children with BCECTS. 12 (18\%) had behavioral or learning difficulties. In the children without medication or on monotherapy, fewer children had behavioral or learning difficulties than in the group of children on two antiepileptic drugs (14\% vs. 36\%). ${ }^{17}$

Fonseca et al studied school performance in 20 children with BCECTS and 20 controls. Children with BCECTS showed significantly lower results, especially in reading. ${ }^{59}$

Lindgren et al studied 32 children aged 7-15 years with BCECTS. 26 children (81 $\%$ ) were tested again 2 $\frac{1}{2-3}$ years later, using the same neuropsychological techniques. A matched group of 25 children without epilepsy was tested twice as well. During the first assessment children with BCECTS scored significantly lower on memory and learning of auditory-verbal material, delayed recall, executive functions, reading and writing ability. No difference in immediate memory, memory and learning of visuospatial material, and intellectual ability was found. On re-examination, no difference between the BCECTS children and control-group was noticed, except for verbal fluency. No EEG recordings were made during the second assessment. ${ }^{60}$ 
Völkl-Kernstock et al studied 21 children with BCECTS and a matched control group. Children with BCECTS showed significant lower results in tests on spatial perception, spatial orientation and spatial memory. ${ }^{61}$

Monjauze et al studied language in 16 children with BCECTS. Seven children were seizure-free and showed no EEG abnormalities for more than one year. Six children repeated a class and nine already had speech-language therapy. ${ }^{62}$ The criteria defined by Staden et al were used: a Z-score below one standard deviation on two or more of the seven language tests..$^{50}$ Nine of 16 children (56\%) fulfilled these criteria. Five children even had very low scores: below 1.65 SD on two or more language tests. The most affected domains were expressive grammar and literacy skills. No difference between children with active BCECTS and BCECTS in remission was found. However, Monjauze et al found that children with a short duration of epilepsy showed better scores on reading and spelling. ${ }^{6}$

Papavasiliou et al studied 32 children with BCECTS. None of them had atypical clinical or EEG features or showed cognitive or behavioral regression. 26 children were on carbamazepine monotherapy and five did not use any antiepileptic medication. Children were tested on reasoning skills, spelling, reading aloud, reading comprehension, and dyslexia. Besides, parents were asked about the school performance of their children. Results were compared to the 36 controls without epilepsy or other chronic disease. As a group, children with BCECTS scored significantly worse on spelling, reading aloud, reading comprehension, dyslexia-type errors. They frequently had a below-average school performance. 11 children had severe written language problems; in nine of them EEG abnormalities and seizures had resolved after 1-41/2 years but the learning problems were persistent. EEG registrations were made in wake and sleep. No relation between EEG characteristics and language problems was found. ${ }^{63}$

Vinayan et al studied 50 children with BCECTS. All of them used anti-epileptic drugs, 11 children used phenobarbitone. Educational problems were found in 26 $(52 \%)$. Deficits in neuropsychological or language tests were found in 19 children $(38 \%) \cdot{ }^{19}$

Northcott et al described 42 children with BCECTS. Children were recruited from six EEG laboratories. 27 (64\%) children used antiepileptic medication. Their mean FSIQ was 105. Test results were compared to normative American data. Their results scored significantly below normative data in memory and phonologic processing skills. An analysis of the relation between neuropsychological and language results, and EEG features in wake, drowsiness, and sleep onset. EEG features were minimally associated with cognitive difficulties. However, a problem in this study is that EEG and neuropsychological testing were not performed during one admission. In only $83 \%$ neuropsychological assessment was performed within 12 months of the EEG analysis. ${ }^{64}$ Several studies about ADHD and childhood epilepsy have been published, but none about ADHD and BCECTS. ${ }^{65}$ 


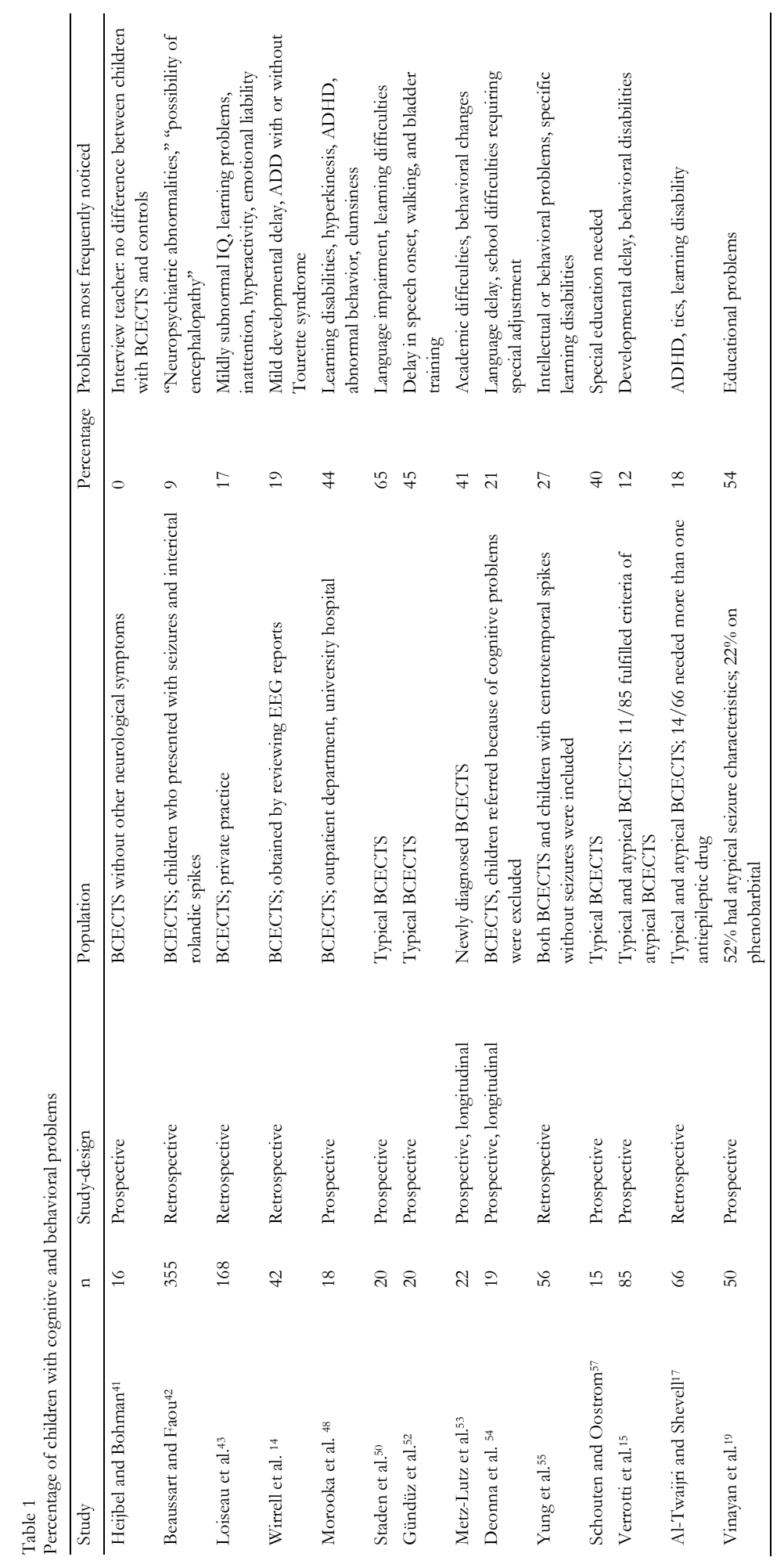




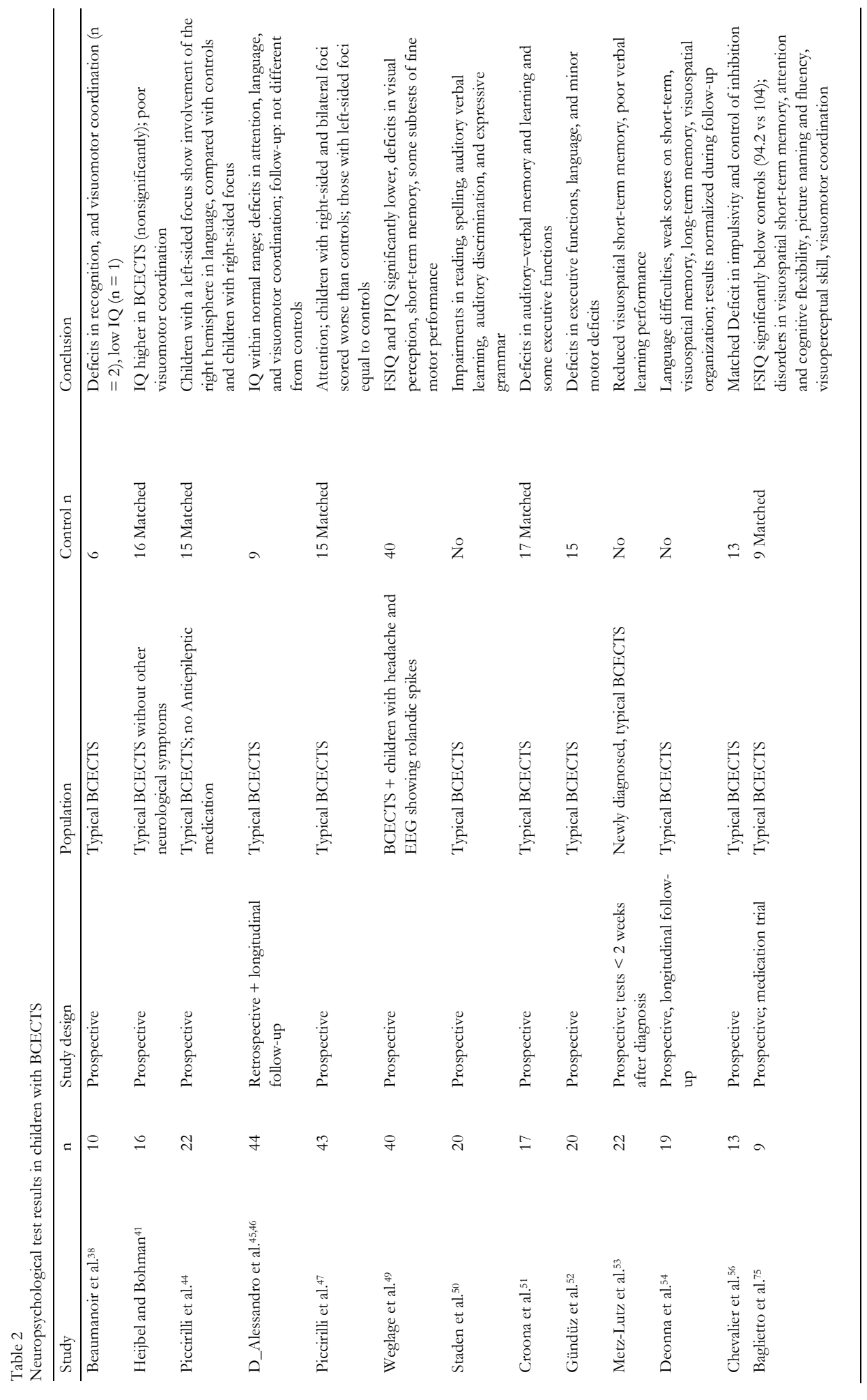




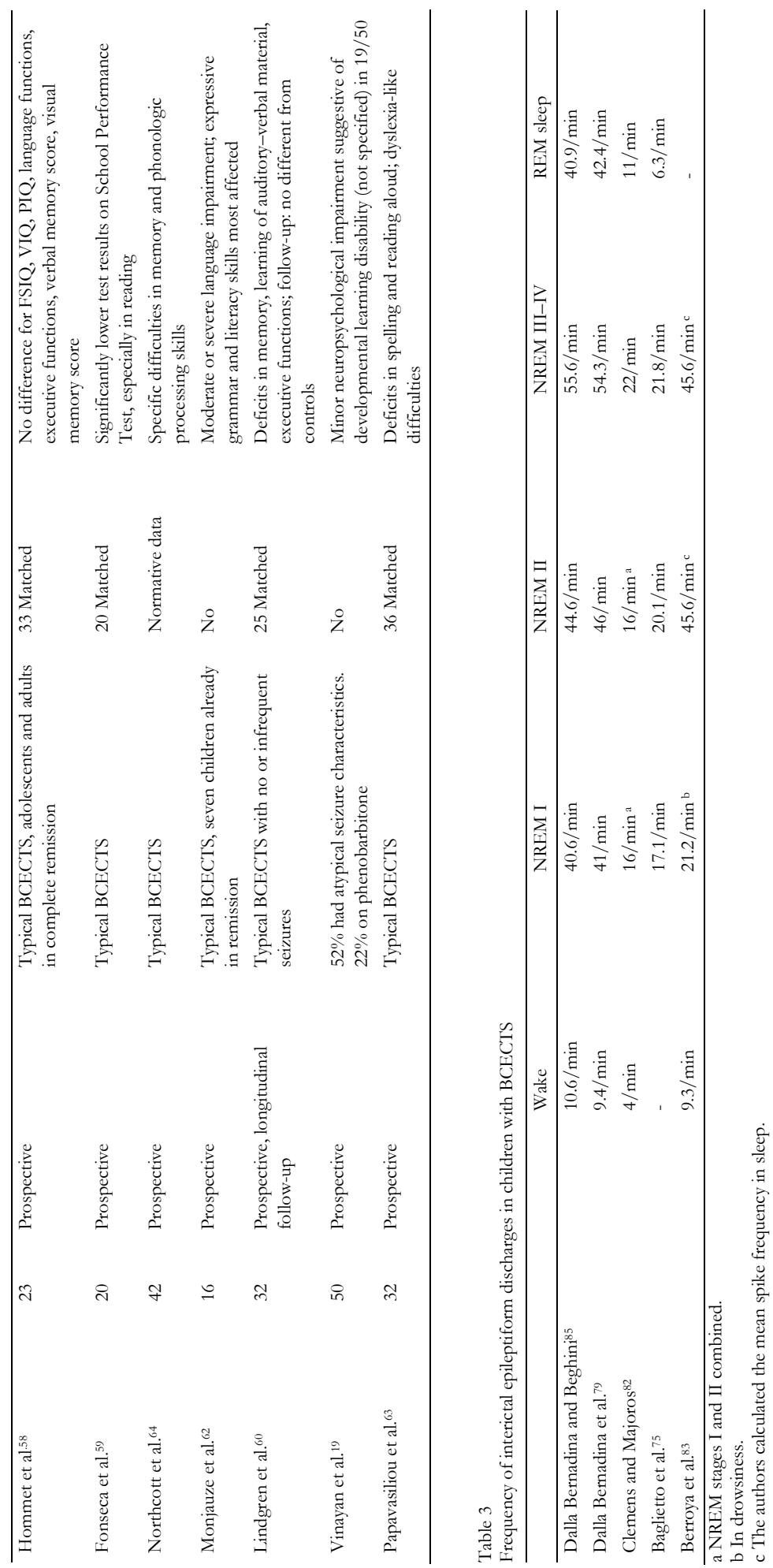


In conclusion, many series about cognitive and behavior difficulties in children with BCECTS have been reported in the last three decades (Table 1). Although the FSIQ is often within the normal range, language delay, learning disabilities, and academic problems are often noted. But also in series of children with uncomplicated BCECTS, children have lower average results on neuropsychological tests involving visuomotor coordination, some executive functions, sustained attention, and language issues like spelling, reading aloud, reading comprehension, memory and learning of auditory-verbal material, delayed recall, and verbal fluency, and compared to controls (Table 2). When children are retested after several years, neuropsychological deficits have disappeared in most of them. No cognitive deficits are noted in adulthood. The social-economic development is normal.

\section{Nocturnal seizures in BCECTS}

Seizures in BCECTS occur mostly when a child is asleep or drowsy when going to sleep or shortly after awakening. ${ }^{66,67}$ Beaussart analyzed the medical history of 221 children with seizures and rolandic spikes or sharp waves. $51 \%$ had nocturnal seizures only. ${ }^{68}$ Blom et al found that in 40 children with BCECTS, $22(55 \%)$ had seizures only during sleep ${ }^{37}$ and in a later study Blom and Heijbel reported 10/17 (59\%). ${ }^{69}$ Loiseau et al analyzed 168 children with BCECTS; 77\% had seizures only during sleep. ${ }^{43}$ Peters et al found that 50/79 (63\%) children had nocturnal seizures only. ${ }^{70}$ In a meta-analysis, Bouma et al found that $79.5 \%$ of seizures had occurred during sleep. ${ }^{71}$

In conclusion: seizures during sleep are common in children with BCECTS and more than half of the children have nocturnal seizures only.

\section{Nocturnal interictal discharges in BCECTS}

Activation of interictal epileptiform discharges during sleep is well known in BCECTS. ${ }^{72-74}$ Several classifications of the frequency of epileptiform discharges are described. The spike-index is calculated by dividing the number of spikes in a sleep stage/ time spent in that sleep stage. ${ }^{73}$ It is classified as "high" ( $>10$ discharges/min) and "low" (<10 discharges/min), ,0,75 or divided into "without spikes", "single spikes" (1-5/min), "frequent spikes" (6-10/min), and "very frequent" (>10/min) [49]. Sometimes, the percentage of time of paroxysmal activity in sleep $(<10 \%, 10 \%-50 \%, 50 \%$ $85 \%,>85 \%$ ) is calculated. ${ }^{76,77}$ Engler et al used another classification and divided the density of discharges into: no discharges $(\mathrm{N})$; rare discharges $(+)$; frequent discharges $(++)$; and continuous or near continuous discharges $(+++) \cdot{ }^{78}$

In the EEG study of 17 children with BCECTS by Blom and Heijbel, sleep was medication-induced. Five (29\%) of the children had rolandic discharges only during sleep with normal EEG recordings when awake. ${ }^{69}$

Dalla Bernadina et al studied 92 children with BCECTS. In 18 children (20\%) rolandic spikes were not present in repeated waking EEG recordings, and only present in sleep. ${ }^{79}$ Deonna et al studied 22 children; 19 had BCECTS. In seven children (32\%), interictal activity was only found during sleep in one or several EEG recordings. ${ }^{54}$ Not 
only during wakefulness, but also in REM sleep, centrotemporal spikes can be absent. ${ }^{80}$

Gozukirmizi et al studied sleep EEGs in 20 children with BCECTS. The spike rate was significantly higher in all NREM stages than during wake. ${ }^{81}$ Clemens and Majoros noticed that the intensity of spike activation of each sleep stage decreases throughout the night. ${ }^{82}$ However, a significant reduction of the amount of spikes between the sleep cycles was not found in 9 children with BCECTS studied by Nobili et al. ${ }^{73}$ Massa et al studied six children with classical BCECTS. They noticed that in the first slow wave sleep cycle; discharges never exceeded $20-40 \%$ of time. In the following sleep cycles, discharges were below $10-20 \%$ of time. ${ }^{18}$ Recently, Berroya et al. noted that spike frequency is equal during sleep onset and slow wave sleep. According to the authors a routine EEG including sleep onset provides information similar to a long overnight recording. ${ }^{83}$

Beaumanoir et al studied 26 children with typical BCECTS. During slow wave sleep, centrotemporal spikes increased in number and amplitude, and in all children, bilaterally synchronous and symmetrical discharges occurred. ${ }^{38}$ During deep NREM sleep, discharges are sometimes more diffuse, involving adjacent regions of the ipsilateral hemisphere and sometimes the Rolandic area of the contralateral hemisphere. ${ }^{79}$ Activation of interictal discharges during sleep is not only seen in children with BCECTS. In healthy children without a history of seizures or febrile convulsions ${ }^{3,84}$ and in children with ADHD and centrotemporal spikes ${ }^{65}$ the same activation can occur.

In summary, activation of centrotemporal discharges during sleep in children with BCECTS is common (Table 3). In about 30\% of children with BCECTS discharges only occur during sleep; this makes a sleep EEG mandatory if a regular EEG does not show epileptiform activity when BCECTS is suspected. ${ }^{66}$ In most other children the frequency of epileptiform discharges is higher in sleep than in wake. In sleep, focal discharges can spread to adjacent regions or become bilaterally synchronized.

\section{Disturbance of sleep in BCECTS}

In a group of 10 children with BCECTS, sleep was registered by Dalla Bernardina and Beghini during one night. The organization of sleep and the percentages of the different sleep stages were normal. No seizures occurred during these registrations. ${ }^{85}$ In the study by Gozukirmizi et al, 20 children with BCECTS had a nocturnal EEG recording. All had normal sleep stages. ${ }^{81}$

Clemens and Oláh studied 11 children with BCECTS and eight controls. Sleep was recorded during the second night of admission to prevent a "first night effect". The children with BCECTS used no medication at all, or only a low dose of one antiepileptic drug, and were seizure-free for more than one month. No differences on sleep parameters between the BCECTS group and controls were found, except for waking after sleep onset. Children with BCECTS were awake for 24 minutes a night; the control group for 6 minutes $(\mathrm{p}<0.05)$. The mean number of awakenings a night did not 
differ (5.1 vs. 4.8). ${ }^{86}$ A nocturnal epilepsy syndrome characterized by paroxysmal EEG discharges in sleep immediately followed by an awakening without other paroxysmal symptoms, has been described. ${ }^{87}$ In children those epileptic awakenings are often preceded by an ictal discharge described as frontal arousal rhythm. ${ }^{88}$ Epileptic awakenings have not been described in BCECTS. No reports about daytime sleepiness in BCECTS have been published.

Dalla Bernadina and Tassinari were the first to describe an EEG registration during a nocturnal rolandic seizure. Despite myoclonias on the right side of his face, the 10year-old boy did not awaken. ${ }^{89}$ This phenomenon of a partial seizure involving the face without awakening is also described by Parmaggiani and Guerrini ${ }^{90}$ and Arzimanoglou et al. ${ }^{35}$

In summary, the organization of sleep is not affected and the number of arousals from sleep is not increased in BCECTS.

\section{Spike frequency and cognitive and behavioral deficits are related in children with BCECTS.}

In the study performed by Weglage et al, children with frequent spikes at the time of testing $(>6 / \mathrm{min})$ scored significantly lower scores for FSIQ and PIQ, but not for VIQ, compared to children with no or single spikes $(<5 / \mathrm{min})$. Children with no or single spikes $(<5 / \mathrm{min})$ did not perform significantly lower than controls. Although EEG registrations in sleep were made in all children, the frequency of spikes in sleep was not mentioned. ${ }^{49}$

Staden et al studied 20 children with BCECTS. 10/13 children with language problems had a discharge rate of centrotemporal spikes of more than $10 / \mathrm{min}$. In the group without language problems only $2 / 7$ children had a rate of more than $10 / \mathrm{min}$ $(\mathrm{P}=0.052) .{ }^{50}$ No sleep EEG was recorded in this study. Also children with BCECTS and reading problems had a significantly higher amount of spikes in wake compared to children with BCECTS without reading problems $\left(11.7 / \mathrm{min}\right.$. vs. 5.0/min.; p < 0.05). ${ }^{59}$

Massa et al studied 35 children with BCECTS. 25 (72\%) children had normal behavioral and intellectual functioning. 10 children $(28 \%)$ had problems in education or social-familial maladjustment. In sleep, the number of electroencephalographic discharges was between $1 / \mathrm{min}$ and $90 / \mathrm{min}$ in the uncomplicated group. In the group with complicated rolandic epilepsy, the number of discharges in sleep was between $5 / \mathrm{min}$ and $120 / \mathrm{min}$. The authors concluded that the frequency of interictal paroxysms in sleep was not sufficient to predict behavioral or cognitive problems in an individual child diagnosed with BCECTS. ${ }^{18}$

In conclusion: several studies indicate that a high spike frequency $(>5 /$ min or $>10 /$ min) in wake is related to language delay, and cognitive or behavioral difficulties. 

cbildren with BCECTS

Gregory and Wong collected EEG recordings retrospectively, looking for rolandic spikes. The authors analyzed EEG recordings of 366 children. Only $77 \%$ of those children had had seizures. A dipole spike was defined as a discharge with negative polarity in the midtemporal region and simultaneous positivity in the ipsilateral frontal region. Subnormal intelligence was found in 20/98 (20\%) of the children with dipole spikes and in $144 / 252(57 \%$; $<$ 0.001) in the children with non-dipole spikes. Also, school difficulties were found significantly less in the children with a dipole spike. ${ }^{91}$

Massa et al studied 35 children with BCECTS. 25 (72\%) children had normal behavioral and intellectual functioning. 10 children $(28 \%)$ had problems in education or social-familial maladjustment. The authors formulated six EEG criteria; I: intermittent slow-wave focus; II: multiple asynchronous spike-wave foci; III: long spike-wave clusters; IV: generalized $3 \mathrm{~Hz}$ (absence-like) spike-wave discharges; V: atonia, myoclonia, or brief alteration of consciousness related to electroencephalographic discharges; and VI: abundance of interictal abnormalities during wakefulness and sleep. Different combinations of at least three of six EEG patterns for a period of at least six months were seen in all children with complicated BCECTS and only in one child with uncomplicated BCECTS. ${ }^{33}$ De Saint-Martin et al found that an intermittent slow wave focus and a strong activation of interictal activity during sleep are significantly related to cognitive deficits and attention disorders. ${ }^{92}$

In summary, cognitive and behavioral problems in children with BCECTS are strongly related to the occurrence of specific atypical EEG characteristics (Table 4). Children with discharges showing a temporal-frontal dipole show less cognitive problems compared to children with focal central, temporal or centrotemporal discharges.

Table 4

EEG characteristics related to complicated BCECTS

\begin{tabular}{ll}
\hline Nondipole spike a & 95 \\
\hline Intermittent slow wave focus & 18,92 \\
Multiple asynchronous spike-wave foci & 18 \\
Long spike-wave clusters & 18 \\
Generalized 3-Hz spike-wave discharges & 18 \\
Atonia, myoclonia, or brief alteration of conciousness & 18 \\
Abundance of interictal abnormalities in awake state or sleep & 18 \\
Strong activation of interictal spikes during sleep & 92 \\
\hline
\end{tabular}

a A dipole spike is defined as a discharge with negative polarity in the midtemporal region and simultaneous positive polarity in the ipsilateral frontal region. ${ }^{95}$ 


\section{Treatment of centrotemporal discharges: medication}

Gross-Selbeck reported a retrospective study of 42 children with BCECTS. They were selected from a series of 60 children with benign partial epilepsies of childhood. 16 children were treated with carbamazepine. The EEG showed a temporary deterioration in two children. In the other children treated with carbamazepine, the EEG did not change. 17 children were treated with sulthiame; one discontinued the medication because of side effects. In seven children the EEG normalized, the EEG showed a clear improvement in another seven, and in two children no change was noticed. ${ }^{93}$

Mutsidome et al reported a trial in 40 newly diagnosed children with BCECTS. 20 were given clonazepam, 10 children sodium valproate, and 10 children received carbamazepine. In each child, two EEGs were recorded; both in natural sleep and awake. The first EEG was recorded before administration of the drug, and the second EEG was made after four weeks of medication. Centrotemporal discharges disappeared in $15 / 20(75 \%)$ children treated with clonazepam. The discharges disappeared only in $1 / 10(10 \%)$ children treated with sodium valproate, and in none of the children treated with carbamazepine. ${ }^{94}$ Later, Mitsudome et al also reported that clonazepam is effective is suppressing rhythmic slow waves in children with BCECTS..$^{95}$

De Negri et al stated that treatment with diazepam $0.5 \mathrm{mg} / \mathrm{kg} /$ day for three weeks is effective in neutralizing the paroxysmal epileptiform activity both in sleep and wake in children with BCECTS.96

A double-blind, randomized, placebo-controlled study evaluating the effect of sulthiame in BCECTS was reported recently. ${ }^{97}$ Sulthiame is a sulphonamide derivative, the best documented effect is inhibition of the CNS carbonic anhydrase enzyme. ${ }^{98} \mathrm{It}$ is particularly effective in treating seizures in BCECTS. $32,93,98$

Bast et al evaluated the effects of sulthiame on the nocturnal EEG registrations made in this trial. 31 children were randomized to sulthiame treatment. EEG recordings during sleep and wake were made at screening, after 4 weeks, 3 and 6 months. In $9 / 31$ children a constant normalization of specific pathologic EEG phenomena occurred, and in 12/31 a transient normalization. In the placebo group 1/35 showed a constant normalization, and $4 / 35$ a transient normalization. ${ }^{99}$ In both the study by Mutsidome et al. ${ }^{94}$ and Bast et al..$^{99}$ no tests on the effect on cognition or behavior were reported.

Kramer et al reported on the effect of carbamazepine and sulthiame on EEG activity in children with BCECTS. 73 children were treated with carbamazepine at any time. In 19 children an EEG was recorded after treatment was initiated. In 8 children (42\%) the EEG normalized. 27 children were treated with sulthiame. In seven children an EEG was made and in five $\left(71 \%, \mathrm{p}=\right.$ not significant) the EEG normalized. ${ }^{100}$ Whether the EEG recording included sleep, was not reported. Because of the fact that an EEG was only repeated in those children who were seizure-free after initiation of the antiepileptic medication, a possible bias was introduced in this study.

Engler et al studied 25 children; 16 children had BCECTS, five children had variants of BCECTS. Four children had cognitive problems only; their EEG showed focal sharp waves but they did not have seizures. All were treated with sulthiame. In 21 
children a control EEG was performed, both in wake and sleep. In four children $(19 \%)$ discharges completely disappeared, in nine children (43\%) the number of discharges decreased and in eight children (38\%) the density did not change. ${ }^{78}$

In summary, treatment with clonazepam, diazepam, and to a lesser extend sultbiame is effective in reducing the number of centrotemporal discharges. There is no study reported about the effectiveness of clobazam. Carbamazepine and sodium valproate are ineffective in suppressing centrotemporal discharges (Table 5).

\section{Treatment of nocturnal EEG discharges: the effects on behavior and cognition}

In a letter, De Negri et al described that treatment with diazepam for three weeks is very effective in suppressing paroxysmal EEG activity both during wake and sleep in children with BCECTS. This effect lasted several months, and only a few children needed a second treatment scheme. With remission of the paroxysmal activity, a consistent improvement of neuropsychological disturbances and behavior was noticed. ${ }^{96}$

Baglietto et al examined nine children in the age of 6-11 years with BCECTS. The children were seizure-free for more than one month and received sodium valproate monotherapy. They all had a marked activation of interictal discharges during sleep; their spike index during sleep was more than $10 / \mathrm{min}$., confirmed by two sleep EEG recordings. The mean spike index was $23.5 / \mathrm{min}$. in NREM sleep. EEG recordings were performed with a 6-month interval in between. The study was started after the second EEG (T0). Children underwent sleep EEG registrations until the spike index was less than $5 / \mathrm{min}$ (T1). Neuropsychological evaluations were performed with a 6-12 month interval. In five children the number of epileptic discharges improved spontaneously (although valproate was continued), four children were treated with diazepam and valproate. Diazepam $0.5 \mathrm{mg} / \mathrm{kg} /$ day (divided in three doses a day) was administered orally for 3-4 weeks and gradually reduced within two weeks. In the group of spontaneous remission, the mean interval between T0 and T1 was 20 months. In the diazepam group, the mean interval was 9 months. Mean spike index at T1 was $2.3 / \mathrm{min}$ in NREM sleep. Full scale IQ improved from 94.2 at T0 to 110.5 at T1 $(\mathrm{p}<0.0001)$. At T1, children showed an increased verbal IQ $(p<0.01)$ and performance IQ $(p<0.0001)$. Also visual motor abilities $(\mathrm{p}<0.0001)$, non-verbal short-term memory, sustained attention and mental flexibility, picture naming, fluency, and visual-perceptual performance $(\mathrm{p}<0.001)$ improved..$^{75}$

Pressler et al treated 61 children with well-controlled or mild epilepsy of various types in a double-blind, placebo-controlled, cross-over study. Treatment was with lamotrigine or placebo. The global rating of behavior improved significantly in those children who showed a significantly reduction in frequency or duration of epileptic discharges. The type of epilepsy did not influence the results; however, the number of children with BCECTS was not given in this abstract. EEG recordings during sleep were not performed in this study. ${ }^{101}$ 


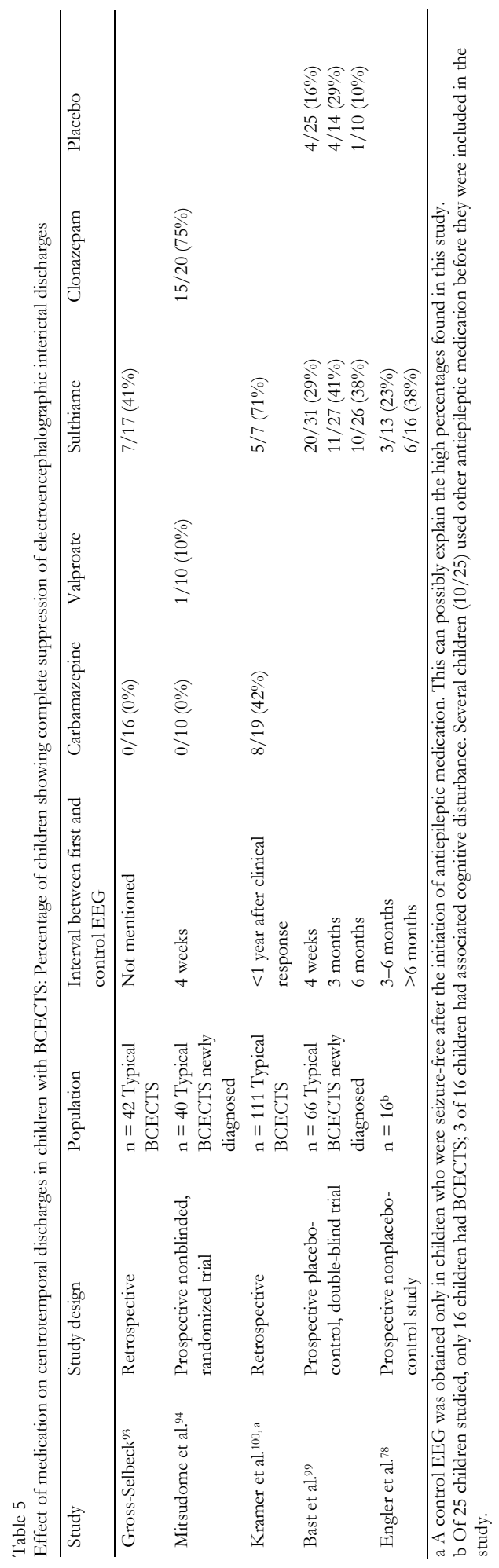


Engler et al treated children with BCECTS, BCECTS-variants and children with cognitive problems associated with electroencephalographic centrotemporal discharges but without seizures. 19 children had neuropsychological testing before and under sulthiame treatment. The results of children with BCECTS and BCECTS-variants are not noted in this article. The four children with electroencephalographic discharges but without seizures, improved. ${ }^{78}$ However, the (average) results of neuropsychological tests of those four children were not given in this article.

Shamdeen et al retrospectively studied 38 children with learning or behavior problems. They all showed electroencephalographic centrotemporal discharges; none had seizures. 16 children had been treated with sulthiame. A significant correlation between treatment with sulthiame and a positive opinion of parents and teachers on behavior and intellectual performance was found. However, this positive effect was not confirmed by neuropsychological testing. ${ }^{102}$ One may argue whether there was any evidence-based argument to start treatment with sulthiame in those 16 children.

In children with BCECTS who are suspected of having a cognitive or learning disorder with no clear explanations, it seems reasonable to try antiepileptic therapy. ${ }^{54}$ But, it remains to be shown whether suppressing EEG discharges by antiepileptic therapy, can improve cognition in children. ${ }^{54}$ Besag advises to perform an overnight EEG monitoring in children with BCECTS if the medical history suggests deterioration in behavior or cognition. If carbamazepine seems to be associated with worsening behavior or school performances, it should be replaced by another antiepileptic drug. If possible, both behavior and EEG should be monitored when a medication change is made. ${ }^{103}$

In conclusion, no double-blind, placebo-controlled study about the effect of treatment of centrotemporal discharges in children with BCECTS on behavior and cognition has been published up till now. One non-blinded, prospective study showed a significant effect of treatment with diazepam for 3-4 weeks. ${ }^{75}$ Also De Negri reported that improvement of neuropsychological test results occurred after treatment with diazepam in children with BCECTS. ${ }^{96}$ There is no prospective trial in children with BCECTS reported concerning the effect of sulthiame on cognition and behavior.

\section{DISCUSSION}

Although BCECTS is generally considered an epilepsy syndrome without a possible major impact on cognitive functions or behavior, ${ }^{104,105}$ many studies showing cognitive and behavioral problems in children with BCECTS have been published in the last three decades. BCECTS in combination with learning or behavioral problems is often classified as complicated BCECTS. But, the definition of complicated BCECTS and the lineation from uncomplicated BCECTS is not made uniformly. In series of nonselected children with BCECTS the percentage of children with learning or behavioral difficulties ranges from $0 \% 0^{41}$ till $6 \%^{50}$. In children with BCECTS and atypical seizure 
characteristics, language delay is significantly more frequent than in children with typical seizures.

But also in series of children with uncomplicated BCECTS, children have lower average results on neuropsychological tests involving visuomotor coordination, some executive functions, and language issues like spelling, reading aloud, reading comprehension, memory and learning of auditory-verbal material, delayed recall, and verbal fluency, compared to controls. Children with a high frequency $\left(>6 / \mathrm{min}^{49}\right.$ or $>10 / \mathrm{min}$ ${ }^{50}$ ) of localized interictal discharges show lower test scores compared to children with low frequent discharges.

Also, problems in sustained attention can be found in children with BCECTS. $3,47,51$ Attention problems are related to right-sided discharges ${ }^{47}$ and to a high rate of epileptiform discharges in sleep. 3,75

In BCECTS, about half of the children have seizures only during sleep. Children with BCECTS have normal sleep organization and the number of arousals is not increased. ${ }^{86}$ Activation of interictal epileptiform activity in sleep is well known. Several classifications have been used; most are based on the average number of spikes per minute.

In a subset of children with BCECTS, no medication is started. When medication is indicated, carbamazepine, oxcarbazepine, valproate or sulthiamine is often prescribed. Carbamazepine ${ }^{93,94}$ and sodium valproate ${ }^{94}$ do not seem to influence the frequency of interictal discharges. Treatment with clonazepam ${ }^{94}$ or diazepam ${ }^{75,96}$ and in a lesser extend sulthiame ${ }^{98}$ is effective in suppressing interictal discharges in wake and sleep.

It is possible that the activation of interictal discharges in BCECTS has clinical relevance. There is evidence in several prospective case-controlled studies that cognitive problems in BCECTS do disappear over a period of time $45,46,54,58,60,75$ and socioeconomic development is normal. ${ }^{43}$ Massa et al have stressed the importance of EEG abnormalities to predict the course of BCECTS. ${ }^{18}$ Only one small $(n=9)$ nonrandomized study indicates that cognition in children improves when the marked activation of rolandic spikes in sleep is treated with diazepam and sodium valproate. ${ }^{75}$ Treatment with diazepam and sodium valproate was successful in both reducing the frequency of discharges in sleep, and improving cognition. ${ }^{75}$ But, it remains to be shown whether treatment of nocturnal rolandic discharges in children with BCECTS is indicated to improve cognitive and behavioral problems. ${ }^{\text {? }}$ 


\section{REFERENCES}

1 Méndez M, Radtke RA. Interactions between sleep and epilepsy. J Clin Neurophysiol 2001;18:106-27.

2 Smith MC, Hoeppner TJ. Epileptic encephalopathy of late childhood: Landau-Kleffner syndrome and the syndrome of continuous spikes and waves during slow-wave sleep. J Clin Neurophysiol 2003;20:462-72.

3 Sánchez-Carpintero R, Neville BGR. Attentional ability in children with epilepsy. Epilepsia 2003;44:1340-9.

4 Kohrman MH, Carney PR. Sleep-related disorders in neurologic disease during childhood. Pediatr Neurol 2000;23:107-13.

5 Stores G. Sleep patterns in the epilepsies. In: Stores G, Wiggs L, editors. Sleep disturbance in children and adolescents with disorders of development: its significance and management. London: Mac Keith Press; 2001.p. 97-106.

6 Doose H, Neubauer B, Carlsson G. Children with benign focal sharp waves in the EEG - developmental disorders and epilepsy. Neuropediatrics 1996;27:227-41.

7 Roubertie A, Humbertclaude V, Rivier F, Cheminal R, Echenne B. Interictal paroxysmal epileptic discharges during sleep in childhood: phenotype variability in a family. Epilepsia 2003;44:864-9.

8 Binnie CD, Marston D. Cognitive correlates of interictal discharges. Epilepsia 1992; 33(Suppl 6):S11-7.

9 Deonna T. Rolandic epilepsy: neuropsychology of the active epilepsy phase. Epileptic Disord 2000;2(suppl 1):S59-61.

10 Binnie CD. Cognitive impairment during epileptiform discharges: is it ever justifiable to treat the EEG? Lancet Neurol 2003;2:725-30.

11 Commission on classification and terminology of the International League Against Epilepsy. Proposal for revised classification of epilepsies and epileptic syndromes. Epilepsia 1989;30:389-99.

12 Lundberg S, Eeg-Olofsson O. Rolandic epilepsy: a challenge in terminology and classification. Eur J Paediatr Neurol 2003;7:239-41.

13 Lerman P. Benign partial epilepsy with centro-temporal spikes. In: Roger J, Dravet C, Bureau M, Dreifuss FE, Wolf P. Epileptic syndromes in infancy, childhood and adolescence. Eastleigh: John Libbey \& Company Ltd.; 1985. p. 150-8.

14 Wirrell EC, Camfield PR, Gordon KE et al. Benign rolandic epilepsy: atypical features are very common. J Child Neurol 1995;10:455-8.

15 Verrotti A, Latini G, Trotta D, et al. Typical and atypical rolandic epilepsy in childhood: a follow-up study. Pediatr Neurol 2002;26:26-9.

16 Aicardi J. Atypical semiology of rolandic epilepsy in some related syndromes. Epileptic Disord 2000; 2(Suppl 1):S5-9.

17 Al-Twaijri WA, Shevell MI. Atypical benign epilepsy of childhood with rolandic spikes: features of a subset requiring more than one medication for seizure control. J Child Neurol 2002;17:901-4.

18 Massa R, de Saint-Martin A, Carcangiu R et al. EEG criteria predictive of complicated evolution in idiopathic rolandic epilepsy. Neurology 2001;57:1071-9.

19 Vinayan KP, Biji V, Thomas SV. Educational problems with underlying neuropsychological impairment are common in children with benign epilepsy of childhood with centrotemporal spikes. Seizure 2005;14:207-12.

20 Shafrir Y, Prensky A. Acquired epileptiform opercular syndrome: a second case-report, review of the literature and comparison to the Landau-Kleffner syndrome. Epilepsia 1995;36:1050-7.

21 De Saint Martin A, Carcangiu R, Arzimanoglou A, et al. . Semiology of typical and atypical epilepsy: a videoEEG analysis. Epileptic Disord 2001;3:173-81.

22 Roulet E, Deonna T, Despland PA. Prolonged intermittent and oromotor dyspraxia in benign childhood epilepsy with centrotemporal spikes. Epilepsia 1989;30:564-8.

23 Kubota M, Takeshita K, Saitoh M, Hirose H, Kimura I, Sakakihara. Magnetoencephalographic analysis of rolandic discharges in a patient with rolandic epilepsy associated with oromotor deficits. J Child Neurol 2004;19:456-9.

24 Deonna TW, Roulet E, Fontan D, Marcoz JP. Speech and oromotor deficits of epileptic origin in benign partial epilepsy of childhood with rolandic spikes (BPERS). Relationship to the aquired aphasia-epilepsy syndrome. Neuropediatrics 1993;24:83-7.

25 Berroya AG, McIntyre J, Webster R, et al. Speech and language deterioraton in benign rolandic epilepsy. J Child Neurol 2004;19:53-8.

26 Fejerman N, Di Blasi AM. Status epilepticus of benign partial epilepsies in children: report of two cases. Epilepsia 1987;28:351-5. 
27 Colamaria V, Sgrò V, Caraballo R. Status epilepticus in benign rolandic epilepsy manifesting as anterior operculum syndrome. Epilepsia 1991;32:329-34.

28 Panayiotopoulos CP. Benign childhood partial seizures and related epileptic syndromes. London: John Libbey; 1999.

29 Genton P, McMenamin J. Aggravation of seizures by antiepileptic drugs: what do we do in clinical practice. Epilepsia 1998; 39(suppl 3):S26-9.

30 Perucca E, Gram L, Avanzzini G, Dulac O. Antiepileptic drugs as a cause of worsening seizures. Epilepsia 1998;39:5-17.

31 Fejerman N, Caraballo R, Tenembaum SN. Atypical evolutions of benign localization-related epilepsies in children: are they predictable? Epilepsia 2000;41:380-90.

32 Rating D. Treatment in typical and atypical Rolandic epilepsy. Epileptic Disord 2000;2(Suppl 1): 69-72.

33 Saint Martin de A, Massa R, Metz-Lutz MN, Hirsch E, Marescaux C. Benign childhood epilepsy with centrotemporal spikes: is it always benign. Neurology 2000;55:1241-2.

34 Corda D, Gelisse P, Genton P, Dravet C, Baldy-Moulinier M. Incidence of drug-induced aggravation in benign epilepsy with centrotemporal spikes. Epilepsia 2001;42:754-9.

35 Arzimanoglou A, Guerrini R, Aicardi J. Aicardi's epilepsy in children. 3rd edition. Philadelphia: Lippincott Williams \& Wilkins;2004. p. 114-85.

36 Guerrini R, Belmonte A, Strumia S, et al. Exacerbation of epileptic negative myoclonus by carbamazepine or phenobarbital in children with atypical rolandic epilepsy. Epilepsia 1995;36(suppl. 3): S65.

37 Blom S, Heijbel J, Bergfors PG. Benign epilepsy of children with centro-temporal EEG foci. Prevalence and follow-up study of 40 patients. Epilepsia 1972;13:609-19.

38 Beaumanoir A, Ballis T, Varfis G, Ansari K. Benign epilepsy of childhood with rolandic spikes. A clinical, electroencephalo-graphic, and teleencephalographic study. Epilepsia 1974;15:301-15.

39 Lerman P, Kivity S. Benign focal epilepsy of childhood. A follow-up study of 100 recovered patients. Arch Neurol 1975; 32:261-4.

40 Camfield P, Camfield C. Epileptic syndromes in childhood: clinical features, outcomes, and treatment. Epilepsia 2002;43(Suppl 3):27-32.

41 Heijbel J, Bohman M. Benign epilepsy in children with centrotemporal EEG foci: intelligence, behavior, and school adjustment. Epilepsia 1975;16:679-87.

42 Beaussart M, Faou R. Evolution of epilepsy with rolandic paroxysmal foci:a study of 324 cases. Epilepsia 1978;19:337-42.

43 Loiseau P, Duché B, Cordova S, Dartigues JF, Cohadon S. Prognosis of benign childhood epilepsy with centrotemporal spikes: a follow-up study of 168 patients. Epilepsia 1988;29: 229-35.

44 Piccirilli M, D’Alessandro P, Tiacci C, Ferroni A. Language lateralization in children with benign partial epilepsy. Epilepsia 1988;29: 19-25.

45 D'Alessandro P, Piccirilli M, Tiacci C, et al. Neuropsychological features of benign partial epilepsy in children. Ital J Neurol Sci 1990;11:265-9.

46 D'Alessandro P, Piccirilli M, Sciarma T, Tiacci C. Cognition in benign childhood epilepsy: a longitudinal study. Epilepsia 1995; 36(Suppl 3):S124.

47 Piccirilli M, D’Alessandro P, Sciarma T, et al. Attention problems in epilepsy: possible significance of the epileptic focus. Epilepsia 1994;35:1091-96.

48 Morooka K, Arimoto K, Takagi K, Hoshino K, Kanzaki M. Developmental disabilities in benign childhood epilepsy with centrotemporal spikes. Epilepsia 1995;36(suppl3):S127.

49 Weglage J, Demsky A, Pietsch M, Kurlemann G. Neuropsychological, intellectual, and behavioral findings in patients with centrotemporal spikes with and without seizures. Dev Med Child Neurol 1997;39:646-51.

50 Staden U, Isaacs E, Boyd SG, Brandl U, Neville BGR. Language dysfunction in children with rolandic epilepsy. Neuropediatrics 1998;29:242-8.

51 Croona C, Kihlgren M, Lundberg S, Eeg-olofsson O, Edebol Eeg-Olofsson K. Neuropsychological findings in children with benign childhood epilepsy with centrotemporal spikes. Dev Med Child Neurol 1999;41:8138 .

52 Gündüz E, Demirbilek V, Korkmaz B. Benign rolandic epilepsy: neuropsychological findings. Seizure 1999;8:246-9.

53 Metz-Lutz MN, Kleitz C, De Saint Martin A, Massa R, Hirsch E, Marescaux C. Cognitive development in benign focal epilepsies of childhood. Dev Neurosci 1999;21:182-90.

54 Deonna T, Zesiger P, Davidoff V, Maeder M, Mayor C, Roulet E. Benign partial epilepsy of childhood: a longitudinal neuropsychological and EEG study of cognitive function. Dev Med Child Neurol 2000;42:595603. 
55 Yung AWY, Park YD, Cohen MJ, Garrison TN. Cognitive and behavioral problems in children with centrotemporal spikes. Pediatr Neurol 2000;23:391-5.

56 Chevalier H, Metz-Lutz MN, Segalowitz SJ. Impulsivity and control of inhibition in benign focal childhood epilepsy (BFCE). Brain Cogn 2000;43:86-90.

57 Schouten A, Oostrom K. Cognition and behaviour of schoolchildren with newly diagnosed idiopathic or cryptogenic epilepsy.Thesis University Utrecht 2001.

58 Hommet C, Billard C, Motte J, et al. Cognitive function in adolescents and young adults in complete remission from benign childhood epilepsy with centro-temporal spikes. Epileptic Disord 2001;3:207-16.

59 Fonseca LC, Tedrus GM, Tonelotto JM, Antunes Td Tde A, Chiodi M. School performance in children with benign childhood epilepsy with centrotemporal spikes. Arq Neuropsiquiatr 2004;62:459-62. Epub 2004 jul.

60 Lingren A, Kihlgren M, Melin L, Croona C, Lundberg S, Eeg-Olofsson O. Development of cognitive functions in children with rolandic epilepsy. Epilepsy Behav 2004;5:903-10.

61 Völkl-Kernstock S, Willinger U, Feucht M. Cognitive disabilities of children with a benign partial epilepsy. Neuropediatrics 2004;35:DOI: 0.1055/s-2004-819383.

62 Monjauze C, Tuller L, Hommet C, Barthez MA, Khomsi A. Language in benign epilepsy with centrotemporal spikes abbreviated form: rolandic epilepsy and language. Brain Lang 2005;92:300-8.

63 Papavasiliou A, Mattheou D, Bazigou H, Kotsalis C, Paraskevoulakos E. Written language skills in children with benign childhood epilepsy with centrotemporal spikes. Epilepsia Behav 2005;6:50-8.

64 Northcott E, Connolly AM, Berroya A, et al. The neuropsychological and language profile of children with benign rolandic epilepsy. Epilepsia 2005;46:924-30.

65 Dunn DW, Austin JK, Harezlak J, Ambrosius WT. ADHD and epilepsy in childhood. Dev Med Child Neurol 2003;45:50-4.

66 Donat JF, Wright FS. Sleep, epilepsy, and the EEG in infancy and childhood. J Child Neurol 1989;4:84-94.

67 Stephani U. Typical semiology of benign childhood epilepsy with centrotemporal spikes (BCECTS). Epileptic Disord 2000;2(suppl 1):3-4.

68 Beaussart M. Benign epilepsy of children with rolandic (centro-temporal) paroxysmal foci. A clinical entity. Study of 221 cases. Epilepsia 1972;13:795-811.

69 Blom S, Heijbel J. Benign epilepsy of children with centro-temporal EEG foci. Discharge rate during sleep. Epilepsia 1975;16:133-40.

70 Peters JM, Camfield CS, Camfield PR. Population study of benign rolandic epilepsy: is treatment needed? Neurology 2001;57:537-9.

71 Bouma PAD, Bovenkerk AC, Westendorp RGJ, Brouwer OF.The course of benign partial epilepsy of childhood with centrotemporal spikes: a meta-analysis. Neurology 1997;48:430-7.

72 Wirrell E. Benign epilepsy of childhood with centrotemporal spikes. Epilepsia 1998;39(Suppl 4):S32-41.

73 Nobili L, Ferrillo F, Baglietto MG, et al. Relationship of sleep interictal epileptiform discharges to sigma activity (12-16 Hz) in benign epilepsy of childhood with rolandic spikes. Clin Neurophysiol 1999;110:39-46.

74 Pan A, Lüders HO. Epileptiform discharges in benign focal epilepsy of childhood. Epileptic disord 2000; 2(suppl 1):29-36.

75 Baglietto MG, Battaglia FM, Nobili L et al. Neuropsychological disorders relate to interictal epileptic discharges during sleep in benign epilepsy of childhood with centrotemporal or Rolandic spikes. Dev Med Child Neurol 2001;43:407-12.

76 Cortesi F, Gianotti F, Ottaviano S. Sleep problems and daytime behavior in childhood idiopathic epilepsy. Epilepsia 1999;40:1557-65.

77 Massa R, de Saint-Martin A, Hirsch E et al. Landau-Kleffner syndrome: sleep characteristics at onset. Clin Neuropsysiol 2000;111(Suppl 2):S87-93.

78 Engler F, Maeder-Ingvar M, Roulet E, Deonna T. Treatment with sulthiame (Ospolot $\left.{ }^{\circledR}\right)$ in benign partial epilepsy of childhood and related syndromes: an open clinical and EEG study. Neuropediatrics 2003;34:1059.

79 Dalla Bernardina B, Bondavalli S, Colamaria V. Benign epilepsy of childhood with Rolandic spikes (BERS) during sleep. In: Sterman MB, Shouse MN, Passouant P, editors. Sleep and epilepsy. New York: Academic Press; 1982. p. 495-506.

80 Kellaway P. The electroencephalographic features of benign centrotemporal (rolandic) epilepsy of childhood. Epilepsia 2000; 41:1053-6.

81 Gozukirmizi E, Dervent A, Altinel A, Zenbilci N. All night sleep recordings in benign childhood epilepsy. Electroencephalogr Clin Neurophysiol 1982;53:28p.

82 Clemens B, Majoros E. Sleep studies in benign epilepsy of childhood with rolandic spikes. II. Analysis of discharge frequency and its relation to sleep dynamics. Epilepsia 1987;28:24-7. 
83 Berroya AM, Bleasel AF, Stevermuer TL, Lawson J, Bye AM. Spike morphology, location, and frequency in benign epilepsy with centrotemporal spikes. J Child Neurol 2005;20:188-94.

84 Duvelleroy-Hommet C, Billard C, Lucas B, et al. Sleep EEG and developmental dysphasia: lack of a consistent relationship with paroxysmal EEG activity during sleep. Neuropediatrics 1995; 26:14-8.

85 Dalla Bernardina B, Beghini G. Rolandic spikes in children with or without epilepsy (20 subjects polygraphically studied during sleep). Epilepsia 1976;17:161-7.

86 Clemens B, Oláh R. Sleep studies in benign epilepsy of childhood with rolandic spikes. I. Sleep pathology. Epilepsia 1987;28:20-3.

87 Peled R, Lavie P. Paroxysmal awakenings from sleep associated with excessive daytime somnolence: a form of nocturnal epilepsy. Neurology 1986;36:95-8.

88 Hughes JR, Daaboul Y. The frontal arousal rhythm. Clin Electroencephalograph 1999;30:16-20.

89 Dalla Bernardina B, Tassinari CA. EEG of a nocturnal seizure in a patient with "benign epilepsy of childhood with Rolandic spikes". Epilepsia 1975;16:497-501.

90 Parmegiani L, Guerrini R. Idiopathic partial epilepsy: electroclinical demonstration of a prolonged seizure with sequential rolandic and occipital involvement. Seizure spread due to regional susceptibility? Epileptic Disord 1999;1:35-40.

91 Gregory DL, Wong PKH. Clinical relevance of a dipole field in rolandic spikes. Epilepsia 1992;33:36-44.

92 Saint-Martin de A, Seegmuller C, Carcangiu R, Kleitz C, Hirsch E, Marescaux C, Metz-Lutz MN. Cognitive consequences of rolandic epilepsy. Epileptic Disord 2001;3(Suppl 2):59-66.

93 Gross-Selbeck G. Treatment of "benign" partial epilepsies of childhood, including atypical forms. Neuropediatrics 1995;26:45-50.

94 Mitsudome A, Ohfu M, Yasumoto S, et al. The effectiveness of clonazepam on the Rolandic discharges. Brain Dev 1997;19:274-8.

95 Mitsudome A, Ohu M, Yasumoto S, Ogawa A. Rhythmic slow activity in benign childhood epilepsy with centrotemporal spikes. Clin Electroencephalogr 1997;28:44-8.

96 Negri De M, Baglietto MG, Gaggero R. Benzodiazepine (BDZ) treatment of benign childhood epilepsy with centrotemporal spikes (BECCT). Brain Dev 1997;19:506.

97 Rating D, Wolf C, Bast T for the sulthiame study group. Sulthiame as monotherapy in children with benign childhood epilepsy with centrotemporal spikes: a 6-month randomized, double-blind, placebo-controlled study. Epilepsia 2000;41:1284-8.

98 Perucca E. The management of refractory idiopathic epilepsies. Epilepsia 2001;42(Suppl 3):31-5.

99 Bast T, Völp A, Wolf C, Rating D. The influence of sulthiame on EEG in children with benign childhood epilepsy with centrotemporal spikes (BECTS). Epilepsia 2003;44:215-20.

100 Kramer U, Shahar E, Zelnik N, et al. Carbamazepine versus sulthiame in treating benign childhood epilepsy with centrotemporal spikes. J Child Neurol 2002;17:913-5.

101 Pressler R, Robinson RO,Wilson GA, Binnie CD. Treatment of interictal EEG discharges improves behaviour in children with epilepsy. Epilepsia 2002;43(Suppl 8):44.

102 Shamdeen MG, Frohnhöfer M, Jost W, Weber R, Rohrer T. Rolandic epileptiform discharges in children with minimal cerebral disorders: is a therapy with sulthiame indicated? Neuropediatrics 2004;35:DOI:10.1055/s2004-819389.

103 Besag FMC. Behavioral aspects of pediatric epilepsy syndromes. Epilepsy Behav 2004;5:S3-13.

104 Dulac O. Benign epilepsies of childhood - distinct syndromes and overlap. Epileptic Disord 2000; 2(suppl 1): 41-3.

105 Camfield P, Camfield C. Childhood epilepsy: what is the evidence for what we think and what we do? J Child Neurol 2003;18:272-87. 


\section{Chapter 3}

The pathophysiological mechanisms of cognitive and behavioral disturbances in children with Landau-Kleffner syndrome or epilepsy with continuous spike-and-waves during slow-wave sleep

Lotte Nieuwenhuis, Joost Nicolai

Seizure 2006; 15: 249-258 


\section{ABSTRACT}

Epilepsy with continuous spike and waves during slow sleep and Landau-Kleffner syndrome are two childhood epilepsy syndromes. The underlying pathophysiology remains unknown. The current opinions about epidemiologic risk factors, genetic predisposition, EEG and MEG findings, influence of anti-epileptic drugs, neuroradiology, positron emission tomography, evoked potentials, auto-immunity and subpial transection are summarized. 


\section{INTRODUCTION}

Cognitive and behavioral disturbances are common in children with epilepsy. These problems can be present independently of the state of seizure control. For example in benign childhood epilepsy with centrotemporal spikes (BCECTS), the most frequent partial epilepsy syndrome in childhood, learning difficulties do occur in children who have been seizure free for a long time. In the epileptic encephalopathies the deterioration of cognitive, sensorial, and/or motor functions predominate the clinical symptoms. In the 2001 International League Against Epilepsy (ILAE) commission report on epileptic seizures and epilepsy, ${ }^{1}$ Landau-Kleffner syndrome (LKS) and epilepsy with continuous spike-and-waves during slow-wave sleep (CSWS) are considered part of the epileptic encephalopathies in which the epileptiform abnormalities may contribute to progressive dysfunction. In recent years, many excellent reviews on CSWS or LKS mainly focused on clinical characteristics, electroencephalography (EEG) treatment, and prognosis have been published..$^{2-10}$ In this article we have tried to summarize the facts and opinions on the mechanisms of cognitive and behavioral impairment in LKS and CSWS.

\section{Epileptic encephalopathies: CSWS and LKS}

CSWS and LKS are two rare childhood epileptic syndromes. In the 1989 International Classification of Epilepsies, ${ }^{11}$ both are included in the group of epileptic syndromes whose focal or generalized origin remains undetermined. In the recent ILAE commission proposal on epileptic seizures and epilepsy, ${ }^{1}$ LKS and CSWS are considered part of the 'epileptic encephalopathies (in which the epileptiform abnormalities may contribute to progressive dysfunction)'. It is frequently suggested that these two syndromes are different clinical expressions of the same pathological entity because both are age-dependent and characterized by the association of seizures, abnormal paroxysmal EEG discharges activated by sleep, and neuropsychological deficits. Whereas the seizures are often easily controlled and the electro-encephalographic epileptiform activity most often remits before adulthood, the prognosis is frequently poor because of the associated neuropsychological disorders. ${ }^{12}$

CSWS is defined by: ${ }^{2}$

1. Epilepsy, with focal and apparently generalized seizures (unilateral or bilateral clonic seizures, tonic-Clonic seizures, absences, partial motor seizures, complex partial seizures or epileptic falls).

2. Neuropsychological impairment: global or selective regression of cognitive functions (excluding the acquired aphasia).

3. Motor impairment: ataxia, dyspraxia, dystonia or unilateral deficit.

4. Typical EEG findings, with the pattern of diffuse SW (more or less unilateral or focal) occurring during more than 85 per cent of slow sleep and persisting on three or more recordings over a period of at least 1 month. 


\section{LKS is defined by: ${ }^{2}$}

The Landau-Kleffner syndrome is an acquired childhood aphasia, characterized by paroxysmal EEG abnormalities (mainly temporal), epileptic seizures that are usually 'benign' and self-limited, a regression or stabilisation of the disease after a variable time, without demonstrable focal brain lesions.

CSWS is a rare, age-related and self-limited disorder. Different series have been reported and suggest that CSWS accounts for approximately 0.2 to $0.5 \%$ of all childhood epilepsies. $5,13,14$ One study suggests a slight male preponderance (63\% vs $37 \%) .15$

The syndrome of Landau-Kleffner is named after William Landau and Frank Kleffner who reported 6 children in 1957. ${ }^{16}$ The Landau-Kleffner syndrome is a childhood aphasia that occurs in previously normal children who have already developed age-appropriate speech. ${ }^{2}$ More than 300 cases have been described. ${ }^{18}$ Also in LKS there is a slight male predominance. ${ }^{15}$ The clinical features of CSWS and LKS are summarized in table 1 .

Table 1

Clinical characteristics CSWS and LKS 2-5,7,13

\begin{tabular}{lll}
\hline & CSWS & LKS \\
\hline Incidence & $0.2-0.5 \%$ of childhood epilepsies & rare \\
Age of onset, peak & $4-5$ years & $5-7$ years \\
Age of onset, range & 2 months-12 years & $11 / 2-12$ years \\
Personal history & $40 \%$ & $3 \%$ \\
Family history of epilepsy & $15 \%$ & $3-12 \%$ \\
(including febrile seizures) & & \\
Initial symptoms & Seizures in $80 \%$ & Seizures in $60 \%$ \\
& Neuropsychological disturbances in 20\% & Aphasia in $40 \%$ \\
Seizures & Majority; only a few children without seizures & in $70-80 \%$ \\
Characteristics & Frequent: numerous seizures a day & Infrequent \\
Type of seizures & Often nocturnal & Often nocturnal \\
& Generalized tonic-clonic & Generalized clonic \\
& Simple partial motor & Simple partial motor \\
& Absences or atypical absences & Atypical absences \\
& Unilateral status & No atonic seizure
\end{tabular}

\section{Epileptic seizures in CSWS and LKS}

Epileptic seizures are the first symptom in about $80 \%$ of the children with CSWS. Neuropsychological disturbances are the first symptom in about $20 \%$. The first seizures occur between the ages of 2 months and 12 years, with a peak at $4-5$ years. In 40 $\%$ of the cases the first seizure is a unilateral seizure, often a hemiclonic status epilepticus. In the other cases seizures are partial motor, clonic, generalized tonic-clonic of complex partial. The first seizure often occurs during sleep. ${ }^{19}$

In LKS, seizures occur in about $70-80 \%$ of the patients. In $20-30 \%$ seizures never occur. Seizures are usually infrequent, appear often during the night, and can be clinically heterogeneous. Reports of complex partial seizures are rare and tonic seizures 
have never been observed. Commonly, seizures are easily controlled by medication. After some time the interictal epileptic activity usually remits and these children are not epileptic as adults. 2,20

\section{Electroencephalographic findings}

CSWS is a clinical syndrome characterized by seizures, cognitive deterioration and ESES. ESES is defined as severe SW activity during sleep with a SW index of 85 to $100 \%$, calculated during all night sleep EEG recordings. ${ }^{21}$ One should realize that the proportion of more than $85 \%$ was set as an assumption, not as the result of scientific work. $^{22}$ This typical EEG pattern occurs during the night as soon as the patient falls asleep (table 2). There is evidence that children with a SW index below $85 \%$ also have impairment in their cognitive functions similar to patients with CSWS. ${ }^{23,24}$

Also in LKS, sleep onset has a remarkable activating effect on epileptic abnormalities and causes an increase in discharge rate and a wider spread of the paroxysmal activities (table 2). At some time during the course of LKS, EEG can present a pattern of ESES. 2,5 At variance with CSWS a persistence and even further increment of the paroxysmal epileptic discharges during REM sleep has been observed in some patients with LKS.2,25,26

\section{Cognitive and behavioral impairment in CSWS and LKS}

Most of the children with CSWS have normal neuropsychological and motor functions prior to the onset of ESES. According to the CSWS definition, all patients experience a decline in intellectual performances during the ESES period. All cognitive functions can be impaired, behavioral changes and, rarely, psychotic changes have been described as well. 6,27

In children with LKS, after a period of normal speech development there is a progressive loss of receptive and later expressive language. The most frequently reported form of language disorder in LKS is verbal agnosia. This implies the failure to give a semantic significance to the different sounds. A receptive aphasia and a rapid reduction of spontaneus speech than appears, with a severe loss in $90 \%$ of children. The child can become completely mute. The language disorder is often characterized by remissions and exacerbations. ${ }^{10}$ After a variable time of a few months to different years the aphasia stabilizes and usually improves before adulthood

Behavioral disturbances are common (50-70\%), especially at the onset of the disorder. The behavior deterioration usually parallels the language deterioration and does not relate to intelligence. The behavior may relate to an acute anxiety of the child with impaired capability of understanding what is going on..$^{2,5}$ 
EEG characteristics CSWS and LKS2,5,6

\begin{tabular}{|c|c|c|}
\hline & CSWS & LKS \\
\hline \multicolumn{3}{|l|}{ Awake } \\
\hline Background activity & Usually normal * & Usually normal \\
\hline Generalized SWs & $\begin{array}{l}\text { Frequent } \\
\text { Isolated or bursts }\end{array}$ & Rare \\
\hline Focal epileptiform activity & $\begin{array}{l}\text { Focal or multifocal } \\
\text { slow spikes }\end{array}$ & $\begin{array}{l}>\text { multiple foci } \\
\text { High amplitude repetitive spikes and SWs }\end{array}$ \\
\hline Focus & Mainly frontotemporal or frontocentral & $\begin{array}{l}>50 \% \text { posterotemporal } \\
>30 \% \text { parieto-occipital }\end{array}$ \\
\hline Non-REM & $\begin{array}{l}\text { Continuous bilateral and diffuse SWs } \\
\text { SW-index }>85 \% * *\end{array}$ & $\begin{array}{l}\text { Activating effect } \\
\text { Focal or generalized ESES in less tahn } \\
50 \% \text { of the children }\end{array}$ \\
\hline REM & No increment of PA compared to awake & $\begin{array}{l}\text { Increment of PA compared to non-REM } \\
\text { sleep is possible }\end{array}$ \\
\hline
\end{tabular}

* In a study of 16 patients with CSWS, Saltik et al found focal slowing at the site of the predominant epileptogenic focus both in wake an non-REM sleep in $25 \%$ of the patients but none of the controls. ${ }^{28}$

** A SW index $50-80 \%$ has also been used for the diagnosis of ESES by some authors. ${ }^{24}$

*** In contrast to CSWS a persistence and even further increment of the paroxysmal epilepticdischarges during REM sleep has been observed in some patients with LKS 2,25,26,32

\section{PATHOPHYSIOLOGY}

\section{Epidemiological riskfactors}

Age of onset is a risk factor for two reasons: first, having seizures at early age are a risk factor for developing CSWS, 28 and secondly, onset of CSWS or LKS at young age is a risk factor for bad outcome. ${ }^{29,30}$ CSWS often presents with partial seizures initially diagnosed as BCECTS or Panayiotopoulos syndrome. ${ }^{28}$ The mean age of seizure onset in children who developed CSWS later, is significantly lower than in children with uncomplicated idiopathic partial epilepsy $(5.5 \mathrm{y}$ vs $7.3 \mathrm{y}) .{ }^{28}$ Also in a large series of children with BCECTS, age of seizure onset in children who developed LKS or CSWS later, was 3-5 years. ${ }^{31}$ Early onset and long duration of ESES in children with CSWS is a major factor for poor prognosis of cognition and behavior. ${ }^{24,32}$

Dulac et al..$^{29}$ and Bishop ${ }^{30}$ were the first to conclude that the prognosis of LKS is strongly related to age of onset. The correlation between age of onset of language regression and final language outcome is higher than the correlation between age of onset of epileptic seizures and language outcome..$^{30}$ Especially, the outcome is often poor in children who developed language regression before the age of five years. Duration of ESES in children with LKS is also a major risk factor; in several studies full recovery to normal language function was confined to those in whom ESES lasted less than three years. ${ }^{8,33}$

\section{Genetic predispositions}

A genetic predisposition called hereditary impairment of brain maturation is recognized in children in a wide group of partial epileptic syndromes including benign child- 
hood epilepsy with centrotemporal spikes, CSWS, and LKS. ${ }^{34}$ Still there is no evidence to suggest that CSWS or LKS is genetically determined. ${ }^{35}$ In literature, more than 300 cases of LKS have been described. ${ }^{18}$ Only two sets of siblings with LKS have been reported. ${ }^{16,36}$ Besides, one monozygotic twins have been described; one boy developed LKS, the other did not. ${ }^{37}$ These findings provide strong support for an environmental trigger in LKS. A pair of monozygotic twins both suffering from CSWS has been reported, ${ }^{38}$ but no others reports on genetic factors in CSWS have been published.

\section{Number/localisation of seizures}

No clear evidence on the influence of seizures on the cognitive functions in CSWS is found. But the epileptic seizures in CSWS and LKS are considered to be benign and self-limited. In LKS, the frequency and type of seizures seems to have no influence on the prognosis of cognition and language development. ${ }^{7}$ Besides, 20-30\% of children with LKS do show language regression without ever having seizures. ${ }^{2}$

\section{EEG/MEG findings}

Two main issues have been addressed in many articles: the mechanism generating ESES and the mechanism responsible for SW-related cognitive and behavioral derangements.

Little is reported on the pre-ESES EEG. Massa et al. analysed EEG characteristics of seven children with nocturnal, partial seizures who developed LKS later and six children with uncomplicated BCECTS. Three criteria predictive for LKS were noted: (1) unilateral slow wave foci; (2) bilateral independent SW discharges; (3) major activation of SW discharges during sleep, exceeding $40 \%$ of the first sleep cycle and $30 \%$ of the following cycles. Those EEG criteria were never recorded in children with uncomplicated BCECTS. ${ }^{39}$

ESES may be the consequence of fast propagation of potential fields within and between hemispheres, originating from the focus found during wake. This suggests a mechanism of secondary bisynchrony where the initial focus triggers a cortico-cortical or cortico-subcortico-cortical loop. ${ }^{40}$ In children with CSWS, LKS and BCECTS, activation of SW activity is strongly related to the occurrence of sleep spindles in nonREM sleep. ${ }^{41}$ In adults, SW activation is related to slow wave activity and not to spindles. Spindles are caused by oscillations of thalamocortical neurons and might develop into paroxysmal synchronization. Neural mechanisms involved in the generation of sleep spindles facilitate SW production. This is an age-related mechanism shared by LKS, CSWS, BCECTS, and other childhood epilepsies. ${ }^{41,42}$ In experimental studies in cats with bilateral thalamic lesions, stimulation of the suprasylvian cortex leads to bilateral synchronize SW activity that lasts for many minutes. No difference in seizure generation after cortical stimulation was noted between normal cats and cats with unilat- 
eral thalamic lesions. ${ }^{43}$ As is discussed later, it is possible that different anti-epileptic drugs are able to augment the tendency to bilateral synchrony.

A lot of EEG studies have shown that epileptic discharges start from one predominant focus in CSWS. The localization of the interictal focus seems to be one of the key factors in determining the degree and type of cognitive impairment. ${ }^{2,44}$ Frontal EEG abnormalities may be superimposed on ESES suggesting an underlying frontal primary focus. An acquired frontal syndrome as long-term outcome has been described in some of these children. ${ }^{45,46}$

In children with LKS a unilateral temporal focus is seen on EEG recordings during wakefulness. Durig sleep, the SWs increases in frequency, becomes bilateral and can evolute into ESES. Bilateral dysfunction seems to be necessary for the occurence of the aphasia. ${ }^{47-50}$ Amplitude EEG mapping in patients with ESES or LKS also have shown that the diffuse appearing paroxysmal activities mostly have a focal origin, frontal or temporal. 40,50

Two tests have been used to distinguish the epileptic focus from its secondary contralateral focus. Morrell ${ }^{44}$ used amobarbital to suppress unilateral SW discharges. In case of a left-sided focus, left-sided intra-carotid injection suppresses SW discharges on both sides. Right-sided injection suppresses SW discharges only on the right side while the left-sided activity is still active, suggesting a leading focus on the left side. In the methoexital suppression test, a short acting barbiturate is given intravenously that suppresses SW activity on both sides. At one side the epileptic activity reappears first; this is considered the site of the active focus.

EEG discharges and cognitive functions fluctuate parallel in time in patients with ESES and LKS. A causal effect is supported by the significant improvement in neuropsychological functions after suppression of the interictal epileptic activity by medication or surgical treatment. The recurrence of electrical abnormality, by example after tapering of steroid medication, is often shortly followed by return of the aphasia. ${ }^{2,44}$ Massa mentioned that EEG and language disturbances develop together in patients with LKS, but she did not find a strict temporal correlation. ${ }^{39}$

Magnetoencephalography (MEG) has been reported in presurgical localization of the epileptic focus. ${ }^{51,52}$ Epileptic activity is generated in the intrasylvian or perisylvian, temporal cortex, in some children one-sided with fast spreading to the contralateral cortex, and in others independent left- and right-sided activity. ${ }^{51,52}$ However, no MEGstudies on the pathogenesis of CSWS or LKS have been published.

\section{Antiepileptic drugs}

There is evidence that carbamazepine, phenytoin and phenobarbital can precipitate CSWS in some children. In benign childhood epilepsy with centrotemporal spikes (BCECTS), treatment with carbamazepine or phenobarbital can result in CSWS. ${ }^{53}$ In children with BCECTS, those with SW are at risk for drug-induced worsening, those with only rolandic spikes are not. ${ }^{54}$ However drug-induced aggravation in BCECTS happens only rarely. ${ }^{55}$ Also in benign partial epilepsy, carbamazepine has been reported 
to induce CSWS. Both carbamazepine and phenytoin can lead to an aggravating of epileptic seizures or even ESES in children with LKS. ${ }^{53}$

\section{Neuroradiological findings}

By definition, neuroradiological studies in children with LKS are negative, because of the fact that the diagnosis of LKS requires the absence of a demonstrable brain lesion. ${ }^{2,3}$ Recently, MRI volumetric studies were described in four children with LKS. ${ }^{56}$ Compared to controls, volume reduction in the superior temporal areas was noted, especially in the planum temporale and superior temporal gyrus. MRI's were made after a mean interval of 2 years after LKS had started. Because of this time-interval, it is impossible to judge whether the volume-loss is the result of a pre-existent dysgenesis or the result of neuronal loss due to the disorder. ${ }^{56}$

In CSWS, neuroradiological abnormalities; unilateral or diffuse atrophy, porencephaly, pachygyria, cortical development disorders, perisylvian polymicrogyria, or hydrocephalus, are noted in 33-50\% of children with CSWS. ${ }^{2,3,5}$ Guzzetta et al. ${ }^{57}$ reported that children with thalamic injuries due to ischemic or hemorrhagic prenatal or perinatal lesions are especially at risk for developing CSWS. In their series of 32 children with thalamic lesions, 12 children developed typical or atypical CSWS. ${ }^{57}$

\section{PET}

The first PET study in children with LKS was performed in 1990 by Maquet et al.58 The authors studied the cerebral glucose utilization during sleep in three patients with LKS. In all the children the cerebral glucose metabolism was disturbed, abnormalities were predominantly seen in the temporal lobes.

These findings were confirmed in different other PET studies. ${ }^{59-62}$ In these studies the cerebral metabolic pattern varied from one patient to another and varied in the same patient over time. Different areas of hyper- and hypometabolism were found. In the study by Maquet et al. ${ }^{59}$ three consistent characteristics were found: (1) a focal or regional dysfunction of the cortex; (2) a predominant involvement of the associative cortices; and (3) metabolic stigmata of an immature brain characterized by a relative higher metabolism in the cortex compared to the subcortical structures. During the active phase of the disease, a regional increase in glucose utilization during sleep and wakefulness was noted, consistent with the predominant location of the EEG abnormalities. ${ }^{59-61}$ In a part of the patients in the study of De Tiège et al. ${ }^{61}$ no areas of significant hypermetabolism were found.

During the recovery phase of the epileptic encephalopathy, a regional decrease in glucose metabolism was seen, both during sleep and wakefulness. The location of this region correlated well with the area of hypermetabolism during the active phase. There is conflicting evidence whether the location and spreading of glucose metabolism disturbances, correlates with neuropsychological findings. $.59,61$ 


\section{Transient cognitive impairment \& evoked potentials}

Transient cognitive impairment (TCI) is an episode of cognitive impairment occurring exclusively during an episode with electroencephalographic epileptiform discharges and without any other clinical sign. ${ }^{63}$ No studies on transient cognitive impairment in children with LKS or CSWS have been reported. However, Seri et al. ${ }^{64}$ performed a nice experiment in children with LKS in order to measure transient, spike-related cerebral dysfunction. The authors measured the latency and amplitude of the Brainstem Auditory Evoked Potential (BAEP). An auditory stimulus was given 4 seconds after a registered spike or during a spike-free period. The cortical N1 peak was used for measuring BAEP latency. N1 latency was significantly longer for left-sided spikes compared to right-sided spikes and N1 latency for right-sided spikes was significantly longer than for non-triggered spikes. This experiment shows that also in case of the LandauKleffner syndrome, interictal epileptiform activity is able to induce a transient impairment in processing auditory information, similar to the phenomena of the transient cognitive impairment.

Wioland et al. ${ }^{65}$ tested five children with LKS who completely recovered from epileptic manifestations and showed persistent one-ear extinction on dichotic listening. In dichotic listening two different acoustic signals are applied simultaneously to the left and to the right ear. ${ }^{66}$ If the child only notes the left-sided signal, this is called rightsided extinction. It is the ear contralateral to the former epileptic focus that shows this extinction-phenomenon. ${ }^{66}$ It was showed that the amplitude of the N1c peak (arising from the associative auditory areas) was strongly reduced on the side of the former epileptic focus, in children with LKS who completely recovered from epileptic manifestations. ${ }^{65}$

In children with CSWS without language deficits, both BAEP latency and amplitude are normal. ${ }^{67}$ Not only cortical dysfunctions can be detected by using evoked potentials; by using MEG, Patau noted that sounds can trigger cortical spikes in LKS patients that are identical to the spontaneous spikes. ${ }^{68}$

\section{Autoimmunity}

A transient clinical and electro-encephalographic response to treatment with intravenous immunoglobulin has been described in several case-reports. Mikati et al. ${ }^{69}$ treated five consecutive children suffering from LKS with immunoglobulin. In two children improvement was remarkable, three children showed mild improvement. Also treatment with steroids is claimed successful. ${ }^{70}$ There are some reports indicating that before immunoglobulin treatment is started, cerebrospinal fluid IgG index can be elevated in children with LKS, indicating intratheacal synthesis of IgG antibodies. ${ }^{69}$ But CSF examination does not show signs of central nervous system infection ${ }^{47}$ and in a report on two LKS patients who were treated surgically, Cole et al. ${ }^{71}$ did not find signs of an encephalitis. 
Because of the unexplained improvement with immune modulating treatment, some research groups have been looking for autoantibodies directed to brain tissue. Connolly et al. ${ }^{72}$ found IgG anti-brain antibodies in 5 of 11 (45\%) of children with Landau Kleffner syndrome variant compared to $2 \%$ in healthy children and children with nonneurological diseases.

Recently, the same group published that IgM autoantibodies directed to brain endothelial cells are increased in children with LKS compared to controls. ${ }^{73}$ However, the same autoantibodies were also increased in children with autism, childhood disintegrative disorder and epilepsy. Boscolo et al. ${ }^{74}$ found autoantibodies directed against rat brain auditory cortex, brainstem and cerebellum in children with Landau Kleffner syndrome or LKS-variant.

\section{Subpial transection}

Most of the cortical neuronal connections lie in the vertically oriented column, perpendicular to the cortical surface. To generate epileptic seizures a critical volume of neurons having side-to-side or horizontal linkages is necessary. Subpial intracortical transection is a surgical approach that selectively interrupts the intracortical horizontal fibers with minimal damage of the vertically aligned fibers. This surgery technique is used to eliminate the capacity of the (unresectable) cortex to prevent cortical spreading of epileptic activity and evolution into seizures with minimal damage to its normal cortical physiological function (Morrell 1995). Morrell et al. ${ }^{33}$ published the results of 14 children with LKS treated with subpial transection of the epileptogenic cortex. All the patients had been without effective speech for at least 2 years. $50 \%$ had recovered age-appropriate speech, $29 \%$ had shown marked improvement. It is intriguing that already two days after operation, some children can speak some words after they had been mute for years.

Also Sawhney et $a .^{75}$ and Grote et al. ${ }^{76}$ published the very good results of subpial transaction on the recovery of language. Recovery of language comes gradually. ${ }^{76} \mathrm{As}$ already mentioned before, the prognoses of language recovery depends mainly on age of onset and duration of symptoms. Grote et al. ${ }^{76}$ did not find any relation between recovery and age of onset.

\section{DISCUSSION}

Two main issues have been addressed in many articles: (1) the mechanism generating ESES and (2) the mechanism responsible for cognitive and behavioral derangement.

Just like BCECTS, CSWS and LKS are age-limited disorders. SW discharges always disappear before the end of adolescence, suggesting that BCECTS, LKS, and CSWS can only occur during brain maturation. On base of these findings the concept of hereditary impairment of brain maturation has been formulated by Doose. ${ }^{34}$ This hypothesis is also supported by PET studies that showed increased cortical metabolism 
in children with CSWS and LKS; a sign of immaturity of the brain. ${ }^{4,59}$ Some antiepileptic drugs that are known to increase synchronization like carbamazepine, phenobarbital, and phenytoin can trigger CSWS in children with idiopathic partial epilepsy, however this complication is considered to be rare. ${ }^{55}$ Structural brain pathology is found in $33-50 \%$ of children with CSWS. Especially, children with thalamic injuries are at risk to develop CSWS. On the contrary, structural brain pathology is, by definition, not found in LKS. Probably, anti-brain autoantibodies do play a role in triggering epileptiform activity in LKS.

Activation of SW activity during non-REM sleep in children and adults with epilepsy is a well known phenomenon. In children with CSWS, LKS and BCECTS, activation of SW activity is strongly related to the occurrence of sleep spindles in nonREM sleep. ${ }^{41}$ In adults, SW activation is related to slow wave activity and not to spindles. Spindles are caused by oscillations of thalamocortical neurons and might develop into paroxysmal synchronization. Neural mechanisms involved in the generation of sleep spindles facilitate SW production. This is an age-related mechanism shared by LKS, CSWS, BCECTS, and other childhood epilepsies. ${ }^{41,42}$

In their original article, Landau and Kleffner ${ }^{16}$ already hypothesized a relation between the severity of electroencephalographic paroxysmal discharges and the severity of the language disturbances. Also Patry et al. ${ }^{21}$ hypothesized a causal relationship between the occurrence of ESES and the appearance of neuropsychological impairment, mental deterioration, and psychiatric disturbances in the first description of CSWS.

The mechanism responsible for cognitive and behavioral deficits in CSWS and LKS is possibly the same. ${ }^{6,9,44,47}$ Age of onset, type of seizures, EEG features, results from PET studies, long-term prog nosis and therapeutic approach are remarkably the same. Furthermore, evolution from LKS to CSWS has been described in longitudinal clinical-EEG studies, ${ }^{26}$ although some symptoms are specific for LKS or CSWS. For example, REM sleep activation is only seen in LKS and not in CSWS, and atonic seizures only occur in children with CSWS and not in LKS. ${ }^{2}$

Both disorders start when the cerebral neuronal synaps formation (synapogenesis) is being established. During the synaptogenesis there is abundant axonal sprouting resulting in a doubling of the number of axonal processes and synaptic contacts. Persistent epileptic activity can strengthen synaptic contacts that normally would be pruned. In ESES, the most prominent epileptic activity appears to be in the frontal area and the prefrontal cortex. ${ }^{9}$ Bilateral involvement of the temporoparietal cortex is obligate in LKS in order to prevent the transfer of language-function to the contralateral cortex. ${ }^{44}$

Since the description by Patry et al. ${ }^{21}$, the definition of ESES is based on the SW density of more than $85 \%$ during slow wave sleep. The proportion of $85 \%$ was set as an assumption, not as the result of statistics. ${ }^{22}$ There is little doubt that continuous spike-wave during slow-wave sleep poses a risk to brain function and that improvement of the EEG pattern (with or without treatment) may lead to improvement of language function and social development. 
Several PET studies demonstrate that in LKS both temporal lobes are involved. The lateralization of the predominant metabolic abnormalities is related to the side of the main EEG disturbances. The differences in metabolic pattern, hypermetabolism or hypometabolism, can be related to the different stages of the disorder. ${ }^{58}$ The primary sensory and primary motor cortex are preserved. The associative auditory cortexes are mainly involved..$^{59}$ Most of the patients experience a focal hypermetabolism at night during the active phase of the disease. The focal hypermetabolism can persist during the day in some children, but in many children focal hypometabolism is noted during the day. Focal hypometabolism can persist after ESES has disappeared. ${ }^{59}$

Recovery from LKS and CSWS without neurological, language, neurophysiological, and behavioural deficits is possible spontaneously and after treatment with antiepileptic drugs, steroids, IgG or subpial transection. Prognosis of recovery of language function is poor after a long duration of ESES (more than 3 years); diminished volume of the temporal lobes indicating neuronal loss with MRI volumetric studies; and longlasting focal areas of hypometabolism, all indicate persistent dysfunction of the cortex involved. 


\section{REFERENCES}

1. Engel Jr J International League Against Epilepsy (ILAE). A proposed diagnostic scheme for people with epileptic seizures and with epilepsy: report on the ILAE task force on classification and terminology. Epilepsia 2001;42:796-803.

2. Tassinari CA, Rubboli G, Volpi L, Billard C, Bureau M. Electrical status epilepticus during slow sleep (ESES or CSWS) including acquired epileptic aphasia (Landau-Kleffner syndrome). In: Roger J, Bureau M, Dravet Ch, Genton P, Tassinari CA, Wolf P, editors. Epileptic syndromes in infancy, childhood and adolescence. 3rd ed. Eastleigh: John Libbey \& Co Ltd; 2002. p. 265-83.

3. Arzimanoglou A, Guerrini R, Aicardi J. Aicardi’s epilepsy in children. 3rd ed. Philadelphia: Lippincott Williams \& Wilkins; 2004. p. 176-87.

4. Gordon N. The Landau-Kleffner syndrome: increased understanding. Brain Dev 1997;19:311-6.

5. Galanopoulou AS, Bojko A, Lado F, Moshe SL. The spectrum of neuropsychiatric abnormalities associated with electrical status epilepticus in sleep. Brain Dev 2000;22:279-95.

6. Tassinari CA, Rubboli G, Volpi L, Meletti S, d'Orsi G, Franca M, et al. Encephalopathy with electrical status epilepticus during slow sleep or ESES syndrome including the acquired aphasia. Clin Neurophysiol 2000;111(Suppl. 2):S94-102.

7. Pearl PL, Carrazana EJ, Holmes GL. The Landau-Kleffner syndrome. Epilepsy Currents 2001;1:39-45.

8. Robinson R, Baird G, Robinson G, Simonoff E. Landau-Kleffner Syndrome: course and correlates with outcome. Dev Med Child Neurol 2001;43:243-7.

9. Smith MC, Hoeppner TJ. Epileptic encephalopathy in late childhood: Landau-Kleffner syndrome and the syndrome of continuos spikes and waves during slow-wave sleep. J Clin Neurophysiol 2003;20:462-72.

10. Trevathan E. Seizures and epilepsy among children with language regression and autistic spectrum disorders. J Child Neurol 2004;19(Suppl. 1):S49-57.

11. Commission on classification and terminology of the International League Against Epilepsy. Proposal for revised classification of epilepsies and epileptic syndromes. Epilepsia 1989;30:389-99.

12. Praline J, Hommet C, Barthez MA, Brault F, Perrier D, Passage GD, et al. Outcome at adulthood of the continuous spike waves during slow sleep and Landau-Kleffner syndromes. Epilepsia 2003;44:1434-40.

13. Kramer U, Nevo Y, Neufeld MY, Fata A, Leitner Y, Harel S. Epidemiology of epilepsy in childhood: a cohort of 440 consecutive patients. Pediatr Neurol 1998;18:46-50.

14. Morikawa T, Seino M, Watanabe Y, Watanabe M, Yagi K. Clinical relevance of continuous spike-waves during slow wave sleep. In: Manelis S, Bental E, Loeber JN, Dreifuss FE, editors. Advances in epileptology, volume 17. New York: Raven Press; 1987. p. 359-63.

15. Bureau M. Outstanding cases of ESES and LKS: analysis of the data sheets provided by the participants. In: Beaumanoir A, Bureau M, Deonna T, Mira L, Tassinari CA, editors. Continuous spikes and waves during slow sleep/electrical status epilepticus during slow sleep: acquired epileptic aphasia and related conditions. London: John Libbey; 1995. p. 213-6.

16. Landau WM, Kleffner FR. Syndrome of acquired aphasia with convulsive disorder in children. Neurology 1957;7:523-30.

17. Hirsch E, Maquet P, Metz-Lutz MN, Motte J, Finck S, Marescaux C. The eponym 'Landau-Kleffner syndrome' should not be restricted to childhood-acquired aphasia with epilepsy. In: Beaumanoir A, Bureau M, Deonna T, Mira L, Tassinari CA, editors. Continuous spikes and waves during slow sleep/electrical status epilepticus during slow sleep: acquired epileptic aphasia and related conditions. London: John Libbey; 1995. p. $57-62$.

18. Camfield P, Camfield C. Epileptic syndromes in childhood: clinical features, outcomes, and treatment. Epilepsia 2002;43(Suppl. 3):27-32.

19. Bureau M. 'Continuous spikes and waves during slow sleep' (CSWS): definition of the syndrome. In: Beaumanoir A, Bureau M, Deonna T, Mira L, Tassinari CA, editors. Continuous spikes and waves during slow sleep/electrical status epilepticus during slow sleep: acquired epileptic aphasia and related conditions. London: John Libbey; 1995. p. 17-26.

20. Deonna T, Roulet E. Acquired epileptic aphasia (AEA): definition of the syndrome and current problems. In: Beaumanoir A, Bureau M, Deonna T, Mira L, Tassinari CA, editors. Continuous spikes and waves during slow sleep/electrical status epilepticus during slow sleep: acquired epileptic aphasia and related conditions. London: John Libbey; 1995. p. 37-45. 
21. Patry G, Lyagoubi S, Tassinari CA. Subclinical 'electrical status epilepticus' induces by sleep in children. A clinical and electroencephalographic study of six cases. Arch Neurol 1971;24:242-52.

22. Nabbout R, Dulac O. Epileptic encephalopathies: a brief overview. J Clin Neurophysiol 2003;20:393-7.

23. Beaumanoir A. EEG data. In: Beaumanoir A, Bureau M, Deonna T, Mira L, Tassinari CA, editors. Continuous spikes and waves during slow sleep/electrical status epilepticus during slow sleep: acquired epileptic aphasia and related conditions. London: John Libbey; 1995. p. 217-23.

24. Billard C, Autret A, Lucas B, Degiovanni E, Gillet P, Santini JJ, et al. Are frequent spike-waves during nonREM sleep in relation with an acquired neuro-psychological deficit in epileptic children? Neurophysiol Clin 1990;20:439-53.

25. Genton P, Guerrini R, Bureau M, Dravet C. Continuous focal discharges during REM sleep in a case of Landau-kleffner syndrome: a 3 year old follow-up. In: Beaumanoir A, Bureau M, Deonna T, Mira L, Tassinari $\mathrm{CA}$, editors. Continuous spikes and waves during slow sleep/electrical status epilepticus during slow sleep: acquired epileptic aphasia and related conditions. London: John Libbey; 1995. p. 155-60.

26. Rossi PG, Parmeggiani A, Posar A, Scaduto MC, Chiodo S, Vatti G. Landau-Kleffner syndrome (LKS): longterm follow-up and links with electrical status epilepticus during sleep (ESES). Brain Dev 1999;21:90-8.

27. Mira L, Oxilia O, Van Lierde A. Cognitive assessment of children with CSWS syndrome: a critical review of data from 155 cases submitted to the Venice colloquium. In: Beaumanoir A, Bureau M, Deonna T, Mira L, Tassinari CA, editors. Continuous spikes and waves during slow sleep/ electrical status epilepticus during slow sleep: acquired epileptic aphasia and related conditions. London: John Libbey; 1995 . p. 229-42.

28. Saltik S, Uluduz D, Cokar O, Demirbilek V, Dervent A. A clinical and EEG study on idiopathic partial epilepsies with evolution into ESES spectrum disorders. Epilepsia 2005;46: 524-33.

29. Dulac O, Billard C, Arthuis M. Aspects electro-cliniques et evolutifs de l'epilesie dans le syndrome aphasieepilepsie. Archives Francaises de Pediatrie 1983;40:299-308.

30. Bishop DV. Age of onset and outcome in 'acquired aphasia with convulsive disorder' (Landau-Kleffner syndrome). DevMed Child Neurol 1985;27:705-12.

31. Fejerman N, Caraballo R, Tenembaum SN. Atypical evolutions of benign localization-related epilepsies in children: are they predictable? Epilepsia 2000;41:380-90.

32. Rossi PG, Parmeggiani A, Posar A, Scaduto MC, Chiodo S, Vatti G. Landau-Kleffner syndrome (LKS): longterm follow-up and links with electrical status epilepticus during sleep (ESES). Brain Dev 1999;21:90-8.

33. Morrell F, Whisler WW, Smith MC, Hoepnner TJ, de Toledo-Morrell L, Pierre-Louis SJ, et al. LandauKleffner syndrome: treatment with subpial intracortical transection. Brain 1995;118:1529-46.

34. Doose H, Neubauer B, Carlsson G. Children with benign focal sharp waves in the EEG-developmental disorders and epilepsy. Neuropediatrics 1996;27:227-41.

35. Scheffer IE, Jones L, Pozzebon M, Howell RA, Saling MM, Berkovic SF. Autosomal dominant rolandic epilepsy and speech dyspraxia: a new syndrome with anticipation. Ann Neurol 1995;38:633-42.

36. Nakano S, Okuno T, Mikawa H. Landau-Kleffner syndrome. EEG topographic studies. Brain Dev 1989;11:43-50.

37. Feekery CJ, Parry-Fielder B, Hopkins IJ. Landau-Kleffner syndrome: six patients including discordant monozygotic twins. Pediatr Neurol 1993;9:49-53.

38. Blennow G, Ors M. Case reports. In: Beaumanoir A, Bureau M, Deonna T, Mira L, Tassinari CA, editors. Continuous spikes and waves during slow sleep/electrical status epilepticus during slow sleep: acquired epileptic aphasia and related conditions. London: John Libbey; 1995. p. 185-6.

39. Massa R, Saint-Martin de A, Hirsch E, Marescaux C, Motte J, Seegmuller C, et al. Landau-Kleffner syndrome: sleep EEG characteristics at onset. Clin Neurophysiol 2000;111(Suppl.2):S87-93.

40. Farnarier G, Kouna P, Genton P. Amplitude EEG mapping in three cases of CSWS. In: Beaumanoir A, Bureau M, Deonna T, Mira L, Tassinari CA, editors. Continuous spikes and waves during slow sleep/electrical status epilepticus during slow sleep: acquired epileptic aphasia and related conditions. London: John Libbey; 1995. p. 91-8.

41. Nobili L, Baglietto MG, Beelke M, De Carli F, De Negri E, Tortorelli S, et al. Spindles-inducing mechanism modulates sleep activation of interictal epileptiform discharges in the Landau-Kleffner syndrome. Epilepsia 2000;41:201-6.

42. Nobili L, Baglietto MG, Beelke M, De Carli F, De Negri E, Gaggero R, et al. Distribution of epileptiform discharges during nREM sleep in the CSWS syndrome: relationship with sigma and delta activities. Epilepsy Res 2001;44: 119-28.

43. Steriade M, Contreras D. Spike-wave complexes and fast components of cortically generated seizures. Role of neocortex and thalamus. J Neurophysiol 1998;80:1439-55. 
44. Morrell F. Electrophysiology of CSWS in Landau-Kleffner syndrome. In: Beaumanoir A, Bureau M, Deonna T, Mira L, Tassinari CA, editors. Continuous spikes and waves during slow sleep/electrical status epilepticus during slow sleep: acquired epileptic aphasia and related conditions. London: John Libbey; 1995. p. 77-90.

45. Roulet Perez E, Davidoff V, Despland PA, Deonna T. Mental and behavioural deterioration of children with epilepsy and CSWS: acquired epileptic frontal syndrome. Dev Med Child Neurol 1993;35:661-74.

46. Veggiotti P, Bova S, Granocchio E, Papalia G, Termine C, Lanzi G. Acquired epileptic frontal syndrome as long-term outcome in two children with CSWS. Neurophysiol Clin 2001;31:387-97.

47. Hirsch E, Marescaux C, Maquet P, Metz-Lutz MN, Kiesmann M, Salmon E, et al. Landau-Kleffner syndrome: a clinical and EEG study of five cases. Epilepsia 1990;31:756-67.

48. Deonna TW. Acquired epileptiform aphasia in children (Landau-Kleffner sydrome). J Clin Neurophysiol 1991;8: 288-98.

49. Roulet E, Deonna T, Gaillard F, Peter-Favre C, Despland PA. Acquired aphasia, dementia, and behavior disorders with epilepsy and continuous spike and waves during sleep in a child. Epilepsia 1991;32:495-503.

50. Metz-Lutz MN, Maquet P, de Saint Martin A, Rudolf G, Wioland N, Hirsch E, et al. Pathophysiological aspects of Lndau-Kleffner syndrome: from the active epileptic phase to recovery. Int Rev Neurobiol 2001;45:505-26.

51. Paetau R, Granstro“m ML, Blomstedt G, Jousma“ki V, Korkman M, Liukkonen E. Magnetoencephalography in presurgical evaluation of children with the Landau-Kleffner syndrome. Epilepsia 1999;40:326-35.

52. Sobel DF, Aung M, Otsubo H, Smith MC. Magnetoencephalography in children with Landau-Kleffner syndrome and acquired epileptic aphasia. Am J Neuroradiol 2000;21:301-7.

53. Perucca E, Gram L, Avanzini G, Dulac O. Antiepileptic drugs as a cause of worsening seizures. Epilepsia 1998;39:5-17.

54. Guerrini R, Belmonte A, Genton P. Antiepileptic drug-induced worsening of seizures in children. Epilepsia 1998;39(Suppl.3):S2-10.

55. Corda D, Gelisse P, Genton P, Dravet C, Baldy-Moulinier M. Incidence of drug-induced aggravation in benign epilepsy with centrotemporal spikes. Epilepsia 2001;42:754-9.

56. Takeoka M, Riviello JJ, Duffy FH, Kim F, Kennedy DN, Makris N, et al. Bilateral volumereductionof thesuperior temporalareas in Landau-Kleffner syndrome. Neurology 2004;63:1289-92.

57. Guzzetta F, Battaglia D, Veredice C, Donvito V, Pane M, Lettori D, et al. Early thalamic injury associated with epilepsy and continuous spike-wave during slow sleep. Epilepsia 2005;46:889-900.

58. Maquet P, Hirsch E, Dive D, Salmon E, Marescaux C, Franck G. Cerebral glucose utilization during sleep in Landau-Kleffner syndrome: a PET study. Epilepsia 1990;31:778-83.

59. Maquet P, Hirsch E, Metz-Lutz MN, Motte J, Dive D, Marescaux C, et al. Regional cerebral glucose metabolism in children with deterioration of one ore more cognitive functions and continuous spike-and-wave discharges during sleep. Brain 1995;118:1497-520.

60. da Silva EA, Chugani DC, Muzik O, Chugani HT. Landau- Kleffner syndrome: metabolic abnormalities in temporal lobe are a common feature. J Child Neurol 1997;12:489-95.

61. De Tie'ge X, Goldman S, Laureys S, Verheulpen D, Chiron C, Wetzburger C, et al. Regional cerebral glucose metabolism in epilepsies with continuous spikes and waves during sleep. Neurology 2004;63:853-7.

62. Luat AF, Asano E, Juha'sz C, Chandana SR, Shah A, Sood S, et al. Relationship between brain glucose metabolism positron emission tomography (PET) and electroencephalography (EEG) in children with continuous spike-and-wave activity during slow-wave sleep. J Child Neurol 2005;20:682-90.

63. Aarts JH, Binnie CD, Smit AM, Wilkins AJ. Selective cognitive impairment during focal and generalized epileptiform EEG activity. Brain 1984;107:293-308.

64. Seri S, Cerquiglini A, Pisani F. Spike-induced interference in auditory sensory processing in Landau-Kleffner syndrome. Electroencephalogr Clin Neurophysiol 1998;108:506-10.

65. Wioland N, Rudolf G, Metz-Lutz MN. Electrophysiological evidence of persisting unilateral auditory cortex dysfunction in the late outcome of Landau and Kleffner syndrome. Clin Neurophysiol 2001;112:319-23.

66. Wioland N, Rudolf G, Metz-Lutz MN, Mutschler V, Marescaux C. Cerebral correlates of hemisperic lateralization during a pitch discrimination task: an ERP study in dichotic situation. Clin Neurophysiol 1999;110:516-23.

67. Isnard J, Fischer C, Bastuji H, Badinand N, Villard de R. Auditory early (BAEP) and middle-latency (MLAEP) evoked potentials in patients with CSWS and Landau-Kleffner syndrome. In: Beaumanoir A, Bureau M, Deonna T, Mira L, Tassinari CA, editors. Continuous spikes and waves during slow sleep/electrical status epilepticus during slow sleep: acquired epileptic aphasia and related conditions. London: John Libbey; 1995. p. 99-103.

68. Paetau R. Sounds trigger spikes in the Landau-Kleffner syndrome. J Clin Neurophysiol 1994;11:231-41. 
69. Mikati MA, Saab R, Fayad MN, Choueiri RN. Efficacy of intravenous immunoglobulin in Landau-Kleffner syndrome. Pediatr Neurol 2002;26:298-300.

70. Sinclair DB, Snyder TJ. Corticosteroids for the treatment of Landau-Kleffner syndrome and continuous spike-wave discharge during sleep. Pediatr Neurol 2005;32:300-6.

71. Cole AJ, Andermann F, Taylor L, Olivier A, Rasmussen T, Robitaille Y, et al. The Landau-Kleffner syndrome of aquired epileptic aphasia: unusual clinical outcome, surgical experience, and absence of encephalitis. Neurology 1988;38:31-8.

72. Connolly AM, Chez MG, Pestronk A, Arnold ST, Mehta S, Deuel RK. Serum autoantibodies to brain in Landau-Kleffner variant, autism, and other neurologic disorders. J Pedriatr 1999;134:607-13.

73. Connolly AM, Chez M, Streif EM, Keeling RM, Golumbek PT, Kwon JM, et al. Brain-derived neurotrophic factor and autoantibodies to neural antigens in sera of children with autistic spectrum disorders, LandauKleffner syndrome, and epilepsy. Biol Psychiatry 2005. [Epub ahead of print].

74. Boscolo S, Baldas V, Gobbi G, Giordano L, Cioni G, Not T, et al. Anti-brain but not celiac disease antibodies in Landau-Kleffner syndrome and related epilepsies. J Neuroimmunol 2005;160:228-32.

75. Sawhney IM, Robertson IJ, Polkey CE, Binnie CD, Elwes RD. Multiple subpial transection: a review of 21 cases. J Neurol Neurosurg Psychiatry 1995;58:344-9.

76. Grote CL, Van Slyke P, Hoeppner JA. Language outcome following multiple subpial transection for LandauKleffner syndrome. Brain 1999;122:561-6. 



\section{Chapter 4}

EEG characteristics related to educational impairments in children with benign childhood epilepsy with centrotemporal spikes

Joost Nicolai, Inge van der Linden, Johan B.A.M. Arends, Saskia G.M. van Mil, Jacobiene W. Weber, Johan S.H. Vles, Albert P. Aldenkamp

Epilepsia 2007; 48: 2093-2100 


\section{ABSTRACT}

Purpose: Learning and behavioural difficulties often occur in benign childhood epilepsy with centrotemporal spikes. In recent years, several EEG characteristics have been related to the occurrence of learning and behavioural problems.

Methods: From 28 children medical, school and psychological reports were present and children were rated according to a 4-point scale for educational and behavioural impairment (Part 1). Thirty 24-h EEG recordings were reanalysed for spike frequency, the presence of atypical EEG criteria, and the presence of a non-dipole spike. EEG's were scored during wakefulness, first hour of sleep and whole night sleep (minus the first hour of sleep) separately (Part 2).

Results: The presence of I: an intermittent slow wave focus during wakefulness, II: a high number of spikes in the first hour of sleep (and during whole night sleep), and III: multiple asynchronous bilateral spike-wave foci in the first hour of sleep correlates significantly with a sum score $\geq 3$ which indicates a complicated course with educational or behavioural impairment. It is sufficient to analyse an EEG during wakefulness and a sleep EEG for only the first hour of sleep instead of a whole night recording to demonstrate those EEG criteria.

Conclusions: On basis of our reanalysis we can possibly conclude that the aforementioned EEG characteristics correlate with educational impairments, and that analysing an EEG recording during wake and the first hour of sleep is sufficient to look adequately for those EEG criteria in children with BCECTS. 


\section{INTRODUCTION}

Benign childhood epilepsy with centrotemporal spikes (BCECTS) or benign rolandic epilepsy is the most frequent partial epilepsy syndrome in childhood. "Benign" refers to the fact that seizure frequency is usually low, epileptic status is rare, and remission of epilepsy usually occurs before puberty, whether antiepileptic medication is started or not. ${ }^{1-3}$

However, in other aspects the evolution of BCECTS is not always benign. Firstly, seizures are not always easy to control; up till $20 \%$ of children need two antiepileptic drugs for adequate seizure control. ${ }^{4}$ Secondly, although rare, deterioration of seizure semiology does occur leading to epilepsy with continuous spike-and-wave during slow wave sleep syndrome (CSWS), Landau-Kleffner syndrome or acquired epileptic aphasia, atypical benign focal epilepsy of childhood (ABFEC or pseudo-Lennox syndrome), intractable seizures, status epilepticus of BCECTS, or oromotor or speech dyspraxia. ${ }^{5-8}$ Thirdly, in children with an uncomplicated seizure evolution, learning and behavioural difficulties, language delay, and deficits on neuropsychological testing may be more common than originally suspected. Those impairments are more prevalent in children with atypical seizure semiology ${ }^{9,10}$ and in children with atypical EEG features. ${ }^{11}$ Besides, common EEG characteristics such as a high spike frequency in wake, ${ }^{12-14}$ abundance of interictal abnormalities in wake or sleep, ${ }^{11}$ a strong activation of interictal spikes during sleep,,$^{15}$ and the occurrence of non-dipole spikes ${ }^{10,16}$ have been related to the occurrence of learning and behavioural impairments (Table 1). In contrast, Massa et al. ${ }^{11}$ and Pinton et al. ${ }^{17}$ both found that spike rate in wakefulness or sleep is not predictive for cognitive impairment in an individual child.

In a random population of children with BCECTS the atypical EEG criteria defined by Massa et al..$^{11}$ are rarely observed. Tzitiridou et al. reported that none of these atypical criteria were observed in wake or in sleep, in a group of 70 children with BCECTS. ${ }^{18}$ However recently, Metz-Lutz \& Filippini found one or more of those atypical EEG criteria in 16/44 (36\%) children with BCECTS. ${ }^{19}$

On the contrary, non-dipole spikes are common and noted in the majority of children with BCECTS $(29 / 50 ; 58 \%)^{10}$ and in the majority $(252 / 350 ; 72 \%)$ of children with centrotemporal spikes (with or without a history of seizures). ${ }^{16}$.

The main reason to search for those special EEG criteria is to be able to select or even predict children with BCECTS at risk for cognitive impairment in order to treat those children more vigorously. But although there is evidence in several prospective studies that cognitive problems in BCECTS do disappear over a period of time, ${ }^{20,21}$ it remains to be shown whether treatment of nocturnal epileptiform discharges in children with BCECTS is indicated to improve cognitive and behavioural problems. ${ }^{22-24}$

In the first part of our study, we wanted to determine the correlation of the different EEG criteria to cognitive and behavioural problems in children with BCECTS. 
Table 1

EEG phenomena associated with educational difficulties or behavioural disorders in children with BCECTS.

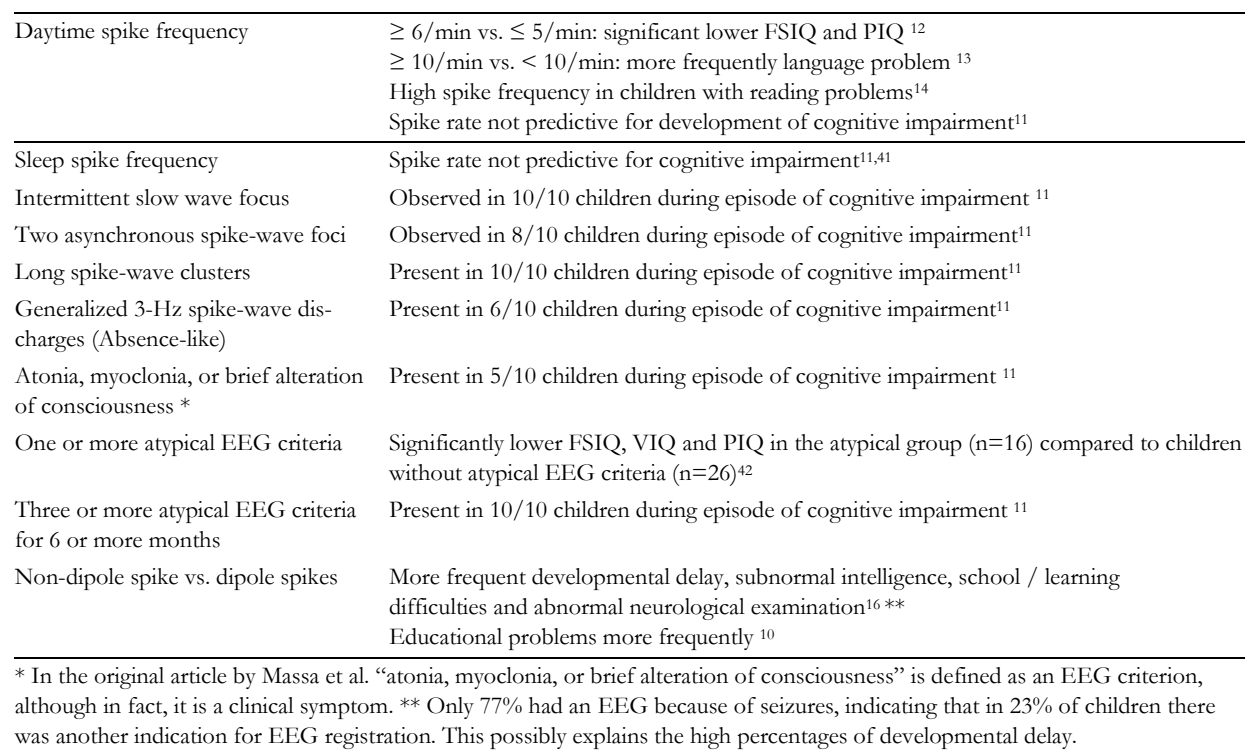

The second part of this study is focused on improvement of the methods to analyse the relevant EEG criteria related to educational and behavioural impairments. Recently, Berroya et al. described that in children with BCECTS a routine EEG including sleep onset provides information similar to a whole night recording, regarding the determination of nocturnal spike frequency. ${ }^{25}$ However, due to the study design, mainly EEG recordings from children with uncomplicated BCECTS were analysed and the atypical EEG criteria were not scored.

If it is sufficient to analyse an EEG during wakefulness and/or sleep EEG for only the first hour of sleep instead of a whole night recording to demonstrate those atypical EEG criteria, EEG analysis looking for those atypical criteria would be less timeconsuming. The question of the second part of our study was to find out whether a regular daytime EEG or sleep onset EEG provides equal information in demonstrating those atypical EEG phenomena compared to a whole night EEG recording.

\section{METHODS}

A computerized search for clinical and EEG reports of children with BCECTS was performed. A child neurologist (JN) analysed reports with the words "rolandic", "central", "centrotemporal" or "centro-temporal". Children who had typical seizures 1,2 and children with an atypical seizure semiology (status epilepticus, daytime-only seizures, screaming as a seizure component, postictal Todd's paresis, and aura) as described by Wirrell et al. ${ }^{26}$ and Verrotti et al. ${ }^{9}$ were included. The occurrence of atypical EEG features (atypical spike location, atypical background) ${ }^{26}$ was accepted as well. Children 
were only included if a 24-hour EEG recording or a recording during wake and whole night sleep had been performed. Children with EEG abnormalities but without a history of seizures were not included and children known with psychomotor retardation (IQ $<70$ ), autism or severe behavioural problems for which medication was already started before seizures occurred, where not included either.

All children were rated on a 4-point scale for educational and behavioural impairment (Table 2). They were scored retrospectively based on their school, medical and psychological reports by a psychologist (SvM) blinded for other information.

The cognitive and behavioural evolution was classified as "benign" (sum score $\leq 2$ ) or "complicated" (sum score $\geq 3$ ) according to the sum of academic and behavioural scores, similar to the study reported by Massa et al. ${ }^{11}$

Table 2

Academic and behavioural impairment score. ${ }^{11}$

\begin{tabular}{ll}
\hline Academic underachievement & Behavioural problems \\
\hline $0=$ absent & $0=$ absent \\
$1=$ mild, reported by teachers but allowing normal schooling & $1=$ mild, reported by parents but causing minor harm to others \\
$2=$ moderate, requiring individualized help (1-year delay) & $2=$ moderate, requiring psychotherapeutic or pharmacologic \\
& intervention \\
$3=$ severe, requiring special educational measures & $3=$ severe, provoking major difficulties despite adequate man- \\
$(\geq 2$-year delay) & agement \\
\hline
\end{tabular}

EEG recordings were reanalysed by an EEG-technician (IvdL) blinded for clinical information. We scored the occurrence of (I) intermittent slow-wave focus; (II) multiple asynchronous (>150 msec) spike-wave foci; (III) long spike-wave clusters ( $>6$ seconds, may be fragmented by pauses less than 1 second; personal communication Dr Massa); (IV) generalized 3-Hz (absence like) spike-wave discharges; (V) atonia, myoclonia, or brief alteration of consciousness related to EEG discharges, as defined in the study by Massa et al. ${ }^{11}$ Abundance of interictal activity was not scored, because there is no strict definition for this criterion (personal communication Dr Massa). The occurrence of left-sided, right-sided or bilateral independent spike activity and the localisation of spikes were scored. The number of spikes was determined by using the Persyst ${ }^{\circledR}$ automatic spike detection system. The Persyst data were reviewed visually for artefacts and all spike activity that was regarded artificial was excluded.

The presence of a dipole spike or non-dipole-spike was classified according to the Gregory and Wong criteria. ${ }^{16}$ The patient was classified to have a dipole spike if the discharge was of negative polarity in the midtemporal region with simultaneous positivity in the ipsilateral frontal region in at least $80 \%$ of discharges. If a frontotemporal dipole was present in less than $80 \%$, the spikes were classified as non-dipole. For three periods (wake, first hour of sleep, whole night sleep minus the first hour), twenty successive EEG discharges were analysed. 


\section{Statistics}

Statistics: SPSS 14.0 was used for data storage and statistical analysis. The correlation between cognitive status and the different EEG scores was assessed by using univariate linear regression analysis. For statistical analysis a p-value $<0.05$ was defined as statistically significant.

\section{RESULTS}

94 children with possible BCECTS were initially found. One child was excluded because the seizure semiology (periods of disorientation) did not fit the diagnosis of BCECTS. One child was excluded because after the diagnosis of BCECTS was made, he developed negative myoclonus and absences. The diagnosis was changed on clinical grounds into atypical benign focal epilepsy of childhood before a 24-hour EEG recording was made. Two children were diagnosed with Landau-Kleffner syndrome. Symptomatic posttraumatic epilepsy was diagnosed in one child and symptomatic epilepsy due to mesial temporal sclerosis in another. 37 children were excluded because they had no history of seizures. Four were excluded because of retardation $(n=3)$ or autism $(\mathrm{n}=1)$ prior to seizure onset. 17 children were excluded because no 24-hour EEG or whole night sleep recording had been performed $(n=15)$ or because it was not possible to reanalyse the EEG because of technical reasons $(\mathrm{n}=2)$.

We found 30 children (12 girls, 18 boys, mean age 11y 4m, range 4y $6 \mathrm{~m}-13 \mathrm{y} 8 \mathrm{~m}$ ) with the diagnosis of BCECTS who had a 24-hour EEG recording or whole night sleep recording. Most EEG recordings were ambulatory recordings. EEG's were made in the period from January 2002 till June 2006. 20 (67\%) children used antiepileptic medication at the time of registration (7 carbamazepine; 2 oxcarbazepine; 7 valproic acid; 1 diazepam; 3 polytherapy).

\section{PART I}

School, psychological and medical reports were present from 28 (93\%) children. Twenty-two children fulfilled the criteria for benign evolution and the remaining six children had a complicated evolution. Educational difficulties were more frequent in our population than behavioural disorders: four children showed severe educational impairment whereas none showed severe behavioural problems (Table 3).

None of the atypical EEG criteria did discriminate absolutely between children with a benign evolution and those with a complicated evolution. Univariate linear regression analysis showed significant correlations between a complicated evolution and I: the presence of an intermittent slow wave focus during wakefulness, II: a high number of spikes in the first hour of sleep, III: the presence of multiple asynchronous bilateral spike-wave foci in the first hour of sleep, and IV: a high number of spikes 
during whole night sleep. The other EEG-parameters did not show a significant correlation (table 4).

Table 3

Distribution of academic underachievement and behavioural problems in 28 children with BCECTS with a benign (sum score $\leq 2$ ) or complicated (sum score $\geq 3$ ) evolution.

\begin{tabular}{lll}
\hline $\mathrm{N}=28$ & Benign $(\mathrm{n}=22)$ & Complicated $(\mathrm{n}=6)$ \\
\hline Academic underachievement & 12 & 0 \\
Absent, score $=0$ & 5 & 0 \\
Mild, score $=1$ & 5 & 2 \\
Moderate, score $=2$ & 0 & 4 \\
Severe, score $=3$ & & \\
Behavioural problems & 17 & 3 \\
Absent, score $=0$ & 3 & 2 \\
Mild, score $=1$ & 2 & 1 \\
Moderate, score $=2$ & 0 & 0 \\
Severe, score $=3$ & & \\
\hline
\end{tabular}

Table 4

Univariate regression analysis, correlation with complicated evolution (sum score $\geq 3$ ).

\begin{tabular}{|c|c|c|c|}
\hline $\mathrm{N}=28$ & Standardized $\beta$ & Coefficient $\mathrm{t}$ & Sig. \\
\hline \multicolumn{4}{|l|}{ Wake } \\
\hline Number of spikes $/ \mathrm{h}$ & 0.265 & 1.404 & 0.172 \\
\hline Localisation SW & 0.275 & 1.460 & 0.156 \\
\hline Lateralization SW & -.158 & -.818 & 0.421 \\
\hline Intermittent slow wave & 0.386 & 2.134 & $0.042 *$ \\
\hline Multiple asynchronous bilateral SW & 0.238 & 1.247 & 0.224 \\
\hline Long rhythmic clusters & 0.200 & 1.039 & 0.308 \\
\hline Non-dipole spike & -.064 & -.293 & 0.772 \\
\hline \multicolumn{4}{|l|}{ First hour of sleep } \\
\hline Number of spikes $/ \mathrm{h}$ & 0.750 & 5.776 & $0.000 *$ \\
\hline Localisation SW & 0.358 & 1.956 & 0.061 \\
\hline Lateralization SW & -.025 & -.130 & 0.898 \\
\hline Intermittent slow wave & 0.248 & 1.304 & 0.204 \\
\hline Multiple asynchronous bilateral SW & 0.397 & 2.206 & $0.036 *$ \\
\hline Long rhythmic clusters & 0.243 & 1.280 & 0.212 \\
\hline Non-dipole spike & 0.226 & 1.114 & 0.277 \\
\hline \multicolumn{4}{|l|}{ Whole night sleep } \\
\hline Number of spikes $/ \mathrm{h}$ & 0.777 & 6.289 & $0.000 *$ \\
\hline Localisation SW & 0.280 & 1.485 & 0.150 \\
\hline Lateralization SW & -.097 & -.495 & 0.625 \\
\hline Intermittent slow wave & 0.248 & 1.304 & 0.204 \\
\hline Multiple asynchronous bilateral SW & 0.367 & 2.012 & 0.055 \\
\hline Long rhythmic clusters & 0.273 & 1.445 & 0.160 \\
\hline Non-dipole spike & 0.047 & 0.225 & 0.824 \\
\hline
\end{tabular}

The significant difference in spike rate between the 22 children with an educational and behavioural sum score of $\leq 2$ vs. the six children with a sum score $\geq 3$ is illustrated in figure 1. This difference only is present in the first hour of sleep and whole night sleep. On the contrary, no difference in spike frequency during wakefulness between the benign and complicated group exists. 


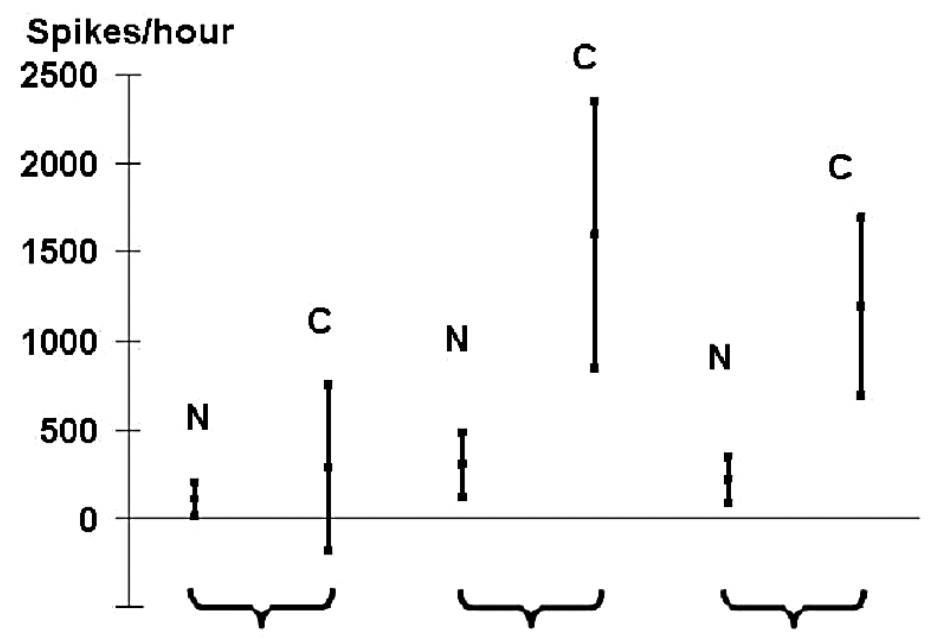

Wakefullness 1st hour sleep Whole night sleep

Figure 1

Spike frequency in 22 children with a benign evolution (sum score $\leq 2 ; \mathrm{N}$ ) and 6 children with a complicated evolution (sum score $\geq 3$; C). The spike frequency was measured for wakefulness, first hour of sleep and whole night sleep (minus the first hour of sleep) separately. Spike frequency was measured by using Persyst $\mathbb{R}$ automatic spike detection. The bars represent the mean spike frequency per hour $+/-2$ standard errors. Note the significant difference in spike frequency between children with a complicated evolution (C) and a benign evolution (N) in the first hour of sleep (mean spike rate 1594/h vs. 300/h) and whole night sleep (mean spike rate 1190/h vs. $215 / \mathrm{h}$ ). No significant difference in wakefulness was found (mean spike rate 284/h vs. 106/h).

\section{PART II.}

In the second part of our study we scored the presence of atypical EEG phenomena in wakefulness compared to whole night sleep (A) and in the first hour of sleep compared to whole night sleep (B). EEG recordings of 30 children were reanalysed in the second part of the study.

I; an intermittent slow-wave focus was found in:

\begin{tabular}{lll}
$\mathrm{A}=30$ & & \\
\hline $\mathrm{N}=$ & Present in whole night sleep & Not present in whole night sleep \\
\hline Present in wake & $\mathrm{N}=9^{*}$ & $\mathrm{~N}=1^{* *}$ \\
Not present in wake & $\mathrm{N}=0$ & $\mathrm{~N}=20$ \\
\hline $\mathrm{B}$ & & Not present in whole night sleep \\
\hline $\mathrm{N}=30$ & Present in whole night sleep & $\mathrm{N}=0$ \\
\hline Present in first hour of sleep & $\mathrm{N}=9^{* * *}$ & $\mathrm{~N}=21$ \\
Not present in first hour of sleep & $\mathrm{N}=0$ &
\end{tabular}

* In six children the slow wave focus had an equal localization during wakefulness and sleep. In one child the slow wave focus moved from central in wakefulness to temporal with onset of sleep, in one from frontal to centrotemporal and in another child from frontal to parietal. No additional or contralateral slow-wave foci were found in sleep.

** In one child a sporadic slow wave focus was recorded in wakefulness that was not seen in sleep onset and whole night sleep.

*** No difference in localization between first hour of sleep and whole night sleep was present. No additional or contralateral slow-wave foci were found. 
II; Presence of multiple (two or more) asynchronous ( $>150 \mathrm{msec}$ ) spike-wave discharges in wakefulness compared to whole night sleep (A) and in the first hour of sleep compared to whole night sleep (B).

A

\begin{tabular}{lll}
\hline $\mathrm{N}=30$ & Present in whole night sleep & Not present in whole night sleep \\
\hline Present in wake & $\mathrm{N}=4$ & $\mathrm{~N}=1^{*}$ \\
Not present in wake & $\mathrm{N}=14$ & $\mathrm{~N}=11 * *$ \\
\hline $\mathrm{B}$ & & \\
\hline $\mathrm{N}=30$ & Present in whole night sleep & Not present in whole night sleep \\
\hline Present in first hour of sleep & $\mathrm{N}=17$ & $\mathrm{~N}=0$ \\
Not present in first hour of sleep & $\mathrm{N}=1 * * *$ & $\mathrm{~N}=12$ \\
\hline
\end{tabular}

* Two foci were recorded during wakefulness and only one during whole night sleep.

** In two recordings no spikes were recorded during wakefulness and sleep. Nine children showed a single focus during wakefulness and sleep.

*** Sporadically firing spikes were recorded at Cz only during sleep later in the night, not during the first hour of sleep.

III; Presence of long spike-wave clusters lasting more than 6 seconds in wakefulness compared to whole night sleep (A) and in the first hour of sleep compared to whole night sleep (B).

A

\begin{tabular}{lll}
\hline $\mathrm{N}=30$ & Present in whole night sleep & Not present in whole night sleep \\
\hline Present in wake & $\mathrm{N}=9$ & $\mathrm{~N}=0$ \\
Not present in wake & $\mathrm{N}=15$ & $\mathrm{~N}=6$ \\
\hline $\mathrm{B}$ & & \\
\hline $\mathrm{N}=30$ & Present in whole night sleep & Not present in whole night sleep \\
\hline Present in first hour of sleep & $\mathrm{N}=24$ & $\mathrm{~N}=0$ \\
Not present in first hour of sleep & $\mathrm{N}=0$ & $\mathrm{~N}=6$
\end{tabular}

IV; Generalized 3-Hz (absence like) spike-wave discharges were found in none of the EEG registrations, not during wake, first hour of sleep or whole night sleep.

$\mathrm{V}$; Atonia, myoclonia, or brief alteration of consciousness related to EEG discharges were not seen in any of our EEG recordings. This is possibly due to the definition of BCECTS: the only child in our series that showed negative myoclonus and absences was diagnosed as ABFEC instead of BCECTS. Besides, those are clinical symptoms which can be missed when reanalysing an EEG.

VI; three or more criteria were noted in five children. Four children fulfilled these criteria during wakefulness and sleep. One child fulfilled two criteria in wakefulness and three criteria in the first hour of sleep and the whole night recording because a second spike-wave focus appeared in sleep.

\section{DISCUSSION}

The first question of our study was to determine the correlation between the existence of learning and behavioural problems on one hand and the frequency of spike activity, presence of atypical EEG criteria, and non-dipole spikes on the other hand. In our series of 28 children with BCECTS, significant correlations were found between educational and behavioural impairment and the presence of I: an intermittent slow wave focus during wakefulness, II: a high number of spikes in the first hour of sleep (and during whole night sleep), III: multiple asynchronous bilateral spike-wave foci in the first hour of sleep.

The aforementioned study by Massa et al. ${ }^{11}$ was prospective and very well designed. However, there could possibly be one structural bias in that study: children were fol- 
lowed over years while the medication was changed if necessary. In seven of the 10 children with complicated BCECTS, benzodiazepines (clonazepam or clobazam) were introduced during the study. One cannot rule out that the behavioural problems are partly related to side effects of the new medication. So the complicated evolution of children in this study is possibly not directly related to EEG abnormalities, but indirectly because the addition of benzodiazepines in children with frequent seizures may lead to behavioural side effects.

Secondly, the preliminary findings of this prospective study were published in 1999.19 At that moment the authors did not mention the analysis of those atypical EEG criteria. So possibly, the atypical EEG criteria have been defined in a post-hoc analysis.

The predictive value of the different EEG criteria reported in the literature is summarised in Table 1. Daytime spike frequency has been related to the occurrence of language delay, ${ }^{13}$ low IQ scores, ${ }^{12}$ and reading problems. ${ }^{14}$ Massa et al. found spike rates between $1 / \mathrm{min}$ and $40 / \mathrm{min}$ in uncomplicated BCECTS and between $5 / \mathrm{min}$ and $60 / \mathrm{min}$ in complicated BCECTS during wakefulness. In slow wave sleep, rates between $1 / \mathrm{min}$ and $90 / \mathrm{min}$ were found in uncomplicated BCECTS and between $5 / \mathrm{min}$ and $120 / \mathrm{min}$ in complicated BCECTS. On the basis of these results the authors concluded that spike rate either in wakefulness or in sleep is insufficient to predict a complicated evolution in an individual child. ${ }^{11}$ We used automatic spike detection (Persyst $\left.{ }^{\circledR}\right)$ and found a major difference regarding the spike rate in sleep between children with a normal evolution and children with a complicated evolution.

Atonia, myoclonia, or brief alterations of consciousness related to EEG discharges are rarely described in children with BCECTS. This is possibly due to the fact that most studies did not look at those symptoms in the detailed way as described by Beaumanoir et al..$^{27}$ or Massa et al. ${ }^{11}$ Besides, the occurrence of frequent inhibitory seizures (negative myoclonus, atypical absences) and myoclonus is considered diagnostic of ABFEC. ${ }^{6,7}$ So those children are possible not included in series of children with BCECTS. In our series, one child was excluded because daily negative myoclonic seizures and absences had changed the diagnosis from BCECTS into ABFEC at time of the EEG recording.

The question of the second part of our study was to find out whether a regular daytime EEG or sleep onset EEG gives information equal to a whole night EEG recording, in demonstrating the EEG criteria that have been related to cognitive disabilities. On basis of our reanalysis of 30 EEG's, we can conclude that EEG recordings during wake and the first hour of sleep are sufficient to look adequately for atypical EEG criteria in children with BCECTS. Negative myoclonus and brief alterations of consciousness are clinical symptoms and can only be registered during wakefulness. Registration during wakefulness only does not suffice either because multiple asynchronous spike-wave discharges and long spike-wave clusters only do occur in sleep in respectively $14 / 30(47 \%)$ and $15 / 30(50 \%)$ of the children. Besides, according to our results, 
spike activity in wakefulness does not correlate to the presence of educational or behavioural problems, whereas spike activity in sleep does.

Frequency and distribution of interictal epileptiform activity during wake and sleep have been studied by many authors. In general, spike frequency increases in non-REM sleep. Spike amplitude increases and spikes become more diffuse involving adjacent areas and sometimes the centrotemporal area of the contralateral hemisphere. ${ }^{25,28-31}$ The presence of the different EEG phenomena in wakefulness and sleep is summarised in Table 5.

Table 5

Characteristics of atypical EEG phenomena in children with BCECTS

\begin{tabular}{|c|c|}
\hline Intermittent slow wave focus & $\begin{array}{l}6.2^{\%} \text { of } 640 \text { children slowing / background abnormalities }{ }^{3} \\
\text { Occurs in same region as spike activity }{ }^{31,42} \\
\text { Often occurs with increasing spike activity } 42 \\
\text { Not related to structural abnormalities }{ }^{40,43} \\
\text { Appearance of slow wave focus only during sleep is uncommon }{ }^{25}\end{array}$ \\
\hline Two asynchronous spike-wave foci & $\begin{array}{l}\text { Appearances of two foci in one registration is common } 20,29,31 \\
\text { Three focuses in } 5 \% 30,38\end{array}$ \\
\hline Long spike-wave clusters & $\begin{array}{l}\text { Runs of discharges lasting more than } 525 \text { or } 6 \text { seconds }{ }^{11} \\
\text { In } 30 \% \text { of children in wakefulness, in } 75 \% \text { of children during sleep onset or slow } \\
\text { wave sleep }{ }^{25} \\
\text { Spike locations do not change from sleep onset to slow wave sleep }\end{array}$ \\
\hline $\begin{array}{l}\text { Generalized 3-Hz (absence-like) spike-wave } \\
\text { discharges }\end{array}$ & $\begin{array}{l}\text { Subclinical bilateral, synchronous and symmetrical 3-Hz discharges are rare }{ }^{44} \\
\text { Brief irregular or asymmetrical, subclinical spike-wave discharges are reported in a } \\
\text { wide range }(0 \%-73 \%)^{27,30} \\
3 \mathrm{~Hz} \text { spike-wave discharges appear especially in nREM I and nREM II sleep but not } \\
\text { in nREM sleep stage III and IV } 29,44\end{array}$ \\
\hline $\begin{array}{l}\text { Atonia, myoclonia, or brief alteration of } \\
\text { consciousness }\end{array}$ & $\begin{array}{l}\text { Inhibitory seizures (negative myoclonus, atypical absences) and myoclonus are } \\
\text { considered diagnostic of ABFEC } 6,7\end{array}$ \\
\hline
\end{tabular}

Only a few prospective studies have been published in which the effect of antiepileptic treatment on cognition and behaviour in children with BCECTS was investigated. ${ }^{18,32-}$ 35 The inclusion criteria used in this kind of studies are crucial. When children with uncomplicated BCECTS without deficits on neuropsychological tests are included, one should not expect a rise in test results after initiation of antiepileptic treatment. In a group of children without cognitive or behavioural problems one can only demonstrate the presence or absence of cognitive deterioration due to the antiepileptic medication. For this reason, a study on the treatment of cognitive deficits with antiepileptic drugs should include a large amount of children with supposed cognitive problems. The selection of children in the studies published till now has been quite different. Only Baglietto et al. ${ }^{21}$ defined nocturnal activation of epileptiform activity (spike index $>10$ /minute, confirmed by two EEG recordings) as an inclusion criterion for their study. In the papers by Gross-Selbeck, ${ }^{32}$ Mitsudome et al., ${ }^{36}$ Kramer et al., ${ }^{37}$ and Bast et al. ${ }^{38}$ children with BCECTS were treated with medication. However, in these studies seizure frequency and EEG abnormalities were scored, but cognition and behaviour were not.

Our results possibly implicate that EEG criteria can be used in future prospective studies looking for the effect of antiepileptic treatment in children with BCECTS and 
educational or behavioural problems. Selecting children with an intermittent slow wave focus in wakefulness seems logical because of the fact that an intermittent slow wave activity has been related to transient cortical dysfunction ${ }^{39}$ and disappears simultaneously with spikes on treatment with clonazepam. ${ }^{40}$ Selection because of a high spike frequency in the first hour of sleep also seems reasonable.

As any retrospective study, our study is at risk for structural bias. Kempenhaeghe is a tertiary epilepsy centre serving the southern and eastern part of the Netherlands. Because of this tertiary nature, a lot of children with BCECTS and co-existent learning problems have been included. This possibly results in an overrepresentation of complicated BCECTS and therefore an overrepresentation of atypical EEG phenomena compared to regional clinics.

In daily practice it is quite common that medication is already started by a paediatrician or neurologist on basis of a first positive EEG before extensive 24 hour EEG recording is performed. Possibly the high frequency of children already using medication at the moment they were analyzed in Kempenhaeghe, especially in case of carbamazepine, which can lead to an aggravation of interictal activity, ${ }^{32}$ disturbs the distribution of epileptiform activity during wake and sleep. However, also in the study by Massa et al. ${ }^{11}$ and in the study by Berroya et al., ${ }^{25} 66 \%$ respectively $58 \%$ of children used antiepileptic drugs at time of the 24 hour EEG recording. These percentages are equal to the $67 \%$ of children using medication in our study.

Another limit of our study is the small study size $(n=28)$ and the fact that we only found six children with a complicated evolution. This small study size poses a risk for false-negative or false positive-results. The clinical relevance of the different EEG criteria can only be determined in a prospective study including children after the first seizure that do not use medication at the moment of enrolment.

\section{Acknowledgement}

Professor T. Deonna (Geneva, Swiss) gave advice on an earlier version of this manuscript. 


\section{REFERENCES}

1 Beaussart M. Benign epilepsy of children with Rolandic (centro-temporal) paroxysmal foci. A clinical entity. Study of 221 cases. Epilepsia. 1972; 13: 795-811.

2 Lerman P, Kivity S. (1975) Benign focal epilepsy of childhood. A follow-up study of 100 recovered patients. Arch Neurol. 32:261-264.

3 Bouma PA, Bovenkerk AC, Westendorp RG, Brouwer OF. (1997) The course of benign partial epilepsy of childhood with centrotemporal spikes: a meta-analysis. Neurology. 48:430-437.

4 Al-Twaijri WA, Shevell MI. (2002) Atypical benign epilepsy of childhood with rolandic spikes: features of a subset requiring more than one medication for seizure control. J Child Neurol. 17:901-904.

5 Roulet E, Deonna T, Despland PA. (1989) Prolonged intermittent drooling and oromotor dyspraxia in benign childhood epilepsy with centrotemporal spikes. Epilepsia. 30:564-568.

6 Fejerman N, Caraballo R, Tenembaum SN. (2000) Atypical evolutions of benign localization-related epilepsies in children: are they predictable? Epilepsia. 41:380-390.

7 Aicardi J. (2000) Atypical semiology of rolandic epilepsy in some related syndromes. Epileptic Disord. 2(Suppl 1):S5-9.

8 Gobbi G, Boni A, Filippini M. (2006) The spectrum of idiopathic rolandic epilepsy syndromes and idiopathic occipital epilepsies: from the benign to the disabling. Epilepsia. 47 (Suppl 2): 62-66.

9 Verrotti A, Latini G, Trotta D, Giannuzzi R, Cutarella R, Morgese G, Chiarelli F. (2002) Typical and atypical rolandic epilepsy in childhood: a follow-up study. Pediatr Neurol. 26:26-29.

10 Vinayan KP, Biji V, Thomas SV. (2005) Educational problems with underlying neuropsychological impairment are common in children with benign epilepsy of childhood with centrotemporal spikes (BECTS). Seizure. 14:207-212.

11 Massa R, de Saint-Martin A, Carcangiu R, Rudolf G, Seegmuller C, Kleitz C, Metz-Lutz MN, Hirsch E, Marescaux C. (2001) EEG criteria predictive of complicated evolution in idiopathic rolandic epilepsy. Neurology. 57:1071-1079.

12 Weglage J, Demsky A, Pietsch M, Kurlemann G. (1997) Neuropsychological, intellectual, and behavioral findings in patients with centrotemporal spikes with and without seizures. Dev Med Child Neurol. 39:646651.

13 Staden U, Isaacs E, Boyd SG, Brandl U, Neville BG. (1998) Language dysfunction in children with rolandic epilepsy. Neuropediatrics. 29:242-248.

14 Fonseca LC, Tedrus GM, Tonelotto JM, Antunes Td Tde A, Chiodi MG. 2004) School performance in children with benign childhood epilepsy with centrotemporal spikes. Arq Neuropsiquiatr. 62:459-62.

15 De Saint Martin A, Carcangiu R, Arzimanoglou A, Massa R, Thomas P, Motte J, Marescaux C, Metz-Lutz MN, Hirsch E. (2001) Semiology of typical and atypical Rolandic epilepsy: a video-EEG analysis. Epileptic Disord. 3:173-182.

16 Gregory DL, Wong PK. (1992) Clinical relevance of a dipole field in rolandic spikes. Epilepsia. 33:36-44.

17 Pinton F, Ducot B, Motte J, Arbues AS, Barondiot C, Barthez MA, Chaix Y, Cheminal R, Livet MO, Penniello MJ, Peudenier S, de Saint Martin A, Billard C. (2006) Cognitive functions in children with benign childhood epilepsy with centrotemporal spikes (BECTS). Epileptic Disord. 8:11-23.

18 Tzitiridou M, Panou T, Ramantani G, Kambas A, Spyroglou K, Panteliadis C. (2005) Oxcarbazepine monotherapy in benign childhood epilepsy with centrotemporal spikes: a clinical and cognitive evaluation. Epilepsy Behav. 7:458-467

19 Metz-Lutz MN, Kleitz C, de Saint Martin A, Massa R, Hirsch E, Marescaux C. (1999) Cognitive development in benign focal epilepsies of childhood. Dev neurosci. 21: 182-190.

20 Deonna T, Zesiger P, Davidoff V, Maeder M, Mayor C, Roulet E. (2000) Benign partial epilepsy of childhood: a longitudinal neuropsychological and EEG study of cognitive function. Dev Med Child Neurol. 42:595-603.

21 Baglietto MG, Battaglia FM, Nobili L, Tortorelli S, De Negri E, Calevo MG, Veneselli E, De Negri M. (2001) Neuropsychological disorders related to interictal epileptic discharges during sleep in benign epilepsy of childhood with centrotemporal or Rolandic spikes. Dev Med Child Neurol. 43:407-412

22 Deonna T. (2000) Rolandic epilepsy: neuropsychology of the active epilepsy phase. Epileptic Disord. 2(suppl 1):S59-61.

23 Gross-Selbeck G, Wegener A, Benkel-Herrenbruck I, Schmitz N. (2004) Das EEG bei den idiopathischen fokalen epilepsien - wann behandeln? Zeitschrift fur Epileptologie 17:90-102. 
24 Nicolai J, Aldenkamp AP, Arends J, Weber JW, Vles JS. (2006) Cognitive and behavioral effects of nocturnal epileptiform discharges in children with benign childhood epilepsy with centrotemporal spikes. Epilepsy Behav. 8:56-70.

25 Berroya AM, Bleasel AF, Stevermuer TL, Lawson J, Bye AM. (2005) Spike morphology, location, and frequency in benign epilepsy with centrotemporal spikes. J Child Neurol. 20:188-194.

26 Wirrell EC, Camfield PR, Gordon KE, Dooley JM, Camfield CS. (1995) Benign rolandic epilepsy: atypical features are very common. Journal of Child Neurology 10:455-458.

27 Beaumanoir A, Ballis T, Varfis G, Ansari K. (1974) Benign epilepsy of childhood with rolandic spikes. A clinical, electroencephalographic, and teleencephalographic study. Epilepsia. 15:301-315.

28 Blom S, Heijbel J. (1975) Benign epilepsy of children with centro-temporal EEG foci. Discharge rate during sleep. Epilepsia. 16:133-140.

29 Dalla Bernardina B, Beghini G. (1976) Rolandic spikes in children with or without epilepsy (20 subjects polygraphically studied during sleep). Epilepsia. 17:161-167.

30 Beydoun A, Garofalo EA, Drury I. (1992) Generalized spike-waves, multiple foci, and clinical course in children with EEG features of benign epilepsy of childhood with centrotemporal spikes. Epilepsia. 33:10911096.

31 Pan A, Lüders HO. (2000) Epileptiform discharges in benign focal epilepsy of childhood. Epileptic Disord. 2(suppl 1):S29-36.

32 Gross-Selbeck G. (1995) Treatment of "benign" partial epilepsies of childhood, including atypical forms. Neuropediatrics. 26:45-50.

33 Engler F, Maeder-Ingvar M, Roulet E, Deonna T. (2003) Treatment with Sulthiame (Ospolot) in benign partial epilepsy of childhood and related syndromes: an open clinical and EEG study. Neuropediatrics. 34:105-109.

34 Stephani U, Carlsson G. (2006) The spectrum from BCECTS to LKS: the rolandic EEG trait-impact on cognition. Epilepsia. 47 (Suppl 2):67-70.

35 Feucht M, Benniger F, Freilinger M, Mayer H, Pahs G, Reiter E, Urak L, Seidl R. (2006) Levetiracetam for the treatment of "not so benign" idiopathic partial epilepsies of childhood. Neuropediatrics. 37 (Suppl 1):S8.

36 Mitsudome A, Ohfu M, Yasumoto S, Ogawa A, Hirose S, Ogata H, Yamada T. (1997) The effectiveness of clonazepam on the Rolandic discharges. Brain Dev. 19:274-278.

37 Kramer U, Zelnik N, Lerman-Sagie T, Shahar E. (2002) Benign childhood epilepsy with centrotemporal spikes: clinical characteristics and identification of patients at risk for multiple seizures. J Child Neurol. 17:1719.

38 Bast T, Völp A, Wolf C, Rating D; Sulthiame Study Group. (2003) The influence of sulthiame on EEG in children with benign childhood epilepsy with centrotemporal spikes (BECTS). Epilepsia. 44:215-220.

39 Shewmon DA, Erwin RJ. (1988) Focal spike-induced cerebral dysfunction is related to the after-coming slow wave. Ann Neurol. 23:131-137.

40 Mitsudome A, Ohu M, Yasumoto S, Ogawa A. (1997a) Rhythmic slow activity in benign childhood epilepsy with centrotemporal spikes. Clin Electroencephalogr. 28:44-48.

41 Metz-Lutz MN, Filippini M. (2006) Neuropsychological findings in rolandic epilepsy and Landau-Kleffner syndrome. Epilepsia. 47(Suppl 2):71-75.

42 Blume WT, Kaibara M. (1999) Atlas of pediatric electroencephalography. Second edition. Lippincott, Wiliams \& Wilkins, Philadelphia. pp.159-160.

43 Petersen J, Nielsen CJ, Gulmann NC. (1983) Atypical EEG abnormalities in children with benign partial (Rolandic) epilepsy. Acta Neurol Scand Suppl. 94:57-62.

44 Gelisse P, Genton P, Bureau M, Dravet C, Guerrini R, Viallat D, Roger J. (1999) Are there generalised spike waves and typical absences in benign rolandic epilepsy? Brain Dev. 21:390-396. 


\section{Chapter 5}

The relative influence of interictal activity vs. non-convulsive seizures on cognition in children with epilepsy

Joost Nicolai, Johan Arends, Jos Hendriksen, Saskia Ebus, Johan S.H. Vles, Albert P. Aldenkamp

submitted 


\section{ABSTRACT}

Introduction: In many childhood epilepsy syndromes educational difficulties or even severe cognitive deterioration do occur. Whether those cognitive deficits are caused by the underlying brain disease underlying the epilepsy syndrome or by the epileptic seizures and/or epileptiform activity is unknown for the greater part. When analysing the relation between epileptiform activity and cognition, ictal activity (short subclinical epileptic seizures) and interictal epileptiform activity has to be distinguished. As the occurrence of seizures and the frequency of interictal epileptiform activity are possibly related, the peri-ictal effects of seizures and the effects of interictal epileptiform discharges could have been overestimated or underestimated. Therefore we analyzed a new cohort of children.

Methods: In this cohort children with seizures during testing were distinguished from those without. In this prospective, descriptive study a combination of EEG and neuropsychological testing was performed in a large group of children. The results of children with subtle seizures during a 2-hour testing session (group 3) were compared with all children with epilepsy without such seizures during the 2-hour cognitive testing session (Group 2) and were compared with controls without epilepsy (Group 1).

Results: We found that children with epilepsy and seizures recorded during a 2-hour test (Group 3) performed worse compared to children with epilepsy without seizures recorded (Group 2) on several neuropsychological tests. This was the case for the Wechsler full-scale IQ, attention tests, speed of central information processing, memory function and educational achievement. Children with epilepsy but without seizures during testing (Group 2) performed less on memory function and educational achievement than controls (Group 1).

In children without seizures during cognitive testing, the occurrence of frequent epileptiform discharges did have an additional impact on cognitive function in our study. We initially divided spike frequency into two categories; $0 \%-<1 \%$ vs. $>1 \%$. Significant differences were noted on the Full-scale IQ, visual-spatial function, and memory function.

Conclusion: We conclude that the type of effect of frequent epileptiform activity (more than $1 \%$ of time) is very similar to the effect of short non-convulsive seizures on cognitive function in children with epilepsy, although the impact is less pronounced in number of areas involved, and magnitude. 


\section{INTRODUCTION}

In many childhood epilepsy syndromes educational difficulties or even severe cognitive deterioration do occur. The cognitive profiles in children with epilepsy are as diverse as the epileptic syndromes themselves. ${ }^{1}$ The cognitive sequels of epilepsy syndromes manifesting with an epileptic encephalopathy (i.e. West syndrome; Lennox syndrome) or an electrical status epilepticus during slow sleep (Landau-Kleffner syndrome; epilepsy with continuous spike-and-waves during slow-wave sleep or CSWS) have been extensively reviewd. ${ }^{2}$

In other epilepsy syndromes there seems to be a milder, although global influence on cognition. For example, in several studies reported, the mean Full-scale IQ in children with benign childhood absence epilepsy is lower compared to controls (Pavone et al., 2001; Henkin et al., 2005). This global lower cognitive function does persist; even when children are seizure free. ${ }^{3,4}$ Interestingly, also specific deficits can be noted in certain epilepsy syndromes. For example, in children with benign childhood epilepsy with centrotemporal spikes, language difficulties and/or dyslexia-like problems are found in a high percentage. 5,6 The subtlest cognitive deficit is seen when the presence of subclinical epileptiform activity is associated with increased reaction time or increased number of missed test-items, a deficit that can only be observed during neuropsychological testing..$^{7-10}$

Whether the cognitive deficits are caused by the underlying brain diseases underlying the epilepsy, or by the epileptic seizures and/or epileptiform activity is unknown. ${ }^{1}$ However, there is evidence that cognitive functions are already impaired at the onset of seizures, ${ }^{1,11}$ indicating that others mechanisms besides epileptic seizures do have to play a role as well.

In analysing the relation between epileptiform activity and cognition, the distinction between ictal activity (short epileptic seizures) and interictal epileptiform activity can only be made when using simultaneous EEG and video registration. But even with optimal registration, it is often difficult or even impossible to distinguish ictal and interictal activity. ${ }^{12}$ The electroencephalographic hallmark for ictal seizure activity is sudden change in frequency, sudden increase in voltage, or sudden loss of voltage. ${ }^{12}$

To which extent short epileptic seizures have effects on cognitive function is still in debate. ${ }^{13-16}$ This question is of more than theoretical interest because treatment decisions in daily clinical practice are sometimes dependent upon the question whether seizures are harmful for cognitive function. It is clear that a more aggressive treatment strategy is needed if seizures have detrimental effects on cognitive function in children. This is especially relevant for subtle non-convulsive seizures. ${ }^{17}$ Subtle non-convulsive seizures are - by definition - difficult to detect, and often these seizures present as behavioural fluctuations or attention disorders ${ }^{18}$ and can therefore persist for a longer period without detection. In a group of children with difficult-to-detect seizures, we reported sudden and unanticipated decline of school performance as the first symptom of the seizures, presumably owing to the cumulative effect of the seizures on cognitive 
development ${ }^{19,20}$ Interestingly, Pressler et al. described that children who showed a significant reduction of subclinical seizures after initiation of lamotrigine, showed significant improvement of behaviour, compared to children in whom the EEG did not improve. ${ }^{21}$

Interictal epileptiform activity is defined by spikes or spike-related discharges. ${ }^{12}$ In the majority of children with epilepsy, interictal epileptiform discharges may present as a complicating factor. ${ }^{8,18,22}$ In the first study that used combined EEG/video telemetry, it was demonstrated that interictal epileptiform discharges may also have cognitive effects and these effects may be very similar to the cognitive impact of short seizures. ${ }^{8}$ This was confirmed in recent studies. ${ }^{23}$ The label "transient cognitive impairment" (TCI) was proposed for episodes with interictal epileptiform discharges associated with increased reaction time or increased number of missed test-items. ${ }^{8}$ No agreement exists about the need for treatment of such interictal discharges. ${ }^{24,25}$ Wirrell et al. recently published a series of 6 children with benign childhood epilepsy with centrotemporal spikes (BCECTS). In this study, treatment with sulthiame even led to a paradox increment of cognitive problems despite a decrease of spike frequency. ${ }^{26}$ In children with learning and behavioral problems, and epileptiform activity, but without clinical seizures, treatment with valproate also leads to a deterioration of functioning. None of eight children improved clinically, and children were more distractible, had an in creased delay in response time, and showed lower memory scores after initiation of valproate. $^{27}$

As yet there are no studies that have systematically evaluated the differential cognitive impact of interictal epileptiform discharges vs. non-convulsive seizures of short duration in a large sample. Our previous study evaluated the effects of type of epilepsy/seizure type versus the peri-ictal effect of seizures and epileptiform discharges in 121 children using a multivariate analysis of variance. ${ }^{23}$ As the occurrence of seizures and the frequency of interictal epileptiform activity are possibly related, the peri-ictal effects of seizures and the effects of interictal epileptiform discharges could have been overestimated (if the presence of both is positive related) or underestimated (if presence is related inversely). Therefore we analyzed a new cohort of children. In this cohort children with seizures during testing were distinguished from those without. Our main aim was to further analyze the influence of frequency of interictal activity on cognitive functions. For this reason analysis was subsequently done only in those children with epilepsy but without seizures during registration.

\section{PATIENTS AND METHODS}

\section{Subject selection and design}

Children, aged $6 \mathrm{y} 0 \mathrm{~m}-17 \mathrm{y} 11 \mathrm{~m}$, were included consecutively in a prospective, standardized, open and non-randomized, clinical controlled and comparative study during the period 2001-2006. The primary inclusion criterion was a clinical question about the 
cognitive impact of epileptiform discharges. Besides, there had to be: a). equivocal seizures and fluctuations in cognitive performance and/or b). epileptiform EEG discharges in a recent EEG with a minimal frequency of $1 \mathrm{p} / 5$ min for subtle seizures $>$ 1 sec duration or a minimal frequency of 1 p/30 seconds for discharges $<1$ second duration (in earlier EEG recording).

Excluded were all children with malignant epilepsy syndromes with etiologies that affect cognitive function. Children with a Full-scale IQ below 70 were not excluded. This was decided because a low intelligence test result can be the temporary result of frequent seizures or ongoing epileptiform activity. ${ }^{15}$ So the exclusion of those children with a Full-scale IQ below 70 would possibly implicate the exclusion of children that are most suffering from cognitive disturbances due to short seizures and/or epileptiform activity. Because many most studies on this issue published before have excluded children with a Full-scale IQ below 70, we performed a post-hoc analysis after exclusion of those children with a Full-scale IQ below 70 as well.

On basis of seizure semiology, clinical signs, and EEG recordings, children were divided into two subgroups (Epilepsy vs. No epilepsy = "pseudocontrols") by one of us (JA). Besides, the patients were divided into subgroups based on the occurrence of subtle epileptic seizures and frequency of interictal epileptiform EEG discharges.

In this prospective study, in a second step, the effects of subtle seizures were compared with all children with epilepsy without such seizures during the 2-hour cognitive testing session and compared with controls. It is important to note that the control group did not consist of a population of schoolchildren or best friends, but of a population of children in whom epilepsy was suspected or diagnosed earlier, but this diagnosis was defeated after analysis in our center. For this reason, the usage of antiepileptic medication was no exclusion criterion for the control group.

\section{Instruments and set-up}

All children were assessed with 32 channel EEG (Brainlab®). The EEG was synchronized with the computerized cognitive FePsy® test system (Alpherts \& Aldenkamp, 1990; Aldenkamp et al., 1991), using a separate software program. Simultaneous videoEEG and neuropsychological testing was always done in the morning.

Cognitive tests were selected for their sensitivity for epileptiform EEG discharges and subtle seizures in earlier experiments, 18-20,23,28-33 and to cover a broad domain of cognitive function. The tests cover global cognitive function or intelligence, endurance of visual attention, mental speed, memory function, language and visual-spatial function, and educational achievement for reading and arithmetic.

Before simultaneous EEG/cognitive recordings were performed, global cognitive function was measured using the Wechsler intelligence test for children (Dutch version of the WISC RN) was used. ${ }^{34}$ Score is the full-scale IQ with an average score of 100. 
The following tests were presented during EEG recording:

\section{Language and visual-spatial function}

- Vocabulary: subtest of the Wechsler Intelligence Test for Children, measuring vocabulary. ${ }^{34}$ Score is the standard score compared to norms with an average score of 10.

- Block Design: subtest of the Wechsler Intelligence Test for Children, measuring visual-spatial skills. ${ }^{34}$ Score is the standard score compared to norms with an average score of 10 .

\section{Attention tests}

- Simple visual reaction-time measurement (Visual RT): reacting to simple visual stimuli (white square on the screen) that are presented at random intervals by the computer. Score is the average reaction time in milliseconds for the dominant hand.

- Simple auditory reaction-time measurement (Auditory RT): reacting to simple auditory stimuli $(800 \mathrm{~Hz}$ tones) that are presented at random intervals by the computer. Score is the average reaction time in milliseconds for the dominant hand.

- Binary Choice Reaction Test (BCRT). The patient has to react differentially to a red square, presented on the left side of the screen than to a green square, presented on the right side. Score is the reaction time in milliseconds.

\section{Speed of central information processing}

- The Computerized Visual Searching Task (CVST24), an adaptation of Goldstein's Visual Searching Task. A centered grid pattern has to be compared with 24 surrounding patterns, one of which is identical to the target pattern. The test consists of 24 trials. The score is the total average searching time in seconds. A second version exists with 10 grid patterns (CVST10). This version was used for children aged 6 and 7-years and older children who had difficulties with the 24-item version. Only the results of CVST24 are mentioned in the results.

\section{Educational acbievement}

- Reading: reading sentences during 1 minute. This test is part of a Dutch short screening test for school achievement, similar to the WRAT for English speaking countries. ${ }^{35}$ Score is the number of months delayed compared to standards.

- Arithmetic: calculations during 1 minute. This test is part of a Dutch short screening test for school achievement, similar to the WRAT for English speaking countries. ${ }^{36}$ Score is the number of months delayed compared to standards.

\section{Memory function}

- Recognition of words. The test stimuli are presented simultaneously during a learning phase. Six words are presented with a presentation time of 1 second per item. After a delay of 2 seconds the screen shows one of these words between distrac- 
ters. The target item has to be recognized. The score is the number correct out of 24.

- Recognition of figures. Equal test-design for four figures. The score is the number correct out of 24.

- Corsi's Block tapping test. This is a continuous performance task in which the children have to repeat sequences of blocks that are presented by the computer. The test measures the nonverbal memory span. The score is the total memory span.

This system was connected with an exactly synchronized video-monitoring system, allowing a computer program to relate in time cognitive performance with EEG and clinical symptoms. Each epoch with epileptic EEG discharges could therefore be linked precisely with the video-recording and the test results during that epoch. The simultaneous EEG/cognitive recording lasted 2 hours per patient. All EEG's were evaluated by the same neurologist (JA) and discussed with colleagues in a weekly meeting. Seizures were classified as non-convulsive if no clinical signs (staring, myoclonias, eye-deviation, etc) were seen on the simultaneous video recording (APA\&JA).

EEG's were recorded using the 20-10 system with Brainlab® equipment and were visually analyzed by JA. Spikes and spike-related activity was scored as interictal activity. Rhythmic epileptiform activity lasting for 1 second or more and with regional spreading over at least one quarter of electrodes was scored as ictal activity. The localization and frequency of interictal epileptiform activity was determined visually. The occurrence of seizures was recorded; and total number and mean duration of seizures were determined.

\section{Sample size and statistical analysis}

The power calculation is based upon an estimate of the effect-size obtained for the CVST during neuropsychological testing in our previous studies. ${ }^{23,37}$ The CVST has shown epilepsy-related cognitive impairment in a number of studies ${ }^{19,29}$. The size of the effect for the CVST is calculated as the difference in mean scores between epilepsy and controls divided by the pooled standard-deviation: $\mathrm{X}_{\mathrm{i}}+\mathrm{X}_{\mathrm{j}} / \sum \mathrm{sd}_{\mathrm{i} / \mathrm{i}}$ : 27.6$21.1 / 7.4+11.5 / 2=0,7 \mathrm{sd}$. Type-1 $(\alpha)$ and type-2 (B) errors with an effect-size index of $0.7 \mathrm{sd}$ are entered in the power calculation as primary factors. The statistical power is set to $1-\beta=80 \%$, and the sensitivity to $\alpha=1 \%$ to be able to detect also mild effects. Power analysis according to conventions set by Cohen ${ }^{38}$ and Cook \& Campbell ${ }^{39}$ sets the required number of subjects at $>40$. However, given the division of the study group into subgroups (see previous variables and statistical model), this requirement is valid for any subgroup. Using a maximum of 4 subgroups (Controls; $<1 \%$; $>1 \%$; Seizures), the total number of patients is 160 .

The data were entered in a database for analysis. ANOVA were used, for comparisons over the subgroups. All calculations were performed with SPSS/PC+. 


\section{RESULTS}

Table 1

Demographical and clinical characteristics of the study population.

\begin{tabular}{lll}
\hline $\mathrm{N}=$ & Epilepsy & Controls \\
\hline Mean age (months) & 151 & 36 \\
Wechsler Full-scale IQ & $118.1(31.3)$ & $129.4(31.0)$ \\
Gender (\% boys) & $84.3(18.2)$ & $94.9(15.8)$ \\
Antiepileptic treatment (\% patients) & $51.7 \%$ & $63.8 \%$ \\
$\quad$ no medication & $29 \%$ & $47 \%$ \\
$\quad$ monotherapy & $44 \%$ & $47 \%$ \\
$\quad$ polytherapy (2 AEDs) & $20 \%$ & $6 \%$ \\
$\quad$ polytherapy (>2 AEDs) & $7 \%$ & $0 \%$ \\
Most frequently used AEDs in monotherapy (\% patients) & & \\
$\quad$ valproate & $15 \%$ & $22 \%$ \\
$\quad$ carbamazepine & $12 \%$ & $8 \%$ \\
$\quad$ oxcarbazepine & $9 \%$ & $6 \%$ \\
$\quad$ lamotrigine & $7 \%$ & - \\
Epilepsy classification & & \\
$\quad$ idiopathic generalized & $15 \%$ & \\
$\quad$ idiopathic localization & $5 \%$ & \\
$\quad$ cryptogenic localization & $61 \%$ & \\
symptomatic generalized & $1 \%$ & \\
$\quad$ symptomatic localization & $18 \%$ & \\
\hline
\end{tabular}

Table 1 shows the most important demographical characteristics. Hundred and fiftyone children with epilepsy were included and 36 controls. The mean age is 118.1 months (9y10m) for the children with epilepsy and 129.4 months $(10 \mathrm{y} 9 \mathrm{~m})$ for the controls $(p=0.054)$. The gender division was comparable as well (Table 1). There was a statistically significant difference between children with epilepsy and controls for Fullscale IQ. Controls showed a Full-scale IQ in the normal range (mean 94.9, sd 15.8), whereas the patients with epilepsy showed a significantly lower IQ: mean 84.3; sd 18.2 $(p=.02)$.

Table 2 shows the clinical characteristics of both children with epilepsy and controls. Most epilepsy patients used antiepileptic drugs in monotherapy (44\%), with valproic acid and carbamazepine as the most commonly used drugs. In the control group, $47 \%$ of children used antiepileptic drugs in monotherapy. As in former studies of our group (Aldenkamp \& Arends, 2004a), complex partial seizures were the dominant seizure type, registered during the two-hour recording in $21 \%$ of the children with epilepsy. Most epilepsy patients (58\%) had interictal epileptiform EEG discharges in $0 \%-<1 \%$ of the recording time; $8 \%$ showed no discharges at all during the two-hour recording and $50 \%$ showed discharges with a frequency of $<1 \% .43 \%$ had epileptiform discharges in $>1 \%$ of time $(1-10 \%: 24 \% ;>10 \%: 19 \%)$. There was a significant positive relation between frequency of interictal epileptiform discharges and the occurrence of seizures during registration (Spearman's non-parametric coefficient $=0.359 ; \mathrm{p}=0.000$ ) (figure 1). 
Table 2

EEG and seizure characteristics during episode.

\begin{tabular}{|c|c|c|}
\hline & Epilepsy & Controls \\
\hline $\mathrm{N}=$ & 151 & 36 \\
\hline \multicolumn{3}{|l|}{$\begin{array}{l}\text { Percentage of time with interictal epileptiform EEG discharges during the 2- } \\
\text { hour cognitive test session ( } \% \text { patients) }\end{array}$} \\
\hline no epileptiform EEG discharges & $8 \%$ & $92 \%$ \\
\hline$<1 \%$ of the time & $50 \%$ & $3 \%$ \\
\hline $1-10 \%$ of the time & $24 \%$ & $3 \%$ \\
\hline $10-50 \%$ of the time & $15 \%$ & $3 \%$ \\
\hline $50-75 \%$ of the time & $2 \%$ & $0 \%$ \\
\hline$>75 \%$ of the time & $2 \%$ & $0 \%$ \\
\hline $\begin{array}{l}\text { Total number of patients with seizures during the two-hour cognitive testing } \\
\text { session }\end{array}$ & $50(33 \%)$ & - \\
\hline Seizures occurring during the two-hour cognitive test session ( $\%$ patients). & & - \\
\hline no seizures & $68 \%$ & \\
\hline complex partial seizures & $21 \%$ & \\
\hline simple partial seizures & $3 \%$ & \\
\hline absence seizures & $2 \%$ & \\
\hline myoclonic seizures & $1 \%$ & \\
\hline atypical absence seizures & $5 \%$ & \\
\hline $\begin{array}{l}\text { Mean number of seizures in the } 50 \text { patients with seizures during the cognitive } \\
\text { testing session }\end{array}$ & $\begin{array}{l}20.4(58.0) \\
\text { range } 1-400\end{array}$ & - \\
\hline $\begin{array}{l}\text { Mean duration of seizures in the } 50 \text { patients with seizures during the cognitive } \\
\text { testing session }\end{array}$ & $\begin{array}{l}8.3 \mathrm{~s}(20.9 \mathrm{~s}) \\
\text { range } 1.0-150 \mathrm{~s}\end{array}$ & - \\
\hline
\end{tabular}

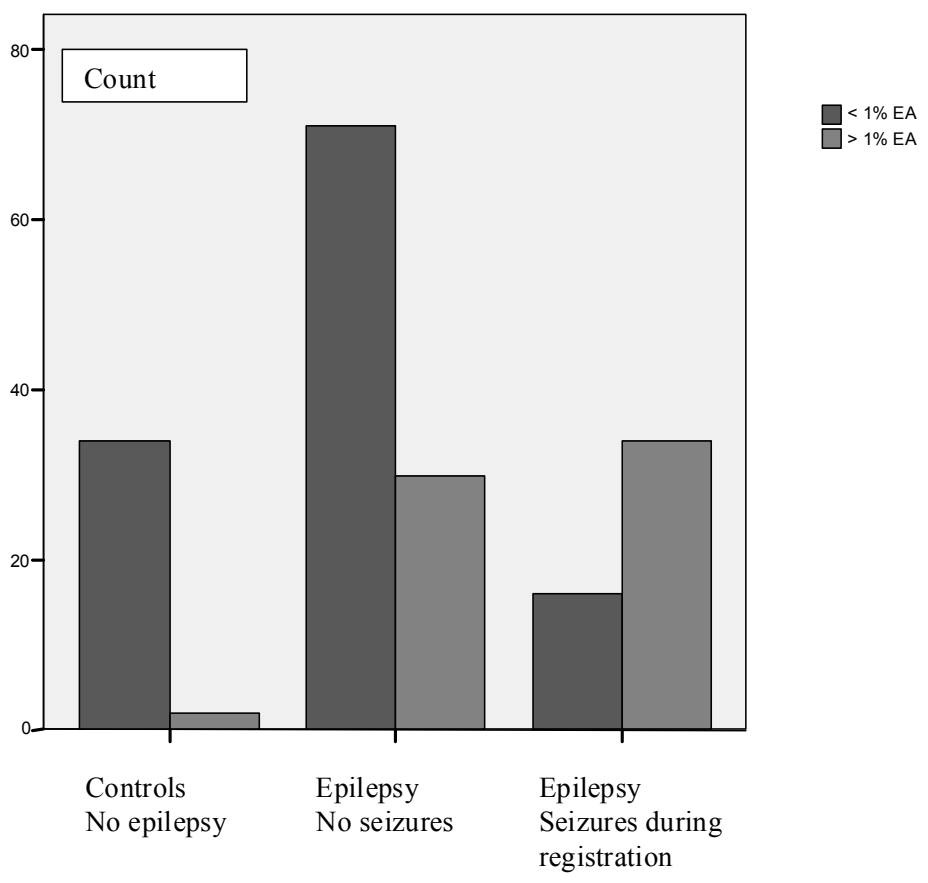

Figure 1

Positive relation between frequency of interictal epileptiform discharges and the occurrence of seizures during registration. 
In a first step we analyzed the peri-ictal effects of seizures. The epilepsy patients were divided into the group in whom no seizures during registration were recorded (group 2) vs. the group of children in whom short subtle seizures occurred during the two hour recording period (group 3). Table 3 provides the data of this comparison.

Table 3

The peri-ictal effects of subtle seizures on cognition.

\begin{tabular}{|c|c|c|c|c|}
\hline & $\begin{array}{l}\text { Group } 1 . \\
\text { Controls } \\
\mathrm{N}=36\end{array}$ & $\begin{array}{l}\text { Group } 2 . \\
\text { Epilepsy } \\
\text { No seizures } \\
\text { during recording } \\
\mathrm{N}=101\end{array}$ & $\begin{array}{l}\text { Group } 3 . \\
\text { Epilepsy } \\
\text { Seizures during } \\
\text { recording } \\
\mathrm{N}=50\end{array}$ & Results of statistical testing* \\
\hline 1. Wechsler Full-scale IQ & $\begin{array}{l}94.9(15.8) \\
\mathrm{n}=34\end{array}$ & $\begin{array}{l}88.0(17.9) \\
\mathrm{n}=96\end{array}$ & $\begin{array}{l}77.1(18.2) \\
\mathrm{n}=48\end{array}$ & $\begin{array}{l}\text { F. } 11.580 \mathrm{p}=<.001 \\
\text { group } 3<1 ; 3<2\end{array}$ \\
\hline $\begin{array}{l}\text { 2. Vocabulary (standard score with } 10 \text { as } \\
\text { average score for age) }\end{array}$ & $\begin{array}{l}8.3(3.6) \\
\mathrm{n}=36\end{array}$ & $\begin{array}{l}8.1(3.1) \\
\mathrm{n}=97\end{array}$ & $\begin{array}{l}6.7(3.2) \\
\mathrm{n}=46\end{array}$ & $\begin{array}{l}\text { F. } 3.633 \mathrm{p}=.028 \\
\text { Group } 3<2\end{array}$ \\
\hline $\begin{array}{l}\text { 3. Block Design (standard score with } 10 \text { as } \\
\text { average score for age) }\end{array}$ & $\begin{array}{l}9.3(3.8) \\
\mathrm{n}=36\end{array}$ & $\begin{array}{l}8.4(3.3) \\
\mathrm{n}=98\end{array}$ & $\begin{array}{l}7.4(3.8) \\
\mathrm{n}=46\end{array}$ & F. $2.883 \mathrm{p}=.059$ (ns) \\
\hline 4. Visual RT (mean rt in $\mathrm{msec})^{* *}$ & $\begin{array}{l}445(213) \\
\mathrm{n}=35\end{array}$ & $\begin{array}{l}421(127) \\
\mathrm{n}=91\end{array}$ & $\begin{array}{l}495(233) \\
\mathrm{n}=49\end{array}$ & F. $2.681 \mathrm{p}=.07(\mathrm{~ns})$ \\
\hline 5. Auditory RT (mean $\mathrm{rt}$ in $\mathrm{msec}$ )** & $\begin{array}{l}344(127) \\
\mathrm{n}=36\end{array}$ & $\begin{array}{l}328(91) \\
\mathrm{n}=97\end{array}$ & $\begin{array}{l}414(175) \\
n=49\end{array}$ & $\begin{array}{l}\text { F. } 7.854 \mathrm{p}=.001 \\
\text { group } 1<3 ; 2<3\end{array}$ \\
\hline 6. BCRT (mean $\mathrm{rt}$ in $\mathrm{msec}$ ) ${ }^{* *}$ & $\begin{array}{l}466(165) \\
n=33\end{array}$ & $\begin{array}{l}485(152) \\
\mathrm{n}=94\end{array}$ & $\begin{array}{l}535(153) \\
\mathrm{n}=46\end{array}$ & F. $2.315 \mathrm{p}=.10(\mathrm{~ns})$ \\
\hline 7. CVST24 (mean $\mathrm{rt}$ in sec) ${ }^{* *}$ & $\begin{array}{l}21.4(9.9) \\
\mathrm{n}=32\end{array}$ & $\begin{array}{l}26.6(12.3) \\
\mathrm{n}=78\end{array}$ & $\begin{array}{l}38.2(15.2) \\
\mathrm{n}=38\end{array}$ & $\begin{array}{l}\text { F. } 13.713 \mathrm{p}=<.001 \\
\text { group } 1<3 ; 2<3\end{array}$ \\
\hline 8. Recog Words (n correct out of 24) & $\begin{array}{l}17.0(3.8) \\
\mathrm{n}=22\end{array}$ & $\begin{array}{l}14.8(4.9) \\
\mathrm{n}=60\end{array}$ & $\begin{array}{l}9.5(7.0) \\
\mathrm{n}=34\end{array}$ & $\begin{array}{l}\text { F. } 15.494 \mathrm{p}=<.001 \\
\text { group } 3<1 ; 3<2\end{array}$ \\
\hline 9. Recog Figures (n correct out of 24) & $\begin{array}{l}12.5(3.9) \\
\mathrm{n}=25\end{array}$ & $\begin{array}{l}10.3(3.3) \\
\mathrm{n}=72\end{array}$ & $\begin{array}{l}6.8(3.9) \\
\mathrm{n}=38\end{array}$ & $\begin{array}{l}\text { F. } 21.873 \mathrm{p}=<.001 \\
\text { group } 2<1 ; 3<1 ; 3<2\end{array}$ \\
\hline 10. Corsi's block tapping test (memory span) & $\begin{array}{l}4.5(1.1) \\
\mathrm{n}=23\end{array}$ & $\begin{array}{l}4.4(1.0) \\
\mathrm{n}=61\end{array}$ & $\begin{array}{l}3.1(1.4) \\
\mathrm{n}=38\end{array}$ & $\begin{array}{l}\text { F. } 18.468 \mathrm{p}=<.001 \\
\text { group } 3<1 ; 3<2\end{array}$ \\
\hline 11. Reading (number of months delayed)** & $\begin{array}{l}0.31(8.6) \\
n=35\end{array}$ & $\begin{array}{l}17.4(18.5) \\
\mathrm{n}=67\end{array}$ & $\begin{array}{l}13.8(14.2) \\
\mathrm{n}=36\end{array}$ & $\begin{array}{l}\text { F. } 14.456 \mathrm{p}=<.001 \\
\text { groups } 1<2 ; 1<3\end{array}$ \\
\hline 12. Arithmetic (number of months delayed)** & $\begin{array}{l}5.5(10.0) \\
n=35\end{array}$ & $\begin{array}{l}15.7(18.8) \\
n=68\end{array}$ & $\begin{array}{l}13.3(13.9) \\
n=38\end{array}$ & $\begin{array}{l}\text { F. } 4.939 \mathrm{p}=.008 \\
\text { Group } 2<1\end{array}$ \\
\hline
\end{tabular}

Statistical testing: ANOVA for the overall comparison of differences between the 3 groups. Only in case of statistical significance post-hoc comparisons between each group were performed, using T-Tests, corrected for multiple testing using the Bonferroni correction. Differences indicated with $<$ show the groups with fastest/smallest/lowest scores; ns= not significant. ${ }^{* *}$ Higher scores signifies a worse result

Group 2 showed significantly lower scores compared to controls (group 1) on three of the twelve tests. There was worse performance compared to the controls for the Reading, Arithmetic, and Recognition of figures. Group 2 does not score significantly lower on any of the tests when compared to group 3.

Group 3 shows more statistically significant effects (eight of the twelve tests). On one test (Reading) the results show worse performance only compared to the controls. On six tests there is also worse performance in comparison with group 2: Full-scale IQ, auditory RT, CVST, recognition words, recognition of figures and Corsi's blocktapping. In one test results were only worse compared to group 2 and not to controls (Vocabulary). In general the effects of subtle seizures are large compared to both controls and the epilepsy patients without seizures during cognitive testing. The effect on full-scale intelligence compared with the children with epilepsy without seizures is 0.6 
[(88.0-77.1)/17.9] standard deviation (sd), for auditory RT $0.9 \mathrm{sd}$, for the CVST $0.9 \mathrm{sd}$, for recognition words and figures, $1.1 \mathrm{sd}$ and $1.1 \mathrm{sd}$ and for Corsi $1.3 \mathrm{sd}$. In general, effects $>0.7$ standard deviation are considered to represent large effects (Cohen, 1977).

To control for the frequency of interictal epileptiform EEG discharges versus the periictal effect of subtle seizures, the group without seizures was divided into two groups. Children who showed no interictal epileptiform EEG discharges or in less than 1\% of the time (Group 2A) vs. those who showed interictal epileptiform discharges in more than $1 \%$ of the time (Group $2 \mathrm{~B}$ ) (table 4 ).

Table 4

The effects of interictal epileptiform EEG discharges on cognition.

\begin{tabular}{|c|c|c|c|}
\hline & Group 2A. & Group 2B & Results of statistical testing* \\
\hline & $\begin{array}{l}\text { Epilepsy No seizures }<1 \% \\
\text { of time with EEDs } \# \\
N=71\end{array}$ & $\begin{array}{l}\text { Epilepsy No seizures } \\
>1 \% \text { of time with EEDs } \\
\mathrm{N}=30\end{array}$ & \\
\hline 1. Wechsler Full-scale IQ & $\begin{array}{l}90.9(17.9) \\
\mathrm{n}=69\end{array}$ & $\begin{array}{l}80.3(15.7) \\
\mathrm{n}=27\end{array}$ & F. $7.288 \mathrm{p}=.008$ \\
\hline $\begin{array}{l}\text { 2. Vocabulary (standard score with } 10 \text { as } \\
\text { average score for age) }\end{array}$ & $\begin{array}{l}8.2(3.3) \\
\mathrm{n}=69\end{array}$ & $\begin{array}{l}7.8(2.7) \\
\mathrm{n}=28\end{array}$ & F. $0.304 \mathrm{p}=.58(\mathrm{~ns})$ \\
\hline $\begin{array}{l}\text { 3. Block Design (standard score with } 10 \text { as } \\
\text { average score for age) }\end{array}$ & $\begin{array}{l}8.9(3.1) \\
\mathrm{n}=70\end{array}$ & $\begin{array}{l}6.9(3.4) \\
\mathrm{n}=28\end{array}$ & F. $8.654 \mathrm{p}=.004$ \\
\hline 4. Visual RT (mean $\mathrm{rt}$ in $\mathrm{msec})^{* *}$ & $\begin{array}{l}409(113) \\
\mathrm{n}=63\end{array}$ & $\begin{array}{l}448(155) \\
\mathrm{n}=28\end{array}$ & F. $1.754 \mathrm{p}=.189$ (ns) \\
\hline 5. Auditory RT (mean $\mathrm{rt}$ in $\mathrm{msec}$ )** & $\begin{array}{l}323(90) \\
\mathrm{n}=67\end{array}$ & $\begin{array}{l}337(94) \\
\mathrm{n}=30\end{array}$ & F. $0.488 \mathrm{p}=.487$ \\
\hline 6. BCRT (mean rt in msec)** & $\begin{array}{l}475(145) \\
\mathrm{n}=65\end{array}$ & $\begin{array}{l}507(165) \\
\mathrm{n}=29\end{array}$ & F. $0.911 \mathrm{p}=.342$ (ns) \\
\hline 7. CVST24 (mean rt in sec)** & $\begin{array}{l}24.3(10.1) \\
\mathrm{n}=55\end{array}$ & $\begin{array}{l}32.3(15.4) \\
\mathrm{n}=23\end{array}$ & F. $7.368 \mathrm{p}=.008$ \\
\hline 8. Recog Words (n correct out of 24) & $\begin{array}{l}15.2(4.6) \\
n=45\end{array}$ & $\begin{array}{l}13.7(5.7) \\
n=15\end{array}$ & F. $1.041 \mathrm{p}=.312(\mathrm{~ns})$ \\
\hline 9. Recog Figures (n correct out of 24) & $\begin{array}{l}10.4(3.2) \\
\mathrm{n}=54\end{array}$ & $\begin{array}{l}9.6(3.3) \\
\mathrm{n}=18\end{array}$ & F. $1.089 \mathrm{p}=.300$ (ns) \\
\hline 10. Corsi's block tapping test (memory span) & $\begin{array}{l}4.7(1.0) \\
n=42\end{array}$ & $\begin{array}{l}3.7(0.9) \\
\mathrm{n}=19\end{array}$ & F. $15.300 \mathrm{p}=<.001$ \\
\hline 11. Reading (number of months delayed)** & $\begin{array}{l}14.9(18.5) \\
\mathrm{n}=47\end{array}$ & $\begin{array}{l}23.4(17.3) \\
\mathrm{n}=20\end{array}$ & F. $3.071 \mathrm{p}=.084(\mathrm{~ns})$ \\
\hline 12. Arithmetic (number of months delayed)** & $\begin{array}{l}14.2(19.5) \\
\mathrm{n}=48\end{array}$ & $\begin{array}{l}19.6(18.8) \\
\mathrm{n}=20\end{array}$ & F. $1.175 \mathrm{p}=.282$ (ns) \\
\hline
\end{tabular}

Statistical testing: ANOVA for the overall comparison of differences between the 4 groups. Only in case of statistical significance post-hoc comparisons between each group were performed, using T-Tests, corrected for multiple testing using the Bonferron correction. Differences indicated with $<$ show the groups with fastest/smallest/lowest scores; ns $=$ not significant. ** Higher scores signifies a worse result \# EEDs: Epileptiform EEG discharges

Group 2B showed statistically significant lower scores compared to group 2A on four of the twelve tests. There is worse performance for Full-scale IQ, Block design, CVST and Corsi's block tapping. For none of the tests performance of group 2A was worse than $2 \mathrm{~B}$. 
The magnitude of these effects was $0.6 \mathrm{sd}$ for Full-scale IQ, 0.6 sd for Block Design, $0.8 \mathrm{sd}$ for CVST24 and $1.0 \mathrm{sd}$ for Corsi's.

In a third step, we also analysed the results for group 2B. Children with interictal epileptiform EEG-discharges in $>1 \%$ but less than $10 \%$ of the time $(2 \mathrm{C})$ were compared to patients with very frequent interictal epileptiform EEG discharges, defined as $>10 \%$ of the recording time (2D) (table 5).

Table 5

The effect of frequency of interictal epileptiform EEG-discharges on cognition.

\begin{tabular}{|c|c|c|c|c|}
\hline & Group 2A & Group 2C & Group 2D & $\begin{array}{l}\text { Results of statistical testing } \\
\text { (not including controls)* }\end{array}$ \\
\hline & $\begin{array}{l}<1 \% \text { of time with } \\
\text { EEDs } \\
N=71\end{array}$ & $\begin{array}{l}1-10 \% \text { of time with } \\
\text { EEDs } \\
N=15\end{array}$ & $\begin{array}{l}>10 \% \text { of time with } \\
\text { EEDs } \\
N=15\end{array}$ & \\
\hline 1. Wechsler Full-scale IQ & $\begin{array}{l}90.9(17.9) \\
\mathrm{n}=69\end{array}$ & $\begin{array}{l}78.9(14.9) \\
\mathrm{n}=14\end{array}$ & $\begin{array}{l}81.9(16.7) \\
n=13\end{array}$ & $\begin{array}{l}\text { F. } 3.718 p=.028 \\
2 C<2 A\end{array}$ \\
\hline $\begin{array}{l}\text { 2. Vocabulary (standard score with } \\
10 \text { as average score for age) }\end{array}$ & $\begin{array}{l}8.2(3.3) \\
\mathrm{n}=69\end{array}$ & $\begin{array}{l}7.5(2.6) \\
\mathrm{n}=15\end{array}$ & $\begin{array}{l}8.2(2.8) \\
\mathrm{n}=13\end{array}$ & F. $0.316 \mathrm{p}=.730(\mathrm{~ns})$ \\
\hline $\begin{array}{l}\text { 3. Block Design (standard score } \\
\text { with } 10 \text { as average score for age) }\end{array}$ & $\begin{array}{l}8.9(3.1) \\
\mathrm{n}=69\end{array}$ & $\begin{array}{l}6.3(3.9) \\
\mathrm{n}=15\end{array}$ & $\begin{array}{l}7.5(2.7) \\
\mathrm{n}=13\end{array}$ & $\begin{array}{l}\text { F. } 4.893 \mathrm{p}=.009 \\
2 \mathrm{C}<2 \mathrm{~A}\end{array}$ \\
\hline 4. Visual RT (mean $\mathrm{rt}$ in $\mathrm{msec})^{* *}$ & $\begin{array}{l}409.4(112.5) \\
\mathrm{n}=63\end{array}$ & $\begin{array}{l}479.1(205.7) \\
n=14\end{array}$ & $\begin{array}{l}416.0(74.1) \\
n=14\end{array}$ & F. $1.758 \mathrm{p}=.178(\mathrm{~ns})$ \\
\hline 5. Auditory RT (mean $\mathrm{rt}$ in $\mathrm{msec}$ )** & $\begin{array}{l}323.2(90.2) \\
\mathrm{n}=67\end{array}$ & $\begin{array}{l}358.9(111.5) \\
\mathrm{n}=15\end{array}$ & $\begin{array}{l}315.5(69.9) \\
\mathrm{n}=15\end{array}$ & F. $1.097 \mathrm{p}=.338(\mathrm{~ns})$ \\
\hline 6. BCRT (mean $\mathrm{rt}$ in $\mathrm{msec}$ ) ${ }^{* *}$ & $\begin{array}{l}474.8(145.2) \\
\mathrm{n}=65\end{array}$ & $\begin{array}{l}508.36(128.1) \\
n=14\end{array}$ & $\begin{array}{l}505.9(198.2) \\
\mathrm{n}=15\end{array}$ & F. $0.452 \mathrm{p}=.638(\mathrm{~ns})$ \\
\hline 7. CVST24 (mean rt in sec) & $\begin{array}{l}24.3(10.1) \\
\mathrm{n}=55\end{array}$ & $\begin{array}{l}36.7(113.9) \\
\mathrm{n}=11\end{array}$ & $\begin{array}{l}28.2(16.1) \\
\mathrm{n}=12\end{array}$ & $\begin{array}{l}\text { F. } 5.274 p=.007 \\
2 A<2 C\end{array}$ \\
\hline $\begin{array}{l}\text { 8. Recog Words } \\
\text { (n correct out of } 24 \text { ) }\end{array}$ & $\begin{array}{l}15.2(4.6) \\
n=45\end{array}$ & $\begin{array}{l}13.5(5.5) \\
\mathrm{n}=8\end{array}$ & $\begin{array}{l}13.9(6.3) \\
\mathrm{n}=7\end{array}$ & F. $0.522 \mathrm{p}=.596(\mathrm{~ns})$ \\
\hline $\begin{array}{l}\text { 9. Recog Figures } \\
\text { (n correct out of } 24 \text { ) }\end{array}$ & $\begin{array}{l}10.5(3.3) \\
\mathrm{n}=54\end{array}$ & $\begin{array}{l}9.2(3.6) \\
\mathrm{n}=9\end{array}$ & $\begin{array}{l}10.0(3.0) \\
\mathrm{n}=9\end{array}$ & F. $0.666 \mathrm{p}=.517(\mathrm{~ns})$ \\
\hline $\begin{array}{l}\text { 10. Corsi's block tapping test } \\
\text { (memory span) }\end{array}$ & $\begin{array}{l}4.7(1.0) \\
\mathrm{n}=42\end{array}$ & $\begin{array}{l}3.6(0.7) \\
\mathrm{n}=10\end{array}$ & $\begin{array}{l}3.8(1.1) \\
\mathrm{n}=9\end{array}$ & $\begin{array}{l}\text { F. } 7.628 \mathrm{p}=.001 \\
\text { group } 2 \mathrm{C}<2 \mathrm{~A} ; 2 \mathrm{D}<2 \mathrm{~A}\end{array}$ \\
\hline $\begin{array}{l}\text { 11. Reading (number of months } \\
\text { delayed)** }\end{array}$ & $\begin{array}{l}14.9(18.3) \\
\mathrm{n}=47\end{array}$ & $\begin{array}{l}25.8(18.6) \\
\mathrm{n}=11\end{array}$ & $\begin{array}{l}20.4(16.2) \\
n=9\end{array}$ & F. $1.736 \mathrm{p}=.184$ (ns) \\
\hline $\begin{array}{l}\text { 12. Arithmetic (number of months } \\
\text { delayed)** }\end{array}$ & $\begin{array}{l}14.2(19.5) \\
\mathrm{n}=48\end{array}$ & $\begin{array}{l}21.4(19.5) \\
\mathrm{n}=12\end{array}$ & $\begin{array}{l}16.8(12.2) \\
\mathrm{n}=8\end{array}$ & F. $0.729 \mathrm{p}=.486(\mathrm{~ns})$ \\
\hline
\end{tabular}

Statistical testing: ANOVA for the overall comparison of differences between the 4 groups. Only in case of statistical significance post-hoc comparisons between each group were performed, using T-Tests, corrected for multiple testing using the Bonferroni correction. Differences indicated with $<$ show the groups with fastest/smallest/lowest scores; ns= not significant.; ** Higher scores signifies a worse result; \# EEDs: Epileptiform EEG discharges

The comparisons showed that for group 2D no statistically significant differences with group 2C occurred. Group 2D showed significantly worse results for Corsi's Block tapping compared with group 2A. Group 2C showed worse results on Full-scale IQ, Block design, CVST, and Corsi's Block tapping.

In addition two types of posthoc analyses were performed. Firstly, a posthoc analysis after exclusion of 41 children with a Full-scale IQ of $<70$ was performed. After exclusion of those values, the total number of children with epilepsy without seizures during 
registration was 85. Only the results of Corsi's block tapping was still significantly different (Table $6 \& 7$ ).

Table 6

Posthoc analysis after removal of data from 32 children with IQ $<70$

\begin{tabular}{|c|c|c|c|}
\hline & Group 2A & Group 2B & Results of statistical testing * \\
\hline & $\begin{array}{l}\text { Epilepsy No seizures }<1 \% \\
\text { of time with EEDs\# } \\
\mathrm{N}=64\end{array}$ & $\begin{array}{l}\text { Epilepsy No seizures }>1 \% \\
\text { of time with EEDs } \\
\mathrm{N}=21\end{array}$ & \\
\hline 1. Wechsler Full-scale IQ & $\begin{array}{l}93.2(16.3) \\
\mathrm{n}=64\end{array}$ & $\begin{array}{l}86.2(15.7) \\
\mathrm{n}=21\end{array}$ & F. $3.296 \mathrm{p}=.073(\mathrm{~ns})$ \\
\hline $\begin{array}{l}\text { 10. Corsi's block tapping test } \\
\text { (memory span) }\end{array}$ & $\begin{array}{l}4.7(1.0) \\
\mathrm{n}=40\end{array}$ & $\begin{array}{l}3.7(0.9) \\
\mathrm{n}=15\end{array}$ & F. $12.750 \mathrm{p}=.001$ \\
\hline
\end{tabular}

Table 7

Posthoc analysis after removal of data from 32 children with IQ $<70$

\begin{tabular}{|c|c|c|c|c|}
\hline & Group 2A & Group 2C & Group 2D & $\begin{array}{l}\text { Results of statistical testing } \\
\text { (not including controls)* }\end{array}$ \\
\hline & $\begin{array}{l}<1 \% \text { of time with } \\
\text { EEDs } \\
\mathrm{N}=64\end{array}$ & $\begin{array}{l}1-10 \% \text { of time with } \\
\text { EEDs } \\
\mathrm{N}=11\end{array}$ & $\begin{array}{l}>10 \% \text { of time with } \\
\text { EEDs } \\
N=10\end{array}$ & \\
\hline $\begin{array}{l}\text { 1. Wechsler Full-scale IQ } \\
\text { (Controls: } 96.0[14.2] \text { ) }\end{array}$ & $\begin{array}{l}93.2(16.3) \\
\mathrm{n}=64\end{array}$ & $\begin{array}{l}84.2(11.8) \\
\mathrm{n}=11\end{array}$ & $\begin{array}{l}88.4(113.0) \\
\mathrm{n}=10\end{array}$ & F. $1.829 \mathrm{p}=.091$ \\
\hline $\begin{array}{l}\text { 10. Corsi's block tapping test } \\
\text { (memory span) }\end{array}$ & $\begin{array}{l}4.7(1.0) \\
\mathrm{n}=40\end{array}$ & $\begin{array}{l}3.6(0.7) \\
n=9\end{array}$ & $\begin{array}{l}3.8(1.0) \\
\mathrm{n}=6\end{array}$ & $\begin{array}{l}\text { F. } 6.450 \mathrm{p}=.003 \\
\text { group } 2 \mathrm{C}<2 \mathrm{~A}\end{array}$ \\
\hline
\end{tabular}

\section{DISCUSSION}

In this prospective study a combination of EEG and neuropsychological testing was performed in a large group of children. The results of children with subtle seizures during a 2-hour testing session (group 3) were compared with all children with epilepsy without such seizures during the 2-hour cognitive testing session (Group 2) and were compared with controls without epilepsy (Group 1). We found that children with epilepsy and seizures recorded during a 2-hour test performed worse compared to children with epilepsy without seizures recorded (Group 2) on several neuropsychological tests. This was the case for the Wechsler full-scale IQ, and for attention tests (Visual reaction time dominant hand), speed of central information processing (CVST 24) and memory function (Recognition of words, Recognition of figures, Corsi's block tapping) and educational achievement (reading). Children with epilepsy but without seizures during testing (Group 2) performed less on memory function (Recognition of figures) and educational achievement (reading and arithmetic) than controls (Group 1) (Table 2).

It is important to note that the control group did not consist of a population of normal schoolchildren or best friends, but of a population of children in whom epilepsy was suspected or diagnosed earlier. This diagnosis was however defeated after analysis in our center. For this reason, the controls also used antiepileptic medication in a high percentage. This is an advantage in that the possible negative effect of antiepileptic drugs is present in all groups. 
Numerous studies have analyzed cognitive function in children with epilepsy. The impact on intelligence may well be a secondary effect, a consequence when memory and information processing impairments persist over time. ${ }^{23}$ The average Full-scale IQ in our epilepsy study group was 84.3. This relatively low value is in line with a recent study describing performance on the WISC III in children with epilepsy, ${ }^{40}$ although possibly exaggerated due to selection of children with educational problems because Kempenhaeghe is a tertiary referral center. The same bias is possibly causing the mean Full-scale IQ of 94.9 in the controls.

The impact of subtle seizures on attention has been demonstrated in several studies. ${ }^{41}$ Especially children with generalized non-convulsive seizures show low cognitive scores. ${ }^{15}$ In children with high frequent subtle seizures and complete disappearance of seizures after introduction of medication, this effect of subtle seizures can be demonstrated. The epilepsy syndrome to theoretically best fit these criteria is childhood absence epilepsy. In childhood absence epilepsy, short seizures predominate, and focal interictal epileptiform activity is rare. Besides, in childhood absence epilepsy the success rate of antiepileptic medication is high. Sirén et al. treated 11 children with newly diagnosed typical absences with generalized 3-Hz spike-wave discharges. Disappearance of absence seizures did not affect general intelligence, but visual memory tasks improved significantly. ${ }^{16}$ These results are in line with Henkin et al. describing attention deficit, verbal learning and memory, word fluency and fine motor deficits in children with childhood absence epilepsy. ${ }^{4}$ In this study 12 children with absence seizures were included; all used valproic acid, but only half were seizure free. ${ }^{4}$ Other studies describe significant deficits on global functioning in children with absence seizures. ${ }^{3}$ This last study was done in a secondary referral center, so possibly relatively low cognitive results in this group are due to selection bias as well, like our study possibly is.

In children without seizures during cognitive testing, the occurrence of frequent epileptiform discharges did have an additional impact on cognitive function in our study. We initially divided spike frequency into two categories; $0 \%-<1 \%$ vs. $>1 \%$. Significant differences were noted on the Full-scale IQ, Block design, CVST24 and Corsi's block tapping test. The type of effect is very similar to the effect of short non-convulsive seizures, although the impact is less pronounced in number of areas involved, and magnitude. In line with our previous study the effect of interictal epileptiform EEG discharges is additional and more limited than the effect of seizures. ${ }^{23}$ So the effects of interictal epileptiform activity can be characterized as a negative effect that is independent from the occurrence of seizures.

There seems to be a certain threshold for the cognitive effects of interictal epileptiform EEG discharges. When the group with interictal epileptiform EEG discharges in $1 \%-10 \%$ of the time (group 2C) is compared to those with interictal epileptiform discharges in $>10 \%$ of the time (group 2D), no statistically significant differences occur (table 4). Apparently the threshold for cognitive effects can be found around between $1 \%$ and below $10 \%$ of the time. The reason for cognitive effects of interictal epilepti- 
form EEG discharges is unclear. Apparently some of these discharges, although focal in the majority of our patients, can have interruptions of cognitive function similar to subtle seizures. However, with simultaneous video registration, we could not demonstrate a interruption of consciousness.

The phenomenon of transient cognitive impairment (TCI) was first described by Aarts et al. ${ }^{8}$ TCI can be demonstrated in about $50 \%$ of patients who show epileptiform activity during testing. ${ }^{25}$ Although of ultimate theoretical interest, the question whether TCI does influence global functioning and school performance is still unsolved. This implicates that the demonstration of TCI in an individual child should not automatically lead to initiation of antiepileptic medication. ${ }^{25}$ When performing combined EEG/cognitive tests in order to objective TCI, it is important to recognize the phenomenon of neuropsychological EEG activation or suppression. ${ }^{42}$ Cognitive tasks can provoke epileptic discharges in idiopathic generalized epilepsies, especially in epilepsy syndromes characterized by myoclonic seizures. ${ }^{42}$ An inhibitory effect on discharges is even more common. 64\% of 208 patients (children and adults) showed inhibition of epileptiform discharges in a large series by Matsuoka et al. ${ }^{42}$ This problem can be tackled by collecting EEG and neuropsychological data at different occasions. ${ }^{43}$ In a recent study using this non-simultaneous paradigm, the mean latency between EEG recording and neuropsychological assessment was 1.5 years. Relevant drug treatment changes can influence spike frequency a lot in between both test data. Whether those children had been excluded or not, was not mentioned in this study.

Also in benign childhood epilepsy wit ${ }^{16}$ centrotemporal spikes, the most frequent partial epilepsy in childhood, suppression of spikes does occur during cognitive tests. ${ }^{10}$ Complex tasks like reading do suppress epileptiform activity more than simple tasks. ${ }^{23,29,31}$ Another problem is the lack of correlation between the presence of TCI and impaired school performance as was recently described in children with benign epilepsy with centrotemporal spikes. ${ }^{10}$

Different studies have identified different cognitive tasks to be involved in children with epilepsy and short seizures or interictal epileptiform activity. This is partly due to the lateralization of spike or spike-wave activity. For example, the presence of leftsided spikes in BCECTS does influence language lateralization, and right-sided spikes do not. ${ }^{43}$ Interestingly, in generalized spike-wave discharges, visual memory tasks are influenced most and the percentage of false answers is related with the total duration of discharges. In our series, Full-scale IQ, Block design, CVST24 and Corsi's block tapping test were significantly worse in the epileptiform discharges $>1 \%$ group. In children with localization-related epilepsy syndromes, the CVST24 is most vulnerable. ${ }^{30}$

Visual memory, CVST24, Block design and Corsi's block tapping all have in common that they combine visual input, spatial recognition and endurance of concentration for each test item. Tasks of visual memory are more at risk for disruption than verbal memory. In childhood absence epilepsy, no lateralization of seizure activity occurs. 
However, two studies have demonstrated disturbances in visual memory tasks, while verbal memory was normal. ${ }^{16,45}$ The reason for this selective vulnerability is unknown.

\section{LIMITATIONS}

Our study has several limitations. First, Kempenhaeghe is a tertiary referral center for epilepsy. For this reason a lot of children with difficult to treat epilepsy, and/or supposed cognitive problems due to their epilepsy are included in our study. This structural selection bias possibly gives rise to the relatively low mean full-scale IQ values in all subgroups. However, concerning the results in table 3,4 and 5, there does not seem to be a logical reason to argument that this aforementioned structural selection bias would influence the results and differences between group 2 and 3 or between group 2A, 2B, 2C and 2D.

Secondly, in our cohort we used a "pseudo-control" population. The control population consisted of children in whom epilepsy was suspected or diagnosed earlier, but this diagnosis was defeated after analysis in our center. For this reason, the controls also used antiepileptic medication in a high percentage, had an average full-scale IQ of 94.9, and were analyzed because of supposed cognitive problems as well. The comparison with this group of "pseudocontrols" enabled us to determine the effect of subtle seizures and epileptiform activity more properly because both groups used antiepileptic medication in a similar percentage and both groups had supposed learning problems as well. For this reason our control group will score lower/slower scores than a population of "normal controls". For this reason the statistical differences we found are possibly more robust and better presenting the relative influence of subtle seizures and epileptiform activity solely.

The distribution of children into the different groups did not fulfill our power analysis requirements. However, in table 1, 2, 3, and 4, the shortages are relatively mild. The small numbers in our post-hoc analyses in table 5, 6, and 7 may have influenced statistics indeed and may have missed a difference that could have been demonstrated in a larger sample.

\section{CONCLUSION}

In conclusion: subtle seizures have an impact on a broad set of cognitive domains, ranging from global cognitive function, to attention, mental speed and memory. But even in the absence of short seizures, a negative effect of interictal epileptiform activity is specifically found on memory functions. In line with earlier studies, visual memory tests are most vulnerable for epileptiform activity and short subclinical seizures. The clinical relevance of our findings is that early detection of the cognitive impact of seizure-related activity and of interictal epileptiform EEG discharges may possibly help to optimize educational support and drug treatment in children with epilepsy.

\section{Acknowledgements}

We thank Leonie Diepman for completing the SPSS database. 


\section{REFERENCES}

1 Elger CE, Helmstaedter C, Kurthen M. Lancet Neurol. 2004; 3: 663-72.

2 MacAllister WS, Schaffer SG. Neuropsychological deficits in childhood epilepsy syndromes. Neuropsychol Rev 2007; 17: 427-44.

3 Pavone P, Bianchini R, Trifiletti RR, Incrpora G, Pavone A, Parano E. Neuropsychological asessment in children with absence epilepsy. Neurology 2001; 56: 1047-51.

4 Henkin Y, Sadeh M, Kivity S, Shabtai E, Kishon-Rabin L, Gadoth N. Cognitive function in idiopathic generalized epilepsy of childhood. Dev Med Child Neurol 2005; 47:126-32.

5 Staden U, Isaacs E, Boyd SG, Brandl U, Neville BGR. Language dysfunction in children with rolandic epilepsy. Neuropediatrics 1998; 29: 242-8.

6 Papavasiliou A, Mattheou D, Bazigou H, Kotsalis C, Paraskevoulakos E. Written language skills in children with benign childhood epilepsy with centrotemporal spikes. Epilepsia Behav 2005; 6: 50-8.

7 Browne TR, Penry JK, Porter RJ, Dreifuss FE. Responsiveness before, during, and after spike-wave paroxysms. Neurology 1974; 24: 659-65.

8 Aarts JHP, Binnie CD, Smit AM, Wilkins AJ. Selective cognitive impairment during focal and generalised epileptiform EEG activity. Brain 1984; 107: 293-308.

9 Fisch BJ. Interictal epileptiform activity: diagnostic and behavioral implications. J Clin Neurophysiol 2003; 20 : 155-62.

10. Fonseca LC, Tedrus GM, Pacheco EM. Epileptiform EEG discharges in benign childhood epilepsy with centrotemporal spikes: reactivity and transitory cognitive impairment. Epilepsy Behav 2007; 11: 65-70.

11. Oostrom KJ, Smeets-Schouten A, Kruitwagen CL, Peters AC, Jennekens-Schinkel A. Not only a matter of epilepsy: early problems of cognition and behaviour in children with "epilepsy only"- a prospective, longitudinal, controlled study starting at diagnosis. Pediatrics 2003; 112: 1338-44.

12. Niedermeyer E, Lopes da Silva F. Electroencephalography: basic principles, clinical applications, and related fields. Philadelphia: Lippincott Williams \& Wilkins; 2005. p. 256-80.

13. Niemann H, Boenick HE, Schmidt RC, Ettlinger G. Cognitive development in epilepsy; the relative influence of epileptic activity and brain damage. Eur Arch Psychiatry Neurol Sci 1985; 234: 399-403.

14. Ellenberg JH, Hirtz DG, Nelson KB. Do seizures in children cause intellectual deterioration? N Engl J Med 1989; 314: 1085-8.

15. Mandelbaum DE, Burack GD. The effect of seizure type and medication on cognitive and behavioral functioning in children with idiopathic epilepsy. Dev Med Child Neurol 1997; 39: 731-5.

16. Sirén A, Kylliäinen A, Tenhunen M, Hirvonen K, Riita T, Koivikko M. Beneficial effects of antiepileptic medication on absence seizures and cognitive functioning in children. Epilepsy Behav 2007; 11: 85-91.

17. Stores G. Electroencephalographic parameters in assessing the cognitive function of children with epilepsy. Epilepsia, 1990; 31(S4): 45-9.

18. Aldenkamp AP, Arends J, Overweg-Plandsoen TC, et al. Acute cognitive effects of nonconvulsive difficultto-detect epileptic seizures and epileptiform electroencephalographic discharges. J Child Neurol 2001; 16 : 119-23.

19. Aldenkamp AP, Overweg-Plandsoen WCG, Arends J. An open nonrandomized clinical comparative study evaluating the effect of epilepsy on learning. J Child Neurol 1999a; 14: 795-801.

20. Aldenkamp AP, Overweg-Plandsoen WC, Diepman LA. Factors involved in learning problems and educational delay in children with epilepsy. Child Neuropsychol 1999b; 5: 130-8.

21. Pressler RM, Robinson RO, Wilson GA, Binnie CD. Treatment of epileptiform discharges can improve behavior in children with behavioral problems and epilepsy. J Pediatr 2005; 146: 112-7.

22. Binnie CD. Significance and management of transitory cognitive impairment due to subclinical EEG discharges in children. Brain Dev 1993; 15: 23-30.

23. Aldenkamp AP, Arends J. The relative influence of epileptic EEG discharges, short nonconvulsive seizures and type of epilepsy on cognitive function. Epilepsia 2004a; 45: 54-63.

24. Besag FM. The therapeutic dilemma: treatment subtle seizures or indulging in electroencephalogram cosmetics? Semin Pediatr Neurol 1995; 2: 261-8.

25. Binnie CD. Cognitive impairment during epileptiform discharges: is it ever justifiable to treat the EEG? Lancet Neurol 2003; 2: 725-30.

26. Wirrell E, Sherman EM, Vanmastrigt R, Hamiwka L. Deterioration in cognitive function in children with benign epilepsy of childhood with central temporal spikes treated with sulthiame. J Child Neurol 2008; 23: $14-21$. 
27. Ronen GM, Richards JE, Cunningham C, Secord M, Rosenbloom D. Can sodium valproate improve learning in children with epileptiform bursts but without clinical seizures? Dev Med Child Neurol 2000; 42: 751-5.

28. Pressler RM, Binnie CD, Coleshill SG, Chorley GA, Robinson RO. Effect of lamotrigine on cognition in children with epilepsy. Neurology 2006; 66: 1495-9.

29. Aldenkamp AP. Effect of seizures and epileptiform discharges on cognitive function. Epilepsia 1997; 38(S1): S52-5.

30. Aldenkamp AP, Overweg J, Gutter Th, Beun AM, Diepman L, Mulder OG. Effect of epilepsy, seizures and epileptiform EEG-discharges on cognitive function. Acta Neurol Scand 1996; 93: 253-9.

31. Aldenkamp AP, Arends J., Verspeek S. Berting M. The Cognitive impact of epileptiform EEG-discharges: relationship with type of cognitive task. Child Neuropsychol 2004; $10: 297-305$.

32. Aldenkamp AP, Beitler J, Arends J, van der Linden I, Diepman L. Acute effects of subclinical epileptiform EEG discharges on cognitive activation. Funct Neurol 2005; 20: 23-8.

33. Aldenkamp, AP, Arends J. Effects of epileptiform EEG discharges on cognitive function: Is the concept of "transient cognitive impairment" still valid? Epilepsy \& Behaviour 2004b; 5 (S1): 25-34.

34. Tromp S., Aldenkamp AP, Arends J, Weber JW, van der Linden I, Diepman L. Relative influence of epileptic seizures and of epilepsy syndrome on cognitive function. J Child Neurol 2003; 18: 407-13.

35. Wechsler D. Manual for the Wechsler Intelligence scale. Revised. New York: The Psychological Corporation, 1974.

36. De Vos, T. Handleiding Tempotest Lezen (Zinnen) (Manual Speedtest Reading - sentences). Nijmegen: Berkhout, 1992

37. De Vos, T. Handleiding Tempotest Rekenen (Manual Speedtest Arithmetic). Nijmegen: Berkhout, 1994.

38. Aldenkamp AP, Alpherts WC, Blennow G, et al. Withdrawal of antiepileptic medication in children--effects on cognitive function: The Multicenter Holmfrid Study. Neurology 1993; 43: 41-50.

39. Cohen J. Statistical Power Analysis for the Behavioral Sciences. Academic Press, New York, 1977.

40. Cook D, Campbell, DT. Quasi-Experimentation; Design \& Analysis Issues for Field Settings. Houghton Mifflin Company, Boston, 1979.

41. O'Leary SD, Burns TG, Borden KA. Performance of children with epilepsy and normal age-matched controls on the WISC-III. Child Neuropsychol 2006; 12: 173-80.

42. Espie CA, Paul A, McColl JH, et al. Cognitive functioning in people with epilepsy plus severe learning disabilities: a systematic analysis of predictors of daytime arousal and attention. Seizure 1999; 8: 73-80

43. Matsuoka H, Takahashi T, Sasaki M, et al. Neuropsychological EEG activation in patients with epilepsy. Brain 2000; 123: 318-30.

44. Koop JI, Fastenau PS, Dunn DW, Austin JK. Neuropsychological correlates of electroencephalograms in children with epilepsy. Epilep Res 2005; 64: 49-62.

45. Piccirilli M, D'Alessandro P, Tiacci C, Ferroni A.. Language lateralization in children with benign partial epilepsy. Epilepsia 1988; 29: 19-25.

46. Jambaque I, Dellatolas G, Dulac O, Ponsot G, Signoret JL. Verbal and visual memory impairment in children with epilepsy. Neuropsychologica 1993; 31: 1321-37. 


\section{Chapter 6}

Neurodevelopmental delay in children exposed to antiepileptic drugs in utero: a critical review directed at structural study-bias

Joost Nicolai, Johan S.H. Vles \& Albert P. Aldenkamp

Journal of the Neurological Sciences 2008; 271: 1-14. 


\section{ABSTRACT}

Introduction: The general issue whether in utero exposure to antiepileptic drugs (AEDs) causes congenital malformations (teratogenicity) was raised as early as 1968. The 'congenital hydantoin syndrome' after intrauterine exposure to phenytoin (PHT) was first described in 1975. In 1984, DiLiberti proposed the label 'Fetal Valproate Syndrome' (FVS) for children with a cluster of minor congenital anomalies in the form of dysmorphic facial appearances with or without major abnormalities after intra-uterine exposure to valproate (VPA). Later, also the presence of central nervous system (CNS) dysfunction became part of the description. The definition and characterization of CNS dysfunction as part of FVS and the question whether developmental delay, educational impairment, or behavioural disorders are also a characteristic of intrauterine exposure to AEDs and especially VPA, is still uncertain.

Methods: literature was searched using MEDLINE and other relevant databases: 53 studies were identified and interpreted.

Results: the identified studies do not allow definite conclusions. The possibility of neurodevelopmental delay, behavioural disorders, or learning disabilities as an outcome of in utero exposure to AEDs and especially VPA, can not be excluded. The literature however does not provide evidence for a valid risk estimate. Moreover the evidence found for a specific increased risk for VPA could be structurally biased. There is no evidence to support the claim that neurodevelopmental delay is an inherent feature of the FVS.

Discussion: the major problem in this field is the methodology and in particular the existence of important confounding factors that complicate any attempt to correlate intra-uterine exposure to AEDs with neurodevelopmental delay. We propose a number of guidelines for studies on behavioural teratogenicity. 


\section{INTRODUCTION}

The general issue whether in utero exposure to antiepileptic drugs (AEDs) causes congenital malformations (teratogenicity) was raised as early as 1968. ${ }^{1}$ Subsequently, the relationship with specific AEDs was explored.2-4 In 1997, Samren et al. conducted an extensive meta-analysis that showed a positive association between AED use in pregnancy and teratogenic effects, with a relative risk of $2.3\left(95 \%\right.$ CI 1.2-4.7). ${ }^{5}$ The most pronounced increase was found in children exposed to valproate (VPA) or carbamazepine (CBZ) monotherapy. ${ }^{5}$ The most recent evaluation of prospective data, collected by the UK Epilepsy and Pregnancy Register showed a 4.2\% risk for all AED exposed children. ${ }^{6}$ The risk for children exposed to VPA monotherapy was significantly higher than for CBZ monotherapy $(6.2 \%$ vs. $2.2 \%$; $p<0.001){ }^{6}$ The risk for women with a history of epilepsy who had not taken AEDs during pregnancy was $3.5 \% .{ }^{6}$ The odds ratio for major congenital malformations after intrauterine exposure to VPA is considered significantly increased not only compared to children exposed to CBZ, ${ }^{6-8}$ but also compared to children exposed to lamotrigine (LTG) ${ }^{8}$ or exposed to AEDs in general other than VPA, ${ }^{9}$ or untreated epilepsy patients. ${ }^{10,11}$ The risk for major congenital malformations is also significantly increased after exposure to Phenobarbital (PB). ${ }^{12} \mathrm{~A}$ high dosage is related to a higher risk in most AEDs, ${ }^{13}$ as is polytherapy. $6,7,14$

In 1980, the first case report was published on a dysmorphic infant whose mother had received VPA throughout pregnancy..$^{15}$ In 1984, DiLiberti et al. proposed the label 'Fetal Valproate Syndrome' (FVS) for patients with a cluster of minor congenital anomalies in the form of dysmorphic facial appearances (epicanthal folds, flat nasal bridge, small upturned nose, long upper lip) with or without major abnormalities. ${ }^{16}$ The issue whether the symptoms of this proposed syndrome are specific for VPA or apply to AED use in general, remains unclear.

As early as the 1970's, Monson et al. ${ }^{17}$ and Hanson \& Smith ${ }^{18}$ recognised a fetal hydantoin syndrome after exposure to phenytoin (PHT). Similarly effects were found for primidone, ${ }^{19} \mathrm{~PB}{ }^{20}$ and $\mathrm{CBZ} .{ }^{21}$

The minor facial anomalies of in utero exposure to VPA, ${ }^{22-24}$ PHT, ${ }^{25}$ and CBZ 24,25 have been explored in many studies. The major problem is the subtle nature of the dysmorphic facial features that are often not different from normal but atypical characteristics. In a study of 375 children by Kini et al., dysmorphic features were scored from photographs on a blind basis by a panel of expert dysmorphologists. No more than $47 \%$ of the children exposed to AEDs in utero were correctly identified as having been exposed. More importantly, $45 \%$ of unexposed children were scored positively on some dysmorphic features. ${ }^{24}$

Recently, also developmental delay and educational difficulties have been claimed to be based on exposure of the fetus to AEDs. ${ }^{26}$ Brain development is intimately related with the development of the craniofacial complex, so the connection between facial dysmorphic features and developmental delay seems reasonable. ${ }^{27}$ Nonetheless, the relationship with in utero exposure to AEDs is even more uncertain here and as 
yet the relationship with specific AEDs is in debate. Yerby et al. reviewed the literature on dysmorphic features and neurodevelopmental delay and found comparable patterns for PHT, VPA, PB and CBZ. ${ }^{28}$ In 2004, Adab and colleagues performed a Cochrane review and concluded that in utero exposure to all AEDs was associated with poorer outcomes, as measured with neuropsychological tests. Most effects were subtle in nature and no difference was found between the AEDs. ${ }^{29}$ Yet the claim that in utero exposure to VPA in particular induces neurodevelopmental delay persists, even from the same group. ${ }^{26}$

Many confounding factors are observed that potentially complicate attempts to correlate in utero exposure to AEDs with neurodevelopmental delay. ${ }^{30} \mathrm{We}$ therefore decided to discuss the literature addressing the most important confounding factors and methodological considerations. This review will evaluate the existing evidence of possible behavioural teratogenic effects of AEDS with a specific focus on structural bias.

\section{METHOD}

All studies in MEDLINE, EMBASE, Pharmline and comparable databases were identified for the period of 1966 to August 2006. Literature reviews and relevant chapters in handbooks were used to find additional references. Also the relevant epileptology journals were searched through separate keywords, article by article through ScienceDirect (for the journals Epilepsy \& Behaviour, Epilepsy Research and Seizure), the John Libbey Eurotext website (Epileptic Disorders) or hand searched (Epilepsia). Lead authors were specifically checked for additional publications.

\section{Search strategy:}

'Antiepileptic drugs (AEDS, anticonvulsants) AND teratogenic effects'; 'Antiepileptic drugs (AEDS, anticonvulsants) AND pregnancy AND developmental delay'; 'FVS (Fetal Valproate Syndrome) AND neurodevelopmental delay'; 'Valproate AND teratogenic effects'; 'Carbamazepine AND teratogenic effects'; Etc. (all AEDs separately named).

The identified articles were all evaluated. Excluded were: Short communications without new data; Articles not in the English language; Articles that only describe major malformations; Single case reports (although they were critically reviewed for possible evidence); Studies on possible mechanisms; Animal studies.

53 studies remained for interpretation (table 1). 
Table 1

Identified studies; claim and confounding factors

Studies (and number of exposed children) Claim

Confounding factors and methodological

complications\#

German et al., (PHT) ${ }^{71}$; Gaetti et al.,

(PB) ${ }^{72}$; Christianson et al. ${ }^{73}$; Hockey et

Single case reports demonstrating neuro- a1, a2, a3, a4, b1, b2, b3, b4

al. ${ }^{74}$; Williams \& Hersh ${ }^{75}$; Gomez ${ }^{76}$; Malm VPA.

et al. ${ }^{77}$ (VPA); Schorry et al. (VPA) ${ }^{78}$

Moore et al. ${ }^{22}$

(57 children; $60 \%$ on VPA) developmental delay for PHT, PB and

Thisted \& Ebbensen ${ }^{79}$

$11 / 17$ on VPA, $6 / 17$ on polytherapy including VPA

Dean et al. ${ }^{33}$

(293 children)

Speidel and Meadow ${ }^{68}$

(427 children)

Relationship between major malforma-

a1,a2, a3,a4, b1 (44/57 children were tions and neurodevelopmental delay after mentally retarded), b2, b3 ('delay'), b4 VPA exposure.

$\mathrm{n}=1$ : slight psychomotor retardation, severe psychomotor retardation: $\mathrm{n}=2$.

a1,a2,a3,a4 (VPA up till 6gram/day), b3

('psychomotor retardation'), b4

Developmental delay in $24 \%$ of the

a1, a2 (Developmental delay in $11 \%$ of the children exposed to AEDS; Developmen- non-exposed children), b1, b2, b3 tal delay significantly more frequently after CBZ, VPA, PHT and polytherapy exposure. Not after PB exposure0.

Type of neurodevelopmental delay: language impairment, motor delay and autism (specifically for VPA).

'mental subnormality' in $1.5 \%$ of children, b1, b2, b3 ('mental subnormality') compared to $0.2 \%$ in case controls; AEDs: PHT; PHB.

Hill et al. ${ }^{80}$

(28 children)

Hanson and Smith ${ }^{18}$

(13 children)

All children exposed to AEDs showed developmental delay at 21 months.

5/13 children exposed to PHT showed developmental delay.

In a second study in same paper ${ }^{81}$ (104 children)

Hill et al. ${ }^{82}$.

(59 children)

IQ 91.7 in PHT exposed and 96.8 in 100 controls.

Compared to 252 non-epileptic controls no statistical significant difference was found for developmental IQ between the group of exposed children (all kinds of AEDS) and controls. The subgroup on combination of PHT/PHB scored lower

Vert et al. ${ }^{66}$ (56 children)

Rasalam et al. ${ }^{83}$ (260 children)

Many children on PHB had 'small heads'. a4, b1, b2, b3 (retardation), b4

12/260 (4.6\%) Autistic disorder or

Asperger syndrome (DSM-IV); no specific effect of an AED. 15/260 (5,7\%) children born to mothers taken AEDs during pregnancy showed delay

Adab et al. ${ }^{43}$

More frequent need for additional educa- b1 (721/1267 (57\%) responded), b2 , b3 (150 children exposed to monotherapy, 74 tion need in children exposed to VPA exposed to polytherapy, 176 not exposed monotherapy or polytherapy. to any drug)

Katz et al. ${ }^{84}$

(65 children)

12 children $(18.5 \%)$ had developmental delay; no relationship with a specific AED.

Jones et al. ${ }^{21}$ (48 children)

Most neurodevelopmental delay after exposure to CBZ (35 children were exposed to CBZ).

Van der Pol et al. ${ }^{85}$

37 children exposed to either $\mathrm{PHB}$, or b2, b3 ('delay')

a1,a2 a3 (no control on parental IQs despite possible interference of socioeconomic background), b1, b2, b3 ('delay'), b4

a1,a2,a3,

a4, b1, b2, b4

('additional educational need'), b4

b2, b3 ('delay'), b4

b1 (35/48 children on CBZ), b2, b3

('delay'), b4

b2, b3 ('delay'), b4

(61 children and a control group of similar CBZ or a combination. Mild developmensize)

tal delay after exposure to PHB. In general maternal epilepsy was the domiThis study controlled
confounding variable. nant factor. 


\begin{tabular}{|c|c|c|}
\hline Studies (and number of exposed children) & Claim & $\begin{array}{l}\text { Confounding factors and methodological } \\
\text { complications\# }\end{array}$ \\
\hline $\begin{array}{l}\text { Vanoverloop et al. }{ }^{86} \\
\text { ( } 20 \text { children) }\end{array}$ & $\begin{array}{l}\text { Lower FSIQ and PIQ for children } \\
\text { exposed to PHT (FSIQ } 109.3 \text { versus } \\
118.2 \text { for controls). }\end{array}$ & $\mathrm{a} 1, \mathrm{a} 2, \mathrm{~b} 2, \mathrm{~b} 4$ \\
\hline $\begin{array}{l}\text { Scolnik et al. }{ }^{87} \\
\text { ( } 70 \text { children and } 65 \text { controls })\end{array}$ & $\begin{array}{l}\text { Effect on IQ for PHT and not for CBZ } \\
\text { (PHT: 103,1; CBZ: 111.5; controls: 114.5). }\end{array}$ & $\mathrm{a} 1, \mathrm{a} 2, \mathrm{~b} 2, \mathrm{~b} 4$ \\
\hline Viinikainen et al. ${ }^{89}$ & $\begin{array}{l}\text { Extension: } 8 / 13(62 \%) \text { exposed to } \mathrm{VPA} \\
\text { required educational support compared to } \\
2 / 13 \text { exposed to } \mathrm{CBZ}\end{array}$ & \\
\hline $\begin{array}{l}\text { Gaily et al. }{ }^{69} \text { (121 children) + } \\
\text { Gaily et al. }{ }^{41} \text { (104 exposed, } 105 \text { controls) } \\
\text { Gaily et al., } 2004 \text { (extension of Gaily et al., } \\
\text { 1988) }\end{array}$ & $\begin{array}{l}\text { Children exposed to AEDs did not have } \\
\text { lower IQs ( } 110 \text { versus } 114.5 \text { for controls); } \\
\text { + in later study } \\
\text { Significantly lower verbal IQs for children } \\
\text { exposed to VPA; in the cognitive study: } \\
\text { lower visual-spatial and auditory- } \\
\text { phonemic skills only in children of } \\
\text { mothers who had seizures during preg- } \\
\text { nancy. Normal VIQ and PIQ for children } \\
\text { exposed to CBZ. }\end{array}$ & $\begin{array}{l}\text { a2 (significant lower IQs for children of } \\
\text { women who had seizures during preg- } \\
\text { nancy), a6 (no effect of exposure to } \\
\text { AEDs during pregnancy but cognitive } \\
\text { dysfunction with partial seizures during } \\
\text { pregnancy or lower maternal IQ), b1 } \\
\text { (tertiary referral centre) }\end{array}$ \\
\hline $\begin{array}{l}\text { Steinhausen et al. }{ }^{90} \\
\text { ( } 113 \text { children; } 78 \text { exposed; } 17 \text { non- } \\
\text { exposed; } 18 \text { children of epileptic fathers) } \\
\text { + Losche et al. }{ }^{91}+\text { Koch et al. } .^{92}\end{array}$ & $\begin{array}{l}\text { Small differences between exposed and } \\
\text { non-exposed children; no specific effects } \\
\text { of separate AEDs. Normal Bailey test in } \\
11 \text { children from epileptic fathers. } \\
\text { Effect of socioeconomic status larger than } \\
\text { effect of exposure to polytherapy }\end{array}$ & $\begin{array}{l}\text { a3 (socioeconomic differences are domi- } \\
\text { nant), b4 }\end{array}$ \\
\hline $\begin{array}{l}\text { Majewski et al. }{ }^{35} \\
\text { ( } 265 \text { children; } 194 \text { children of epileptic } \\
\text { mothers and } 71 \text { of epileptic fathers) }\end{array}$ & $\begin{array}{l}\text { Exposure to PHB and PHT leads to } \\
\text { neurodevelopmental delay. No cerebral } \\
\text { disturbances in children from epileptic } \\
\text { fathers }\end{array}$ & $\mathrm{a} 1, \mathrm{a} 2, \mathrm{~b} 2, \mathrm{~b} 3, \mathrm{~b} 4$ \\
\hline $\begin{array}{l}\text { Nelson \& Ellenberg }{ }^{93} \\
\text { (number of children unclear; epidemiol- } \\
\text { ogical study in } 45,000 \text { pregnant women) }\end{array}$ & $\begin{array}{l}\text { Most problems in children of mothers } \\
\text { who suffered seizures during pregnancy. }\end{array}$ & $\mathrm{a} 1, \mathrm{a} 2, \mathrm{~b} 2, \mathrm{~b} 3, \mathrm{~b} 4$ \\
\hline $\begin{array}{l}\text { Fujioka et al. }{ }^{45} \\
\text { ( } 45 \text { children) }\end{array}$ & $\begin{array}{l}\text { More developmental problems when } \\
\text { mothers had partial seizures during } \\
\text { pregnancy; no effect of AED exposure. }\end{array}$ & $\begin{array}{l}\text { a1, a2, a4 ( } 5 \text { children on monotherapy), } \\
\text { b2, b3, b4 }\end{array}$ \\
\hline $\begin{array}{l}\text { D'Souza et al. }{ }^{94} \\
\text { ( } 61 \text { children) }\end{array}$ & $\begin{array}{l}\text { Developmental quotient } 98 \text { for controls } \\
\text { and } 94 \text { for children exposed to AEDs; no } \\
\text { significant effect for AED exposure. }\end{array}$ & $\begin{array}{l}\text { b2, b3 ("DQ" investigatons at early age), } \\
\text { b4 }\end{array}$ \\
\hline
\end{tabular}




\begin{tabular}{|c|c|c|}
\hline Studies (and number of exposed children) & Claim & $\begin{array}{l}\text { Confounding factors and methodological } \\
\text { complications\# }\end{array}$ \\
\hline $\begin{array}{l}\text { Laegreid et al. }{ }^{57} \\
(7 \text { children) }\end{array}$ & $\begin{array}{l}\text { VPA plus benzodiazepines cause devel- } \\
\text { opmental delay. }\end{array}$ & $\begin{array}{l}\text { a1, a2, a3, a4 (almost all on polytherapy), } \\
\text { b1, b2, b3, b4 }\end{array}$ \\
\hline $\begin{array}{l}\text { Mawer et al. } 55 \\
\text { ( } 69 \text { pregnancies and } 56 \text { children) }\end{array}$ & $\begin{array}{l}\text { Developmental delay in } 8 / 18 \text { cases on } \\
\text { VPA and in } 5 / 17 \text { on CBZ }\end{array}$ & $\begin{array}{l}\text { a1, a2, a3, b1 (tertiary centre; } 22 / 56 \text { cases } \\
\text { on VPA), b2 (partly retrospective study } \\
\text { design) b3, b4 }\end{array}$ \\
\hline $\begin{array}{l}\text { an extension is the study by Vinten et al. }{ }^{99} \\
\text { ( } 249 \text { children) }\end{array}$ & $\begin{array}{l}\text { Lower Verbal IQ in children exposed to } \\
\text { VPA. However maternal IQ and seizures } \\
\text { during pregnancy strong confounders. }\end{array}$ & \\
\hline $\begin{array}{l}\text { Hirano et al. }{ }^{101} \\
(71 \text { children) }\end{array}$ & $\begin{array}{l}71 \text { children exposed to AEDs were } \\
\text { compared with } 99 \text { controls and matched } \\
\text { on a number of relevant factors. } \\
\text { At the age of } 1.5 \text { year development was } \\
\text { negatively associated with exposure to } \\
\text { AEDs but also with maternal seizures } \\
\text { during pregnancy. These factors disap- } \\
\text { peared at the age of } 3 \text { were social factors } \\
\text { became more important. }\end{array}$ & $\begin{array}{l}\text { a4, b1, b2, b3 ("DQ" investigatons at } \\
\text { early age), b4 }\end{array}$ \\
\hline $\begin{array}{l}\text { Dessens et al. }{ }^{102} \\
\text { ( } 275 \text { children) }\end{array}$ & $\begin{array}{l}275 \text { children exposed to PB, PHT or } \\
\text { PHT/PB or PHT/PB/amphetamine } \\
\text { combination therapy. } 275 \text { controls. } \\
\text { Children on PHT/PB combination } \\
\text { therapy significant smaller head circum- } \\
\text { ference. On follow-up } 172 \text { children } \\
\text { exposed to AED and } 168 \text { controls. } 12 \% \\
\text { of exposed children and } 1 \% \text { of controls } \\
\text { had persisting learning problems. }\end{array}$ & $\begin{array}{l}\text { a2, a4 (seizures and AED doses not } \\
\text { documented), b1, b2, b3 (special educa- } \\
\text { tion secondary school) }\end{array}$ \\
\hline $\begin{array}{l}\text { Reinisch et al. }{ }^{54} \\
\text { (33 adult men) }\end{array}$ & $\begin{array}{l}\text { Maternal epilepsy was exclusion criterion! } \\
33 \text { men included in study } 1,81 \text { men in } \\
\text { study } 2 \text {. Data were selected from the } \\
\text { Danish military service draft. Institutional- } \\
\text { ized children were excluded. Significantly } \\
\text { lower verbal IQ, non-significantly lower } \\
\text { total and performal IQ. }\end{array}$ & $\begin{array}{l}\text { b1 (retrospective), b2; study } 1 \text { (institution- } \\
\text { alized children excluded), b2 study } 2 \\
\text { (inclusion of military only possibly } \\
\text { implicates exclusion of men with mild } \\
\text { retardation) }\end{array}$ \\
\hline $\begin{array}{l}\text { Shapiro et al. }{ }^{31} \\
\text { (33574 children) }\end{array}$ & $\begin{array}{l}217 \text { children exposed to PB ( } n=35) \text {, PTH } \\
\text { ( } n=40) \text { or PB\&PTH }(n=107) \text { or other } \\
\text { medication }(n=35) .5525 \text { children from } \\
\text { non-epileptic mothers exposed to PB, } \\
27832 \text { children from non-epileptic } \\
\text { controls. } \\
\text { No difference in mental and motor score } \\
\text { at } 8 \text { months or IQ at } 4 \text { years after expo- } \\
\text { sure to PB or PTH. } \\
\text { Mental and motor score at } 8 \text { months or } \\
\text { IQ at } 4 \text { years lower in children of epileptic } \\
\text { mothers, not in children of epileptic } \\
\text { fathers. }\end{array}$ & $\begin{array}{l}\text { a2, a3 (adjusted for socioeconomic status, } \\
\text { not for intelligence), b3 (no definition } \\
\text { given of mental and motor score and } \\
\text { intelligence quotient. }\end{array}$ \\
\hline $\begin{array}{l}\text { Parisi et al. }{ }^{103} \\
\text { (11 children) }\end{array}$ & $\begin{array}{l}11 \text { children exposed to PB, VPA, CBZ, } \\
\text { LTG or the combination of PB and } \\
\text { primidone. Mean DQ (Brunet-Lezine } \\
\text { scale) at } 30 \text { months lower than normal } \\
\text { population. }\end{array}$ & $\mathrm{a} 1, \mathrm{a} 2, \mathrm{a3}, \mathrm{a4}, \mathrm{b} 1, \mathrm{~b} 4$ \\
\hline
\end{tabular}




\begin{tabular}{lll}
\hline Studies (and number of exposed children) & Claim & $\begin{array}{l}\text { Confounding factors and methodological } \\
\text { complications\# }\end{array}$ \\
\hline $\begin{array}{l}\text { Holmes et al.104 } \\
(80 \text { children) }\end{array}$ & $\begin{array}{l}80 \text { children included, 76 had neuropsy- } \\
\text { chological testing. Three children had } \\
\text { microcephaly and did significantly worse }\end{array}$ & \\
& (FSIQ, VIQ and PIQ) compared to \\
& children with normal head circumference. \\
& Significant worse results (FSIQ and VIQ) \\
& for combination of midface and digit & \\
& hypoplasia. & \\
& 30 children included and 30 matched & a1, a2, b3 (final assessment at 12 months), \\
& controls. Significant delay on locomotor & b4 (only 3 VPA-exposed children) \\
Arulmozhi et al.64 & scale at 2, 6, and 12 months. No differ- & \\
(30 children) & ence in reaching behaviour and per- & \\
& sonal/social scores. & \\
& & \\
\hline
\end{tabular}

a. confounding factors

a1. maternal epilepsy

a2. seizures during pregnancy

a3. socio-economic factors \& intelligence

a4. AED-related factors

b. methodological factors

b1. selection bias

b2. design problems: retrospective design

b3. inadequate or confusing outcome measures

b4. insufficient power due to small sample size 


\section{RESULTS}

Many confounding factors are observed that potentially complicate attempts to investigate any connection between in utero exposure to AEDs and neurodevelopmental delay. ${ }^{30} \mathrm{We}$ also found many methodological problems that complicated the interpretation of published data. The potential confounders of the studies are summarized in table 1.

\section{a. Confounding factors}

These are factors that interfere with the effect of drug exposure and thus complicate the interpretation of a certain outcome.

\section{a1. 'Epilepsy or the AEDS'}

A possible important confounding factor is the effect of maternal epilepsy on the development of the fetus and consequently on postnatal cognitive development. The possibility that the epilepsy of the mother may lead to teratogenicity was first raised when studies found that PB is not associated with fetal malformations when prescribed for other indications than for epilepsy and that the malformation rate in children born to mothers with epilepsy is increased by $60 \% .{ }^{31}$ Delgado-Escueta \& Janz estimated the risk of birth defects in children of mothers with epilepsy to be 2-3 times that of infants of mothers without epilepsy. ${ }^{32}$ However, the authors point to an important confounder: they could not distinguish between the epilepsy of the mother and the medication used during pregnancy as main causal effect. Other evidence is provided in the study by Dean et al. comparing children of epileptic mothers on AEDs during pregnancy with children of epileptic mothers without AEDs during pregnancy. Developmental delay was found in $24 \%$ of the exposed children and $11 \%$ of the non-exposed siblings. ${ }^{33}$ This latter high percentage (several times increased compared to the general population) shows that AED use during pregnancy is not the only factor in children of mothers with epilepsy; epilepsy itself increases the risk for malformations, although those high frequencies are possibly also caused by selection bias. Janz also showed that children of epileptic mothers show approximately twice as many malformations as children of mothers without epilepsy. ${ }^{34}$ In children from epileptic fathers, the malformation rate is also increased. ${ }^{31}$ Majewski et al. noted that the children from epileptic fathers showed no signs of the hydantoin/barbiturate embryopathy, but malformation rate was as high as the malformation rate in children of mothers with AEDs. ${ }^{35}$ This increased rate cannot be explained by teratogenic drug-effects and illustrates that also parental epilepsy is associated with an increased malformation rate, so that the epilepsy in either parent may be an independent factor, causing malformations in the child. It must, however, be noted that not all studies found this effect of maternal epilepsy. A recent meta-analysis performed by Fried et al. found that the odds ratio for women with untreated epilepsy $(\mathrm{n}=400)$ was not higher than non-epileptic controls (OR 1.92; 95\% CI 0.92-4.00). ${ }^{36}$ After correction for publication bias the odds ratio decreased to 0.99 (95\% CI 0.49-2.01). ${ }^{36}$ The same conclusion was made in a cohort of 57 respec- 
tively 98 children from mothers with a history of epilepsy who did not use medication during pregnancy. ${ }^{37,38}$ However, women with untreated epilepsy will represent less severe epilepsy syndromes with a lower frequency of seizures or non-threatening seizures or age-related epilepsy syndromes. ${ }^{36}$ This confounding factor is further complicated when, with more severe types of epilepsy, there is also an increase of drug load or there is a need to use polytherapy. Thus an increased percentage of developmental delay could be caused by polytherapy with highest risk for teratogenicity, but could theoretically be caused by the more severe maternal epilepsy syndrome as well.

\section{a2. 'Seizures or the AEDs'}

A high percentage of women (range 19\% to 41\%) who are exposed to AEDs during pregnancy also suffer from seizures during pregnancy. ${ }^{12,39}$ Convulsive or nonconvulsive status epilepticus occurs in almost $2 \%$ of pregnancies. ${ }^{39}$ In this recent EURAP report the rate of stillbirth was 1 in 36 cases of status epilepticus, which is much lower than figures reported earlier. Majewski et al. found more 'cerebral disturbance' $(16.5 \%$ versus $5.7 \%$ ) in children of mothers who had seizures during pregnancy than children of mothers who remained seizure free, irrespective of the type of AED. ${ }^{35}$ Also Lösche et al., ${ }^{40}$ Gaily et al., ${ }^{41}$ and Lindhout \& Omtzigt ${ }^{42}$ found an increase in malformations in offspring of mothers who had seizures during pregnancy; odds ratio of 2.0 for specific cognitive dysfunction associated with seizures during pregnancy in the study by Gaily et al. ${ }^{41}$ Adab et al. found that children from mothers who had four or more seizures during pregnancy had impaired cognition. ${ }^{43}$ All these authors emphasize that the factor of seizures during pregnancy can not be easily isolated from other factors. Clinical observations suggest that fetal distress and bradycardia is secondary to acidosis and hypoxia, not to other mechanisms. ${ }^{44}$ An indirect proof of the effect of seizures can be found in some studies that showed that seizure type is important, with a specific effect of partial seizures. ${ }^{45}$ There is no evidence that absence or myoclonic seizures influence pregnancy outcome, other than by trauma. ${ }^{46}$

\section{a3. 'Socio-economic factors and intelligence'}

Studies seldom compensate for or control social-cultural background. When analyzing neurodevelopmental delay this may, however, be an important factor in relation to any condition. For epilepsy this is a factor of particular importance. Numerous studies have shown that epilepsy has an effect on the social position, either by affecting the neurocognitive possibilities of those involved or by the still significant social stigmata attached to the condition. ${ }^{47}$ This brings the majority of the patients with active epilepsy (those who require continuing treatment, i.e. all women who require continuation of AED treatment during pregnancy) into a social deprived position. This has effects on the position of the offspring, their opportunities and their education. Many studies have also suggested that the neurocognitive and social effects of epilepsy have carryover effects to the second generation and further; in the study by Moore et al. 15 of the 38 mothers had a family history of epilepsy. ${ }^{22}$ The separation of the effects of AED use in pregnancy from the aforementioned social factors is extremely difficult. 
Sometimes socio-economic factors have a more indirect influence. For example, folic acid intake before pregnancy is demonstrated to be lower in lower social classes, ${ }^{48,49}$ whereas the use of life-style intoxications, in particular smoking and drinking during pregnancy is higher in lower social classes. ${ }^{50}$ Another possible bias occurs when the cost of treatment is important in the prescription of AEDS. Phenobarbital is likely to be used by the economically deprived part of the population instead of the newer AEDS. ${ }^{51}$ Because malformation rates are higher in the economically deprived section of the population because of general health issues, this may introduce bias. ${ }^{51}$

Parental IQ and parental level of education are two factors that must be controlled in any study on neurodevelopmental outcome. Interestingly, the FSIQ of women using VPA has been reported to be significantly lower compared to women using carbamazepine (95.6 vs. 109.2) or women with untreated epilepsy (95.6 vs. 108.8).52 Also, the level of education in VPA treated mothers was lower in two studies. ${ }^{52,53}$ Adab et al. did not find a relation between maternal IQ and choice of AED. ${ }^{26}$ However, those figures possibly indicate that women using VPA for their epilepsy represent a unique group of patients. ${ }^{52}$

We must, however, realize that the parental IQs and parental educational level are not the full story. The socio-economic circumstances may have a role, independent of IQ and education of the parent, for example when socio-economic position is associated with psychosocial complications such as in the case of domestic violence or frequently changing partnerships of the mother. Interestingly in a Danish study, mean intelligence of PB-exposed adult men born from "unwanted" pregnancies, was significantly lower than PB-exposed men from "wanted" pregnancies. ${ }^{54}$

\section{a4. 'AED-related factors'}

The period of in utero exposure to AEDs may be an important factor. The major malformations are related to exposure in the first trimester of pregnancy because this is the period of organogenesis. There are claims that developmental delay is associated with exposure during the second and third trimesters, in the phase of brain development. Hardly any study controls for actual drug intake (or medication compliance) during pregnancy or even provide data when a specific drug is used. Most studies are actually not in a position to control as they are retrospective in nature. Dose is a possible additional factor. Mawer et al. studied women exposed to doses of VPA between 200 and $3,000 \mathrm{mg} /$ day and found effects only for doses of 1,000 $\mathrm{mg}$ and above. ${ }^{55} \mathrm{This}$ is also reported in the study by Samren et al. ${ }^{56}$ Of course this is related to the type of epilepsy and seizure factors as some patients need higher doses to control the seizures during pregnancy. ${ }^{39}$ Dose must therefore be included in any study as an important factor. However, only a few studies give details on dose. As most studies are retrospective the reliability of these data must be questioned. Laegreid et al. ${ }^{57}$ and McElhatton ${ }^{58}$ point to the effect that benzodiazepines may have teratogenic effects. Benzodiazepines are frequently used as adjuncts in the treatment of epilepsy (often not mentioned, even in controlled studies). Similarly, the focus may be entirely on the use of AEDs, whereas 
many patients possibly also use psychiatric drugs during pregnancy. The teratogenic potential of many of these drugs is still unclear. ${ }^{59}$

\section{a5. 'Epilepsy in the offspring'}

Children of parents with epilepsy may develop epilepsy themselves and especially severe types of epilepsy (and its treatment often with polytherapy) may seriously impact development. When outcomes such as educational attainment are used, it is important to realize that even benign types of epilepsy may have a serious impact on educational possibilities. ${ }^{60}$ and the effect of the epilepsy in the child can not be isolated from the effect of in utero exposure to AEDs.

\section{a6. 'Medical complications during pregnancy'}

An increased frequency of almost all pregnancy complications has been reported in women with epilepsy. These include pre-eclampsia, spontaneous abortion, bleeding in pregnancy, rupture of the placenta and premature labour and Cesarean deliveries. ${ }^{61,62}$ There is a 1.2-3 fold increase in perinatal mortality (stillbirth and death within the first week of life. ${ }^{61}$ In addition, women with epilepsy have a higher risk of suffering from gestational diabetes mellitus. ${ }^{62}$

\section{b. Methodological issues}

These are more general scientific problems that may occur with the design of the study or with the way the data are handled.

\section{b1. 'selection bias'}

This can be summarized as the issue of 'where do the patients come from?'. Studies should ensure that the sample included in the study is representative for the population to which they generalize their results ('patients with epilepsy'). Mostly the studies use 'convenience populations', i.e. patients that are easily available. In the study of Moore et al.,22 most mothers (52 of the 57) were obtained through a parents' support group (The National Fetal Anticonvulsant Syndrome Association), a group highly focused on possible teratogenic effects of AEDs. Not surprisingly, $77 \%$ of the children had developmental delay or learning difficulties, $77 \%$ required speech therapy, $56 \%$ had gross motor delay, and $81 \%$ had behavioural problems. Non-response may be a factor causing selection bias. In the study by Adab et al., ${ }^{26}$ women in the region were asked to participate but the response rate was $40 \%$, which is too low to exclude the possibility that these patients represent a selective sample (for example only women that have children who may have neurodevelopmental problems as they may have a particular interest in a study in which the children will have a free psychological assessment). The study by Dean et al. started by reviewing the hospital records at the Aberdeen Maternity Hospital. ${ }^{33}$ This is already a source for bias as this is the tertiary referral centre for women with medical complications during pregnancy. Of the 411 mothers who took AEDs during pregnancy, 258 were eligible to participate in the study and of these only 149 actually did participate. Hence this is $36 \%$ of the possible study population with a 
non-response of $64 \%$. When they report a $13.8 \%$ malformation rate, this percentage does not exclude the possibility that in reality the percentage for the total group would be $5 \%(0.36 \mathrm{X} 13.8 \%+0.64 \mathrm{X} 0 \%)$. In addition the confidence intervals are large. $\mathrm{A}$ rather peculiar source of bias is cultural bias. There seems to be a cultural difference in the definition of FVS. UK studies define FVS by dysmorphic features and neurodevelopmental delay. Studies from France focus on craniosynostosis, especially trigonocephaly. ${ }^{63}$ In general, it is remarkable that the vast majority of the studies on FVS are from the UK. Only two nation-wide population-based studies have been published till now. 7,11 Unfortunately, neither study scored cognition or developmental delay.

\section{b2. 'Study design'}

The only design that allows valid interpretation of neurodevelopmental outcome is a prospective longitudinal comparison design that allows assessment the mothers at baseline (i.e. during pregnancy) to ascertain the drug intake with a certain level of reliability (dose, changes during pregnancy) and assessment of neurodevelopmental progression over time. In contrast, almost all studies are retrospective, testing children (mostly once only at an arbitrary age) born to epileptic mothers without using a baseline. This is especially a case of 'never trust memory'. Most data in retrospective studies are gathered, using the memory of the patients and their ability to provide data of events (such as dose or changes of dose during pregnancy) that happened sometimes a decade ago (e.g. when a group of 10 year old children are included and their mothers are asked to provide data on their AED use during pregnancy). Only a prospective study can provide reliable data on whether the mother actually took AEDs during pregnancy, which drug, dose, etc. Also a study should be a follow-up study with reassessments to decide whether a delay is temporary (due to coincidental factors) or permanent.

The time of study-enrolment can lead to bias. In the recent study by Meador et al. the mean gestational age at time of enrolment was $17-19$ weeks. ${ }^{8} 35-50 \%$ of the mothers already had had an ultrasound at time of enrolment. Possibly foetuses with severe malformations like spina bifida or anencephaly were already diagnosed before this gestational age and the pregnancy had been terminated. This bias will lead to an underscore of severe malformations, but most likely not to a structural bias of minor anomalies or developmental delay. Sometimes this problem is properly addressed; for example Arulmozhi et al. excluded women who reported their pregnancy after the first trimester from their study. ${ }^{64}$

\section{b3. 'Outcome measures'}

One of the major problems in analyzing the published studies is the definition of 'developmental delay' that varies from 'mental retardation', 'learning disabilities', 'school problems', 'behaviour problems' to 'psychiatric symptoms'. Even more complicated is the use of the somewhat nebulous outcomes such as 'extra educational need' or other similar types of surrogate measures. An indirect feature, related to neurodevelopmental 
delay is low birth weight that is observed in some cases. ${ }^{16}$ Also when using psychometric scales, the validity varies from study to study.

An interesting, although seldom controlled design issue, is the effect of age at the time of assessment. For example Beck-Mannagetta \& Janz ${ }^{65}$ showed a group of children exposed to AEDs in utero that had a delay in reaching early developmental milestones, but these differences disappeared at the time of school entry. Other studies have found conflicting effects: no effect on early milestones but problems in primary education. As most studies only have one assessment (often at an arbitrary endpoint) these types of processes can not be analyzed. This factor is even more apparent in studies (most prospective studies actually) that have varying follow-up periods. In the study of Vert et al. ${ }^{66}$ for example the follow-up was 6 months for some children to 6 years for others. An additional important observation is that assessments at an early age will be less sensitive to small changes and therefore must always be complemented with re-assessments at a later age.

\section{b4. 'Power of the study'}

Any study must be sufficiently powered to detect differences at a statistically significant level. That is, conclusions only make sense if the study has a reasonable a priori chance (say, $80 \%$ or better) of detecting an effect, when in fact one is there. This probability, i.e., the statistical power, is heavily dependent on sample size. According to Cohen a difference or change in the range of more than $0.7 \mathrm{SD}$ represent large effect. ${ }^{67}$ Differences in the range of 0.5 to $0.7 \mathrm{SD}$ represent moderate effects. Power analysis consequently sets the required number of patients at 26 in order to detect large effects. With large samples, power is not an issue, but when sample sizes tend to be small (e.g., less than 20 subjects per group), power may be inadequate to support a meaningful conclusion and the risk of false-negative findings will be high. The problem in achieving power in studies on behavioural teratogenicity is that epilepsy affects 3-6 in 1000 pregnancies and neurodevelopmental delay is not affecting more than approximately 10 $15 \%$ of the included children. Thus 10,000 pregnancies would yield 30-60 cases of which would have 3 to 9 neurodevelopmental delay. Given the large number and combination of drugs involved it is not surprising that studies rarely achieve power. Power analysis of the 53 studies, listed in table 1 only shows sufficient power for five studies: Speidel and Meadow, ${ }^{68}$ [427 children of 186 women]; Shapiro et al., ${ }^{31}$ [305 children for epileptic mothers, 7836 from mothers without epilepsy although using PB]; Gaily et al., ${ }^{69}$ [121 children of 148 mothers]; Dean et al., ${ }^{33}$ [293 children of 149 women]; Rasalam et al., ${ }^{70}$ [260 children]. All these studies, except the studies by Shapiro et al. and Gaily et al are retrospective studies.

\section{Description of the studies}

Table 1 summarises the main claim of each study, as well as the basic methodological problems. Some factors have not been mentioned in the studies, or at least no information on those factors was provided: genetic factors, medical complications during pregnancy and possible epilepsy in the studied children. Therefore the table concen- 
trates on the remaining factors. Also the table does not provide complete information as in many of the studies only limited information was provided on the confounders: maternal epilepsy, seizures during pregnancy and possible socio-economic confounders. Hence, the confounders and methodological problems that are mentioned probably underestimate the actual problems in the study. The studies are somewhat arbitrarily grouped around major topics (for example, type of outcome measures, or 'seizures during pregnancy').

\section{DISCUSSION}

\section{Developmental delay}

The studies presented in this review included approximately 2000 children exposed to AEDs during pregnancy from mothers with epilepsy. Although this is an impressive number of patients, the studies do not allow definite conclusions because of the many complicating factors induced by study designs and the interference of confounders. In the light of the 2000 exposed children, the approximately 200 children included in prospective studies seem insubstantial. Only the study by Gaily et al. ${ }^{41,53,69}$ remains as an adequately powered, prospective study without major confounding or methodological bias. In the first reports the authors did not find an effect of drug exposure on IQ. ${ }^{41,69}$ Later extensions of this same study did report lower verbal IQs for children exposed to VPA ${ }^{53}$, but the independent effects of VPA therapy are uncertain because mothers with VPA showed a significant lower educational level. The same was true for mothers who used polytherapy during pregnancy. Maternal IQ was not studied so one other possible major confounder persisted in this study. Although none of the studies are free from methodological pitfalls or interfering factors, the more convincing studies allow the tentative conclusions that neurodevelopmental delay as a possible outcome in small subgroups of children after in utero exposure to AEDs in general seems possible. Neurodevelopmental delay has been described in somewhat larger studies after exposure to PB, PHT, CBZ and VPA. Moreover some studies point to the potential role of (intermittent) use of benzodiazepines. ${ }^{57,58}$ The evaluated studies, however, do not provide evidence for a valid risk estimate for AED use during pregnancy on neurodevelopment in general. Moreover no evidence has been found for an increased risk of any specific AED, including VPA. Also there is no evidence to support the belief that neurodevelopmental delay is an inherent feature of the 'Valproate Fetal Syndrome'. The evaluation on cognitive deficits of the prospective observational study involving 25 epilepsy centres in the USA and UK has not been finished and reported yet, ${ }^{8}$ although preliminary results have shown an increased rate of developmental delay measured by the Bayley's scale at the age of 2 years in children exposed to VPA compared to CBZ, LTG or PHT. ${ }^{105}$ This study will collect possible information on confounding factors like maternal IQ, education, race, seizure type and frequency, AED dosage and compliance, socioeconomic status, use of folic acid preconceptionally, use

of alcohol, tobacco or other drugs, history of pregnancy abnormalities, gestational age 
at enrolment and birth weight prospectively, which may give a better estimation of the risk of developmental delay and cognitive deficits. ${ }^{106}$ The 53 studies evaluated show that a specific effect of VPA is claimed in five studies (studies indicated in grey in table 1). Two studies are retrospective and underpowered (Mawer et al. ${ }^{55}$; Ardinger et al. ${ }^{98}$ ) with respectively 23 and 19 children exposed to VPA. One study is subject to serious selection bias and has a retrospective design (Moore et al. ${ }^{22}$ ). One retrospective study (Adab et al. $^{26}$ ) has serious methodological problems (claim of VPA effect without statistical significance). Finally the group of Gaily and coworkers first claim an absence of effect of drug exposure and later, ${ }^{41,69}$ in an extension of their study an effect on verbal IQ, they show an effect. ${ }^{53}$ The claim of specific VPA induced behavioural teratogenicity is therefore not evidence based. A specific effect of PHT on neurodevelopment is claimed in some other studies, ${ }^{18,35,81,86,87}$ although these studies suffer from similar methodological problems.

\section{Autistic disorder and Asperger syndrome}

The first case-reports describing an autistic disorder after exposure to VPA were published in the mid-nineties. ${ }^{73,75}$ Williams et al. described a series of five children with cognitive deficits, manifestations of autism, and typical phenotypic characteristics of FVS. In a series of 57 children with anticonvulsant syndrome, Moore et al. found four children with autism and two with Asperger syndrome; three were exposed to VPA monotherapy, two to VPA polytherapy and one child had been exposed to the combination of CBZ and diazepam. ${ }^{22}$ Recently, Rasalam et al. reported that $4.6 \%$ of 260 children exposed to AED fulfilled the DSM IV criteria for autistic disorder or Asperger syndrome. ${ }^{70}$ VPA was the drug most commonly associated with autistic disorder, five of $56(8.9 \%)$ of the children exposed to VPA monotherapy in this study had either autistic disorder or Asperger syndrome. ${ }^{70}$ Although the publication of case-reports automatically indicates a selection bias, it is noteworthy that of 24 children with in utero exposure to AEDs and autism or Asperger syndrome, 20 (83\%) had been exposed to VPA (monotherapy or combination therapy). We did not include the children reported by Dean et al. ${ }^{33}$ in our calculations because this study partly overlaps with the study by Rasalam et al. ${ }^{70}$

\section{Mechanisms of action}

It must be emphasized that, although there may be an elevated risk for malformations, anomalies and neurodevelopmental problems, the vast majority of children born to a mother with epilepsy do not have any problems. Some studies therefore point to genetic factors that increase susceptibility to the detrimental effects of maternal epilepsy or in utero exposure to AEDs; i.e. only the interaction between genetic factors and AEDs would result in teratogenicity. ${ }^{34,77,108}$ This hypothesis would explain why the vast majority of children that have been exposed to AEDs during pregnancy are not affected. Deficiencies of the enzyme epoxide hydrolase and mutations in the methylenetetrahydrolate gene have been mentioned as reason for increased susceptibility. $38,109,110$ 
Several other mechanisms have been described, among others the interference of AEDs with folic acid metabolism ${ }^{109}$ and an increase in free radical formation. ${ }^{38}$ Indeed for most of the older AEDs a reduction of serum folic acid levels have been established. ${ }^{111}$ However, the AED's that decrease folic acid levels most (PHT) are not associated with spina bifida and in a study of 125 pregnant women using PHT, no relation between the occurrence of Fetal Hydantoin syndrome and maternal folate concentrations was found. ${ }^{111} \mathrm{VPA}$ is associated with the highest spina bifida risk but has only little effect on folic acid metabolism. ${ }^{51}$

In relation to the mechanism of neurodevelopmental delay, two findings seem to be important. Children exposed to VPA polytherapy, CBZ monotherapy or polytherapy and $\mathrm{PB}$ monotherapy or polytherapy ${ }^{56,112}$ and children exposed to the combination of PHT and $\mathrm{PB}^{102}$ have a significantly smaller head circumference at birth compared to controls, indicating a smaller brain volume. In many population-based studies a relation between small head circumference at birth and later cognitive outcome has been found. ${ }^{113}$ Holmes et al. studied children exposed to PHT, PB or CBZ and observed a significant lower FSIQ (-23.7 points) in three children with microcephaly (head circumference $<-2$ SD) compared to children with a normal head circumference. ${ }^{104}$ However, also head circumference in children exposed to AED is prone to bias. Gaily et al. reported that the paternal head circumference contributes most in the small head circumference of children exposed to AED. Although the authors state that a mild drug effect cannot be excluded. ${ }^{114}$

Secondly, in experimental studies it has been shown that injection with AEDs at therapeutic doses leads to widespread apoptosis of neurons. The rat brain is most sensitive for degeneration during a time window that is comparable to the third trimester of the human fetus. ${ }^{115,116}$ Many studies describing a neuroprotective effect of AEDs have been published. However, it may not be possible to extrapolate those results to the human fetus; AEDs protecting the adult brain from stroke or SE-induced injury can cause apoptosis in immature brain. ${ }^{117}$

\section{Future studies}

Given the confounding factors and the results of this review we can provide the following guidelines for a study on behavioural teratogenic effects:

- The study should be prospective and longitudinal.

- Compliance should be monitored throughout pregnancy; each dose change must be recorded with a specific date.

- The use of folic acid should be recorded.

- A seizure diary should be provided and checked on a regular basis, preferably once a month.

- Each hospital visit and each injury or event during pregnancy must be recorded.

- The mothers on AEDs with seizures during pregnancy should not be excluded. Maintaining effective AED therapy during pregnancy is crucial. An "intention to 
treat" analysis is essential to evaluate the risk of a certain drug. The teratogenic risk of the medication sole and the teratogenic risk of seizures due to lack of efficiency together summates the risk of AED treatment in pregnancy.

- The mothers should be included through a random population-based procedure; preferably through the large pregnancy-in-epilepsy case registers (by example EURAP) to avoid selection bias.

- Only mothers using monotherapy should be included.

- Mothers with medical complications that potentially affect neurodevelopment must be considered as drop outs.

- Children that develop epilepsy must be considered as a drop out.

- Any study on the behavioural teratogenic effects of AEDs must have controls. A control group of mothers without epilepsy but in matched socio-economic circumstances is used in many studies. This study-design helps to give physicians and parents a risk estimate. However, the knowledge that the risk to the fetus is increased twofold in the case of a certain AED does not help physicians or women to make choices on AED treatment during pregnancy. A woman cannot choose to be a control without epilepsy instead of a woman with epilepsy. More important is to enable physicians and parents to compare to the risk of several drugs in pregnancy. This information is essential in making treatment choices because it enables physicians and women to make a choice for treatment with the drug that is known to have the lowest teratogenic risk. This information can only be achieved in a study design comparing different drugs in women with epilepsy.

One should realize that the question whether the teratogenic risk of lowering the dosage of AEDS and accepting the risk of recurrence of seizures during pregnancy outweighs the risk of stable (relatively high dose) medication cannot be answered in a prospective descriptive study. Seizure control during pregnancy is also important because of the risk of stillbirth. A lower risk of teratogenic outcomes needs to be balanced against the efficacy in controlling seizures that possibly lead to stillbirth. ${ }^{118}$

Parental IQs and educational level should be assessed in the same period in which the assessments of the children are carried out. Types of tests necessary in such a study have been discussed elsewhere. ${ }^{119}$ The IQ of the parents should be assessed with the Wechsler Adult intelligence scales (WAIS).

Outcomes: only scales with sufficient psychometric validations should be used:

- Bayley Scales of Infant Development: Age range 2 months up to $2 \frac{1}{2}$ years. ${ }^{120}$

- McCarthy Scales of Children's Abilities: Age range $2 \frac{1}{2}$ years up to $8 \frac{1}{2}$ years. ${ }^{121}$

- Wechsler intelligence scale (WISC) and school performance (WRAT) (from about 6 years of age). ${ }^{122}$ 


\section{REFERENCES}

1. Meadow SR. Anticonvulsant drugs and congenital abnormalities. Lancet 1968; 2(7581): 1296.

2. Bird AV. Anticonvulsant drugs and congenital abnormalities. Lancet 1969; 1(7589): 311.

3. Pashayan H, Pruzansky D, Qruzansky S. Are anticonvulsants teratogenic? Lancet 1971; 2(7726): 702-3.

4. South J. Teratogenic effect of anticonvulsants. Lancet 1972; 2(7787): 1154.

5. Samren EB, van Duijn CM, Koch S, Hiilesmaa VK, Klepel H, Bardy AH, Mannagetta GB, Deichl AW, Gaily E, Granstrom ML, Meinardi H, Grobbee DE, Hofman A, Janz D, Lindhout D. Maternal use of antiepileptic drugs and the risk of major congenital malformations: a joint European prospective study of human teratogenesis associated with maternal epilepsy. Epilepsia 1997; 38: 981-90.

6. Morrow J, Russell A, Guthrie E, Parsons L, Robertson I, Waddell R, Irwin B, McGivern RC, Morrison PJ, Craig J. Malformation risks of antiepileptic drugs in pregnancy: a prospective study from the UK Epilepsy and Pregnancy Register. J Neurol Neurosurg Psychiatry 2006; 77: 193-8.

7. Wide K, Winbladh B, Kallen B. Major malformations in infants exposed to antepileptic drugs in utero, with emphasis on carbamazepine and valproic acid: a nation-wide population-based register study. Acta Paediatr 2004; 93:174-6.

8. Meador KJ, Baker GA, Finnell RH, Kalayjian LA, Liporace JD, Loring DW, Mawer G, Pennell PB, Smith JC, Wolff MC; NEAD Study Group. In utero antiepileptic drug exposure: fetal death and malformations. Neurology 2006; 67: 407-12.

9. Wyszynski DF, Nambisan M, Surve T, Alsdorf RM, Smith CR, Holmes LB; Antiepileptic Drug Pregnancy Registry. Increased rate of major malformations in offspring exposed to valproate during pregnancy. Neurology 2005; 64: 961-5.

10. Artama M, Auvinen A, Raudaskoski T, Isojarvi I, Isojarvi J. Antiepileptic drug use of women with epilepsy and congenital malformations in offspring. Neurology 2005; 64: 1874-8.

11. Artama M, Ritvanen A, Gissler M, Isojarvi J, Auvinen A. Congenital structural anomalies in offspring of women with epilepsy — a population-based cohort study in Finland. Int J Epidemiol 2006; 35: 280-7.

12. Holmes LB, Wyszynski DF, Lieberman E. The AED (antiepileptic drug) Pregnancy Registry: a 6-year experience. Arch Neurol 2004; 61: 673-8.

13. Nomura Y, Takebe Y, Nomura Y, Shinagawa S, Kaneko S, Sato T. The physical and mental development of infants bom to mothers treated with antiepileptic drugs. In: Sato T, Shinagawa S, editors. Antiepileptic Drugs in Pregnancy; Proceedings of a seminar on antiepileptic drugs and pregnancy; Excerpta Medica; 1984. p. $187-$ 95.

14. Kaneko S, Otani K, Fukushima Y, Ogawa Y, Nomura Y, Ono T, Nakane Y, Teranishi T, Goto M. Teratogenicity of antiepileptic drugs: analysis of possible risk factors. Epilepsia 1988; 29: 459-67.

15. Dalens B, Raynaud EJ, Gaulme J. Teratogenicity of valproic acid. J Pediatr 1980; 97: 332-3.

16. DiLiberti JH, Farndon PA, Dennis NR, Curry CJ. The fetal valproate syndrome. Am J Med Genet 1984; 19: 473-81.

17. Monson RR, Rosenberg L, Hartz SC, Shapiro S, Heinonen OP, Slone D. Diphenylhydantoin and selected congenital malformations. N Engl J Med 1973; 289: 1049-52.

18. Hanson JW, Smith DW. The fetal hydantoin syndrome. J Pediatr 1975; 87: 285-90.

19. Rudd NL, Freedom RM. A possible primidone embryopathy. J Pediatr 1979; 94: 835-7.

20. Seip M. Growth retardation, dysmorphic facies and minor malformations following massive exposure to phenobarbitone in utero. Acta Paediatr Scand 1976; 65: 617-21.

21. Jones KL, Lacro RV, Johnson KA, Adams J. Pattern of malformations in the children of women treated with carbamazepine during pregnancy. N Engl J Med 1989; 320: 1661-6.

22. Moore SJ, Turnpenny P, Quinn A, Glover S, Lloyd DJ, Montgomery T, Dean JC. A clinical study of 57 children with fetal anticonvulsant syndromes. J Med Genet 2000; 37: 489-97.

23. Kozma C. Valproic acid embryopathy: report of two siblings with further expansion of he phenotypic abnormalities and a review of the literature. Am J Med Genet 2001; 98: 168-75.

24. Kini U, Adab N, Vinten J, Fryer A, Clayton-Smith J; Liverpool and Manchester Neurodevelopmental Study Group. Dysmorphic features: an important clue to the diagnosis and severity of fetal anticonvulsant syndromes. Arch Dis Child Fetal Neonatal Ed 2006; 91: F90-5.

25. Nulman I, Scolnik D, Chitayat D, Farkas LD, Koren G. Findings in children exposed to phenytoin and carbamazepine monotherapy: independent effects of epilepsy and medications. Am J Med Genet 1998; 68: $18-24$. 
26. Adab N, Kini U, Vinten J, Ayres J, Baker G, Clayton-Smith J, Coyle H, Fryer A, Gorry J, Gregg J, Mawer G, Nicolaides P, Pickering L, Tunnicliffe L, Chadwick DW. The longer term outcome of children born to mothers with epilepsy. J Neurol Neurosurg Psychiatry 2004; 75: 1575-83.

27. Ornoy A. Neuroteratogens in man: An overview with special emphasis on the teratogenicity of antiepileptic drugs in pregnancy. Reprod Toxicol 2006: 22: 214-26.

28. Yerby MS, Leavitt A, Erickson DM, McCormick KB, Loewenson RB, Sells CJ, Benedetti TJ. Antiepileptics and the development of congenital anomalies. Neurology 1992; 42(4 Suppl 5): 132-40.

29. Adab N, Tudur Smith C, Vinten J, Williamson P, Winterbottom J. Common antiepileptic drugs in pregnancy in women with epilepsy. Cochrane Database Syst Rev 2004; (3): CD004848.

30. Perucca E, Tomson T. Prenatal exposure to antiepileptic drugs. Lancet 2006; 367: 1467-9.

31. Shapiro S, Hartz SC, Siskind V, Mitchell AA, Slone D, Rosenberg L, Monson RR, Heinonen OP. Anticonvulsants and parental epilepsy in the development of birth defects. Lancet 1976; 1(7954): 272-5.

32. Delgado-Escueta AV, Janz D. Consensus guidelines: preconception counseling, management, and care of the pregnant woman with epilepsy. Neurology 1992; 42(4 Suppl 5) : 149-60.

33. Dean JC, Hailey H, Moore SJ, Lloyd DJ, Turnpenny PD, Little J. Long term health and neurodevelopment in children exposed to antiepileptic drugs before birth. J Med Genet 2002; 39: 251 - 9.

34. Janz D. On major malformations and minor anomalies in the offspring of parents with epilepsy: review of the literature. In: Janz D, Dam M, Richens A, Bossi L, Helge H, Schmidt D, editors. Epilepsy, Pregnancy and the Child. New York: Raven Press; 1982. p. 211-222.

35. Majewski F, Steger M, Richter B, Gill J, Rabe F. The teratogenicity of hydantoins and barbiturates in humans, with considerations on the etiology of malformations and cerebral disturbances in the children of epileptic parents. Int J Biol Res Pregnancy 1981; 2: 37-45.

36. Fried S, Kozer E, Nulman I, Einarson TR, Koren G. Malformation rates in children of women with untreated epilepsy. Drug saf 2004; 27: 197-202.

37. Holmes LB, Rosenberger PB, Harvey EA, Khoshbin S, Ryan L. Intelligence and physical features of children of women with epilepsy. Teratology 2000; 61: 196-202.

38. Holmes LB, Harvey EA, Coull BA, Huntington KB, Khoshbin S, Hayes AM, Ryan LM. The teratogenicity of anticonvulsant drugs. New Engl J Med 2001; 344: 1132-8.

39. EURAP Study Group. Seizure control and treatment in epilepsy: observations from the EURAP epilepsy pregnancy registry. Neurology 2006; 66: 354-60.

40. Losche G, Steinhausen HC, Koch S, Helge H. The psychological development of children of epileptic parents. Il. The differential impact of intrauterine exposure to anticonvulsant drugs and further influential factors. Acta Paediatr 1994; 83: 961-6.

41. Gaily E, Kantola-Sorsa E, Granstrom ML. Specific cognitive dysfunction in children with epileptic mothers. Dev Med Child Neurol 1990; 32: 403-14.

42. Lindhout D, Omtzigt JG. Pregnancy and the risk of teratogenicity. Epilepsia 1992; 33 (Suppl 4): S41-8.

43. Adab N, Jacoby A, Smith D, Chadwick D. Additional educational needs in children born to mothers with epilepsy. J Neurol Neurosurg Psychiatry 2001; 70: 15-21.

44. Goetting MG, Davidson BN. Status epilepticus during labor. A case report. J Reprod Med 1987; 32: 313-314.

45. Fujioka K, Kaneko S, Hirano T, Fujita S, Sato T, Matsui M et al. A study of the psychomotor development of the offspring of epileptic mothers. In: Sato T, Shinagawa S, editors. Antiepileptic Drugs in Pregnancy; Proceedings of a seminar on antiepileptic drugs and pregnancy; June 3-4, 1983. Excerpta Medica; 1984. p. $196-$ 206.

46. Tettenborn B, Genton P, Polson D. Epilepsy and women's issues: An update. Epileptic Disord 2002; 4(Suppl 2): S23-31.

47. Jacoby A, Snape D, Baker GA. Epilepsy and social identity: the stigma of a chronic neurological disorder. Lancet Neurol 2005; 4: 171-8.

48. Relton CL, Hammal DM, Rankin J Parker L. Folic acid supplementation and social deprivation. Public Health Nutr 2005; 8: 338-340.

49. Ray JG, Singh G, Burrows RF. Evidence for suboptimal use of periconceptional folic acid supplements globally. BJOG 2004; 111: 399-408.

50. Jacobson SW, Chiodo LM, Sokol RJ, Jacobson JL. Validity of maternal report of prenatal alcohol, cocaine, and smoking in relation to neurobehavioral outcome. Pediatrics 2002; 109: 815-825.

51. Tettenborn B. Management of epilepsy in women of childbearing age. Practical recommendations. CNS Drugs 2006; 20: 373-87. 
52. Eriksson K, Viinikainen K, Monkkonen A, Aikia M, Nieminen P, Heinonen S, Kalviainen R. Children exposed to valproate in utero--population based evaluation of risks and confounding factors for long-term neurocognitive development. Epilepsy Res 2005; 65: 189-200.

53. Gaily E, Kantola-Sorsa E, Hiilesmaa V, Isoaho M, Matila R, Kotila M, Nylund T, Bardy A, Kaaja E, Granstrom ML. Normal intelligence in children with prenatal exposure to Carbamazepine. Neurology 2004; 62: $28-32$.

54. Reinisch JM, Sanders SA, Mortensen EL, Rubin DB. In utero exposure to phenobarbital and intelligence deficits in adult men. JAMA 1995; 274: 1518-25.

55. Mawer G, Clayton-Smith J, Coyle H, Kini U. Outcome of pregnancy in women attending an outpatient epilepsy clinic: adverse features associated with higher doses of sodium valproate. Seizure 2002; 11: 512-8.

56. Samren EB. Maternal epilepsy and pregnancy outcome. A population study. Thesis Erasmus University Rotterdam 1998.

57. Laegreid L, Kyllerman M, Hedner T, Hagberg B, Viggedahl G. Benzodiazepine amplification of valproate teratogenic effects in children of mothers with absence epilepsy. Neuropediatrics 1993; 24: 88-92.

58. McElhatton PR. The effects of benzodiazepine use during pregnancy and lactation. Reprod Toxicol 1994; 8: 461-75.

59. Arnon J, Shechtman S, Ornoy A. The use of psychiatric drugs in pregnancy and lactation. Isr J Psychiatry Relat Sci 2000; 37: 205-22.

60. Aldenkamp AP, Weber B, Overweg-Plandsoen WC, Reijs R, van Mil S. Educational underachievement in children with epilepsy: a model to predict the effects of epilepsy on educational achievement. J Child Neurol 2005; 20: 175-80.

61. Hillesmaa V. Effects of maternal seizures on the fetus. In: Tomson T, Gram L, Sillanpaa M, Johannesen, eds. Epilepsy and pregnancy. Peterfield, UK and Bristol, PA: Wrightson Biomedical, 1996: 135-141.

62. Katz O, Levy A, Wiznitzer A, Sheiner E. Pregnancy and perinatal outcome in epileptic women: a populationbased study. J Matern Fetal Neonatal Med 2006; 19: 21-25.

63. Lajeunie E, Barcik U, Thorne JA, El Ghouzzi V, Bourgeois M, Renier D. Craniosynostosis and fetal exposure to sodium valproate. J Neurosurg 2001; 95: 778-82.

64. Arulmozhi T, Dhanaraj M, Rangaraj R, Vengatesan A. Physical growth and psychomotor development of infants exposed to antiepileptic drugs in utero. Neurol India 2006; 54: 42-46.

65. Beck-Mannagetta $G$ and Janz D. Data on psychomotor and mental development in children of epileptic parents: a review. In: Janz D, Dam M, Richens A, Bossi L, Helge H, Schmidt D, editors. Epilepsy, Pregnancy and the Child. New York: Raven Press; 1982. p.443-445.

66. Vert P, Deblay MF, Andre M. Follow-up study on growth and neurologic development of children bom to epileptic mothers. In: Janz D, Dam M, Richens A, Bossi L, Helge H, Schmidt D, editors. Epilepsy, Pregnancy and the Child. New York: Raven Press; 1982. p.433-436.

67. Cohen J. Statistical power analysis for the behavioral sciences. New York: Academic Press, 1977.

68. Speidel BD, Meadow SR. Maternal epilepsy and abnormalities of the fetus and newborn. Lancet 1972; 2(7782): 839-43.

69. Gaily E, Kantola-Sorsa E, Granstrom ML. Intelligence of children of epileptic mothers. J Pediatr 1988; 113 : 677-84.

70. Rasalam AD, Hailey H, Williams JH, Moore SJ, Turnpenny PD, Lloyd DJ, Dean JC. Characteristics of fetal anticonvulsant syndrome associated autistic disorder. Dev Med Child Neurol 2005; 47: 551-5.

71. German J, Kowal A, Ehlers KH. Trimethadione and human teratogenesis. Teratology 1970; 3: 349-62.

72. Gaetti MT, Carotti G, Vianelli P, Pellegrini L, Bini PL, Scalseggi V. Dysmorphisms and psychomotor retardation in infants of mothers treated with anticonvulsants in pregnancy. Minerva Pediatr. 1979; 31: 1261-6.

73. Christianson AL, Chesler N, Kromberg JG. Fetal valproate syndrome: clinical and neuro-developmental features in two sibling pairs. Dev Med Child Neurol 1994; 36: 361-9.

74. Hockey A, Bower C, Goldblatt J, Knowles S. Fetal valproate embryopathy in twins: genetic modification of the response to a teratogen. Birth Defects Orig Artic Ser 1996; 30: 401-5.

75. Williams PG, Hersh JH. A male with fetal valproate syndrome and autism. Dev Med Child Neurol 1997; 39: 632-4.

76. Gomez MR. Possible teratogenicity of valproic acid. J Pediatr 1981; 98: 508-9.

77. Malm H, Kajantie E, Kivirikko S, Kaariainen H, Peippo M, Somer M. Valproate embryopathy in three sets of siblings: further proof of hereditary susceptibility. Neurology 2002; 59: 630-3.

78. Schorry EK, Oppenheimer SG, Saal HM. Valproate embryopathy: clinical and cognitive profile in 5 siblings. Am J Med Genet A. 2005; 133: 202-6. 
79. Thisted E, Ebbesen F. Malformations, withdrawal manifestations, and hypoglycaemia after exposure to valproate in utero. Arch Dis Child 1993; 69: 288-91.

80. Hill RM, Verniaud WM, Horning MG, McCulley LB, Morgan NF. Infants exposed in utero to antiepileptic drugs. A prospective study. Am J Dis Child 1974; 127: 645-53.

81. Hanson JW, Myrianthopoulos NC, Harvey MA, Smith DW. Risks to the offspring of women treated with hydantoin anticonvulsants, with emphasis on the fetal hydantoin syndrome. J Pediatr 1976; 89: 662-8.

82. Hill RM, Verniaud WM, Rettig GM, Tennyson LM, Craig JP. Relationship between antiepileptic drug exposure of the infant and developmental potential. In: Jantz D, Dam M, Richens A, Bossi L, Helge H, Schmidt D., editors. Epilepsy, Pregnancy and the Child. New York: Raven Press; 1982, pp 409-417.

83. Rasalam AD, Hailey H, Williams JH, Moore SJ, Turnpenny PD, Lloyd DJ, Dean JC. Characteristics of fetal anticonvulsant syndrome associated autistic disorder. Dev Med Child Neurol. 2005; 47: 551-5.

84. Katz JM, Pacia SV, Devinsky O. Current management of epilepsy and pregnancy: Fetal outcome, congenital malformations, and developmental delay. Epilepsy Behav 2001; 2: 119-23.

85. Van der Pol MC, Hadders-Algra M, Huisjes HJ, Touwen BC. Antiepileptic medication in pregnancy: late effects on the children's central nervous system development. Am J Obstet Gynecol 1991; 164: 121-8.

86. Vanoverloop D, Schnell RR, Harvey EA, Holmes LB. The effects of prenatal exposure to phenytoin and other anticonvulsants on intellectual function at 4 to 8 years of age. Neurotoxicol Teratol 1992; 14: 329-35.

87. Scolnik D, Nulman I, Rovet J, Gladstone D, Czuchta D, Gardner HA, Gladstone R, Ashby P, Weksberg R, Einarson T, Koren G. Neurodevelopment of children exposed in utero to phenytoin and carbamazepine monotherapy. JAMA 1994; 271: 767-70.

88. Hattig H, Helge H, Steinhausen HC. Infants of epileptic mothers: developmental scores at 18 months. In: Advances in Epileptology, Vol. 16, edited by Wolf P, Dam M, Janz D, and Dreifuss FE, New York: Raven Press, 1987,p. 579-81.

89. Viinikainen K, Eriksson K, Monkkonen A, Aikia M, Nieminen P, Heinonen S, Kalviainen R. The effects of valproate exposure in utero on behavior and the need for educational support in school-aged children. Epilepsy \& Behav 2006; 9: 636-640.

90. Steinhausen HC, Lösche G, Koch S, Helge H. The psychological development of children of epileptic parents. I. Study design and comparative findings. Acta Paediatr 1994; 83: 955-60.

91. Losche G, Steinhausen HC, Koch S, Helge H. The psychological development of children of epileptic parents. II. The differential impact of intrauterine exposure to anticonvulsant drugs and further influential factors. Acta Paediatr 1994: 83: 961-966.

92. Koch S, Titze K, Zimmermann RB, Schroder M, Lehmkuhl U, Rauh H. Long-term neuropsychological consequences of maternal epilepsy and anticonvulsant treatment during pregnancy for school-age children and adolescents. Epilepsia 1999; 40: 1237-43.

93. Nelson KB, Ellenberg JH. Maternal seizure disorder, outcome of pregnancy, and neurologic abnormalities in the children. Neurology 1982; 32: 1247-54.

94. D’Souza SW, Robertson IG, Donnai D, Mawer G. Fetal phenytoin exposure, hypoplastic nails, and jitteriness. Arch Dis Child 1991; 66: 320-4.

95. Leavitt AM, Yerby MS, Robinson N, Sells CJ, Erickson DM. Epilepsy in pregnancy: developmental outcome of offspring at 12 months. Neurology 1992; $42(4$ Suppl 5) :141-3.

96. Ornoy A, Cohen E. Outcome of children born to epileptic mothers treated with carbamazepine during pregnancy. Arch Dis Child 1996; 75: 517-20.

97. Wide K, Winbladh B, Tomson T, Sars-Zimmer K, Berggren E. Psychomotor development and minor anomalies in children exposed to antiepileptic drugs in utero: a prospective population-based study. Dev Med Child Neurol 2000; 42: 87-92.

98. Ardinger HH, Atkin JF, Blackston RD, Elsas LJ, Clarren SK, Livingstone S, Flannery DB, Pellock JM, Harrod MJ, Lammer EJ, Majewski F, Schinzel A, Toriello HV, Hanson JW. Verification of the fetal valproate syndrome phenotype. Am J Med Genet 1988; 29: 171-85.

99. Vinten J, Adab N, Kini U, Gorry J, Gregg J, Baker GA. Neuropsychological effects of exposure to anticonvulsant medication in utero. Neurology 2005; 64: 949-54.

100. Specchio, L. M., Perniola, T., LaNeve, A., Ostillio, G., Vandruccio, M., Martiriggiano, A., Mautone, A., and Baisi, F. Psychomotor development in children with epileptic mothers: a prospective study of the first year of life. Seizure 1992; 1 (Suppl A): p6/13.

101. Hirano T, Fujioka K, Okada M, Iwasa H, Kaneko S. Physical and psychomotor development in the offspring born to mothers with epilepsy. Epilepsia 2004; 45 (Suppl 8): 53-7. 
102. Dessens AB, Cohen-Kettenis PT, Mellenbergh GJ, Koppe JG, van de Poll NE, Boer K. Association of prenatal phenobarbital and phenytoin exposure with small head size at birth and with learning problems. Acta Paediatr 2000; 89: 533-41.

103. Parisi P, Francia A, Vanacore N, Fiore S, Giallonardo AT, Manfredi M. Psychomotor development and general movements in offspring of women with epilepsy and anticonvulsant therapy. Early Hum Develop 2003; 73:97-108.

104. Holmes LB, Coull BA, Dorfman J, Rosenberger PB. The correlation of deficits in IQ with midface and digit hypoplasia in children exposed in utero to anticonvulsant drugs. J Pediatr 2005; 146: 118-22.

105. Meador KJ, Loring DW, Baker G, Clayton Smith J, Pennell P, Liporace J, Kalayjian L, Kini U. Differential and dose dependent effects of in utero antiepileptic drugs. Neurology 2005; 64 (Suppl 1): A427.

106. Ben-Menachem E, Schnitz B, Tomson T, Vajda F. Role of valproate across the ages Treatment of epilepsy in adults. Acta Neurol Scand 2006; 114 (Suppl 184): 14-27.

107. Williams, King J, Cunningham M, Stephan M, Kerr B, Hersh JH. Fetal valproate syndrome and autism: additional evidence of an association. Dev Med Child Neurol 2001; 43: 202-6

108. Gardner RJ, Savarirayan R, Dunne KB, McLellan JA, Coleman LT, Suthers GK. Microlissencephaly with cardiac, spinal and urogenital defects. Clin Dysmorphol 2001; 10: 203-8.

109. Dean JC, Moore SJ, Osborne A, Howe J, Turnpenny PD. Fetal anticonvulsant syndrome and mutation in the maternal MTHFR gene. Clin Genet 1999; 56: 216-20.

110. Shepard TH, Brent RL, Friedman JM, Jones KL, Miller RK, Moore CA, Polifka JE. Update on new developments in the study of human teratogens. Teratology 2002; 65: 153-61.

111. Hiilesmaa VK, Teramo K, Granstrom ML, Bardy AH. Serum folate concentrations during pregnancy in women with epilepsy: relation to antiepileptic drug concentrations, number of seizures, and fetal outcome. $\mathrm{Br}$ Med J (Clin Res Ed) 1983; 287: 577-579.

112. Hiilesmaa VK, Teramo K, Granstrom ML, Bardy AH. Fetal head growth retardation associated with maternal antiepileptic drugs. Lancet 1981; 2(8239): 165-167.

113. Hansen D, Lou HC. Brain development, head circumference and medication. Acta Paediatr 2000; 89. 505-7.

114. Gaily EK, Granstrom ML, Hiilesmaa VK, Bardy AH. Head circumference in children of epileptic mothers: contributions of drug exposure and genetic background. Epilepsy Res 1990; 5: 217-222.

115. Bittigau P, Sifringer M, Ikonomidou C. Antiepileptic drugs and apoptosis in the developing brain. Ann N Y Acad Sci 2003; 993:103-114.

116. Motamedi GK, Meador KJ. Antiepileptic drugs and neurodevelopment. Curr Neurol Neurosc Rep 2006; 6 : 341-6.

117. Pitkanen A, Kubova H. Antiepileptic drugs in neuroprotection. Expert Opin Pharmacother 2004; 5: 777-98.

118. Vajda FJ, Hitchcock A, Graham J, Solinas C, O’Brien TJ, Lander CM, Eadie MJ. Foetal malformations and seizure control: 52 month data of the Australian pregnancy registry. Eur J Neurol 2006; 13: 645-654.

119. Barrett C, Richens A. Epilepsy and pregnancy; report of an epilepsy research foundation workshop. Epilepsy Res 2003; 52:147-187.

120. Bayley N. Manual for the Bayley scales of infant development. The Psychological corporation 1969. New York

121. McCarthy D. The McCarthy scales of infant abilities. In: Manual. The Psychological corporation 1972. New York

122. Wechsler D. Manual for the Wechsler Intelligence scale. Revised. New York: The Psychological Corporation, 1974. 



\section{Chapter 7}

Cognitive side effects of valproic acid-induced hyperammonemia in children with epilepsy

Joost Nicolai, Albert P. Aldenkamp, Johannes R. Huizenga, Laura K. Teune, Oebele F. Brouwer

Journal of Clinical Phychopharmacology 2007; 27: 221-4

This study has been supported by a grant from the Dutch National Epilepsy Fund (03-17). 
Valproic acid (VPA) is one of the most widely used antiepileptic drugs in children. Hyperammonemia without laboratory evidence of liver failure is an adverse effect frequently seen in children treated with VPA monotherapy or polytherapy. ${ }^{1,2}$ Symptomatic VPA induced hyperammonemia results in vomiting, ataxia, behavioral changes, lethargy, somnolence or coma, and increased seizure frequency. ${ }^{3}$ However, increased ammonia concentrations seem to be asymptomatic in most children. ${ }^{1,2}$ The clinical relevance of moderate hyperammonemia is unclear. Besides, it is unclear at what ammonia concentrations clinical symptoms do appear. In series evaluating the incidence of hyperammonemia in children, venous ammonia concentrations as high as 140 $\mu \mathrm{mol} / \mathrm{L}^{1}$ are reported without symptoms. On the other side, lethargy, stupor, and coma have been reported with relatively low or even normal ammonia concentrations. ${ }^{4,5}$

It has never been investigated whether "asymptomatic" VPA-induced hyperammonemia, which does not lead to complaints or clinical symptoms, may lead to subtle central nervous system problems. This information is important when to decide whether hyperammonemia should be accepted or not. This pilot study was initiated to study the effects on cognition of an elevation of ammonia as is often seen in children treated with VPA.

We used a prospective, comparative, clinical, nonrandomized, and repeated testing (before and after lunch) design. Children were tested and retested on the same day. We have chosen a test and retest design because it enabled us to study the effect of hyperammonemia most properly. The neuropsychological test results are determined by the intelligence of the child, whether the child is seizure free or not, the antiepileptic medication, and possibly the ammonia concentration. By testing a child twice with 3 hours in between, most factors are stable, but a rise in ammonia is expected after lunch. This makes it possible to relate ammonia levels to neuropsychological results.

Children with epilepsy between 8 and 16 years without cognitive side effects of their antiepileptic medication were asked to participate in this study. Both children on VPA monotherapy or on combination therapy including VPA and children who were about to start or withdraw VPA treatment were included. Children who started VPA treatment were tested at least 4 weeks after a stable dose was achieved. Besides, ammonia concentrations were determined in children who started medication when they were still without medication. Ammonia was also analysed in children who were allowed to withdraw medication 4 weeks after VPA had been completely stopped. The parents gave written informed consent. In children 12 years or older, the child gave informed consent as well. Approval to perform this study was given by the local ethic committee.

Capillary blood was collected from the earlobe. The earlobe was cleaned with chlorhexidine in $70 \%$ ethanol. Twenty microliters of blood was collected with a Gilson pipette with disposable tips. Ammonia was measured immediately using the Blood Ammonia Checker II. ${ }^{6}$ If it was possible to fill a second pipette with capillary blood, a second measurement was done, and the mean value of both measurements was used. 
Arterial ammonia levels correlate better with severity of encephalopathy than venous ammonia, and sampling venous blood underestimates the ammonia concentration. ${ }^{7}$ We have chosen to determine ammonia in earlobe capillary blood because this closely resembles arterial ammonia concentration. ${ }^{8}$ Besides, it is quite a friendly method because it is hardly painful.

In the initial study protocol, we planned to collect earlobe blood for measuring VPA concentrations and free, total, and acylcarnitine concentrations as well. In every child, earlobe bleeding quickly stopped spontaneously, so we were only able to fill 1 or sometimes 2 pipettes. For this reason, we only determined ammonia concentrations. The study protocol approved by the ethical committee did not allow us to perform an additional venous puncture.

Because symptomatic hyperammonemia results in lethargy, somnolence, and mental slowing, we selected tests for psychomotor speed, reaction time, and memory. The following tests were used: Finger Tapping for the dominant hand and the nondominant hand, Simple Reaction Time Measurement for the dominant hand and the nondominant hand, Binary Choice Reaction Test for the dominant hand and the nondominant hand, Computerized Visual Searching Task, Recognition of Words, and Recognition of Figures. All the selected tests are part of the FePsy neuropsychological testbattery. This is a computerized neuropsychological test battery that has been especially developed and validated for children. ${ }^{9}$ Because the consecutive sessions consist of different words, figures, and so on, there is no learning effect when tests are repeated. ${ }^{9}$

The first ammonia level was measured at 12 noon. Immediately afterward, neuropsychological testing was performed, and this lasted about 45 to 55 minutes. Consecutively, children had a non standardized lunch. They returned at 3:00 PM for a second identical session.

The SPSS 14.0 for windows was used for statistical analysis. The paired-samplest test was used because of the test-retest design. The paired-samplest test is the most appropriate statistical test for comparing continuous variables of 1 person on 2 different occasions.

Twelve children, 8 girls and 4 boys, were included in the study. Their age ranged from 8 years, 8 months to 15years, 11 months. One child was diagnosed as having juvenile absence epilepsy, 1 with juvenile myoclonic epilepsy, 1 with idiopathic generalized epilepsy with tonic-clonic seizures, and 3 with benign childhood epilepsy with centrotemporal spikes. Three children had symptomatic epilepsy caused by cerebral palsy, postmeningitis, and a syndrome with congenital ataxia and secondary generalized seizures of unknown aetiology. Two children were diagnosed as having cryptogenic partial epilepsy and 1 with cryptogenic generalized epilepsy. All children were controlled with antiepileptic drugs. Six children were on a stable regimen with VPA, 4 children recently started VPA therapy (and were on a stable regimen for more than 4 weeks), and 2 children were allowed to withdraw VPA (but stable at the time of testing). The VPA dosage ranged from $14 \mathrm{mg} / \mathrm{kg}$ per day up to $30 \mathrm{mg} / \mathrm{kg}$ per day. All had 
a twice-a day medication regimen. Two children used other antiepileptic medications as well; 1 child used carbamazepine, and another child used oxcarbazepine.

One girl (with congenital ataxia and generalized seizures) was unable to read or recognize the figures. She had problems understanding the reaction time tests, and tapping results were more than 2 times slower than average (dominant hand tapping; mean, 19). Her results were not included. In total, 22 combined ammonia measurements and FePsy results were analysed.

In those 11 children treated with VPA, mean ammonia concentration rose from 66 $\mu \mathrm{mol} / \mathrm{L}$ (range, 36-92 $\mu \mathrm{mol} / \mathrm{L}$ ) to $81 \mu \mathrm{mol} / \mathrm{L}$ (range, 44-117 $\mu \mathrm{mol} / \mathrm{L}$ ). Five children were also tested during a period that they did not use VPA. Mean ammonia levels without VPA rose from $48 \mu \mathrm{mol} / \mathrm{L}$ (range, 33-70 $\mu \mathrm{mol} / \mathrm{L}$ ) before lunch to 69 $\mu \mathrm{mol} / \mathrm{L}$ (range, 44-85 $\mu \mathrm{mol} / \mathrm{L}$ ) after lunch.

The $23 \%$ rise in ammonia-when treated with VPA-was not significant $(\mathrm{P}=0.125)$. The paired results of the different tests correlated significantly, except for the Recognition of Words Test and Recognition of Figures Test. A significant difference was found for Simple Reaction Time dominant hand. Mean results on retesting were 12\% slower compared with the initial results (460 milliseconds vs. 410 milliseconds). However, no relation between ammonia concentration and Simple Reaction Time dominant hand was noted. The mean Simple Reaction Time nondominant hand was 5\% slower on retesting as well (455 milliseconds vs. 434 milliseconds), although not significantly $(\mathrm{P}=0.06)$.

\section{DISCUSSION}

Amino acids, the products of protein digestion, are degraded in the liver to produce ammonia. Ammonia is converted to urea that is excreted by the kidneys. Any disruption to this process has the potential to cause hyperammonemia. ${ }^{3}$ Venous ammonia levels are significantly higher in children receiving VPA compared with healthy controls or compared with children treated with other antiepileptic drugs. ${ }^{1}$ The reported incidence of hyperammonemia in children treated with VPA ranges from $16 \%$ to $52 \%{ }^{2}$ and is even higher in children treated with VPA in combination with phenytoin or phenobarbital. ${ }^{2}$ However, it is difficult to compare these series because the upper limit for normal ammonia differed between 35 and $60 \mu \mathrm{mol} / \mathrm{L}$ in the different studies.

In VPA-treated children, protein ingestion can result in significant transient increase of venous ammonia. ${ }^{10} \mathrm{Gidal}$ et al. ${ }^{10}$ described 11 children on VPA monotherapy or polytherapy, who had baseline ammonia concentrations (mean, $39.1 \mu \mathrm{mol} / \mathrm{L}$ ) before breakfast within the reference range. Venous ammonia concentrations increased significantly (mean, 73. $4 \mu \mathrm{mol} / \mathrm{L}$ ), 2 hours after a protein-enriched breakfast. At 4 hours, ammonia concentrations (mean, $51.8 \mu \mathrm{mol} / \mathrm{L}$ ) had decreased in all children.

The mechanism of VPA-induced hyperammonemia is not completely understood. ${ }^{3,11}$ It has been linked to secondary carnitine deficiency, and many series have 
shown a deficiency of carnitine in VPA-treated children. Two mechanisms causing hyperammonemia have been proposed in recent years. First, VPA enhances glutamine uptake and ammonia release in the kidney. Second, VPA and carnitine deficiency causes decreased urea formation and ammonia accumulation in the liver through inhibition of carbamoyl phosphate synthetase I. ${ }^{3,11}$ Several prospective studies have shown a decrease in ammonia concentrations after supplementing l-carnitine. ${ }^{10}$ Whether preventing hyperammonemia with 1-carnitine supplementation has any relevant clinical effect in children is unclear. Freeman et al. ${ }^{11}$ examined the effect of l-carnitine supplementation in children aged 3 to 17 years with epilepsy in a double blind, placebocontrolled crossover study. Both treatment groups experienced a similar improvement on a general wellbeing questionnaire. But in this study, neither ammonia concentrations nor cognition deficits were measured. ${ }^{11}$

Recently, Raja and Azzoni ${ }^{12}$ published a large series of 123 adult psychiatric patients using VPA. Fifty-one percent had ammonia concentrations above the upper limit. No physical or psychic symptoms due to hyperammonemia were found. However, no standardized neuropsychological assessment was used.

The problem why some children with relatively low venous ammonia concentrations show severe symptoms, whereas other children with even higher levels are asymptomatic, is intriguing. Normally, the brain ammonia concentration is 2 times higher than the arterial blood concentration. ${ }^{13}$ In case of an acute rise of blood ammonia, the brain/blood ratio can increase to about a factor 8 , magnifying the cerebral toxicity of ammonia. ${ }^{13}$

Removal of brain ammonia relies only on the formation of glutamine. The enzyme glutamine synthetase converts ammonia and glutamate to glutamine. Cerebrospinal fluid glutamine levels are elevated in most patients with VPA-related encephalopathy, even in the absence of hyperammonemia, ${ }^{5}$ suggesting that glutamine accumulation is more important than ammonia. High intracellular glutamine levels in astrocytes give rise to increased intracellular osmolarity that leads to cerebral edema. High ammonia levels also lead to an inhibition of glutamate uptake by astrocytes. A decreased intracellular glutamate uptake in astrocytes leads to an increased excitotoxicity. ${ }^{14}$ The central nervous system effect of hyperammonemia in children treated with the combination of VPA and topiramate can lead to severe symptoms of encephalopathy. ${ }^{15}$ Also phenobarbital, phenytoin, and carbamazepine may exacerbate the symptoms of hyperammonic encephalopathy. ${ }^{3}$ Interestingly, when topiramate is stopped and VPA is continued, patients recover, although ammonia levels remain elevated. ${ }^{15}$ It has been suggested that by inhibiting cerebral glutamine synthetase and subsequently ammonia breakdown, topiramate facilitates encephalopathy in case of hyperammonemia. ${ }^{14,15}$ Topiramate also inhibits carbonic anhydrase, and inhibition of this enzyme has been shown to increase blood ammonia levels. ${ }^{14,15}$

Several recommendations have been published how to handle VPA induced asymptomatic hyperammonemia in children and adults. No study about the cognitive effects of moderate ammonia elevations in children treated with VPA has been published before. The results of our pilot study possibly indicate that in case of earlobe 
capillary ammonia concentrations up to $117 \mu \mathrm{mol} / \mathrm{L}$, no signs of mental slowing are noted in children. We recommend not measuring ammonia in children treated with VPA, unless they show symptoms of hyperammonic encephalopathy. Moderate hyperammonemia without clinical symptoms is no reason to withdraw or lower VPA or to start L-carnitine supplementation. One should be aware that symptomatic VPAinduced hyperammonemia can occur at relatively low or even normal ammonia concentrations.

There are several methodological shortcomings in our experiment: (1) it was a nonblinded pilot study; (2) we included only 11 children; (3) because of the fact that we did not succeed in collecting enough blood from the earlobe, we only determined ammonia concentrations and did not measure VPA concentrations; (4) because of the fact that children had a nonstandardized nonprotein-enriched lunch, elevation of ammonia was only moderate $(23 \%)$ compared with that $(86 \%)$ of the study of Gidal et al, ${ }^{10}$ making it difficult to draw conclusions.

Acknowledgments

F. Kessels gave statistical advice. 


\section{REFERENCES}

1. Murphy JV, Marquardt K. Asymptomatic hyperammonemia in patients receiving valproic acid. Arch Neurol. 1982; 39: 591-592.

2. Haidukewych D, John G, Zielinski JJ, et al. Chronic valproic acid therapy and incidence of increases in venous plasma ammonia. Ther Drug Monit. 1985; 7: 290-294.

3. Verrotti A, Trotta D, Morgese G, et al. Valproate-induced hyperammonemic encephalopathy. Metab Brain Dis. 2002; 17: 363-367.

4. Coulter DL, Allen RJ. Secondary hyperammonaemia: a possible mechanism for valproate encephalopathy. Lancet. 1980; 8181: 1310-1311.

5. Vossler DG, Wilensky AJ, Cawthon DF, et al. Serum and CSF glutamine levels in valproate related hyperammonic encephalopathy. Epilepsia. 2002; 43: 154-159.

6. Huizenga JR, Tangerman A, Gips CH. A rapid method for blood ammonia determination using the new blood ammonia checker (BAC) II. Clin Chim Acta. 1992; 210: 153-155.

7. Zaret BS, Marini AM. Standardization of VPA-induced hyperammonemia. Neurology. 1985; 35: 136-137.

8. Huizenga JR, Gips CH, Conn HO, et al. Determination of ammonia in ear-lobe capillary blood is an alternative to arterial bloodammonia. Clin Chim Acta. 1995; 239: 65-70.

9. Alpherts WC, Aldenkamp AP. Computerized neuropsychological assessment of cognitive functioning in children with epilepsy. Epilepsia. 1990; 31(suppl 4): S35-S40.

10. Gidal BE, Inglese CM, Meyer JF, et al. Diet and valproate-induced transient hyperammonemia: effect of 1carnitine. Pediatr Neurol. 1997; 16: 301-305.

11. Freeman JM, Vining EP, Cost S, et al. Does carnitine administration improve the symptoms attributed to anticonvulsant medications? A double-blinded, crossover study. Pediatrics. 1994; 93: 893-895.

12. Raja M, Azzoni A. Valproate-induced hyperammonaemia. J Clin Psychopharmacol. 2002; 22: 631-633.

13. Butterworth RF. Pathophysiology of hepatic encephalopathy: a new look on ammonia. Metab Brain Dis. 2002; 17: 221-227.

14. Segura-Bruna N, Rodriguez-Campello A,Puente V, et al. Valproate-induced hyperammonemic encephalopathy. Acta Neurol Scand. 2006; 114: 1-7.

15. Hamer HM, Knake S, Schomburg U, et al. Valproate-induced hypeammonemic encephalopathy in the presence of topiramate. Neurology. 2000; 54: 230-232. 



\section{Chapter 8}

Discussion 
In Chapter 2, the different aspects of nocturnal icterictal epileptiform activity in benign childhood epilepsy with centrotemporal spikes (BCECTS) are reviewed.

Benign childhood epilepsy with centrotemporal spikes (BCECTS) is the most frequent epilepsy syndrome in children, accounting for $15-24 \%$ of children with epilepsy. According to the 1989 International League against Epilepsy (ILAE) classification, it is characterized by "brief, simple, partial, hemifacial motor seizures, frequently having associated somatosensory symptoms that have a tendency to evolve into generalized tonic-clonic seizures. Both seizure types are often related to sleep. Onset occurs between the ages of 3 and 13 years (peak 9-10 years), and recovery occurs before the age of 15-16 years. Genetic predisposition is frequent, and there is a male predominance. The EEG has blunt high-voltage centrotemporal spikes, often followed by slow waves that are activated by sleep and tend to spread or shift from side to side". ${ }^{1}$

Two phenomena are especially interesting in BCECTS: the activation of electroencephalographic epileptiform activity during sleep and the secondary cognitive disturbances in this syndrome possible caused by frequent (nocturnal) epileptiform activity.

Activation of electroencephalographic epileptiform activity refers to an increased frequency of activity during sleep. This can even lead to an absolute on/off situation; in $20-30 \%$ of children with BCECTS no epileptiform activity is recorded during wakefulness, while abundant activity is noted while asleep. In addition to the increased frequency, the amplitude of epileptiform activity often increases involving adjacent regions of the same hemisphere and sometimes the centrotemporal area of the opposite hemisphere, and bilaterally synchronous and symmetrical discharges occur while asleep.

Although in the original description a normal neurological and cognitive development was a prerequisite for the diagnosis, a diversity of cognitive problems is seen in a high percentage of children with BCECTS. The Full-scale intelligence quotient (FSIQ) is often within the normal range, but language delay, learning disabilities, and academic problems are often noted. Moreover in series of children without overt educational problems, low results are reported on neuropsychological tests involving visuomotor coordination, some executive functions, sustained attention, and language issues like spelling, reading aloud, reading comprehension, memory and learning of auditoryverbal material, delayed recall, and verbal fluency, compared with controls.

The first conclusion of our review of the literature was that children with a high frequency of localized interictal discharges $(>5 / \mathrm{min}$ or $>10 / \mathrm{min})$ show lower test scores on many cognitive items compared to children with low frequent discharges.

Treatment with clonazepam, diazepam, and to a lesser extend sulthiame is effective in reducing the number of centrotemporal discharges. Both carbamazepine and valproic acid are ineffective in suppressing centrotemporal discharges.

No double-blind, placebo-controlled study about the effect of treatment of centrotemporal discharges in children with BCECTS on behavior and cognition has been published. Two non-blinded, prospective studies showed a significant effect of treatment with diazepam. But both studies suffer from major methodological bias. There is 
no prospective trial in children with BCECTS reported concerning the effect of sulthiame on cognition and behavior. On basis of this information, the second and main conclusion of the review was that there is no clear evidence suggesting that treatment of centrotemporal spikes in children with BCECTS is indicated to improve cognitive and behavioral problems.

After publication of the review article, two small trials have been published analysing the effect of suppression of spikes on cognition in children with BCECTS. Wirrell et al. ${ }^{2}$ treated six children with BCECTS who did not use any medication till that moment. Treatment was with sulthiame $8.0-9.3 \mathrm{mg} / \mathrm{kg} /$ day (divided into twice-daily doses) for a 6-month period. Sulthiame is a sulphonamide derivative; the bestdocumented effect is inhibition of the CNS carbonic anhydrase enzyme. It is particularly effective in treating seizures in BCECTS. Spike frequency during stage II sleep (mean spike frequency during two 30-minute periods of stage II sleep) was determined. Initial spike frequency ranged from 162-2883 spikes/hour. At 6 months, all children had a spike reduction (range 8-1486 spikes/hour). In three children, spike frequency decreased to less than $10 \%$ of baseline frequency. In none of the children complete suppression of interictal activity was achieved. Most of the children showed a significant deterioration in neuropsychological test results across a number of cognitive domains. Interestingly, none of the parents perceived this deterioration in their child's learning capabilities. Kossoff et al. reported a pilot study with six children with BCECTS and with parent's or teacher's reports of worsening of language function at seizure onset. All used antiepileptic medication; four used carbamazepine and two oxcarbazepine. After initiation of levetiracetam, the carbamazepine/oxcarbazepine was reduced in a two week period. Levetiracetam was given in a relatively high dose between $40-60 \mathrm{mg} / \mathrm{kg} / \mathrm{day}$. At the 6-month visit, three children had a normal EEG, in two the EEG had improved and in one showed no improvement. Parents reported a subjective improvement in all six subjects regarding reading and writing. Auditory comprehension, auditory verbal memory showed a statistically non-significant trend towards improvement. ${ }^{3}$ The study-design used in this pilot makes it impossible to differentiate whether levetiracetam is truly beneficial or the discontinuation of carbamazepine or oxcarbazepine was in fact.

So, in addition to the conclusions of chapter 2 , treatment with sulthiame is effective in reducing the number of centrotemporal discharges but possibly leads to a paradox deterioration of cognitive functions. Possibly, changing carbamazepine or oxcarbazepine treatment into levetiracetam could be effective in children with BCECTS and language dysfunction. The statement that there is no evidence that treatment of nocturnal rolandic discharges in children with BCECTS is indicated to improve cognitive and behavioral problems, is still valid.

Until further research is finished, it seems reasonable to start medication in a child with BCECTS and educational difficulties only if the child is monitored by repeated neuropsychological testing and the effect of treatment evaluated regularly. Benzodi- 
azepines have to be the treatment of first choice as treatment with diazepam or clonazepam has been proven effective in suppressing centrotemporal spikes.

Chapter 3 reviews the literature published about the Landau-Kleffner Syndrome and epilepsy with continuous spike-and-waves during slow-wave sleep.

Landau-Kleffner syndrome or acquired epileptic aphasia is a rare epileptic disorder in children between 3 and 8 years old. Only in $80 \%$ of children seizures do occur. Secondary to the nocturnal epileptiform activity, global deterioration of language function develops. Classically, loss of comprehension of spoken language or verbal auditory agnosia is the first sign. Deterioration of language is the major symptom in LandauKleffner syndrome, in epilepsy with continuous spike-and-waves during slow-wave sleep (CSWS) there is a more global deterioration of intelligence and behavior. LandauKleffner syndrome and CSWS have several characteristics in common. Both are considered rare complications of BCECTS. Moreover, both syndromes are characterized by a major activation of encephalographic epileptiform activity during sleep, although the definitions for the percentage of activity are different.

In chapter 3, we review the mechanisms underlying Landau-Kleffner syndrome and CSWS. Just like BCECTS, CSWS and Landau-Kleffner syndrome are age-limited disorders. Epileptiform discharges always disappear before the end of adolescence, suggesting that BCECTS, Landau-Kleffner syndome, and CSWS can only occur during brain maturation. In CSWS, the most prominent epileptic activity appears to be in the frontal area and the prefrontal cortex. Bilateral involvement of the temporoparietal cortex is obligate in Landau-Kleffner syndrome in order to prevent the transfer of language-function to the contralateral cortex. Structural brain pathology is found in 33$50 \%$ of children with CSWS. Especially, children with thalamic injuries are at risk to develop CSWS. On the contrary, structural brain pathology is, by definition, not found in Landau-Kleffner syndrome. Probably, anti-brain autoantibodies do play a role in triggering epileptiform activity in Landau-Kleffner.

A recent study provided circumstantial evidence that the disturbance of language function in children with BCECTS and Landau-Kleffner syndrome probably have mechanisms in common. Bulgheroni et al. studied the Verbal Dichotic Listening test in children with BCECTS. ${ }^{4}$ In Dichotic Listening two different acoustic signals are applied simultaneously to the left and to the right ear. If the child only notes the leftsided signal, this is called right-sided extinction. It is the ear contralateral to the former epileptic focus that shows this extinction-phenomenon. In children with LandauKleffner syndrome who are completely recovered from epileptic manifestations, extinction can still be found. ${ }^{5}$ Typically, controls have a language lateralization with right ear/ left hemisphere advantage indicating a dominant representation of language in the left hemisphere. In 24 children with BCECTS a loss of the usual right ear/ left hemisphere advantage was found, suggesting that interictal epileptiform activity may disturb the cerebral organization of speech perception. This was found both for children with left-sided and with right-sided epileptiform activity, but particularly evident in the 
group with multifocal spikes. ${ }^{4}$ In Landau-Kleffner syndrome, the occurrence of bilateral epileptiform activity is a prerequisite for deterioration of (verbal auditory) language function.

Recently, the magnetoencephalography (MEG) findings of two children with Landau-Kleffner syndrome were published. MEG recordings showed that epileptiform discharges were localized in the left primary auditory cortex of the temporal lobe. The first child with severe language dysfunction only showed activation of the left superior temporal gyrus after auditory response. The second child with clear linguistic improvement also exhibited activation of the right temporal region. These findings suggest that functional reorganization of language involving the right hemisphere possibly leads to a less severe language deficit. ${ }^{6}$

When combining the information of chapter 3 and the studies described above, It seems reasonable that in Landau-Kleffner syndrome and in BCECTS the frequent epileptiform discharges in sleep lead to a post-ictal exhaustion of neurons, as an equivalent of a postictal paresis after an partial motor seizure. In BCECTS this postictal cortical dysfunction is mild, and able to recover as soon as epileptiform activity diminishes spontaneously over time. In Landau-Kleffner syndrome, the effect of epileptiform activity is much more severe, leading to atrophy of parts of the temporal lobe that are involved in language-comprehension, ${ }^{7}$ and resulting in severe language disruption with only partial recovery of language taking many years. The capacity to reorganize cortical functions to other undamaged cortical areas is known as plasticity. Recovery of language functions in Landau-Kleffner syndrome is largely dependent on the plasticity of the right temporal lobe to take over and accommodate language function.

In chapter 4, we describe a study analyzing the relation between different EEG characteristics and a complicated course with learning or behavioural difficulties in children with BCECTS.

Two important EEG studies had been published the years before publication of our review in 2006 (Chapter 2). Massa et al. formulated six EEG criteria; I: intermittent slow-wave focus; II: multiple asynchronous spike-wave foci; III: long spike-wave clusters; IV: generalized $3 \mathrm{~Hz}$ (absence-like) spike-wave discharges; V: atonia, myoclonia, or brief alteration of consciousness related to electroencephalographic discharges; and VI: abundance of interictal abnormalities during wakefulness and sleep. ${ }^{8}$ Different combinations of at least three of six EEG patterns for a period of at least six months were seen in all children with complicated BCECTS (with learning and/or behavioural problems) and only in one child with uncomplicated BCECTS (without those learning and/or behavioural problems).

The other study by Berroya et al. found that in children with BCECTS, registration of the first hour of sleep is sufficient to calculate spike frequency; registration of a whole night recording had no additional value. ${ }^{?}$ 
In order to try to combine the findings of both studies, we performed a an EEG study in 30 children. EEG's were re-examined and scored according to the "Massa" criteria. One hour of EEG recording during wake, the first hour of sleep and whole night sleep recording (minus the first hour) was scored for the presence of the separate "Massa criteria". Because the presence of nondipole spikes has been related to cognitive problems, we also scored for the presence of nondipole spikes. Besides, spike frequency was determined using an automatic spike detection system. These data were reviewed visually for artefacts.

The main finding of this EEG study is that the presence of I: an intermittent slowwave focus during wakefulness, II: a high number of spikes in the first hour of sleep (and during whole night sleep), and III: multiple asynchronous bilateral spike-wave foci in the first hour of sleep, correlates significantly with a complicated course with educational or behavioural impairment.

Secondly, that it suffices to analyse an EEG during wakefulness and a sleep EEG for only the first hour of sleep instead of a whole night recording to demonstrate those EEG criteria.

After publication of the EEG study, several recent studies have tried to relate cognitive difficulties and EEG characteristics in children with BCECTS as well. Piccinelli et al. studied 20 children with BCECTS and 21 controls. All children presented with normal IQ, memory, and visuospatial ability. Specific problems in reading, writing and arithmetic were found were found in 9/20 children with BCECTS vs. $2 / 21$ controls $(\mathrm{p}=$ 0.01). Sleep recordings after partial sleep deprivation were recorded and during wakefulness. Interictal epileptiform discharges in sleep were scored in three categories: I: less than $50 \%$ of time; II: $50-85 \%$; and III: more than $85 \%$ of time. Children with BCECTS and specific learning difficulties showed significantly more long-lasting $(>1$ year) EEG abnormalities in sleep ( $>50 \%$ of time) compared to children without learning difficulties. EEG recordings during wakefulness did not show any significant difference. Although scoring of electroencephalographic epileptiform activity was different in this study and in chapter 4, the results are similar; cognitive difficulties in children with BCECTS correlate with a high frequency of interictal epileptiform activity in sleep but do not correlate with the spike rate during wakefulness.

A second study did not find a relation between spike frequency during NREM sleep and test performance. ${ }^{10}$ But this is possibly due to the fact that children with atypical EEG's were excluded from this study creating a structural bias towards children without educational difficulties.

Riva et al. studied 24 children with BCECTS and 16 controls. Children with BCECTS had mild language defects compared to controls. ${ }^{11}$ The EEG recordings were obtained within 2 months of the neuropsychological examination. Spike frequency was determined during wake and non-REM sleep according to a 4-point classification: absent; $<10$ spikes $/ \mathrm{min} ;>10$ spikes $/ \mathrm{min}$ and $10-50 \%$ of time; $>50 \%$ of time. A significant correlation between spike rate during wakefulness and Full-scale IQ and verbal IQ was found. In contrast to the article by Piccinelli et al. ${ }^{12}$ and the results of 
chapter 4, no correlation between spike frequency in sleep and any neuropsychological test item was noted. ${ }^{11}$

Metz-Lutz \& Filippini compared 28 children with typical EEG findings and 16 children with atypical finding like a slow wave focus, asynchronous foci or generalized 3-Hz discharges. The atypical group had a significantly lower Full-scale IQ and Verbal IQ at seizure onset, during the active period and when recovered. Performance IQ was lower at seizure onset and at active phase. ${ }^{13}$ The results of this study are similar to the results of chapter 4; the occurrence of atypical EEG characteristic correlates with the presence of cognitive difficulties.

In chapter 5, we describe a study analyzing the effect of interictal epileptiform activity and short non-convulsive seizures on cognition in children with epilepsy.

In many childhood epilepsy syndromes severe cognitive deterioration can occur. The cognitive profiles in children with epilepsy are as diverse as the epileptic syndromes themselves. The cognitive sequelae of epilepsy syndromes like West syndrome and Lennox syndrome have been extensively studied (for recent review ${ }^{14}$ ). In other epilepsy syndromes there seems to be a milder, although global influence on cognition. For example, in several studies reported, the mean Full-scale IQ of children with benign childhood absence epilepsy is lower compared to controls. This global lower cognitive function does persist; even when children are seizure free,${ }^{15}$ indicating that there are more mechanisms responsible than seizures only. In children with epilepsy, adjustment of medication is often based only on the occurrence of seizures. If seizures recur after medication is initiated, the dosage of antiepileptic medication is increased, or an additional antiepileptic drug is added. Subtle seizures, seizures without overt clinical signs, can easily be missed. Performing simultaneous EEG-video monitoring is the indicated technique to detect these subtle seizures. The main clinical question in those children with epilepsy and infrequent overt clinical seizures was whether epileptiform activity and/or subtle seizures influenced cognitive performance or not.

In our study, we analyzed the effect of subtle seizures on cognition. In this crosssectional, descriptive study a combination of EEG and neuropsychological testing was performed in a large group of children. Children with seizures during testing were distinguished from those without. The results of children with subtle seizures during a 2-hour testing session (group 3) were compared with all children with epilepsy without such seizures during the 2-hour cognitive testing session (Group 2) and were compared with controls without epilepsy (Group 1).

We found that children with subtle seizures performed less than children with epilepsy without seizures during registration (group 2). Group 2 was divided in to group: children with $>1 \%$ epileptiform activity vs. $<1 \%$ epileptiform activity. The children with $>1 \%$ epileptiform activity showed lower results compared to the low frequency group on the Full-scale IQ and three other items.

Although the study designs and conclusions of chapter 4 (analyzing nighttime activity) and chapter 5 (analyzing daytime activity) seem to be in contrast with each other, they 
are not. Epileptiform activity disrupts cortical functions. The term "transient cognitive impairment" (TCI) is used for episodes with interictal epileptiform discharges associated with increased reaction time or increased number of missed test-items. This phenomenon can be demonstrated during a few seconds after a discharge. But TCI solely does not influence the child's everyday functioning; Fonseca et al. recently found no correlation between the presence of TCI and impaired school performance in children with benign epilepsy with centrotemporal spikes. ${ }^{16}$ In children with more frequent epileptiform activity or subtle seizures, "postictal" exhaustion of certain cortical areas is more long-lasting, leading to cognitive difficulties. This exhaustion develops both in case of daytime epileptiform activity and daytime subtle seizures and in case of frequent epileptiform activity during sleep. Permanent functional "postictal" cortical damage with only partial recovery develops in Landau-Kleffner syndrome and CSWS.

In chapter 6, we reviewed studies analysing the cognitive effects of intrauterine exposure to antiepileptic medication and focussed especially on structural study bias.

Many antiepileptic drugs do give rise to congenital birth defects. Recently, Meador et al. conducted a meta-analysis of the published registries and cohorts. The overall incidence of congenital malformations in children born from mothers with epilepsy is threefold the risk of healthy women. The risk is significantly higher for children exposed to valproic acid monotherapy, or to polytherapy including phenobarbital, phenytoin or valproic acid. ${ }^{17}$ Some malformations are drug-specific: for example in mothers using valproic acid during pregnancy, the frequency of children born with a spina bifida is about $1-2 \%$.

In the last decade a lot of studies and reviews have been published analyzing the effect of exposure to antiepileptic drugs during pregnancy on the cognition of the child. In chapter 6 these different articles are summarized. We concluded that all studies are marked by major structural bias. Selection bias is a major problem in most studies and most problematic in retrospective studies that selected children from organizations focussed on teratogenic effects of antiepileptic medication. The second main problem is the lack of information on maternal IQ. Mothers using anti-epileptic drugs often show a lower Full-scale IQ than the general population. Because of the fact that children's intelligence is partly dependent of the parents' intelligence, this mechanism moves the average Full-scale IQ of the child downwards.

Only one article has been published on the subject of cognitive development of infants exposed to antiepileptic drugs during pregnancy after publication of chapter 5 . Thomas et al. published a prospective study evaluating mental and developmental quotients of 395 infants of mothers with epilepsy. ${ }^{18}$ The daily dosage of antiepileptic medication was recorded every month. Women were monitored for folic acid supplementation, exposure to other teratogens, substance abuse, and seizure frequency as well. Maternal education was significantly correlated with motor development. Infants not exposed to medication $(n=32)$ had a significantly higher mental and motor developmental quotient than children exposed to medication $(n=363)$. Children exposed to polytherapy had significantly lower quotients than children exposed to monotherapy. 
Children exposed to valproic acid performed significantly worse on motor development than children exposed to carbamazepine (86.1 vs. 95; $\mathrm{p}=0.031$ ).

This study meets the guidelines for a study on behavioural teratogenic effects given in chapter 6 , except one. The main limitation of this study is that the influence of maternal intelligence on developmental scores was not evaluated. This possibly leads to structural bias as mothers using valproic acid showed a significant lower IQ compared to women using carbamazepine and compared to women who did not use any medication in a Finnish study reported by Eriksson et al. ${ }^{19}$ On the contrary, this study by Thomas et al. corrected for maternal education, making it the best structured study published till now.

Chapter 7 describes a pilot study investigating the effect of valproic acid-induced hyperammonemia on cognition in children with epilepsy.

Children who use valproic acid often show normal ammonia concentrations before breakfast. A rise in ammonia is seen in normal children after protein of carbohydrate intake, but this rise is more marked in children (and adults) using valproic acid. In symptomatic hyperammonemia, this lead to vomiting, disturbances of consciousness and even coma.

However, if this frequently occurring mild elevation of ammonia has any clinical consequences is not known. We have tested whether a post-prandial rise of ammonia was associated with problems in reaction time, attention or memory in children. In our pilot study ammonia concentrations up to $110 \mathrm{micromol} / 1 \mathrm{did}$ not influence reaction time, attention, or memory function.

In 2007, a review was published in Epilepsy and Behavior stating that the measurement of ammonia blood levels in patients taking valproic acid was looking for nonexisting problems. ${ }^{20}$ Many opinions given in this review were countered in a letter to the editor. ${ }^{21}$ The most problematic statement; the fact that hyperammonemic encephalopathy occurs only acutely after initiation of valproic acid, was also contradicted by a recent article; describing symptomatic hyperammonemia in a 76-year-old man after valproic acid treatment for 11 years. ${ }^{22}$

The implication for daily clinical practice is that one has to decide whether hyperammonia is relevant on basis of the assumed symptoms, not on basis of ammonia values. Ammonia levels up to $110 \mathrm{micromol} / \mathrm{l}$ do not necessary lead to subclinical signs, even when reaction time and concentration are measured (Chapter 7). On the contrary, symptoms of hyperammonemic encephalopathy (with elevated ammonia breakdown metabolites in the cerebrospinal fluid indicating an similar pathophysiological mechanism) can be found in patients with normal ammonia concentrations. ${ }^{23}$

\section{FUTURE RESEARCH}

Future research will be directed on the clinical issue of the relation between EEG characteristics and learning and behavioral problems in children with benign childhood 
epilepsy with centrotemporal spikes and the efficacy of antiepileptic treatment in improving those problems. As was summarized in chapter 2, all studies that have tried to answer both questions have structural bias in their study design. Also the studies published by Wirrell et al. (2008) and Kossoff et al. (2007) have structural difficulties.

The conclusion of chapter 2, chapter 4 and the few articles summarized in this discussion all point in the same direction: cognitive problems in children with BCECTS are related to a high spike frequency during sleep and the occurrence of atypical EEG phenomena. Whether this is a causal relation or not is unclear. Some authors hypothesize a problem in cerebral maturation that is responsible for both learning problems and epileptic seizures. In a cerebral maturation theory, epilepsy and cognitive disturbances will disappear simultaneously when the child grows older. If antiepileptic medication is able to suppress epileptiform activity and cognition improves as well during the same period, a causal relation is plausible.

A new study should be prospective and only involving children with benign childhood epilepsy with centrotemporal spikes.

One issue is mainly of scientific interest; is epileptiform activity really the cause of educational impairment or do both only occur simultaneously as part of a cerebral maturation problem.

But the main clinical question will be whether treatment with benzodiazepines (diazepam, clobazam or clonazepam) improves cognition in children with BCECTS and an educational impairment?

The inclusion criteria used in this study will be crucial. When children with uncomplicated BCECTS without deficits on neuropsychological tests are included, one should not expect a rise in test results after initiation of antiepileptic treatment. In a group of children without cognitive or behavioral problems one can only demonstrate the presence or absence of cognitive deterioration due to the antiepileptic medication. For this reason, a study on the treatment of cognitive deficits with antiepileptic drugs should include a large percentage of children with supposed cognitive problems.

Secondary questions:

- Do atypical seizure characteristics predict the occurrence of educational impairment.

- Do atypical EEG characteristics after the first seizure predict the occurrence of educational impairment.

- Do atypical EEG characteristics at the time of cognitive deterioration correlate with the occurrence of educational impairment.

- Is treatment with clobazam effective in suppressing epileptiform discharges both during wakefulness and in sleep.

- Epileptiform discharges could recur in a certain amount of children after treatment with benzodiazepines has been stopped. Is there a recurrence of cognitive problems in this subgroup of children or not? 
Only a prospective study including children with BCECTS who have not started medication yet, is able to answer those questions properly.

In parallel studies, the same questions can possibly be studied in children with ADHD and centrotemporal spikes, dyslexia and centrotemporal spikes, and developmental dysphasia and centrotemporal spikes. 


\section{REFERENCES}

1 Commission on Classification and Terminology of the International League Against Epilepsy. Proposal for revised classification of epilepsies and epileptic syndromes. Epilepsia 1989; 30: 389-99.

2 Wirrell E, Sherman EM, Vanmastrigt R, Hamiwka L. Deterioration in cognitive function in children with benign epilepsy of childhood with central temporal spikes treated with sulthiame. J Child Neurol 2008; 23: 14-21.

3 Kossoff EH, Los JG, Boatman DF. A pilot study transitioning children onto levetiracetam monotherapy to improve language dysfunction associated with benign rolandic epilepsy. Epilepsy Behav 2007; 11: 514-7.

4 Bulgheroni S, Franceschetti S, Vago C, Usilla A, Pantaleoni C, D’Arrigo S, Riva D. Verbal dichotic listening performance and its relationship with EEG features in benign childhood epilepsy with centrotemporal spikes. Epilepsy Res 2008; 79: 31-8.

5 Wioland N, Rudolf G, Metz-Lutz MN. Electrophysiological evidence of persisting unilateral auditory cortex dysfunction in the late outcome of Landau and Kleffner syndrome. Clin Neurophysiol 2001; 12: 319-23.

6 Castillo EM, Butler IJ, Baumgarner JE, Passaro A, Pananicolaou AC. When epilepsy interferes with word comprehension: findings in Landau-Kleffner syndrome. J Child Neurol 2008; 23: 97-101.

7 Takeoka M, Riviello JJ, Duffy FH, Kim F, Kennedy DN, Makris N, et al. Bilateral volume reduction of the superior temporal areas in Landau-Kleffner syndrome. Neurology 2004; 63: 1289-92.

8 Massa R, de Saint-Martin A, Carcangiu R et al. EEG criteria predictive of complicated evolution in idiopathic rolandic epilepsy. Neurology 2001; 57: 1071-9.

9 Berroya AM, Bleasel AF, Stevermuer TL, Lawson J, Bye AM. Spike morphology, location, and frequency in benign epilepsy with centrotemporal spikes. J Child Neurol 2005; 20: 188-194.

10 Volkl-Kernstock S, Willinger U, Feucht M. Spatial peception and spatial memory in children with benign chilhood epilepsy with centro-temporal spikes (BCECTS). Epilepsy Res 2006; 72: 39-48.

11 Riva D, Vago C, Franceschetti S, Pantaleoni C, D'Arrigo S, Granata T, Bulgheroni S. Intellectual and language findings and their relationship to EEG characteristics in benign childhood epilepsy with centrotemporal spikes. Epilepsy Behav 2007; 10: 278-85.

12 Piccinelli P, Borgatti R, Aldini A, et al. Academic performance in children with rolandic epilepsy. Dev Med Child Neurol 2008; 50: 353-6.

13 Metz-Lutz MN, Filippini M. (2006) Neuropsychological findings in rolandic epilepsy and Landau-Kleffner syndrome. Epilepsia. 47(Suppl 2):71-75.

14 MacAllister WS, Schaffer SG. Neuropsychological deficits in childhood epilepsy syndromes. Neuropsychol Rev 2007; 17: 427-44.

15 Henkin Y, Sadeh M, Kivity S, Shabtai E, Kishon-Rabin L, Gadoth N. Cognitive function in idiopathic generalized epilepsy of childhood. Dev Med Child Neurol 2005; 47:126-32.

16 Fonseca LC, Tedrus GM, Pacheco EM. Epileptiform EEG discharges in benign childhood epilepsy with centrotemporal spikes: reactivity and transitory cognitive impairment. Epilepsy Behav 2007; 11: 65-70.

17 Meador K, Reynolds MW, Crean S, Fahrbach K, Probst C. Pregnancy outcomes in women with epilepsy: A systematic review and meta-analysis of published pregnancy registries and cohorts. Epilepsy Res 2008: E-pub ahead of print.

18 Thomas SV, Ajaykumar B, Sindhu K, Nair MK, George B, Sarma PS. Motor and mental development of infants exposed to antiepileptic drugs in utero. Epilepsy Behav 2008; 13: 229-36.

19 Eriksson K, Viinikainen K, Monkkonen A, Aikia M, Nieminen P, Heinonen S, Kalviainen R. Children exposed to valproate in utero--population based evaluation of risks and confounding factors for long-term neurocognitive development. Epilepsy Res 2005; 65: 189-200.

20 Chicharro AV, de Marinis AJ, Kanner AM. The measurement of ammonia blood levels in patients taking valproic acid: looking for problems where they do not exist? Epilepsy Behav 2007; 11: 361-6.

21 Nicolai J, Carr RB. The measurement of ammonia blood levels in patients taking valproic acid: looking for problems where they do not exist? Epilepsy Behav 2008 ; 12: 494-6.

22 Stewart JT. A case of hyperammonemic encephalopathy after 11 years of valproate. J Clin Psychopharmacol 2008; 28: 361-2.

23 Vossler DG, Wilensky AJ, Cawthon DF, et al. Serum and CSF glutamine levels in valproate-related hyperammonic encephalopathy. Epilepsia 2002;43:154-9. 


\section{Chapter 9}

Summary

Samenvatting

Dankwoord

Curriculum Vitae

Publicaties 


\section{Summary}

This thesis is made up from an introduction (Chapter 1), six main chapters (Chapter 27 ), a conclusion (Chapter 8), and this summary. The six chapters have one central issue in common: probable causal factors related to cognitive disturbances in children with epilepsy.

All these factors can be characterized as 'non-convulsive' an inaccurate label to designate all factors than can affect cognitive development in addition to seizureactivity. Seizures and the underlying syndrome have of course a major impact on behaviour and on cognitive development. This has been studied in detail. Possibly as a consequence other factors have been underestimated. This thesis has concentrated on such additional factors and aims at analysing the impact of such 'non-convulsive' factors on cognitive development. The chapters that describe BCECTS and LandauLeffner/CSWS analyse the impact of nocturnal epileptiform EEG-discharges that can be particularly studied in detail in these syndromes. An additional study is the effect of epileptiform EEG-discharges in daytime, during cognitive function using simultaneous EEG-recording and cognitive testing. A final factor is the impact of side effects of medication. We have concentrated on two side effects that have been incompletely studied: a) the cognitive teratogenicity of antiepileptic medication and b). the effects of VPA-induced hyperammonemia on cognitive function.

Benign childhood epilepsy with centrotemporal spikes (BCECTS) is the most common partial epilepsy syndrome in childhood. Seizures are characterized by brief, simple, partial, hemifacial motor seizures, frequently with associated somatosensory symptoms. These seizures have a tendency to evolve into generalized tonic-clonic seizures. Both partial and secondary generalized seizures often occur in sleep. Onset occurs between the ages of 3 and 13 years and recovery is before the age of 15-16 years. Chapter Two is a review that addresses the relation between epileptiform activity that is found during electroencephalographic (EEG) recordings during sleep in children with BCECTS and cognitive or behavioural problems in these children. In children with BCECTS, the intelligence measured by the Full-scale Intelligence Quotient (FSIQ) is often within the normal range. However, language delay and learning difficulties are often noted in children with BCECTS, with percentages ranging from $0-65 \%$ in different studies related to this issue. Behavioural problems have been less often studied, but emotional liability, ADHD, and "behavioural problems" or "abnormal behaviour" without further description are often reported. When children without overt cognitive or behavioural problems are tested, neuropsychological tests reveal deficits in visuomotor coordination, executive functions, sustained attention, and many language issues like spelling. When children were retested in some studies after several years, neuropsychological deficits had disappeared in most of them. 
In children with BCECTS, most seizures occur while a child is asleep, drowsy when going to sleep, or shortly after awakening. More than half of the children have nocturnal seizures only. In children with BCECTS, the amount of epileptiform activity often increases during sleep, and in $20-30 \%$ of children, epileptiform activity is only present during sleep and not present at all during wakefulness. This makes a sleep EEG mandatory if a regular EEG does not show epileptiform activity and BCECTS is suspected. Beside an increment in frequency, epileptiform activity can also spread to adjacent areas or become bilaterally synchronized during sleep. It is well known that sleep in not disturbed in children with BCECTS and the number of arousals from sleep is not increased.

Many research groups have tried to relate the presence of a high spike frequency and the occurrence of cognitive and behavioural problems. A high spike frequency during wakefulness ( $>5 /$ minute or $>10 /$ minute) is related to language delay, reading problems and lower FSIQ scores. In 2001, Dr Massa and colleagues published a study on six atypical EEG characteristics in children with BCECTS. The presence of each of those EEG features was related to the occurrence of a complicated evolution, i.e. children with educational and behavioural disturbances. Different combinations of at least three of six EEG patterns were observed in all children with a complicated evolution and only in one child with a normal, uncomplicated evolution.

The goal of treatment with antiepileptic drugs is the prevention of seizures. In many medication trials or studies, EEG patterns were scored as well. Epileptiform activity in children with BCECTS in often completely suppressed after introduction of diazepam, clonazepam, and to a lesser extends, sulthiame. There are no trials testing the effectiveness of clobazam. Carbamazepine and sodium valproate are ineffective in suppressing epileptiform discharges in children with BCECTS. In order to find out whether suppression of epileptiform activity is able to improve cognition in children with BCECTS, several studies have been published. No double-blind, placebocontrolled study has been published to date. One nonblinded, prospective study showed a significant increase in FSIQ of treatment with diazepam for 3-4 weeks and sodium valproate for a long term. However, this study suffers from a peculiar design which makes it difficult to interpret the findings.

Chapter Three is a review discussing the mechanisms that are responsible for the occurrence of the Landau-Kleffner syndrome and of the epilepsy syndrome called epilepsy with continuous spike-and-waves during slow-wave sleep (CSWS). Although the clinical manifestations and definitions of both syndromes are slightly different, both are considered expression of the same pathological entity. Both rare epileptic encephalopathy syndromes are age-dependent, and characterized by the association of seizures, abnormal EEG discharges activated by sleep, and severe neuropsychological deficits. The diagnosis epileptic encephalopathy is based on the assumption that epileptiform abnormalities contribute to progressive dysfunction of the cerebral cortex.

In CSWS, seizures are often the presenting symptom, neuropsychological disturbances are the presenting symptom in about $20 \%$, but seizures almost always do occur. 
In Landau-Kleffner syndrome seizures are only present in $70-80 \%$ of children. Commonly, seizures are easy to control in both syndromes.

The EEG reveals severe increment of epileptiform activity during sleep. In CSWS, continuous bilateral spike-waves are seen during more than $85 \%$ of time during sleep. Also in Landau-Kleffner syndrome there is an increase in focal or generalized epileptiform activity, however, the more than $85 \%$ of time criterion is found in less than half of children. In CSWS, cognitive functions on the whole deteriorate. Behavioural changes do occur and rarely, psychotic changes are seen. In Landau-Kleffner syndrome, there is progressive loss of receptive language (verbal auditory agnosia) and later expressive language. Also in Landau-Kleffner syndrome, behavioural changes are common.

There is evidence that carbamazepine, phenytoin and phenobarbital can precipitate CSWS in some children, but this mechanism is rare. In CSWS, structural abnormalities are seen with MR imaging in 33-50\% of children. The MRI is normal in children with Landau-Kleffner syndrome by definition. Although, volume reduction of the superior temporal areas is noted when using special volumetric techniques.

By using PET, cerebral glucose metabolism can be measured. Several studies have been done in Landau-Kleffner syndrome, but no consistent data are reported. In children with Landau-Kleffner syndrome children have high change missing auditory information when this information is applied several seconds after a registered spikewave.

Landau-Kleffner syndrome is possibly an auto-immune disorder. The cerebrospinal IgG index can be elevated, indicating intrathecal synthesis of IgG antibodies, autoantibodies directed to brain tissue are found, and treatment with steroids or immunoglobulins can be effective.

Recovery from CSWS or Landau-Kleffner syndrome without sequels is possible spontaneously or after treatment with antiepileptic drugs, immunoglobulins, steroids or subpial transection.

The study described in Chapter Four tries to answer some questions that were originated in Chapter Two. In 2005, Berroya et al. published a paper describing the finding that in children with benign childhood epilepsy with centrotemporal spikes (BCECTS) a routine EEG including sleep onset provides information similar to a whole night recording, regarding the determination of nocturnal spike frequency. However, due to the study design, mainly EEG recordings from children with uncomplicated BCECTS were analysed and the atypical "Massa" EEG criteria were not scored. For this reason we performed a study that consisted of two parts. Part 1 consisted of a study that related the presence of cognitive or behavioural disturbances and the presence of the atypical EEG criteria, spike frequency, and the presence of a non-dipole spike. EEG recordings were reanalyzed and the different items were scored separately for wakefulness, first hour of sleep and whole night sleep.

School, medical and psychological data were present from 28 children. 22 fulfilled the criteria for benign evolution, 6 had a complicated cognitive or behavioural evolu- 
tion. Univariate linear regression analysis showed significant correlations between a complicated evolution and I: the presence of an intermittent slow-wave focus during wakefulness; II: a high number of spikes in the first our of sleep; III: the presence of multiple asynchronous bilateral spike-wave foci in the first hour of sleep; and IV: a high number of spikes during whole night sleep. No significant difference in spike frequency during wakefulness between both groups was found.

In part II we reanalysed EEG's from 30 children and scored whether the different EEG criteria were present in wakefulness, first hour of sleep or whole night sleep. On basis of these data we concluded that a regular EEG during wake and registration of the first hour of sleep is sufficient to look for those EEG criteria.

In Chapter Five we studied the relation between EEG characteristics and the results of neuropsychological tests. In this prospective, descriptive study a combination of EEG and neuropsychological testing was performed simultaneously in a large group of children with epilepsy. A cohort of control children, initially send to our centre with the suspicion of epilepsy, was tested as well along the same procedure. Children with subtle seizures during testing were distinguished from those without. The results of children with subtle seizures during a 2-hour testing session were compared with all children with epilepsy without such seizures during the 2-hour cognitive testing session and were compared with controls without epilepsy.

We found that children with epilepsy and seizures recorded during a 2-hour test performed worse compared to children with epilepsy without seizures recorded on several neuropsychological tests. This was the case for the Wechsler full-scale IQ, attention tests, speed of central information processing, memory function and educational achievement. Children with epilepsy but without seizures during testing performed less on memory function and educational achievement than controls.

In children without seizures during cognitive testing, the occurrence of frequent epileptiform discharges did have an additional impact on cognitive function in our study. We initially divided spike frequency into two categories; $0 \%-<1 \%$ vs. $>1 \%$. Significant differences were noted on the Full-scale IQ, visual-spatial function, and memory function.

We conclude that the type of effect of frequent epileptiform activity (more than $1 \%$ of time) is very similar to the effect of short non-convulsive seizures on cognitive function in children with epilepsy, although the impact is less pronounced in number of areas involved, and magnitude.

Chapter Six is a review discussing the structural bias in studies focused on developmental delay in children exposed to antiepileptic drugs during pregnancy. It is well known that intrauterine exposure to the older antiepileptic drugs is a hazard for the development of major congenital malformations. For example, the risks for children exposed to valproate are significantly increased compared to controls not exposed to antiepileptic drugs, but also increased compared to children exposed to carbamazepine. More recently, developmental delay, without the presence of major malformations or 
dysmorfic facial appearances, has been described in several studies. We searched all articles on this subject published between 1966 and February 2008.

The possible bias was classified into two groups: confounding factors and methodological factors involving the design of the study.

We suggested four possible confounding factors. I: Epilepsy of the mother leads to an increment of congenital malformations as well. Mothers with difficult to treat epilepsy use antiepileptic drugs, mothers with relatively harmless seizures stop their medication during pregnancy. This mechanism leads to incorrectly relating medication and congenital malformations and /or cognitive problems. II: Seizures during pregnancy increase the risk of congenital malformations. III: In subgroups of mothers with epilepsy, the intelligence and level of education is lower compared to controls. This possibly influences the cognitive outcome of their children. The same is true for socioeconomic status. IV: Doses of medication is a possible etiological factor as well.

The four methodological factors: I: Selection bias because of the fact that patient were selected from tertiary centres or from parents' support groups. II: problematic study-design. III: The use of unclear outcome measures or testing in a wide range of age. IV: insufficient power due to small sample sizes.

56 studies were identified and interpreted. All studies had possible problematic confounding factors and methodological factors that complicate any attempt to correlate intra-uterine exposure to antiepileptic drugs and developmental delay. The possibility of neurodevelopmental delay, behavioural disorders, or learning disabilities as an outcome of in utero exposure to AEDs and especially VPA, is plausible. The literature however does not provide evidence for a valid risk estimate. Moreover the evidence found for a specific increased risk for VPA could be structurally biased. We propose a number of guidelines for studies on behavioural teratogenicity.

Chapter Seven is a study relating hyperammonemia and possible cognitive disturbances in children with epilepsy.

Valproate is an antiepileptic drug used in many children (and adults) with epilepsy. One of the side effects is a rise in serum ammonia: hyperammonemia. The reported incidence of hyperammonemia in children treated with valproate ranges from 16-52\% and is even higher in children treated with valproate in combination with other antiepileptic drugs. Hyperammonemia is often without clinical symptoms but sometimes symptoms like lethargy or even coma occur. Clinical symptoms have also been reported with relatively low or even normal serum ammonia concentrations. This uncertainty about the clinical relevance results in quite different advises how to handle in case of valproate-induced hyperammonemia.

Twelve children in the range of 8 years till 16 year were included in our pilot-study. Dietary intake and breakdown of protein leads to a rise of serum ammonia within a few hours. For this reason, all children were tested twice the same day: before and two hours after lunch. The other conditions that can influence cognitive performance like the intelligence of the child, epilepsy type, drug concentrations and whether the child was seizure free or not, were considered stable between both episodes. We used sev- 
eral tests from the FePsy, with the emphasis on psychomotor speed, reaction time and memory. The first episode started at 12.00 AM, lasted 45-55 minute. At 15.00 PM the children returned for a second episode. During the second episode, a different version of the same test with different questions was used. Capillary blood was collected from the earlobe. Because of this study design, we were able to compare cognitive functions at normal ammonia concentrations and at relatively higher concentrations, in the same child.

Because of the fact that one child had severe difficulties to understand the neuropsychological tests, her results were not included. In the eleven remaining children, the mean ammonia concentration rose $23 \%$ from $66 \mu \mathrm{mol} / 1$ (range $36-92 \mu \mathrm{mol} / \mathrm{l}$ ) to 81 $\mu \mathrm{mol} / 1$ (range $44-117 \mu \mathrm{mol} / \mathrm{l}$ ) (statistically not significant). The pre-lunch and postlunch results correlated for all tests. No significant differences were found except for the Simple Reaction Time of the dominant hand. The mean results for this test were $12 \%$ slower on retesting ( $460 \mathrm{~ms}$ vs. $410 \mathrm{~ms}$ ). But no correlation between ammonia concentrations and the reaction time was found. The mean reaction time for the nondominant was also slower, although not significantly (455 ms vs $434 \mathrm{~ms} ; \mathrm{p}=0.06$ ). This pilot-study has several methodological shortcomings. We concluded that the results of our study possibly indicate that in case of earlobe ammonia levels up to $117 \mu \mathrm{mol} / \mathrm{l}$, no signs of mental slowing are noted.

Chapter Eight is the discussion of the chapters 2-7. Some suggestions for future research are given. 


\section{Samenvatting}

Dit proefschrift bestaat uit een inleiding (hoofdstuk 1), zes hoofdstukken (hoofdstuk 2-7), een bespreking (hoofdstuk 8) en deze samenvatting. De zes hoofdstukken hebben één centraal thema gemeen: het beschrijven van mogelijk oorzaken van cognitieve ontregeling bij kinderen met epilepsie.

Het betreffen die factoren die van invloed zijn naast de aanvalsactiviteit. Aanvallen en het onderliggende syndroom hebben natuurlijk een zeer belangrijke invloed op het functioneren van een kind en dus ook op de cognitieve ontwikkeling en daaraan is in het verleden veel aandacht besteed. Mede daardoor zijn andere factoren mogelijk onderbelicht gebleven. Dit proefschrift probeert deze 'niet aanvalsgerelateerde factoren' systematisch te analyseren, met name waar het hun invloed op de cognitieve ontwikkeling betreft. De hoofdstukken die zich richten op BCECTS en Landau-Leffner/CSWS belichten met name de invloed van epileptiforme activiteit hetgeen zich juist bij deze syndromen goed laat bestuderen. Het accent ligt hier op de invloed van nachtelijke ontladingen. Een andere invalshoek is de studie naar correlaten tussen epileptiforme EEG ontladingen overdag en simultaan cognitief onderzoek. Een andere factor betreft de bijwerkingen van de antiepileptica, waarbij we gekozen hebben voor twee factoren die onvoldoende geanalyseerd waren: a). de cognitieve teratogeniciteit van antiepileptica, dus de invloed van blootstelling aan antiepileptica tijdens de zwangerschap op de cognitieve ontwikkelingen en b). de verhoogde waarden van het ammoniak bij gebruik van natrium valproaat en de effecten hiervan op cognitieve functies.

Benigne epilepsie met centrotemporale pieken (BCECTS) of benigne Rolandische epilepsie is de meest voorkomende partiële vorm van epilepsie op de kinderleeftijd. De aanvallen worden gekenmerkt door korte, partiële aanvallen waarbij het gelaat halfzijdig meedoet met een behouden bewustzijn. Vaak zijn er ook sensibele sensaties als onderdeel van de aanval. Deze aanvallen kunnen zich uitbreiden tot tonisch-clonische aanvallen. Beide soorten aanvallen treden met name gedurende de slaap op. De aanvallen debuteren tussen het $3^{\mathrm{e}}$ en $13^{\mathrm{e}}$ levensjaar en kinderen zijn er overheen gegroeid voor de leeftijd van 15 a 16 jaar.

Hoofdstuk 2 is een overzicht van de gepubliceerde studies waarin het verband tussen epileptische activiteit in het electroencefalogram (EEG) gedurende slaap bij kinderen met BCECTS enerzijds en cognitieve of gedragsproblemen anderzijds bij deze kinderen beschreven wordt. De intelligentie van kinderen met BCECTS is veelal normaal. Maar spraakachterstand en leerproblemen komen veelvuldig voor bij kinderen met BCECTS, verschillende studies komen tot percentages met een spreiding van $0 \%$ en $65 \%$. Gedragsproblemen zijn minder vaak bestudeerd, maar emotionele labiliteit, ADHD of "gedragsproblemen" of "abnormaal gedrag" zonder verdere beschrijving, wordt vaak gerapporteerd. Als kinderen zonder duidelijke cognitieve of gedrags- 
problemen neuropsychologisch worden onderzocht, worden vaak problemen gevonden bij de visueel- motore coördinatie, uitvoerende functies, volhouden van aandacht, en vele taalgerelateerde taken als spelling. Als deze kinderen na enkele jaren opnieuw worden getest, zijn de uitslagen van deze neuropsychologische testen veelal genormaliseerd.

Bij kinderen met BCECTS treden de aanvallen vaak op als een kind slaapt, doezelig is voor het gaat slapen of na het ontwaken. Meer dan de helft van de kinderen heeft alleen aanvallen in slaap. De frequentie van epileptische activiteit neemt vaak toe tijdens slaap en in zo'n 20-30\% van de kinderen met BCECTS is epileptische activiteit alleen maar aanwezig in slaap. Dit maakt een slaap EEG noodzakelijk indien het normale EEG geen epileptische activiteit laat zijn en aan BCECTS gedacht wordt. Behalve een toename in frequentie, kan de epileptische activiteit ook uitbreiden naar omringende gebieden van de hersenen of beiderzijds synchroon ontladen. De slaapopbouw zelf is bij kinderen met BCECTS niet veranderd en ook het aantal perioden van ontwaken is niet verhoogd.

Vele onderzoeksgroepen hebben getracht om de aanwezigheid van een hoge frequentie van epileptische activiteit en het bestaan van cognitieve of gedragsproblemen te correleren. Een hoge piekfrequentie in waak (meer dan 5 per minuut of meer dan 10 per minuut afhankelijk van de gebruikte definitie) is gerelateerd aan een spraakachterstand, leesproblemen en lagere intelligentie scores. In 2001 publiceerde Dr. Massa en haar medeauteurs een studie waarin zij 6 atypische EEG fenomenen beschreven bij kinderen met BCECTS. De aanwezigheid van elk van deze EEG fenomenen was gerelateerd aan het optreden van een gecompliceerd beloop, in deze studie gedefinieerd als het optreden van leer en/of gedragsproblemen. Bij alle kinderen met een gecompliceerd beloop werden 3 of meer van de 6 EEG criteria aangetoond, terwijl dit slechts bij één kind met een normaal, ongecompliceerd beloop werd gezien.

Het doel van behandeling van kinderen met epilepsie met antiepileptica is het voorkomen van aanvallen. In meerdere medicatie studies werd het EEG ook beoordeeld als uitkomstmaat. Epileptische activiteit wordt vaak volledig onderdrukt na starten van diazepam, clonazepam en in mindere mate ook bij sulthiame bij kinderen met BCECTS. Er zijn geen studies die de effeciviteit van clobazam bij deze kinderen heeft onderzocht. Carbamazepine en natrium-valproaat zijn niet effectief in het onderdrukken van epileptische activiteit. Er zijn meerdere studies verricht om na te gaan of het onderdrukken van epileptische activiteit zinvol is om de cognitieve functies van kinderen met BCECTS te verbeteren. Maar er is geen dubbel-blinde, placebo-gecontroleerde studie gepubliceerd tot op dit moment. Eén niet-geblindeerde, prospectieve studie toonde een statistisch significante verbetering van de intelligentie quotiënt na behandeling met diazepam gedurende 3 a 4 weken en natriumvalproaat gedurende een lange periode. Maar, deze studie heeft een eigenaardige opzet en is daardoor lastig te interpreteren.

Hoofdstuk 3 is een literatuuroverzicht waarbij de mechanismen besproken worden die verantwoordelijk zijn voor het optreden van het Landau-Kleffner syndroom en het 
epilepsiesyndroom met continue optreden van piekgolfcomplexen gedurende de diepe slaap (CSWS). Alhoewel de klinische manifestaties en de definities van beide syndromen licht verschillen, worden beiden beschouwd een uiting te zijn van hetzelfde spectrum. Beide epilepsiesyndromen zijn leeftijdsafhankelijk, en worden gekenmerkt door het optreden van epileptisch aanvallen, epileptische afwijkingen in het EEG die sterk toenemen tijdens slaap, en ernstige cognitieve problemen. De diagnose "epileptische encefalopathie" is gebaseerd op de veronderstelling dat voortdurende epileptische activiteit de progressieve verslechtering van de verschillende hersenfuncties veroorzaakt.

CSWS begint meestal met epileptische aanvallen, in slechts $20 \%$ van de kinderen is de cognitieve verslechtering het eerste verschijnsel, maar epileptische aanvallen komen ook in deze groep eigenlijk altijd voor. Bij het Landau-Kleffner syndroom komen epileptische aanvallen maar voor bij 70-80\% van de kinderen. In beide syndromen zijn de aanvallen veelal relatief makkelijk onder controle te krijgen met medicatie.

In het EEG wordt een ernstige toename van epileptische activiteit gezien gedurende slaap. Bij CSWS is continue aanwezige epileptische activiteit over beide hersenhelften gedurende slaap aanwezig in meer dan 85\% van de tijd. Ook in het LandauKleffner syndroom is er een toename in slaap van focale of gegeneraliseerde epileptische activiteit, maar hier wordt het $85 \%$ criterium door meer dan de helft van de kinderen niet bereikt. Bij CSWS verslechteren de cognitieve functies globaal. Gedragsveranderingen treden op en een psychose kan, weliswaar zeldzaam, worden gezien. Bij het Landau-Kleffner syndroom is er progressief verlies van het taalbegrip met name van de gesproken taal (auditieve verbale agnosie) en later verlies van de andere taalfuncties. Ook in het beloop van het Landau-Kleffner syndroom komen veel gedragsproblemen voor.

Er is bewijs dat het gebruik van carbamazepine, fenytoine en fenobarbital de aanleiding kan zijn voor het ontwikkelen van CSWS, maar dit mechanisme is zeldzaam. Beeldvorming middels MRI toont bij 33-50\% van de kinderen met CSWS structurele hersenafwijkingen of beschadigingen. In de definitie van het Landau-Kleffner syndroom staat als criterium vermeld dat er geen afwijkingen bij beeldvorming mogen worden gezien. Maar, met speciale technieken kan wel worden aangetoond dat er sprake is van volume verlies van de bovenste gebieden van de temporaalkwab.

Middels PET kan het glucose metabolisme van de hersenen worden gemeten. Meerdere studies zijn verricht bij kinderen met het Landau-Kleffner syndroom, maar de resultaten zijn inconsistent, zowel verminderd als toegenomen metabolisme wordt beschreven. Kinderen met het Landau-Kleffner syndroom hebben een grote kans om auditief aangeboden informatie te missen als deze informatie, in een onderzoeksopzet, enkele seconden na een piekgolf wordt aangeboden.

Landau-Kleffner syndroom is mogelijk een auto-immuun stoornis. De IgG index is soms verhoogd, een aanwijzing voor vorming van antilichamen binnen de bloedhersen-barriere. Auto-antilichamen tegen hersenweefsel worden gevonden, en behandeling met steroïden of immunoglobulines kan effectief zijn. Herstel van CSWS of het 
Landau-Kleffner syndroom zonder restverschijnselen is spontaan mogelijk en na behandeling met anti-epileptica, immunoglobulines, steroïden of na epilepsiechirurgie.

De studie beschreven in hoofdstuk 4 tracht enkele vragen die zijn gerezen in hoofdstuk 2 te beantwoorden. In 2005 publiceerde Berroya en medeauteurs een artikel waarin zij beschreven dat bij kinderen met BCECTS een routine EEG met registratie van het begin van de slaap dezelfde informatie oplevert met betrekking tot vastleggen van de piekfrequentie als een EEG registratie van de gehele nacht. Door de studieopzet werden echter met name EEG's van kinderen met een normaal ongecompliceerd beloop beoordeeld en werd niet op de atypische EEG criteria gescoord. Daarom hebben wij een studie opgezet die uit twee delen bestaat. Het eerste deel bestaat uit een studie waarin de aanwezigheid van cognitieve of gedragsproblemen gerelateerd wordt aan de aanwezigheid van de atypische EEG criteria volgens Massa, de piekfrequentie en het optreden van non-dipool epileptische activiteit. Hiervoor zijn EEG bestanden opnieuw bekeken en separaat gescoord voor waak, het eerste uur van de slaap en rest van de slaap. Gegevens over school, medisch en psychologische rapporten waren beschikbaar van 28 kinderen. 22 kinderen voldeden aan de criteria voor een normaal beloop, 6 hadden een gecompliceerd beloop. Univariaat lineaire regressie analyse toonde statistisch significante relaties tussen het optreden van een gecompliceerd beloop en I: de aanwezigheid van een intermitterend focus van trage hersenactiviteit in waak; II: een hoge piekfrequentie in het eerste uur van de slaap; III: de aanwezigheid van meerdere asynchroon optredende foci van epileptische activiteit in het eerste uur van de slaap; en IV: en een hoge piekfrequentie in de rest van de slaap. In waak werd geen verschil in piekfrequentie gevonden tussen de groepen met normaal beloop en gecompliceerd beloop. In het tweede deel zijn 30 EEG's herbeoordeeld. Gescoord werd op aanwezigheid van de verschillende EEG fenomenen in waak, eerste uur slaap en rest van de slaap. Op grond van de bevindingen hebben we geconcludeerd dat een regulier EEG in waak en het eerste uur slaap volstaat om de EEG criteria te kunnen scoren.

Hoofdstuk 5 beschrijft een studie waarin de relatie tussen EEG kenmerken en de resultaten van verschillende neuropsychologische testen beschreven wordt. In deze prospectieve, beschrijvende studie werd gelijktijdig EEG registratie en neuropsychologisch onderzoek verricht in een grote groep kinderen met epilepsie. En controlegroep bestaande uit kinderen die initieel verwezen waren met de verdenking epilepsie maar in tweede instantie deze diagnose verworpen was, ondergingen dezelfde procedure. Kinderen met subtiele aanvallen, dat wil zeggen een epileptisch aanval in het EEG en geen duidelijke verschijnselen bij gelijktijdige videoregistratie, werden onderscheiden van hen zonder deze subtiele aanvallen. De resultaten van de verschillende neuropsychologische testen werden gedurende een 2 uur durende registratie verricht werden verzameld. De resultaten van kinderen met subtiele aanvallen werden vergeleken met de kinderen zonder subtiele aanvallen en vergeleken met de controles.

We vonden dat kinderen met epilepsie en subtiele aanvallen tijdens registratie slechter scoorden op verschillende testen dan kinderen zonder subtiele aanvallen. Dit was 
het geval bij de Wechsler Intelligentie schaal voor totaal IQ, aandachtstesten, snelheid van informatie verwerking, geheugen functies en daarnaast voor de reeds bereikte schoolprestaties. Kinderen met epilepsie maar zonder subiele aanvallen deden het slechter dan controles bij geheugen functies en bereikte schoolprestaties.

Bij kinderen zonder subtiele aanvallen gedurende de registratie, was de frequentie van losse epileptiforme afwijkingen gerelateerd an de cognitie uitslagen. De piekfrequentie werd verdeeld in 2 groepen: kleiner van 1\% van de tijd en meer dan $1 \%$ van de tijd. Significante verschillen werden gevonden voor het totaal IQ, visueel- ruimtelijke oriëntatie en geheugen functies.

Op grond van deze resultaten hebben wij geconcludeerd dat het effect van frequent optredende epileptiforme activiteit ( $>1 \%$ van de tijd) op cognitieve functies lijkt op het effect van kortdurende subtiele aanvallen, maar minder sterk is en een kleiner aantal cognitieve functies betreft.

Hoofdstuk 6 is een literatuuroverzicht waarin het probleem van structurele bias beschreven wordt van studies over het probleem van ontwikkelingsachterstand bij kinderen die tijdens de zwangerschap blootgesteld zijn aan antiepileptica. Bias betekent hier dat door de opzet van een studie of selectie van patiënten de uitkomst van een studie niet meer representatief is voor de oorspronkelijke vraag en de uitkomst hierdoor als het ware een bepaalde kant opgestuurd wordt. Het is uitgebreid bekend dat blootstelling al langer in gebruik zijnde antiepileptica een risico is voor het ontwikkelen van ernstige aangeboren afwijkingen tijdens de zwangerschap. Bij voorbeeld, de kinderen die zijn blootgesteld aan natriumvalproaat hebben een statistisch verhoogde kans op aangeboren afwijkingen vergeleken met kinderen die niet aan medicatie zijn blootgesteld, maar ook vergeleken met kinderen blootgesteld aan carbamazepine. De recente jaren zijn er meerdere studie gepubliceerd over het voorkomen van achterstand in ontwikkeling zonder andere aangeboren afwijkingen of gelaatskenmerken. We hebben alle artikelen over dit onderwerp gepubliceerd tussen 1966 en begin 2008 nagezocht op dit onderwerp.

De mogelijke bias werd uitgesplitst in 2 groepen: factoren die tot vertroebeling leiden en methodologische problemen in de studie opzet.

We hebben 4 mogelijk vertroebelende factoren gedefinieerd. I: het feit dat de moeder bekend is met epilepsie geeft ook een verhoogd risico op aangeboren afwijkingen. Moeders met moeilijk te behandelen epilepsie gebruiken veelal meerdere medicamenten en moeders met relatief onschuldige aanvallen kunnen hun medicatie vaak stoppen tijdens de zwangerschap. Dit mechanisme kan ertoe leiden dat de relatie tussen antiepileptica en congenitale afwijkingen en of cognitieve problemen foutief wordt geinterpreteerd. II: Epileptische aanvallen gedurende de zwangerschap verhogen de kans op congenitale afwijkingen. III: In bepaalde subgroepen van moeders met epilepsie ligt de gemiddelde intelligentie lager dan gemiddeld. De gemiddelde cognitie van hun kinderen is daardoor mogelijk lager. Hetzelfde mechanisme speelt bij de sociaaleconomische status. IV: De doseringen van antiepileptica is een mogelijke oorzakelijke factor waarvoor gecorrigeerd moet worden. 
De 4 methodologische factoren zijn: I: selectiebias doordat patiënten benaderd werden vanuit een derdelijns centrum of vanuit een patiëntenorganisatie. II: problemen in e studieopzet. III: het gebruik van onduidelijke uitkomstmaten of een uitkomstmaat gebruiken in een zeer diverse leeftijdsgroep. IV: berekeningen over een onvoldoende grote groep kan ertoe leiden dat een bepaalde verbanden statistisch niet meer aangetoond kunnen worden.

56 artikelen werden gevonden en geïnterpreteerd. Al deze artikelen hebben potentieel problematische vertroebelende factoren of methodologische problemen die interpretatie van de relatie tussen blootstelling aan anti-epileptica tijdens de zwangerschap en ontwikkelingsachterstand bemoeilijkt. Het is zeer goed mogelijk dat blootstelling tijdens de zwangerschap aan anti-epileptica leidt tot ontwikkelingsachterstand, gedragsproblemen of leerproblemen op school. Maar een inschatting van de groote van deze kans is niet mogelijk. Daarnaast zou het kunnen zijn dat het specifiek verhoogde risico na blootstelling aan natriumvalproaat deels op bias berust. In het hoofdstuk stellen wij een aantal richtlijnen voor waaraan onderzoek naar deze vorm van ontwikkelingsachterstand zou moeten voldoen.

Hoofdstuk 7 beschrijft een studie waarbij de relatie tussen hyperammoniaemie en cognitive problemen onderzocht wordt bij kinderen met epilepsie. Natriumvalproaat is een anti-epilepticum dat door vele kinderen (en volwassenen) met epilepsie wordt gebruikt. Een van de bijwerkingen is een stijging van de ammoniak concentratie in het bloed: hyperammoniaemie. Deze bijwerking wordt bij kinderen in studies met een frequentie van $16-52 \%$ gerapporteerd en dit percentage is zelfs hoger als kinderen behandeld worden met natriumvalproaat in combinatie met andere medicijnen tegen epilepsie.

Hyperammoniaemie is veelal een bevinding zonder klinische verschijnselen, maar soms treden deze wel op bijvoorbeeld mentale traagheid of coma. Klinische verschijnselen zijn echter ook gerapporteerd bij relatief lage of zelfs normale ammoniak concentraties. Deze onduidelijkheid over de klinische relevantie van door natriumvalproaat veroorzaakte hyperammoniaemie heeft tot gevolg dat in de literatuur zeer diverse adviezen worden gegeven hoe hiermee om te gaan.

12 kinderen in de leeftijd van 8 tot 16 jaar werden in onze pilot-studie geïncludeerd. Bij deze kinderen werd capillair bloed uit de oorlel geprikt. Inname van eiwithoudende voeding en de afbraak hiervan in het lichaam leidt normaal binnen enkele uren tot een stijging van het ammoniak. Om deze reden hebben we ervoor gekozen kinderen tweemaal te testen: voor de lunch en 2 uur na de lunch. De andere condities die de cognitie en daarmee de testuitslagen kunnen beïnvloeden zoals de intelligentie van het kind, epilepsiesyndroom, concentraties van medicijnen en of het kind aanvalsvrij is of niet, werden stabiel geacht op beide tijdstippen. Als test gebruikten we verschillende onderdelen van de FePsy waarbij de nadruk gelegd werd op snelheid van motorisch handelen, reactietijd en geheugen. De eerste sessie begon om 12 uur en duurde 45-55 minuten. Om 15 uur kwam het kind terug voor een tweede episode. Bij deze tweede episode werd een andere versie van dezelfde testen gebruikt. Door deze studieopzet 
was het mogelijk om cognitieve functies van een kind bij normale ammoniak concentraties en bij relatief verhoogde concentraties te vergelijken.

Een kind had zeer grote problemen om de opdrachten te begrijpen, haar gegevens werden niet in de studie meegenomen. Bij de 11 resterende kinderen steeg de gemiddeld ammoniak concentratie van $66 \mu \mathrm{mol}$ (spreiding 36-92 $\mu \mathrm{mol}$ ) naar $81 \mu \mathrm{mol}$ (spreiding 44-117 $\mu \mathrm{mol}$ ) een stijging van 23\% (statistisch niet significant). Er was een duidelijk verband tussen de uitslagen van alle testen voor de lunch en na de lunch. Er werden geen statistisch significante verschillen gevonden tussen de voor de lunch en na de lunch uitslagen, behoudens voor de reactietijd voor de rechterhand. Hierbij was de uitslag bij hertesten na de lunch 12\% trager (460 milliseconden vs. 410 milleseconden). Maar er werd geen verband gevonden tussen ammoniak waarden en deze reactietijd. De gemiddelde reactietijd voor de niet-dominante hand was ook trager (455 milliseconden vs. 434 milliseconden) maar dit verschil was niet significant. Deze pilot-studie heeft meerdere methologische tekortkomingen. Onze conclusie was dat onze studie laat zien dat ammoniak waarden tot $117 \mu \mathrm{mol}$ waarschijnlijk geen aanleiding geeft tot vertraging van de cognitieve functies.

Hoofdstuk 8 is een bespreking van alle hoofdstukken. Het bevat een reflectie op de eerdere hoofdstukken en suggesties voor toekomstig onderzoek. 


\section{Dankwoord}

Het verschijnen van dit proefschrift geeft mij de gelegenheid een aantal personen te bedanken die op enigerlei wijze hebben bijgedragen aan het tot stand komen hiervan. Ik wil hen daar allen voor bedanken. Een paar mensen wil ik apart noemen.

Prof. dr. Hans Vles en Prof. dr. Bert Aldenkamp, mijn promotoren, en Dr. Johan Arends, co-promotor, dank ik in het bijzonder voor de plezierige samenwerking en begeleiding. Ook het geduld en vertrouwen en scherpzinnige discussies over de exacte samenstelling van dit proefschrift heb ik bijzonder gewaardeerd.

Ik ben de leden van de beoordelingscommissie, Prof. dr. Zimmermann, Dr. van Kranen-Mastenbroek, Prof. dr. van Nieuwenhuizen, Prof. dr. Steinbusch en Prof. dr. Swaab-Barneveld erkentelijk voor de bereidheid om het manuscript kritisch te beoordelen en van commentaar te voorzien.

Dank gaat uit naar mijn collega stafleden van de vakgroep Neurologie van het MUMC+. Dank aan Hans Vles en Sylvia Klinkerberg en in het bijzonder aan Biene Weber. Zij waren diegene die mijn werkzaamheden waarnamen tijdens mijn afwezigheid, zodat ik door kon werken, waarvoor dank.

Prof. dr. Oebo Brouwer, kinderneuroloog, thans in Groningen maar voorheen in Leiden. Hij was diegene die doorhad dat de kinderneurologie het vak voor mij was en mij de heeft opgeleid tot kinderneuroloog. Ik heb geen dag spijt gehad van die keuze.

Reint Huizenga, chemicus en werkzaam bij het Medisch Onderwijs Instituut in Groningen, stond altijd om 12 uur paraat met de Ammonia Checker en 3 uur later opnieuw.

Laura Teune voor de hulp bij het testen van de kinderen voor de hyperammoniaemie studie. Elk kind dat zij zelfstandig getest heeft, heeft mij 9 uur treinen gescheeld.

Inge van der Linden voor het opnieuw beoordelen van de EEG's.

Saskia van Mil voor hulp bij het scoren van de gegevens gebruikt in hoofdstuk 4 .

Leonie Diepman voor hulp bij het aanvullen van ontbrekende gegevens in de database.

Alle medewerkers van de afdeling G.W.D., medewerkers van de Klinische Neurofysiologie, medewerkers van het secretariaat, en neurologen van Kempenhaeghe. 
Onmisbare ondersteuning werd verleend door Desiree Serpenti.

Caroline van der Linden voor haar steun en ontwerpen van de kaft.

Bas Polman en John Smit, mijn paranimfen.

Mijn ouders.

Met de eerste stappen van dit proefschrift ben ik begonnen begin 2005. Enkele maanden daarna leek het leven definitief te veranderen toen Elsbeth, mijn zusje, ziek werd. Dank aan iedereen die mij steunde, die werk overnam, die ik avonds thuis nog mocht bellen. Nooit gedacht, maar wonderen bestaan dus! 


\section{Curriculum Vitae}

Joost Nicolai, geboren te Delft op 12 mei 1966

1972-1978 Basisschool “De Klipper” Lelystad

1978-1984 OSG “De Rietlanden” Lelystad

1984-1989 Studie Geneeskunde 1e fase, Rijksuniversiteit Utrecht

1990-1992 Studie Geneeskunde 2 $2^{\mathrm{e}}$ fase, Rijksuniversiteit Utrecht

1992-1993 AGNIO Interne Geneeskunde, Diaconessenhuis, Voorburg

1993-1995 AGNIO Interne Geneeskunde, Ziekenhuis Leyenburg, Den Haag

1995-1996 AGNIO Neurologie, academisch ziekenhuis Maastricht

1997-2001 Arts-assistent in opleiding Neurologie, Ziekenhuis Leyenburg, Den Haag. Opleider: Dr. T.C.A.M. van Woerkom.

Hiervan 8 maanden Leids Universitair Medisch Centrum, Leiden

2001-2002 Fellow Kinderneurologie, Academisch Ziekenhuis Groningen

Opleider: Prof. dr. O.F. Brouwer

2003-2003 Arts-assistent Kindergeneeskunde in kader opleiding tot kinderneuroloog, Academisch Ziekenhuis Groningen

2004-heden Kinderneuroloog, academisch ziekenhuis Maastricht 


\section{Publicaties}

Stam CJ, Nicolai J, Keunen RW. Nonlinear dynamical analysis of periodic lateralized epileptiform discharges. Clinical Electroencephalography 1998; 29: 101-5.

Stam CJ, Vliegen JH, Nicolai J. Investigation of the dynamics underlying periodic complexes in the EEG. Biological Cybernetics 1999; 80: 57-69.

Nicolai J, van Putten MJ, Tavy DL. BIPLEDs in akinetic mutism caused by bilateral anterior cerebral artery infarction. Clinical Neurophysiology 2001; 112: 1726-8.

Nicolai J, Smith SJ, Keunen RW. Simultaneous side effects of both clozapine and valproate. Intensive Care Medicine 2001; 27: 943.

Nicolai J, van Kranen-Mastenbroek VHJM, Wevers RA, Hurkx WAPT, Vles JSH. Folinic acid-responsive seizures initially responsive to pyridoxine. Pediatric Neurology 2006; 34: 164-7.

Nicolai J, Aldenkamp AP, Arends J, Weber JW, Vles JSH. Cognitive and behavioral effects of nocturnal epileptiform discharges in children with benign childhood epilepsy with centrotemporal discharges. Epilepsy \& Behavior 2006; 8: 56-70.

Nieuwenhuis L, Nicolai J. The pathophysiological mechanisms of cognitive and behavioral disturbances in children with Landau-Kleffner syndrome or epilepsy with continuous spike-and-waves during slow-wave sleep. Seizure 2006; 15: 249-258.

Nicolai J, Aldenkamp AP, Huizenga JR, Teune LK, Brouwer OF. Cognitive side effects of valproic acid-induced hyperammonemia in children with epilepsy: a pilotstudy. Journal of Clinical Psychopharmacology 2007; 27: 221-4.

Kotsopoulos I, Faber CG, Raaijmakers J, van Alfen N, Nicolai J, van KranenMastenbroek VHJM. Idiopathic neuralgic amyotrophy in childhood. Neuropediatrics 2007; 38: 36-7.

Schieveld JN, Leroy PL, van Os J, Nicolai J, Vos GD, Leentjens AF. Pediatric delirium in critical illness: phenomenology, clinical correlates and treatment response in 40 cases in the pediatric intensive care unit. Intensive Care Medicine 2007; 33: 1033-40. 
Nicolai J, van der Linden I, Arends JB, van Mil SGM, Weber JW, Vles JSH, Aldenkamp AP. EEG characteristics related to educational impairments in children with benign childhood epilepsy with centrotemporal spikes. Epilepsia 2007; 48: 2093-2100.

Nicolai J. Pyridoxineafhankelijke epilepsie. Tijdschrift voor Neurologie en Neurochirurgie 2007; 108: 49-50.

Nicolai J, Gunning BW, Leroy PL, Ceulemans B, Vles JSH. Acute hepatic injury in four children with Dravet syndrome: valproic acid, topiramate, or acetaminophen? Seizure 2008; 17: 92-7.

Feron FJ, Hendriksen JG, Nicolai J, Vles JSH. New-onset seizures: a possible association with clonidine? Pediatric Neurology 2008; 38: 147-9.

Nicolai J, Carr RB. The measurement of ammonia blood levels in patients taking valproic acid: Looking for problems where they do not exist? Epilepsy \& Behavior 2008; 12: 494-6.

Nicolai J, Vles JSH, van Tellingen V, van Kranen-Mastenbroek VH. Inverted fixationoff sensitivity in atypical benign partial epilepsy. Pediatric Neurology 2008; 38: 279283.

Nicolai J, Vles JSH, Aldenkamp AP. Neurodevelopmental delay in children exposed to antiepileptic drugs in utero: a critical review directed at structural study-bias. Journal of the Neurological Sciences 2008; 271: 1-14.

Schieveld JN, Lousberg R, Berghmans E, Smeets I, Leroy PL, Vos GD, Nicolai J, Leentjens AF, van Os J. Pediatric illness severity measures predict delirium in a pediatric intensive care unit. Critical Care Medicine 2008; 36: 1933-6. 